\title{
Coffee Productivity and Water Use in Open vs Shaded Systems along an Altitudinal Gradient at Mt. Elgon, Uganda
}

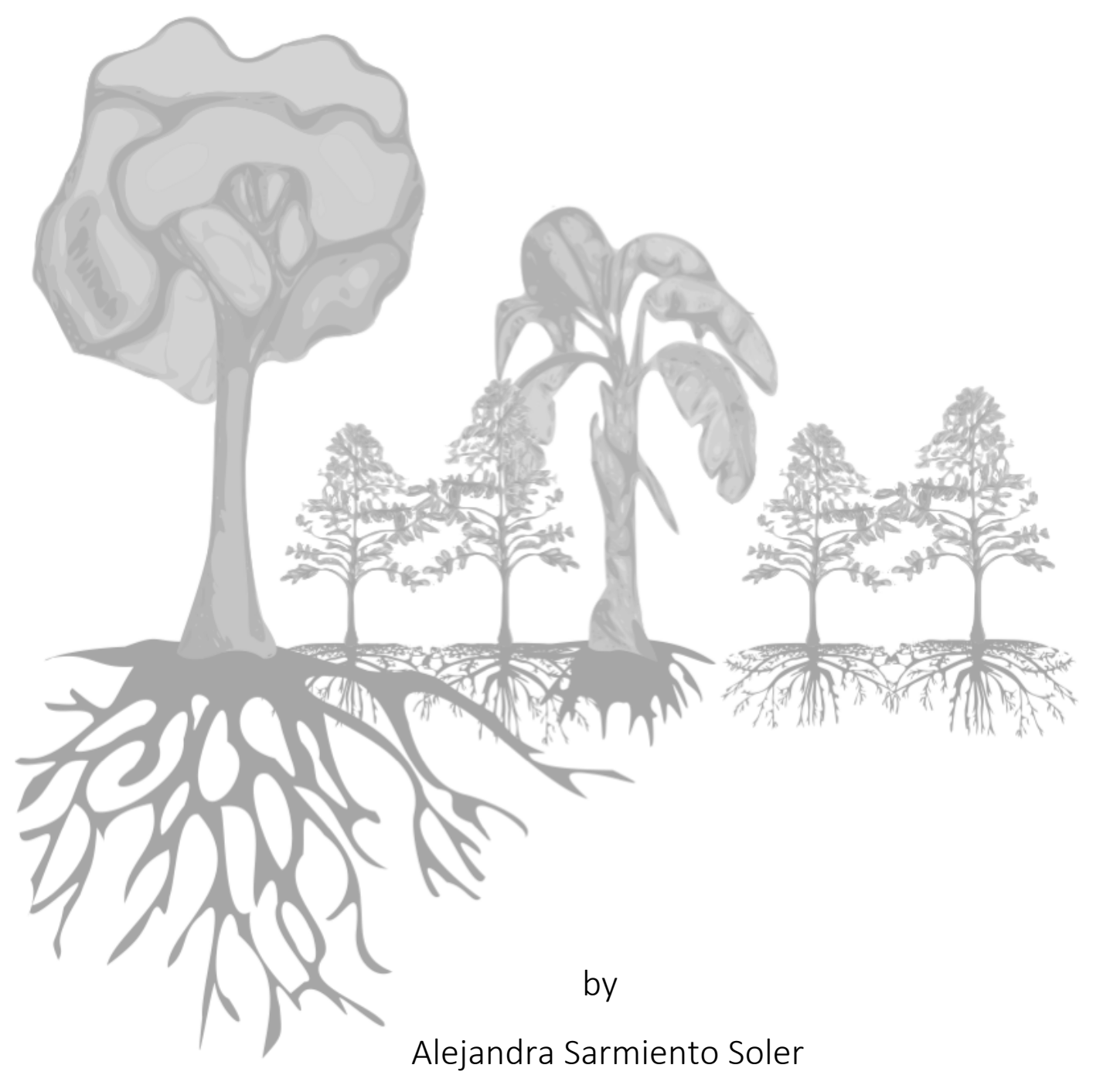

Göttingen 2021 


\title{
Coffee Productivity and Water Use in Open vs Shaded Systems along an Altitudinal Gradient at Mt. Elgon, Uganda
}

\author{
Dissertation \\ to obtain the doctoral degree in the \\ International PhD Program for Agricultural Science in Göttingen (IPAG) \\ Faculty of Agricultural Sciences, \\ Georg-August-University Göttingen, Germany \\ Name of supervisor: Prof. Dr. Reimund P. Rötter \\ Name of co-supervisor: Prof. Dr. Teja Tscharntke \\ Name of co-supervisor: PD. Dr. Martin Worbes
}

Written in the

Division Tropical Plant Production and Agricultural Systems Modelling Department of Crop Science Georg-August-University Göttingen 


\section{Summary}

Coffee is one of the most important agricultural products worldwide. It provides the livelihood of 25 million farmers in tropical countries and of approximately 125 million people along the production chain. Furthermore, coffee demand has steadily increased in the last decades; a trend that is projected to continue in the coming years. Although coffee production is a crucial source of income for several million people, it also contributes to the current environmental crisis. Coffee cultivation and boom and bust cycles lead to deforestation, negatively affecting carbon and water cycles and biodiversity. On the other hand, coffee, as a shade tolerant species, can be intercropped with shade trees in agroforestry systems (AGF). And if appropriately managed, AGF can provide several ecosystem services, such as climate protection, microclimate regulation, biodiversity conservation, soil protection, and income diversification among others.

At the smallholder coffee farmers' scale, the intercropping of coffee and shade trees can generate a range of benefits (i.e. more biodiversity, improved pest control and income diversification) as well as trade-offs such as competition for water and nutrients between coffee and shade trees. The degree to which these benefits and trade-offs develop depends on the specific environmental conditions, management practices and cropping systems. This study aimed to understand the functioning of three coffee cropping systems on the slopes of Mt. Elgon Uganda, in particular to gain insights on how these cropping systems affected coffee productivity, water use and microclimate regulation at different altitudes - ranging beween 1100 and 2100 m.a.s.l. The cropping systems studied were coffee open (i.e. shade cover $<20 \%$, CO), coffee intercropped with bananas (CB) and coffee intercropped with shade trees (CT). The data collection consisted of two main components: (i) a field experiment on water use, and (ii) a coffee tree inventory and monitoring of reproductive and vegetative growth. The results were structured in three research articles as presented below.

Coffee yield $\left(\mathrm{kg} \mathrm{ha}^{-1}\right)$ and coffee yield component performance in different coffee cropping systems along an altitudinal gradient and shade cover gradient was evaluated in the first article: "Effect of cropping system, shade cover along and altitudinal gradient on coffee yield components at Mt. Elgon, Uganda". Fruit load per branch, productive nodes per branch and number of productive branches per stem were monitored on 810 coffee stems distributed over 27 plots ( 9 belonging to each cropping system). Additionally, coffee cherry weight, productive stems per ha and shade cover was monitored in each plot for two harvest seasons (2015 and 2016). CB system had higher yields per ha (1086 $\pm 736 \mathrm{~kg}$ green beans) than CO (670 $\pm 457 \mathrm{~kg}$ green beans) and CT (428 $\pm 259 \mathrm{~kg}$ green beans). Fruit load per branch and number of productive branches per stem were the most important yield components. Both 
decreased with shade cover above $30 \%$ and were negatively correlated with the number of stems per coffee tree. Overall, we did not find differences in cherry weight or productive stems per ha across cultivation systems, nor did altitude show a clear effect on yield components.

In the second article, "Water use of Coffea arabica in open versus shaded systems under smallholder's farm conditions in Eastern Uganda" we explored the water relationships of the three previously mentioned cropping systems ( $C O, C B$ and $C C$ ). We found that (i) coffee water use rates did not differ across systems, (ii) coffee trees benefited from the microclimate provided by shade trees (banana and C. africana), and (iii) CB is an attractive system for smallholder farmers, as it also provides food. Soil water content was reduced in shaded systems ( $C B$ and $C C$ ) compared to $C O$ ), especially in coffee intercropped with C. africana. This suggested that under harsher conditions (hotter and dryer) than the ones recorded in our study, water competition between coffee and shade trees could become a problem.

In the third article, "Disentangling effects of altitude and shade cover on coffee fruit dynamics and vegetative growth in smallholder coffee systems", we investigated coffee fruit development (from fruit initiation to harvest) and vegetative growth during two production cycles (2015 and 2016) in 810 coffee stems distributed over 27 coffee plots. Additionally, microclimate and soil water content were monitored (in 18 plots and 16 plots respectively). Shaded systems buffered microclimate. Fruit set was not limited by temperature but reduced by increases in shade cover. Whilst fruit drop was similar along the shade gradient and was positively related to initial fruit set. Finally, leaf set was the most important variable to ensure vegetative and reproductive growth along several production cycles.

Coffee cultivation systems at the slopes of Mt. Elgon are not intensively managed and mostly have low yields; but as such they fall within the average range of conditions faced by smallholders in Eastern African. There is scope to improve yields by reducing the number of stems per coffee tree (pruning) and increasing coffee tree density. Furthermore, a certain level of shade should be maintained to protect coffee from increased maximum temperatures and avoid high temperature amplitudes, regardless of the system type. Coffee intercropped with bananas showed an optimal balance between microclimate regulations, fruit set, fruit drop and yields, and provide staple food and an extra source of income. 


\section{Acknowledgements}

Writing a PhD thesis was like running a marathon, long, challenging, demanding, exhausting and after all rewarding. In this run I have had the pleasure to meet many people who have supported me, encouraged me and taught me so much about Uganda, coffee, agriculture, science, friendship, love and beyond.

I am very (very!!!) thankful to the coffee farmers from Mt. Elgon, the IITA Uganda team, the TROPAGS team, my friends and family.

I am also of course very thankful to the organizations which made this project financially and logistically feasible: the Division of Tropical Plant Production and Agricultural systems Modelling, University of Göttingen (TROPAGS), International Institute for Tropical Agriculture (IITA) and International enter for Tropical Agriculture (CIAT) and German Ministry for Development (BMZ). 



\section{Table of contents}

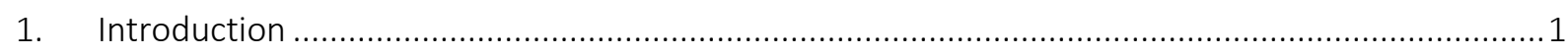

2. Background information about coffee and coffee in Uganda ..................................................11

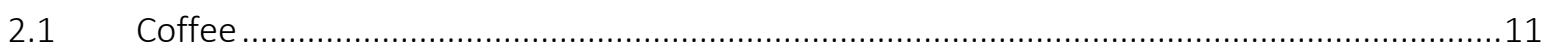

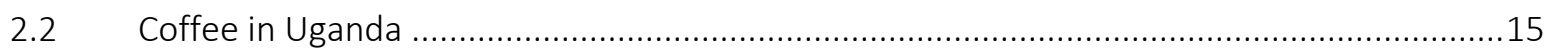

3. Effect of cropping system, shade cover and altitude gradient on coffee yield components at Mt.

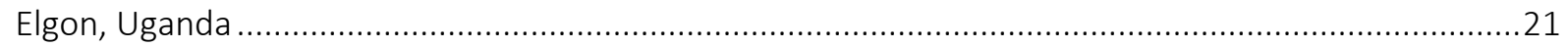

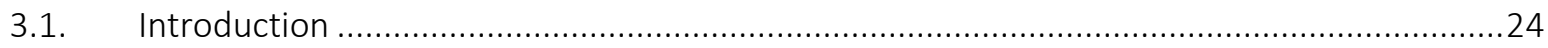

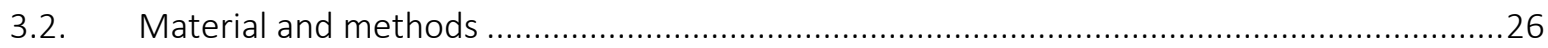

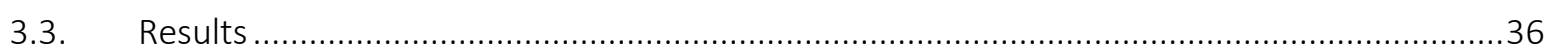

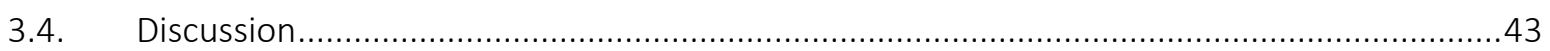

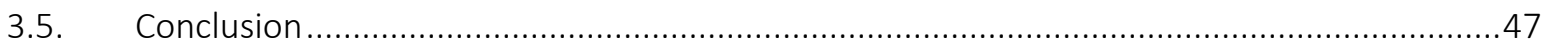

4. Water use of Coffea arabica in open versus shaded systems under smallholder's farm conditions

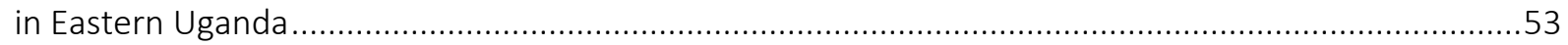

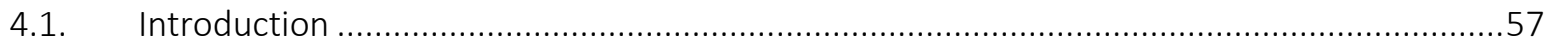

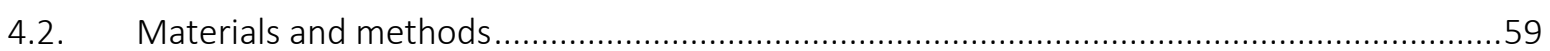

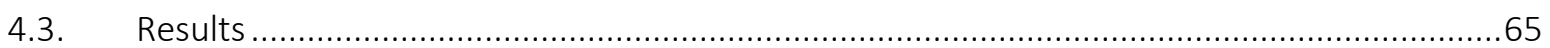

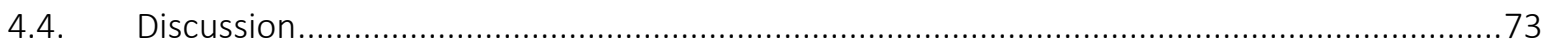

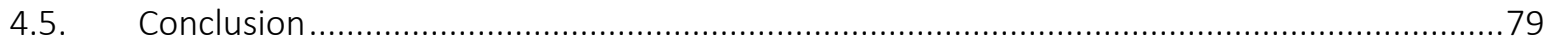

5. Disentangling effects of altitude and shade cover on coffee fruit dynamics and vegetative growth

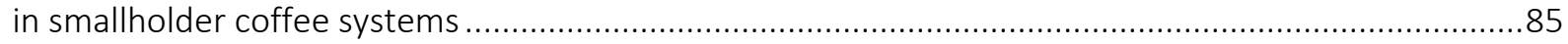

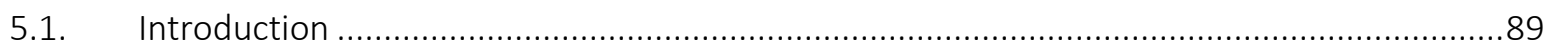

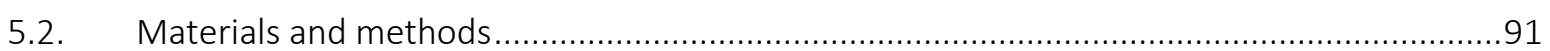

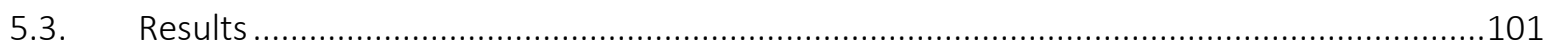

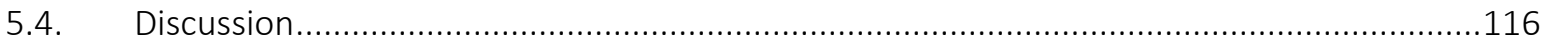

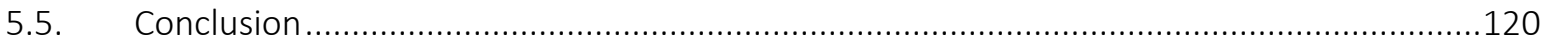

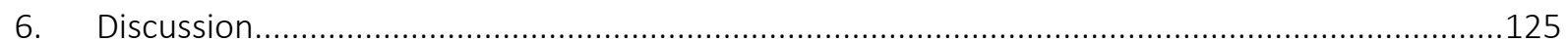

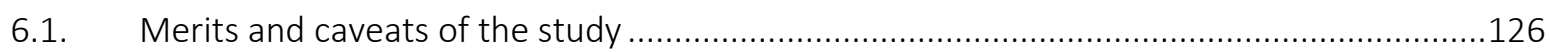

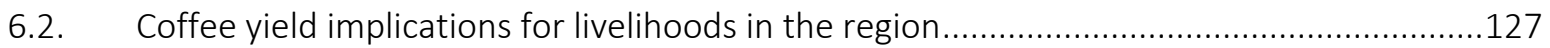

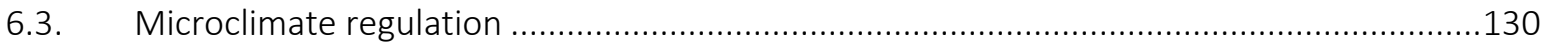

6.4. Shaded systems for sustainable intensification and climate smart agriculture ..................133

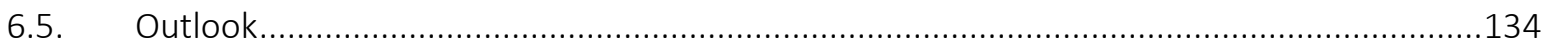

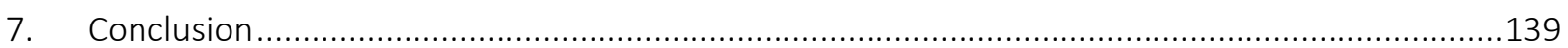

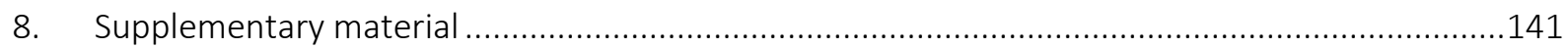

8.2. Chapter 2: Background information about coffee and coffee in Uganda ..........................141

8.3. Chapter 3: Effect of cropping system, shade cover and altitude gradient on coffee yield

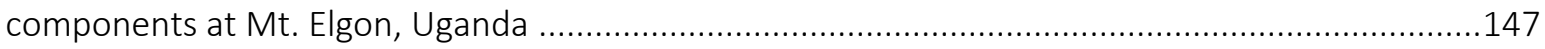


8.4. Chapter 4: Water use of Coffea arabica in open versus shaded systems under smallholder's farm conditions in Eastern Uganda.

8.5. Chapter 5 Disentangling effects of altitude and shade cover on coffee fruit dynamics and vegetative growth in smallholder coffee systems

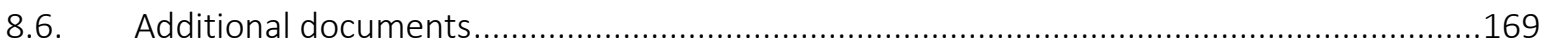

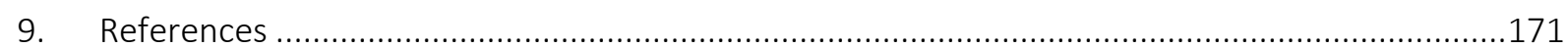




\section{Introduction}

Coffee is a major commodity in the international trade (ITC, 2012). Since its introduction in the market in the $15^{\text {th }}$ century and its migration to Europe in the $16^{\text {th }}$ century, coffee demand has steadily increased (Pendergrast, 1999; Clay, 2004). In 1980 consumption growth rate reached $1.2 \%$ according to the International Coffee Organization (ICO, 2011/12) and it is expected to further increase in the coming years $^{1}$ (ICO, 2011; FAO, 2015; USDA, 2018). Coffee is cultivated in around 70 countries across the tropical belt (ITC, 2012; FAO, 2015). Brazil, Vietnam and Colombia are listed as the top coffee producers in this order. These three countries were accountable for approximately $59 \%$ of the coffee exports in 2018 (FAOSTAT, 2018; ICO, 2018).

Coffee also plays a crucial role in the economies of Eastern Africa. This is particularly true for Ethiopia, Tanzania, Uganda, Rwanda and Burundi, where coffee production contributes up to $30 \%$ to the national foreign earnings (DaMatta et al., 2007; ITC, 2012; Nzeyimana et al., 2013; Moat et al., 2017). Moreover, coffee provides livelihoods for about 25 million famers, from which $70 \%$ are smallholders, who own farms smaller than 10 ha (ITC, 2012; Fridell, 2014). As well, along the value chain, another 125 million people benefit from coffee production (ITC, 2012). However, despite the high demand and prolific market, a high percentage of smallholder coffee producers are poor and highly vulnerable - mostly due to price volatilities, market inequalitites, land pressure, climatic shocks (linked to climate variability), pest and diseases outbreaks, poor or declining soil fertility, lack of capital and saving mechanisms, within others (DaMatta, 2004; Daviron \& Ponte, 2005; Gay et al., 2006; Méndez et al., 2007; Morton, 2007; Laderach et al., 2011; Baca et al., 2014).

Coffee plants are highly vulnerable to climate variability, since coffee tree phenology and fruit loads are closely linked to microclimate (solar radiation, temperature, rainfall amount and distribution). For instance, coffee trees need a stress period (meteorological or agricultural drought) to start flower bud development (Alvim, 1960; Cannell, 1985; Carr, 2001) and a distinct rainy period to trigger flowering (Cannell, 1985). Frequent rainfall events without a defined dry period would cause scatter flower formation and yield reduction (DaMatta \& Ramalho, 2006). On the contrary, too extended dry spells

\footnotetext{
${ }^{1}$ Some of reasons behind this steady growth in coffee consumption are: (i) transformation of coffee consumption from a luxury habit to a daily routine in a vast portion of the population (Pendergrast, 1999; Clay, 2004), (ii) increase in production linked to a price reduction (Clay, 2004; Perfecto et al., 2005), (iii) coffee consumption has expanded to new markets (i.e. Asia) (ITC, 2012), (iv) coffee is nowadays used in several other products (cosmetic, pharmaceutic, soft drinks) apart from beverages (ITC, 2012).
} 
and high temperature might cause flower abortion, fruit drops and smaller fruits ${ }^{2}$ (Cannell, 1974; Cannell, 1985; Drinnan \& Menzel., 1995).

Increases in temperature and rainfall variability due to climate change put extra pressure on the coffee sector in general and on small producers in particular (Laderach et al., 2011; Baca et al., 2014; Hirons et al., 2018). In fact, climate change is expected to have severe negative impacts on coffee yield, quality and the extent of suitable areas for coffee cultivation (i.e. a reduction of up to $50 \%$ by 2050) (Gay et al., 2006; Bunn et al., 2014; Craparo et al., 2015; Ovalle-Rivera et al., 2015; Moat et al., 2017). The various projections, quoted or made by these authors, provide estimates of climate change impact on coffee from a global perspective and in particular indicate which regions are likely to be strongly affected, for instance Central America (Bunn et al., 2014; Lara Estrada et al., 2017). Such projections help to underline the importance of increasing climate resilience in the coffee sector, starting with smallholders who are most vulnerable to such changes.

Nevertheless, the applicability of such coarse-resolution projections for guiding actions at field level is very limited. The models used for projecting suitability for coffee production in the above mentioned studies are very sensitive to initial input data (i.e. current coffee distribution) as well as to the type of future climatic scenarios (i.e. the different temperature and rainfall patterns that result from different combinations of climate model and emissions scenario) (Luedeling et al., 2014). Moreover, those models took into consideration only climatic variables and excluded other important factors, such as soil characteristics and social or economic prevailing contiditions, which also play a relevant role to face climate change impacts (Lara Estrada et al., 2017; Rahn et al., 2018). In this context, local empirical studies on cropping cultivation systems, including their environmental, social and economy dimensions and their climate change adaptation potential are crucial for the development and implementation of appropriate and sustainable practices (Coe et al., 2014).

Coffee is cultivated in a wide range of cropping systems, from intensified monocrops with "compact" 3 high yielding varieties to complex agroforestry systems ${ }^{4}$ (Perfecto et al., 2005). Complex agroforestry systems can even resemble secondary forest structure and functions (Perfecto et al., 2005; Tscharntke et al., 2011). These systems have been associated with the provision of several ecosystem services - in addition to producing coffee - such as providing extra food, fiber and wood, regulating microclimate,

\footnotetext{
2 More information about coffee phenology in section 2.2

${ }^{3}$ Compact coffee varieties refer to dwarf high yielding coffee varietites, in some cases also resistant to specific pest or disease

${ }^{4}$ Agroforestry systems are complex land-use systems that combine in space and time different woody and herbaceous plant species and/or animals and provide different products and ecosystem services (Zhang et al., 2007).
} 
maintainance of nutrient cycling, within others - due to the multi strata and multi taxa in terms of species, space and time (Perfecto et al., 2005; Zhang et al., 2007; Tscharntke et al., 2011; De Beenhouwer et al., 2013; Jha et al., 2014; Mbow et al., 2014a; Rapidel et al., 2015; Vaast et al., 2016; Perfecto et al., 2019). Agroforestry systems are advocated as providing the best opportunity for implementing climate-smart agriculture $(\mathrm{CSA})^{5}$ since they can strengthen farmers' livelihood by diversifying products and income source (Gay et al., 2006; Verchot et al., 2007; Mbow et al., 2014b; Vaast et al., 2016), capture carbon dioxide (Hergoualc'h et al., 2012; van Rikxoort et al., 2014), and lead to higher biodiversity levels than found in intensified monocultures(De Beenhouwer et al., 2013; Jha et al., 2014). These aspects are particularly relevant and desirable under the current sustainability crisis and the need for serious and effective actions regarding climate change mitigation and adaptation.

Moreover, growing coffee under the shade of other species has been shown to improve cultivation conditions for coffee; especially in areas were environmental conditions fall outside the optimal thresholds ${ }^{6}$ (DaMatta, 2004; Vaast et al., 2016). Shade trees modify the microclimate for coffee underneath - resembling the kind of conditions under which coffee naturally evolved (DaMatta, 2004) -, and buffer from extreme temperatures (Barradas \& Fanjul, 1986; Lin, 2007; Siles et al., 2009; Partelli et al., 2014; Araújo et al., 2016). Moreover, at high radiation levels, decoupling of the photosystems at chloroplast level can induce leaf senescence, due to an excess of electrons, which stimulate the accumulation of reactive oxygen species (DaMatta et al., 2007). Thus, agroforestry systems provide benefits at different scales, from plot-farm level to landscape or regional (Tscharntke et al., 2005; Coe et al., 2014; van Noordwijk et al., 2014; Vaast et al., 2016).

On the other hand, agroforestry systems have also been associated with some dis-services, competition for water and nutrients is one of the most important (Zhang et al., 2007). In the case of coffee, many studies argue that shade reduces coffee yields (Campanha et al., 2004; DaMatta, 2004; Franck et al., 2005; Vaast et al., 2006; Vaast et al., 2008). This is attributed to larger vegetative growth in shaded plants, less fruiting nodes and flowers per nodes (Cannell, 1976; DaMatta, 2004). On the contrary, several other authors have demonstrated that under appropriate shade management coffee can produce comparable yields as in open conditions (Soto-Pinto et al., 2000; Cerda et al., 2017; Meylan et al., 2017). Furthermore, reduction of fruit load under shade is offset by reduction of fruit drop, larger bean size and heavier beans (Vaast et al., 2008; Boreux et al., 2016; Nesper et al., 2017). Besides, coffee

5 Climate Smart Agriculture address three major issues (i) sustainable increase of productivity and income, (ii) increasing resilience to climate change and climate variability and (iii) reducing greenhouse gas emissions (FAO 2018).

${ }^{6}$ More about coffee environmental requirements in section 2.2 .2 
biannual productivity patterns ${ }^{7}$ appeared to be less severe under shade, which in the long term, improves cumulative years compared to those achieved under open conditions and reduces the risk of die-back (DaMatta, 2004; Vaast et al., 2008).

Nonetheless, beyond the debate of shade or no shade for coffee cultivation, which should always be specifically addressed in the light of to the prevailing environmental conditions, it is also worthwhile to point out that coffee cultivation is always from one hand affected by environmental conditions and climate change, and on the other hand has a strongs impact on the environment (van Rikxoort et al., 2014). Coffee (as any other so-called cash crops such as cocoa or oil palm) becomes a serious environmental problem, when due to market price fluctuations, farmers feel motivated to expand their coffee areas at the expense of forest areas (Clay, 2004; Clough et al., 2009; Cunningham et al., 2013; Hylander et al., 2013). This is in particular serious, because, coffee cultivation areas usually match with biodiversity hots pots and/or adjoining protected areas (Moguel \& Toledo, 1999; Bhagwat et al., 2008; Hylander et al., 2013; Jha et al., 2014). Moreover, through intensification of shade systems in pursuit higher yields, the incremental use of synthetic fertilizers is also an issue. Since, use of synthetic fertilizers leads to emission of $\mathrm{N}_{2} \mathrm{O}$ and contamination of water (Hergoualc'h et al., 2012; van Rikxoort et al., 2014; Capa et al., 2015; Gomes et al., 2016).

At a global scale, the coffee sector faces the challenge of meeting the growing global coffee demand, while ensuring livelihoods and (hopefully) reducing environmental impact. At a local scale the challenge turns into how to integrate sound scientific knowledge with local practices and needs, and the development of measures which can be adapted to those local conditions. Within this context, understanding the functioning of cropping systems already practiced, shade-coffee yield relationships, ecosystem services and opportunities for sustainable intensification ${ }^{8}$ are of high interest. Despite Africa being the cradle of coffee, quantitative information referring to coffee agroforestry systems from the region is rather scarce, but necessary to adequatey address the challenges mentioned above (De Beenhouwer et al., 2013; Wang et al., 2015).

To help closing the various knowledge gaps, this study aims to contribute to a better understanding of the agronomic performance and ecological functioning of coffee production systems used at Mt. Elgon,

\footnotetext{
7 Moreover, coffee plants usually bear more fruit than can physiologically maintain, resulting in a reduction of vegetative growth which compromises fruits production in the following year, resulting in biannual bearing patterns (Wintgens, 2004; DaMatta et al., 2008; Bote \& Vos, 2016)(DaMatta et al., 2008; Wintgens, 2009; Bote and Jan 2016)

8 Sustainable intensification aims to improve yields of farming systems while reducing their environmental impact (Godfray, 2015).
} 
Uganda ${ }^{9}$ The overall goals were to identify major benefits and limitations of the current coffee production systems along a climatic gradient (imposed by an altitudinal gradient), and identify potential management strategies which could improve yield performance and increase household resilience within sustainable intensification boarders (Godfray, 2015). This work focuses on the study of two of the four types of ecosystem services ${ }^{10}$ described by Zhang et al. (2007), coffee yield as provision service, microclimate buffering and water balance as regulation services.

Thereby we specify the following research objectives and hypotheses:

a) To determine coffee yield $\left(\mathrm{kg} \mathrm{ha}^{-1}\right)$ and the performance of coffee yield components in different coffee cultivation systems along an altitudinal and a shade cover gradient

We hypothesize a reduction in coffee yield with increases in shade cover under optimal climatic conditions (midle and high altitude). While, under sub-optimal conditions, hot and dry (low altitude), we expect lower or nonexistent yield reduction as a result of shade cover increases.

b) To determine the effects of coffee cultivation system and seasonal variation on microclimate, soil water content and water use patterns of coffee and associated shade species at suboptimal climatic conditions, hotter and drier (Low altitude).

We hypothesize shaded systems do better regulate microclimate but face lower soil water contents due to higher transpiration from coffee and shade species combination. In addition, we expect coffee trees in shaded systems transpire more than in open systems, since stomata closure due to high vapor pressure is less likely to occur under shaded conditions.

\footnotetext{
9 This work took place within the project "Trade-offs and Synergies of Climate Change Adaptation in Coffee and Cacao cultivation Systems" supported by the German Ministry for Development (BMZ) (through GIZ (under prime agreement no. 12.1433.7-001.00)). The project included a multidisciplinary team with researchers from different institutions: TROPAGS (Division of Tropical Plant Production and Agricultural Systems Modelling, University of Göttingen), International Institute for Tropical Agriculture (IITA) and CIAT (International Center for Tropical Agriculture). The main objectives of the project were characterized the coffee cultivation systems at the Mt. Elgon region and identify climate change adaptation and mitigation management opportunities. The knowledge provided by this work and in general by the project are valuable to coffee farmers and Ugandan coffee authorities to support the path towards increasing resilience to climate change and increase coffee productivity at the household and national level.

${ }^{10}$ Ecosystem services refer to all processes and functions occurring in an ecosystem, which enable and support human life. Zhang et al. (2007)
} 
c) To disentangle the effects of the altitudinal gradient and the shade gradient on coffee fruit dynamics, fruit drop and vegetative growth.

We hypothesize that lower fruit initiation will occur in heavier shaded systems compared to low shaded system, but larger fruit set will lead to larger fruit drop. And this will result in comparable fruit sets at harvest along the shade gradient.

These research questions and hypotheses are addressed in detail in chapters 3, 4 and 5. Chapter 2 provides insights of to the study area, the coffee sector in this region, and how this research helps in filling some of the knowledge gaps and address important research needs. Chapters 3, 4 and 5 are presented as research articles. In Chapter 3, we explored the effect of cropping system, shade cover and altitudinal gradient on coffee yield components. This chapter has been published in the journal Agriculture, Ecosystems and Environment (Sarmiento-Soler et al., 2020). In Chapter 4 we examined the water use of Coffea arabica in open and shaded systems in smallholder farms in Eastern Uganda. This chapter was published in the journal Agriculture and Forest Meteorology ((Sarmiento-Soler et al., 2019). Chapter five, "Disentangling effects of altitude and shade cover on coffee fruit dynamics and vegetative growth in smallholder coffee systems" was submitted to the Journal Agriculture, Ecosystems and Environment in 2020, and has been accepted under Major reviews by the time this thesis is submitted. Finally, a summary of key findings of this investigation is presented in Chapter 6, in which the results are discussed in a global context, also looking at the main implications of this work, suggesting management strategies for the region and pointing out possible future research opportunities. 


\section{References}

Alvim, P. d. T. (1960). Moisture stress as a requirement for flowering of coffee. Science, 132(3423).

Araújo, A. V., Partelli, F. L., Oliosi, G., \& Pezzopane, J. R. M. (2016). Microclimate, development and productivity of robusta coffee shaded by rubber trees and at full sun. Revista CiÊncia AgronÔmica, 47. doi:10.5935/1806-6690.20160084

Baca, M., Laderach, P., Haggar, J., Schroth, G., \& Ovalle, O. (2014). An integrated framework for assessing vulnerability to climate change and developing adaptation strategies for coffee growing families in Mesoamerica. PLoS One, 9(2), e88463. doi:10.1371/journal.pone.0088463

Barradas, V. L., \& Fanjul, L. (1986). Microclimate characterization of shaded and open-grown coffee (Coffea arabica L.) plantations in Mexico. Agricultural and Forest Meteorology, 38, 101-112.

Bhagwat, S. A., Willis, K. J., Birks, H. J., \& Whittaker, R. J. (2008). Agroforestry: a refuge for tropical biodiversity? Trends Ecol Evol, 23(5), 261-267. doi:10.1016/j.tree.2008.01.005

Boreux, V., Vaast, P., Madappa, L. P., Cheppudira, K. G., Garcia, C., \& Ghazoul, J. (2016). Agroforestry coffee production increased by native shade trees, irrigation, and liming. Agronomy for Sustainable Development, 36(3). doi:10.1007/s13593-016-0377-7

Bote, A. D., \& Vos, J. (2016). Branch growth dynamics, photosynthesis, yield and bean size distribution in response to fruit load manipulation in coffee trees. Trees(30), 1275-1285. doi:10.1007/s00468-016-1365-x

Bunn, C., Läderach, P., Ovalle Rivera, O., \& Kirschke, D. (2014). A bitter cup: climate change profile of global production of Arabica and Robusta coffee. Climatic Change, 129(1-2), 89-101. doi:10.1007/s10584-014-1306-x

Campanha, M. M., Silva Santos, R. H., De Freitas, G. B., Prieto Martinez, H. E., Ribeiro Garcia, S. L., \& Finger, F. L. (2004). Growth and yield of coffee plants in agroforestry and monoculture systems in Minas Gerais, Brazil. Agroforestry Systems, 63, 75-82.

Cannell, M. G. R. (1974). Factors affecting Arabica coffee bean size in Kenya. Journal of Horticultural Science, 49(1), 65-76. doi:10.1080/00221589.1974.11514552

Cannell, M. G. R. (1976). Crop physiological aspects of coffee bean yield - a review. Kenya Coffee, 41, 245-253.

Cannell, M. G. R. (1985). Physiology of the Coffee Crop. In M. N. Clifford \& K. C. Willson (Eds.), Coffee: Botany, Biochemistry and Production of Beans and Beverage (pp. 108-134). Boston, MA: Springer US.

Capa, D., Pérez-Esteban, J., \& Masaguer, A. (2015). Unsustainability of recommended fertilization rates for coffee monoculture due to high N2O emissions. Agronomy for Sustainable Development, 35(4), 1551-1559. doi:10.1007/s13593-015-0316-z

Carr, M. K. V. (2001). The water relations and irrigation requirements of coffee. Experimental Agriculture, 37, 1-36.

Cerda, R., Allinne, C., Gary, C., Tixier, P., Harvey, C. A., Krolczyk, L., Mathiot, C., Clément, E., Aubertot, J.-N., \& Avelino, J. (2017). Effects of shade, altitude and management on multiple ecosystem services in coffee agroecosystems. European Journal of Agronomy, 82, 308-319. doi:10.1016/j.eja.2016.09.019

Clay, J. (2004). World Agriculture and the Environment: a commodity-by-commodity guide to impacts and practices. Washington: Island Press.

Clough, Y., Faust, H., \& Tscharntke, T. (2009). Cacao boom and bust: sustainability of agroforests and opportunities for biodiversity conservation. Conservation Letters, 2(5), 197-205. doi:10.1111/j.1755-263X.2009.00072.x

Coe, R., Sinclair, F., \& Barrios, E. (2014). Scaling up agroforestry requires research 'in' rather than 'for' development. Current Opinion in Environmental Sustainability, 6, 73-77. doi:10.1016/j.cosust.2013.10.013

Craparo, A. C. W., Van Asten, P. J. A., Läderach, P., Jassogne, L. T. P., \& Grab, S. W. (2015). Coffea arabica yields decline in Tanzania due to climate change: Global implications. Agricultural and Forest Meteorology, 207, 1-10. doi:10.1016/j.agrformet.2015.03.005

Cunningham, S. A., Attwood, S. J., Bawa, K. S., Benton, T. G., Broadhurst, L. M., Didham, R. K., Mclntyre, S., Perfecto, I., Samways, M. J., Tscharntke, T., Vandermeer, J., Villard, M.-A., Young, A. G., \& Lindenmayer, D. B. (2013). To close the yield-gap while saving biodiversity will require multiple locally relevant strategies. Agriculture, Ecosystems \& Environment, 173, 20-27. doi:10.1016/j.agee.2013.04.007

DaMatta, F. M. (2004). Ecophysiological constraints on the production of shaded and unshaded coffee: a review. Field Crops Research, 86(2-3), 99-114. doi:10.1016/j.fcr.2003.09.001

DaMatta, F. M., Cunha, R. L., Antunes, W. C., Martins, S. C. V., Araujo, W. L., Fernie, A. R., \& Moraes, G. A. B. K. (2008). In field-grown coffee trees source-sink manipulation alters photosynthetic rates, independently of carbon metabolism, via alterations in stomatal function. New Phytologist, 178, 348-357. doi:10.1111/j.14698137.2007.02367.x

DaMatta, F. M., \& Ramalho, J. C. (2006). Impacts of drought and temperature stress on coffee physiology and production: a review. Brazilian Journal of Plant Physiology, 18(1), 55-81.

DaMatta, F. M., Ronchie, C. P., Maestri, M., \& Barros, R. S. (2007). Ecophysiology of coffee growth and production. Brazilian Journal of Plant Physiology, 19(4), 485-510.

Daviron, B., \& Ponte, S. (2005). The coffee paradox: Global markets, commodity trade and the elusive promise of development. London: Zed Books.

De Beenhouwer, M., Aerts, R., \& Honnay, O. (2013). A global meta-analysis of the biodiversity and ecosystem service benefits of coffee and cacao agroforestry. Agriculture, Ecosystems \& Environment, 175, 1-7. doi:10.1016/j.agee.2013.05.003 
Drinnan, J. E., \& Menzel., C. M. (1995). Temperature affects vegetative growth and flowering of coffee (Coffea arabica L.). Journal of Horticultural Science, 70(1), 25-34.

FAO. (2015). FAO Coffee Pocketbook.

FAOSTAT. (2018). Food and Agriculture Organiaztion of the United Nations. FAOSTAT Statistics Database.

Franck, N., Vaast, P., \& Dauzat, J. (2005). Coffee a shade-adapted plant: implications on its carbon balance and consequences on coffee yield and quality in agroforestry systems. ASIC.

Fridell, G. (2014). Coffee. Cambridge, UK: Polity Press.

Gay, C., Estrada, F., Conde, C., Eakin, H., \& Villers, L. (2006). Potential Impacts of Climate Change on Agriculture: A Case of Study of Coffee Production in Veracruz, Mexico. Climatic Change, 79(3-4), 259-288. doi:10.1007/s10584-0069066-x

Godfray, H. C. J. (2015). The debate over sustainable intensification. Food Security, 7(2), 199-208. doi:10.1007/s12571-0150424-2

Gomes, L. d. C., Cardoso, I. M., Mendonça, E. d. S., Fernandes, R. B. A., Lopes, V. S., \& Oliveira, T. S. (2016). Trees modify the dynamics of soil CO2 efflux in coffee agroforestry systems. Agricultural and Forest Meteorology, 224, 30-39. doi:10.1016/j.agrformet.2016.05.001

Hergoualc'h, K., Blanchart, E., Skiba, U., Hénault, C., \& Harmand, J.-M. (2012). Changes in carbon stock and greenhouse gas balance in a coffee (Coffea arabica) monoculture versus an agroforestry system with Inga densiflora, in Costa Rica. Agriculture, Ecosystems \& Environment, 148, 102-110. doi:10.1016/j.agee.2011.11.018

Hirons, M., Mehrabi, Z., Gonfa, T. A., Morel, A., Gole, T. W., McDermott, C., Boyd, E., Robinson, E., Sheleme, D., Malhi, Y., Mason, J., \& Norris, K. (2018). Pursuing climate resilient coffee in Ethiopia - A critical review. Geoforum, 91, 108116. doi:10.1016/j.geoforum.2018.02.032

Hylander, K., Nemomissa, S., Delrue, J., \& Enkosa, W. (2013). Effects of coffee management on deforestation rates and forest integrity. Conserv Biol, 27(5), 1031-1040. doi:10.1111/cobi.12079

ICO. (2011). Annual Review.

ICO. (2018). Coffee Market Report.

ITC. (2012). The Coffee Exporters's Guide. Retrieved from Geneva:

Jha, S., Bacon, C. M., Philpott, S. M., Ernesto Méndez, V., Läderach, P., \& Rice, R. A. (2014). Shade Coffee: Update on a Disappearing Refuge for Biodiversity. BioScience, 64(5), 416-428. doi:10.1093/biosci/biu038

Laderach, P., Lundy, M., Jarvis, A., Ramirez, J., Portilla, E. P., Schepp, K., \& Eitzinger, A. (2011). Predicted Impact of Climate Change on Coffee Supply Chains. In The Economic, Social and Political Elements of Climate Change (pp. 703-723).

Lara Estrada, L., Rasche, L., \& Schneider, U. A. (2017). Modeling land suitability for Coffea arabica L. in Central America. Environmental Modelling \& Software, 95, 196-209. doi:10.1016/j.envsoft.2017.06.028

Lin, B. B. (2007). Agroforestry management as an adaptive strategy against potential microclimate extremes in coffee agriculture. Agricultural and Forest Meteorology, 144(1-2), 85-94. doi:10.1016/j.agrformet.2006.12.009

Luedeling, E., Kindt, R., Huth, N. I., \& Koenig, K. (2014). Agroforestry systems in a changing climate-challenges in projecting future performance. Current Opinion in Environmental Sustainability, 6, 1-7. doi:10.1016/j.cosust.2013.07.013

Mbow, C., Smith, P., Skole, D., Duguma, L., \& Bustamante, M. (2014a). Achieving mitigation and adaptation to climate change through sustainable agroforestry practices in Africa. Current Opinion in Environmental Sustainability, 6, 814. doi:10.1016/j.cosust.2013.09.002

Mbow, C., Van Noordwijk, M., Luedeling, E., Neufeldt, H., Minang, P. A., \& Kowero, G. (2014b). Agroforestry solutions to address food security and climate change challenges in Africa. Current Opinion in Environmental Sustainability, 6, 61-67. doi:10.1016/j.cosust.2013.10.014

Méndez, E. V., Gliessman, S. R., \& Gilbert, G. S. (2007). Tree biodiversity in farmer cooperatives of a shade coffee landscape in western El Salvador. Agriculture, Ecosystems \& Environment, 119(1-2), 145-159. doi:10.1016/j.agee.2006.07.004

Meylan, L., Gary, C., Allinne, C., Ortiz, J., Jackson, L., \& Rapidel, B. (2017). Evaluating the effect of shade trees on provision of ecosystem services in intensively managed coffee plantations. Agriculture, Ecosystems \& Environment, 245, 32-42. doi:10.1016/j.agee.2017.05.005

Moat, J., Williams, J., Baena, S., Wilkinson, T., Gole, T. W., Challa, Z. K., Demissew, S., \& Davis, A. P. (2017). Resilience potential of the Ethiopian coffee sector under climate change. Nat Plants, 3, 17081. doi:10.1038/nplants.2017.81

Moguel, P., \& Toledo, V. M. (1999). Biodiversity Conservation in Traditional Coffee Systems of Mexico. Conservation Biology, 13, 11-21.

Morton, J. F. (2007). The impact of climate change on smallholder and subsistence agriculture. Proceedings of the national academy of science of the united states of america(104), 19680-19685.

Nesper, M., Kueffer, C., Krishnan, S., Kushalappa, C. G., \& Ghazoul, J. (2017). Shade tree diversity enhances coffee production and quality in agroforestry systems in the Western Ghats. Agriculture, Ecosystems \& Environment, 247, 172-181. doi:10.1016/j.agee.2017.06.024

Nzeyimana, I., Hartemink, A. E., \& de Graaff, J. (2013). Coffee Farming and Soil Management in Rwanda. Outlook on Agriculture, 42(1), 47-52. doi:10.5367/oa.2013.0118

Ovalle-Rivera, O., Laderach, P., Bunn, C., Obersteiner, M., \& Schroth, G. (2015). Projected shifts in Coffea arabica suitability among major global producing regions due to climate change. PLoS One, 10(4), e0124155.

doi:10.1371/journal.pone.0124155 
Partelli, F. L., Araújo, A. V., Vieira, H. D., Dias, J. R. M., Menezes, L. F. T. d., \& Ramalho, J. C. (2014). Microclimate and development of 'Conilon' coffee intercropped with rubber trees. Pesquisa Agropecuária Brasileira, 49(11), 872881. doi:10.1590/s0100-204x2014001100006

Pendergrast, M. (1999). Uncommon grounds: the history of coffee and how it transformed our world (Vol.

). New York, NY: Basic Books.

Perfecto, I., Jiménez-Soto, M. E., \& Vandermeer, J. (2019). Coffee Landscapes Shaping the Anthropocene: Forced Simplification on a Complex Agroecological Landscape. Current Anthropology, 60(S20), S236-S250. doi:10.1086/703413

Perfecto, I., Vandermeer, J., Mas, A., \& Pinto, L. S. (2005). Biodiversity, yield, and shade coffee certification. Ecological Economics, 54(4), 435-446. doi:10.1016/j.ecolecon.2004.10.009

Rahn, E., Vaast, P., Läderach, P., van Asten, P., Jassogne, L., \& Ghazoul, J. (2018). Exploring adaptation strategies of coffee production to climate change using a process-based model. Ecological Modelling, 371, 76-89. doi:10.1016/j.ecolmodel.2018.01.009

Rapidel, B., Ripoche, A., Allinne, C., Metay, A., Deheuvels, O., Lamanda, N., Blazy, J.-M., Valdés-Gómez, H., \& Gary, C. (2015). Analysis of ecosystem services trade-offs to design agroecosystems with perennial crops. Agronomy for Sustainable Development, 35(4), 1373-1390. doi:10.1007/s13593-015-0317-y

Sarmiento-Soler, A., Vaast, P., Hoffmann, M. P., Jassogne, L., van Asten, P., Graefe, S., \& Rötter, R. P. (2020). Effect of cropping system, shade cover and altitudinal gradient on coffee yield components at Mt. Elgon, Uganda. Agriculture, Ecosystems \& Environment, 295. doi:10.1016/j.agee.2020.106887

Sarmiento-Soler, A., Vaast, P., Hoffmann, M. P., Rötter, R. P., Jassogne, L., van Asten, P. J. A., \& Graefe, S. (2019). Water use of Coffea arabica in open versus shaded systems under smallholder's farm conditions in Eastern Uganda. Agricultural and Forest Meteorology, 266-267, 231-242. doi:10.1016/j.agrformet.2018.12.006

Siles, P., Harmand, J.-M., \& Vaast, P. (2009). Effects of Inga densiflora on the microclimate of coffee (Coffea arabica L.) and overall biomass under optimal growing conditions in Costa Rica. Agroforestry Systems, 78(3), 269-286. doi:10.1007/s10457-009-9241-y

Soto-Pinto, L., Perfecto, I., Castillo-Hernandez, J., \& Caballero-Nieto. (2000). Shade Effect on Coffee Production at the Northern Tzeltal Zone of the State of Chiapas, Mexico. Agriculture, Ecosystems \& Environment, 80((1-2)), 61-69.

Tscharntke, T., Clough, Y., Bhagwat, S. A., Buchori, D., Faust, H., Hertel, D., Hölscher, D., Juhrbandt, J., Kessler, M., Perfecto, I., Scherber, C., Schroth, G., Veldkamp, E., \& Wanger, T. C. (2011). Multifunctional shade-tree management in tropical agroforestry landscapes - a review. Journal of Applied Ecology, 48(3), 619-629. doi:10.1111/j.13652664.2010.01939.x

Tscharntke, T., Klein, A. M., Kruess, A., Steffan-Dewenter, I., \& Thies, C. (2005). Landscape perspectives on agricultural intensification and biodiversity â " ecosystem service management. Ecology Letters, 8(8), 857-874. doi:10.1111/j.1461-0248.2005.00782.x

USDA. (2018). Coffee: World Markets and Trade. Retrieved from

Vaast, P., Bertrand, B., Perriot, J.-J., Guyot, B., \& Génard, M. (2006). Fruit thinning and shade improve bean characteristics and beverage quality of coffee (Coffea arabica L.) under optimal conditions. Journal of the Science of Food and Agriculture, 86(2), 197-204. doi:10.1002/jsfa.2338

Vaast, P., Harmand, J.-M., Rapidel, B., Jagoret, P., \& Deheuvels, O. (2016). Coffee and Cocoa Production in Agroforestry-A Climate-Smart Agriculture Model. In Climate Change and Agriculture Worldwide (pp. 209-224).

Vaast, P., Van Kanten, R., Siles, P., Angrands, J., \& Aguilar, A. (2008). Biophysical interactions between timber trees and Arabica coffee in suboptimal conditions of Central America. In Toward Agroforestry Design (pp. 133-146): Springer.

van Noordwijk, M., Namirembe, S., Catacutan, D., Williamson, D., \& Gebrekirstos, A. (2014). Pricing rainbow, green, blue and grey water: tree cover and geopolitics of climatic teleconnections. Current Opinion in Environmental Sustainability, 6, 41-47. doi:10.1016/j.cosust.2013.10.008

van Rikxoort, H., Schroth, G., Läderach, P., \& Rodríguez-Sánchez, B. (2014). Carbon footprints and carbon stocks reveal climate-friendly coffee production. Agronomy for Sustainable Development, 34(4), 887-897. doi:10.1007/s13593014-0223-8

Verchot, L. V., Van Noordwijk, M., Kandji, S., Tomich, T., Ong, C., Albrecht, A., Mackensen, J., Bantilan, C., Anupama, K. V., \& Palm, C. (2007). Climate change: linking adaptation and mitigation through agroforestry. Mitigation and Adaptation Strategies for Global Change, 12(5), 901-918. doi:10.1007/s11027-007-9105-6

Wang, N., Jassogne, L., van Asten, P. J. A., Mukasa, D., Wanyama, I., Kagezi, G., \& Giller, K. E. (2015). Evaluating coffee yield gaps and important biotic, abiotic, and management factors limiting coffee production in Uganda. European Journal of Agronomy, 63, 1-11. doi:10.1016/j.eja.2014.11.003

Wintgens, J. N. (2004). Coffee: Growing, Processing, Sustainable Production. Weinheim, Germany: Wiley-VCH Verlag GmbH \&Co.

Zhang, W., Ricketts, T. H., Kremen, C., Carney, K., \& Swinton, S. M. (2007). Ecosystem services and dis-services to agriculture. Ecological Economics, 64(2), 253-260. doi:10.1016/j.ecolecon.2007.02.024 



\section{Background information about coffee and coffee in Uganda}

\subsection{Coffee}

The genus Coffea belongs to the Rubiaceae family. From the (approximately) seventy species described in the Coffea genus, two of them dominate $99 \%$ of the international market: Coffea arabica L. (Arabica) and Coffea canephora Pierre ex A.Froehner. (Robusta) (DaMatta \& Ramalho, 2006). Arabica and Robusta are both native to Africa; the first one evolved as an understory shrub in the highlands of south-west Ethiopia, while Robusta evolved from the lowland forest of the Congo river basin to the African Great Lakes region (Burundy, the Democratic Republic of the Cong, Kenya, Malawi, Rwanda, Tanzania and Uganda (Coste, 1992; DaMatta, 2004; ITC, 2012). This geographically separated distribution resulted in different environmental requirements for the two species. Nowadays, coffee is grown at the tropical belt (until $23^{\circ}$ North and $23^{\circ}$ South from the Equator, approximately), Arabica dominates at high altitudes between $600-2800$ m.a.s.I. while Robusta is widely distributed in the lowlands between 0 to 1400 m.a.s.I., depending on the distance to the Equator (DaMatta, 2004). In this study we focus mainly on Arabica.

\subsubsection{Environmental requirements for coffee cultivation}

It is difficult to define exact environmental thresholds for coffee cultivation, since the interaction of several factors, namely temperature (minima, maxima, mean) rainfall amount and distribution, type of soil and topography, play a major role in determining coffee performance (DaMatta, 2004). However, several studies agree that optimal mean temperature for Arabica ranges between $18{ }^{\circ} \mathrm{C}$ to $23^{\circ} \mathrm{C}$, and $24^{\circ} \mathrm{C}-26^{\circ} \mathrm{C}$ for Robusta (See Table 1 for Arabica). Moreover, continuous temperatures above $30^{\circ} \mathrm{C}$ have been associated with leaf chlorosis, blossom wilting, defective fruit set, reduction of photosynthesis, development of coffee leaf rust, and accelerate maturation (Heath \& Orchard, 1957; Franco, 1958; Willson, 1985b; Descroix \& Snoeck, 2008). Low temperatures $\left(<4^{\circ} \mathrm{C}\right)$ have also been associated with plant injuries and death (Descroix \& Snoeck, 2008).

Optimal rainfall for Arabica ranges from 1200 to 1800 mm per year (Alégre, 1959) and although Robusta can stand higher temperatures than Arabica, generally it needs higher relative humidity and rainfall (>75 $\%$ and $2000-2500 \mathrm{~mm}$ ). Moreover, for coffee trees, the amount of rainfall per year is as important as its distribution (Willson, 1985b) because the production cycle of coffee is intimately related to the 
distribution of rains. According to Haarer (1958), the presence of a dry season (2 - 4 months, with less than $36 \mathrm{~mm}$ per month) is a fundamental element in the induction of flower formation. Later on, rainfall is necessary to initiate flowering, and constant water supply is crucial during the fruit filling time, when the water requirements of the coffee trees are very high (Wintgens, 2004).

Air humidity also plays an important role for coffee physiology, regulation of water loss and coffee transpiration. Robusta can stand higher air humidity, close to saturation point, while Arabica develops better under drier conditions (DaMatta et al., 2007), although too high vapor pressure deficit can also limit coffee growth (Carr, 2001). Optimal relative humidity values are around $60 \%$ for Arabica and around $75 \%$ for Robusta. High relative humidity can stimulate the development of pest and diseases with possible detrimental effects on coffee quality and productivity. Strong winds can also have a negative effect on coffee yields by reducing leaf area and internode length (Caramori et al., 1986). Therefore, windy places or places prone to cyclones should be avoided when establishing coffee plantations (Wintgens, 2004).

Regarding soil requirements, coffee trees are ubiquitous, this means that coffee trees are able to prosper on a wide range of soil types (Willson, 1985b). Nevertheless, proper drainage is very important for the coffee roots, as well as sufficient soil depth and good water holding capacity. Coffee roots should be able to explore deeper layers of soil when needed. And soils with tendency of being flooded or waterlogged, i.e. heavy clays, or sandy, shallow and/or very rocky soils should be avoided. Nutrients should be at reasonable levels and macro-nutrient contents should be adequatey balanced (See Willson (1985a) for more details). Nitrogen is important for vegetative growth and coffee bean development (Clemente at al., 2015) and might also enhance tree resistance to drought (DaMatta, 2004).

When environmental factors fall below or beyond optimal ranges, plants suffer from stress and disturbance of their physiological functions (DaMatta \& Ramalho, 2006). Ultimately, stress will have a detrimental effect on growth, yields and also bean quality (DaMatta \& Ramalho, 2006). Long dry spells have a deleterious effect on the coffee trees, as well as too abundant rainfall during the year is reported to have a negative effect on coffee yields (Maestri \& Barros, 1977). 
Table 1: Environmental requirements for Arabica cultivation

\begin{tabular}{|c|c|c|c|}
\hline Factor & Optimal & Marginal & Non Optimal \\
\hline \multicolumn{4}{|l|}{ Temperature } \\
\hline Mean & $18-21^{\circ}(4) ; 18-20^{\circ} \mathrm{C}^{(17)}$ & $\begin{array}{l}>24^{\circ} \mathrm{C}^{(2)} ; 25^{\circ} \mathrm{C}^{(1)} ; 23^{\circ} \mathrm{C}(4) ; 24-26^{\circ} \mathrm{C}^{(17)} \\
<14-15^{\circ} \mathrm{C}^{(17)} ; 17-18^{\circ} \mathrm{C}^{(6)} ; 15-16^{\circ} \mathrm{C}^{(13,14)}\end{array}$ & $>30^{\circ} \mathrm{C}^{(5)} ; 26^{\circ} \mathrm{C}<14^{\circ} \mathrm{C}^{(17)}$ \\
\hline Max & $25-26^{\circ} \mathrm{C}(17)$ & $>28-32^{\circ} \mathrm{C}^{(17)}$ & $>34^{\circ}(2) ; 32^{\circ} \mathrm{C}(17)$ \\
\hline Min & $15-17^{\circ} \mathrm{C}(17)$ & $<12^{\circ} \mathrm{C}^{(2)} ; 6^{\circ} \mathrm{C}^{(3)} ; 4-7^{\circ} \mathrm{C}^{(17)}$ & $<4^{\circ} \mathrm{C}^{(15)} ; 4^{\circ} \mathrm{C}^{(17)}$ \\
\hline Relative Humidity & $50-60 \%(17)$ & $\begin{array}{l}>80-90 \%(17) \\
<30-40 \%(17)\end{array}$ & $<20 \%(17)$ \\
\hline $\begin{array}{l}\text { Duration of dry } \\
\text { spell (months) }\end{array}$ & $2-4^{(7)} ; 2.5-3^{(17)}$ & $>5-6^{(17)}$ & $>6^{(17)}$ \\
\hline $\begin{array}{l}\text { Water availability } \\
\left(\mathrm{mm} \text { year }^{-1}\right)\end{array}$ & $1200-1800(4)$ & $\begin{array}{c}<1000-1200 \text { and } \\
>2000 \mathrm{~mm}^{(17)}\end{array}$ & \\
\hline \multicolumn{4}{|l|}{ Soil } \\
\hline $\mathrm{pH}$ & $5.5-6^{(17)}$ & $4.5-5^{(17)}$ & $<4.5^{(17)}$ \\
\hline Texture & $\begin{array}{l}\text { Clay, Clayey-silty and silty- } \\
\text { clayey }^{(17)}\end{array}$ & Sand (17) & Sand (17) \\
\hline Wind & & Strong (5); (12) & \\
\hline Altitude & & $<800^{(1)}$ & \\
\hline Soil Temperature & $\begin{array}{l}<26^{\circ} \mathrm{C} \text { (Day) }{ }^{(16)} \\
>20^{\circ} \text { (Night) }{ }^{(16)}\end{array}$ & & \\
\hline \multicolumn{4}{|c|}{$\begin{array}{l}\text { (1) (Vaast et al., 2006); (2) (Nunes et al., 1968); (3) (Bauer et al., 1985); (4) (Alégre, 1959); (5) (Franco, 1958); (Camargo, } 1985 \\
\text { (7) (Haarer, 1958); (8) (Coste, 1992); (9) (Matiello, 1998); (Willson, 1999); (11) (Maestri \& Barros, 1977); (Matiello et al., } 2002 \\
\text { (13) (Barros et al., 1991); (14) (Silva et al., 2004); (15) (Ramalho et al., 2003); (16) (Wintgens, 2004); (18) (Descroix \& Snoeck } \\
\text { 2008) }\end{array}$} \\
\hline
\end{tabular}

\subsubsection{Coffee phenology}

Coffee plants need around three years to reach the productive stage and can have one or two harvests per year depending on the environment. Flower bud formation occurs during a period of stress, either induced by drought or by low temperatures (Alvim, 1960; Camargo, 1985; Carr, 2001). When the first rains come, flower bud dormancy is stopped and flowering occurs (Browning, 1975). This happens in conjunction with the flush of new leaves, to ensure fruit expansion during the rainy season with high water availability. Flowers are open up to 6 days waiting for pollination (Wintgens, 2004). In the case of Arabica, auto-pollination is possible, and wind is the most frequent pollination agent. From the pollinated flowers, first the so-called pinhead emerges; pinhead stage takes 6 to 8 weeks after fecundation (Cannell, 1985). After the $6^{\text {th }}$ week approximately, rapid expansion of the fruits starts and it can take from 6 up to 9 months to complete fruit development (Cannell, 1985; Barros et al., 1991; DaMatta et al., 2007). Free availability of water is indispensable for fruit filling and ripening (Cannell, 
1974; DaMatta et al., 2007). Usually, coffee tends to fruit more than what can be physiologically maintained by the tree, resulting in a reduction of vegetative growth which compromises fruits production in the following year. Extreme over-bearing can lead to die-back, in which the shoots or branches die. Die- back is exacerbated by drought stress (Vaast et al., 2006; DaMatta et al., 2007).

During the maturation process, the chlorophyll content is reduced, and fruits turn into red, increasing its sugar content. The beans with a sigmodial shape locate inside the fruits and have three layers: silver skin, parchment and pulp. Productivity of coffee can be measured as fresh weight, parchment or green beans. However, at international markets, the standard used is dry Green beans over a production area and a unit of time (Dry green beans $\mathrm{kg} \mathrm{ha}^{-1} \mathrm{year}^{-1}$ ). Normal lifespan of a coffee plantation is 30 years. Nevertheless, under appropriate management, coffee trees can be productive up to 80 years (Wintgens, 2004).

\subsubsection{Coffee physiology}

Coffee developed in the understory of African rain forests (DaMatta et al., 2007). Therefore, its physiology corresponds to a shade adapted species, in which photosynthesis rates are inhibited in full sun leaves $\left(7 \mu \mathrm{mol} \mathrm{m} \mathrm{m}^{-2}\right)$, compared to shaded leaves $\left(14 \mu \mathrm{mol} \mathrm{m}{ }^{-2} \mathrm{~s}^{-1}\right)$ (Altman \& Dittmer, 1964; Kumar \& Tieszen, 1980b; Cannell, 1985; Carr, 2001; Wintgens, 2004). Furthermore, Kumar and Tieszen (1980a) reported relatively low saturating irradiance values, of the range from 300 to $700 \mu \mathrm{mol}$ phothon $\mathrm{m}^{-2} \mathrm{~s}^{-}$

1. Also, damage in photosynthetic organs has been reported when coffee plants were exposed to elevated radiation (DaMatta \& Ramalho, 2006). Furthermore, Kumar and Tieszen (1980a) reported a reduction of photosynthesis rate when temperatures increased above $25^{\circ} \mathrm{C}$ - which is probably related to stomata sensitivity to high VPD.

Trees function as a medium between the soil and the atmosphere through which water is flowing following a water potential (Soil $\rightarrow$ Plant $\rightarrow$ Atmosphere). Thus, vapour pressure deficit becomes the driving force in this water movement. On the other hand, coffee, and plants more generally, have developed certain mechanisms to affect this water movement, such as stomata closure at certain critical soil moisture levels, or at high evaporative demand. With respect to coffee's sensitivity to water stress, coffee can be considered as a "water saving" rather than a "dehydrating" species (Sade et al., 2009; Moshelion et al., 2015) because it is very sensitive to atmospheric drought (Da Matta et al., 1993). Coffee reduces stomata opening in response to high VPD (i.e. above $1.5 \mathrm{kPa}$ ) independent of soil moisture water content (Carr, 2001; DaMatta \& Ramalho, 2006; Ronquim et al., 2006). On the other hand, it has been reported that Arabica can maintain transpiration rates even at less than $50 \%$ of the 
field capacity (Kummar, 1979). Furthermore, Arabica is able to maintain photosynthetic rates at leaves that are dehydrated to some degree ( $\Psi=-4 \mathrm{MPa}$ ) (Kanechi et al., 1995). To conclude, coffee stomata aperture seems to depend initially on radiation levels; next, stomatal conductance is related to dryness of the air (VPD), and only thereafter to soil water content when this falls below certain thresholds $(<50$ \% field capacity) (Kummar, 1979).

\subsection{Coffee in Uganda}

Uganda is a landlocked country, surrounded by South Sudan, Kenya, Tanzania, Rwanda and the Democratic Republic of Congo. It has an area of $241.000 \mathrm{~km}^{2}$ and lies on average at 1.000 m.a.s.l. It has two main mountain chains, in the south west, Ruwenzori Mountains (with the highest peak over 5.000 m.a.s.l.) and in the east, Mount Elgon (with the highest peak over 4.000 m.a.s.I.). 39 million people live in Uganda, of which 32 million populate the rural areas and depend mostly on agriculture. Agriculture contributes $28.1 \%$ to the gross domestic product (FAOSTAT, 2016). Coffee is the most important exported crop grown in Uganda and it contributes up to $20 \%$ of the value of the total exports of the country (UCDA, 2013). Furthermore, it provides the livelihood of approximately 3.5 million farmers, of whom $90 \%$ have less than 2 hectares of land (UCDA, 2016).
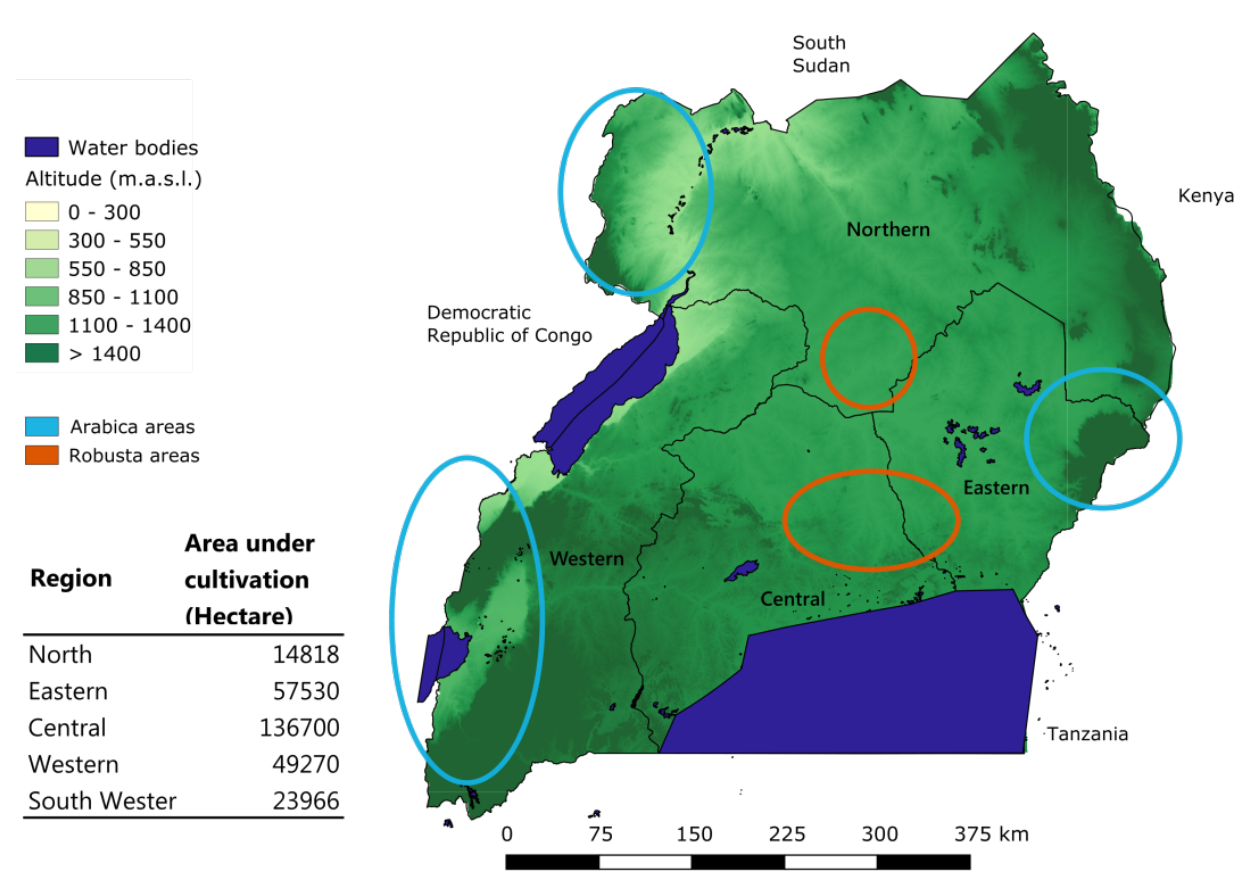

Fig. 1. Map of Uganda with coffee regions. Elaborated based on STRM digital elevation maps and data from UCDA (2016) 
In Uganda, both coffee species, Arabica and Robusta are cultivated, covering approximately 282,284 ha (UCDA, 2018)(UCDA 2018). Robusta dominates the lowlands, from 1100 up to 1.500 m.a.s.l. There are two main Robusta zones in Uganda, central and northern Uganda (Fig. 1). On the contrary, Arabica is cultivated at higher elevation, from around 1300.up to 2600 m.a.s.I. - mainly om the slopes of the Ruwenzori Mountains, at Mt. Elgon and in North West Uganda. Despite the higher international price of Arabica, Robusta constitutes more than 76 \% of the coffee produced in Uganda (Fig. 2) (UCDA, 2016).

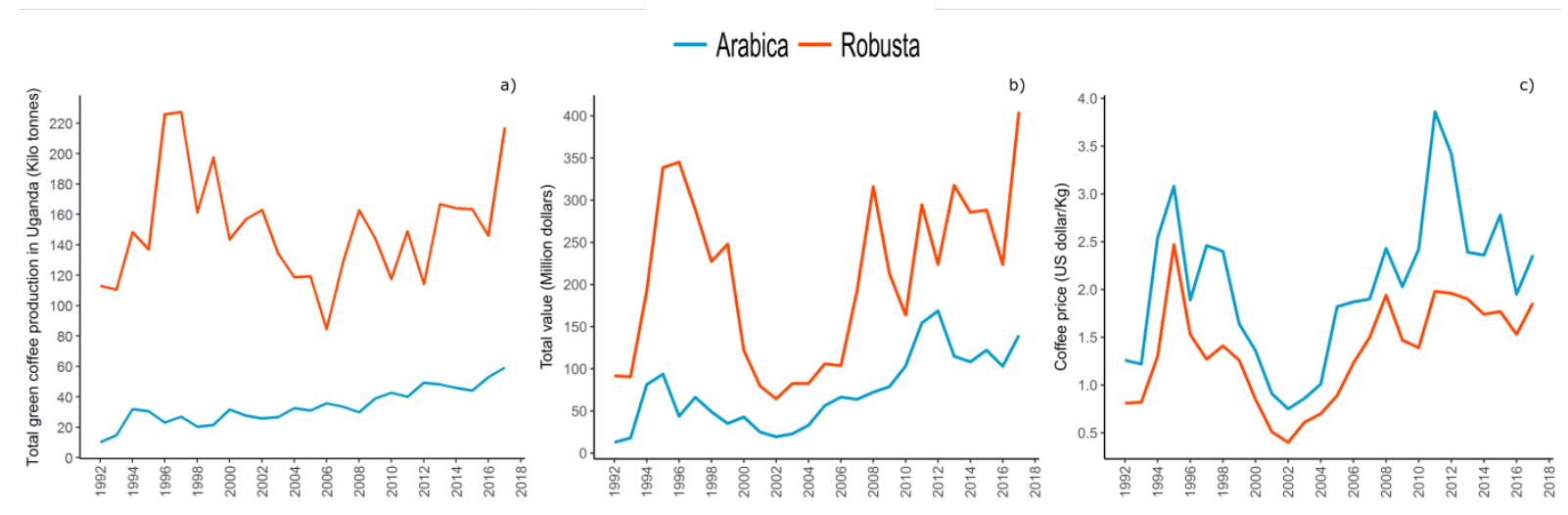

Fig. 2. Developments from 1990 to 2017 by coffee species: (a) coffee production, (b) total coffee value in US dollars and (c) coffee price (US dollars $/ \mathrm{kg}$ ) in Uganda; (Arabica=Blue and Robusta = Orange). Based on data provided by the Ugandan Coffee Development Authority (UCDA) accessed April 2018.

Although coffee is native from Africa, and even some Robusta populations originated in Uganda, coffee started to be cultivated for economic purposes in Uganda only at the beginning of the $20^{\text {th }}$ century. The sector had an exponential growth the following years, until 1959, when the sector started to decline due to inefficient management of the cooperatives system (Crawford et al., 1981; Brett, 1992). Farmers were forced to sell their coffee to the cooperatives and did not any power on the transaction prices. Moreover, the payments were frequently delayed even up to 3 months (Crawford et al., 1981).Thus, interest in the coffee sector reduced, and farmers switched to grow other products, especially food crops. Then, in 1990, the Ugandan coffee market was liberalize and the previous cooperatives system was replaced by the Ugandan Coffee Development Authority (UCDA) (Baffes, 2006). These appeared to have had on the sector, especially for the farmers, according to Baffes (2006).

Since 2014/15, the Ugandan government through the UCDA has started the "National Coffee Strategy". This strategy aims to promote the Ugandan coffee sector and lead to the recognition of the Ugandan coffee by the international market (UCDA, 2015).Actions will be carried out at different levels of the production chain, from producers to retailers, with the objective to increase production and value. Nevertheless, currently fundamental knowledge about farmers' primary productivity, yield gaps and yield constraining factors is lacking for most coffee cultivation areas in Uganda. The same holds true for 
knowledge about the marketing chain (UCDA, 2015). Therefore, results and knowledge gained during the project and this dedicated PhD research, aims to reduce some important knowledge gaps. Likewise, it may add support to the coffee farmers and Ugandan coffee Development Authority in its effort to successfully achieve the National Coffee Strategy goals (UCDA, 2015) and concurrently increase climate resilience of coffee cropping systems in the country.

\subsubsection{Cultivation systems at Mt. Elgon}

Coffee production in Uganda is performed mostly by smallholders. Thus, coffee cultivation is rather at a low level of intensification, with no mechanization, and only scarce use of chemical inputs, and usually based on family labor (ITC, 2012; UCDA, 2015). Coffee is mostly intercropped with food crops such as: bananas, corn, beans, passion fruits, cassava - among others - and with shade trees, which provide a variety of products, such as fruits, timber, firewood, within others (Odoul \& Aluma, 1990; Rahn et al., 2018). Mixing coffee with other crops appears to reduce negative impacts such as crop failure and phases of low coffee prices, and it also provides alternative income and food sources beyond the coffee harvesting seasons (Odoul \& Aluma, 1990; Rutherford, 2006; van Asten et al., 2011). The most common coffee cropping system is the so-called Coffee-Banana system, in which coffee trees, as the main cash source, are intercropped with bananas, the main staple crop (Odoul \& Aluma, 1990; van Asten et al., 2011).

Mount Elgon is famous for its Arabica coffee. Most of the farmers in the region are involved in coffee cultivation on large or small scale. Usually, coffee is intercropped with different species, such as shade trees, bananas and annual crops as beans, hence creating a gradient of management intensity and also shade intensity (Rahn et al., 2018). As base line of the research project "Trade-off and synergies in climate change adaptation in coffee and cocoa systems", a characterization of coffee cultivation systems at Mt Elgon was performed (more results of this study can be found in Rahn et al. (2018).

One hundred forty four farmers were selected following a random stratified sampling according to the previously identified altitude classes (Low < 1400 m.a.s.I., Middle 1400 - 1700 m.a.s.I., and High > 1700 m.a.s.l) and administrative boundaries (2 sub-counties per Altitude Class: 2 parrishes per sub-county: 2 villages per parrish). A cluster analysis was performed based on plot structure ${ }^{11}$ to identify different cultivation systems. Evident classification of smallholder systems is not easy, since there is high level of variability between plots, which are specifically tailored to the farmers' needs and labor availability.

11 Plot size, Shade cover (\%), density of banana mats, density of shade trees and shade tree species richness 
Nevertheless, as result of cluster analysis, three different coffee cultivation systems were identified in the area, named as:

1. Coffee- Open (CO): low shade intensity (Shade cover $<20 \%$ )

2. Coffee- Banana (CB): Shade cover $>20 \%$ and dominated by Musa sp., although scattered presence of other shade tree species.

3. Coffee-Shade Tree (CT): dense shaded systems, shade provided by diverse shade trees species.

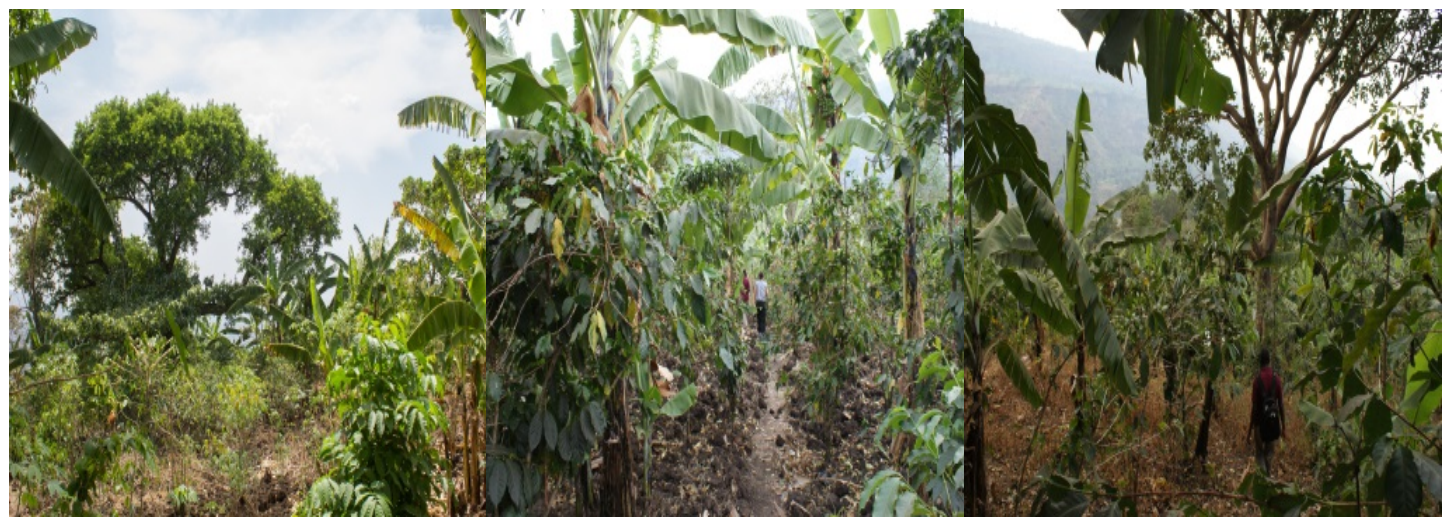

Fig. 3. Coffee cropping systems at Mt. Elgon. From left to right, Coffee-Open (CO), Coffee-Banana (CB) and Coffee - Shade Tree (CT)

Coffee cropping systems had an average size of $0.14 \pm 0.16$ ha and around $2147( \pm 163)$ coffee trees per $h^{-1}$. Type and intensity of shade followed the altitudinal gradient, with higher shade cover and shade tree diversity at lower altitudes. Banana densities, on the other hand, increased with altitude and coffee open systems were more frequent at higher altitudes (Rahn et al., 2018). Up to 37 different shade tree species were identified in the study area. Moreover, shaded systems at low altitude tend to retain higher number of shade tree species than systems at high altitude. Climatic conditions and access to forest and wealth were identified as the most important determinants of type of coffee system adoption. At lower altitudes, temperature is higher and more extreme, and access to forest it is limited. Hence, farmers tend to have higher shade tree density and diversity, especially for farmers that had a reduced number of coffee plots. On the other hand, wealthier farmers were less likely to have coffee intercropped (Rahn et al., 2018).

Further details on materials and methods are given in the following chapters. 


\section{References}

Alégre, C. (1959). Climates et caféiers d' Arabie. Agronomia Tropical, 58, 14-23.

Altman, P. L., \& Dittmer, D. S. (1964). BIOLOGY DATA BOOK. AMRL-TR-64-100. Amrl tr, 1-631.

Alvim, P. d. T. (1960). Moisture stress as a requirement for flowering of coffee. Science, 132(3423).

Baffes, J. (2006). Restructuring Uganda's Coffee Industry:

Why Going Back to Basics Matters. Oxford, UK: Blackwell Publishing.

Barros, R. S., Maestri, M., \& rena, A. B. (1991). Physiology of Growth and Production of the coffee tree. A review. Journal of Coffee Research(27), 1-54.

Bauer, H., Wierer, R., Hatheway, W. H., \& Larcher, W. (1985). Photosynthesis of Coffea arabica after chilling. Physiologia Plantarum, 64(4), 449-454. doi:https://doi.org/10.1111/j.1399-3054.1985.tb08521.x

Brett, E. A. (1992). Providing for the rural poor: institutional decay and transformation in Uganda. Brighton, UK: Institute of Development Studies, Brighton.

Browning, G. (1975). Environmental control of flower bud dormancy in Coffea arabica L. In J. J. Landsberg \& C. V. Cutting (Eds.), Environmentall Effects on Crop Physiology. London, UK: Academic Press.

Camargo, A. P. (1985). O clima e a cafeicultura no Brasil. Agropec, 11, 13-26.

Cannell, M. G. R. (1974). Factors affecting Arabica coffee bean size in Kenya. Journal of Horticultural Science, 49(1), 65-76. doi:10.1080/00221589.1974.11514552

Cannell, M. G. R. (1985). Physiology of the Coffee Crop. In M. N. Clifford \& K. C. Willson (Eds.), Coffee: Botany, Biochemistry and Production of Beans and Beverage (pp. 108-134). Boston, MA: Springer US.

Caramori, P. H., Ometto, J. C., Nova, N. A., \& Costa, J. D. (1986). Efeitos do vento sobre mudas de cafeeiro Mundo Novo e Catuaí Vermelho. Pesquisa Agropecuária Brasileira, 21, 1113-1118.

Carr, M. K. V. (2001). The water relations and irrigation requirements of coffee. Experimental Agriculture, 37, 1-36.

Coste, R. (1992). Coffee: the plant and the product.

Crawford, Y., P., S. N., \& H., R. T. (1981). Cooperatives and development: agricultural politics in Ghana and Uganda. Madison, Wisconsin: The University of Wisconsin.

Da Matta, F. M., Maestri, M., Barros, R. S., \& Regazzi, A. J. (1993). Water relations of coffee leaves (Coffea arabica and C. canephora) in response to drought. Journal of Horticultural Science, 68(5), 741-746. doi:10.1080/00221589.1993.11516407

DaMatta, F. M. (2004). Ecophysiological constraints on the production of shaded and unshaded coffee: a review. Field Crops Research, 86(2-3), 99-114. doi:10.1016/j.fcr.2003.09.001

DaMatta, F. M., \& Ramalho, J. C. (2006). Impacts of drought and temperature stress on coffee physiology and production: a review. Brazilian Journal of Plant Physiology, 18(1), 55-81.

DaMatta, F. M., Ronchie, C. P., Maestri, M., \& Barros, R. S. (2007). Ecophysiology of coffee growth and production. Brazilian Journal of Plant Physiology, 19(4), 485-510.

Descroix, F., \& Snoeck, J. (2008). Environmental Factors Suitable for Coffee Cultivation. In Coffee: Growing, Processing, Sustainable Production (pp. 164-177).

FAOSTAT. (2016). Food and Agriculture Organization of the United Nations. FAOSTAT Statistics Database.

Franco, C. m. (1958). Influence of temperature on growth of coffee plant. Retrieved from New York, NY:

Haarer, A. E. (1958). Modern Coffee Production.

Heath, O. V. S., \& Orchard, B. (1957). Midday Closure of Stomata: Temperature Effects on the Minimum Intercellular Space Carbon Dioxide Concentration “ $\Gamma$ ". Nature, 180(4578), 180-181. doi:10.1038/180180a0

ITC. (2012). The Coffee Exporters's Guide. Retrieved from Geneva:

Kanechi, M., Uchida, N. U., Yasuda, T., \& Yamaguchi, T. (1995). Water stress effects on leaf transpiration and photosyntheis of Coffea arabica L. under different irradiance conditions. Paper presented at the 16th International Scientific Colloquium on Coffee, Kyoto, Japan.

Kumar, D., \& Tieszen, L. L. (1980a). Photosynthesis in Coffea arabica. I. Effects of Light and Temperature. Experimental Agriculture, 16(1), 13-19. doi:10.1017/S0014479700010656

Kumar, D., \& Tieszen, L. L. (1980b). Photosynthesis in Coffea arabica. II. Effects of Water Stress. Experimental Agriculture, 16(1), 21-27. doi:10.1017/S0014479700010668

Kummar, D. (1979). Some aspects of the physiology of Coffea arabica L. A review. Kenya Coffee, 44, 9 - 47.

Maestri, M., \& Barros, R. S. (1977). Coffee. London, UK: Adameic Press.

Matiello, J. (1998). Café Conillon: Como Plantar, Tratar, Colher, Preparar e Vender. Retrieved from Rio de Janeiro, Brazil:

Matiello, J. B., Santinato, R., Garcia, A. W. R., Almeida, S. R., \& Fernandes, D. R. (2002). Cultura de Café no Brasil: Novo Manual de Recomendações. Rio de Janeiro: MAPA/PROCAFÉ.

Moshelion, M., Halperin, O., Wallach, R., Oren, R., \& Way, D. A. (2015). Role of aquaporins in determining transpiration and photosynthesis in water-stressed plants: crop water-use efficiency, growth and yield. Plant Cell Environ, 38(9), 1785-1793. doi:10.1111/pce.12410

Nunes, M. A., Bierhuizen, J. F., \& Ploegman, C. (1968). STUDIES ON PRODUCTIVITY OF COFFEE: I. EFFECT OF LIGHT, TEMPERATURE AND CO2 CONCENTRATION ON PHOTOSYNTHESIS OF COFFEA ARABICA. Acta Botanica Neerlandica, 17(2), 93-102. doi:10.1111/j.1438-8677.1968.tb00109.x

Odoul, P. A., \& Aluma, J. R. W. (1990). The banana (Musa spp.) - Coffee robusta: traditional 
agroforestry system of Uganda. Agroforestry Systems, 11, 213-226.

Rahn, E., Liebig, T., Ghazoul, J., van Asten, P., Läderach, P., Vaast, P., Sarmiento, A., Garcia, C., \& Jassogne, L. (2018). Opportunities for sustainable intensification of coffee agro-ecosystems along an altitudinal gradient on Mt. Elgon, Uganda. Agriculture, Ecosystems \& Environment, 263, 31-40. doi:10.1016/j.agee.2018.04.019

Ramalho, J. C., Quartin, V. L., Leitão, E., Campos, P. S., Carelli, M. L. C., Fahl, J. I., \& Nunes, M. A. (2003). Cold Acclimation Ability and Photosynthesis among Species of the Tropical Coffea Genus. Plant Biology, 5(6), 631-641. doi:10.1055/s-2003-44688

Ronquim, J. C., Prado, C. H. B. A., Novaes, P., Fahl, J. I., \& Ronquim, C. C. (2006). CARBON GAIN IN COFFEA ARABICA DURING CLEAR AND CLOUDY DAYS IN THE WET SEASON. Experimental Agriculture, 42(2), 147-164. doi:10.1017/S0014479705003121

Rutherford, M. A. (2006). Current knowledge of coffee wilt disease, a major constraint to coffee production in Africa. Phytopathology, 96(6), 663-666. doi:10.1094/PHYTO-96-0663

Sade, N., Vinocur, B. J., Diber, A., Shatil, A., Ronen, G., Nissan, H., Wallach, R., Karchi, H., \& Moshelion, M. (2009). Improving plant stress tolerance and yield production: is the tonoplast aquaporin SITIP2;2 a key to isohydric to anisohydric conversion? New Phytol, 181(3), 651-661. doi:10.1111/j.1469-8137.2008.02689.x

Silva, E. A., DaMatta, F. M., Ducatti, C., Regazzi, A. J., \& Barros, R. S. (2004). Seasonal changes in vegetative growth and photosynthesis of Arabica coffee trees. Field Crops Research, 89(2-3), 349-357. doi:10.1016/j.fcr.2004.02.010

UCDA. (2013). Annual Report. Retrieved from https://ugandacoffee.go.ug/annual-reports

UCDA. (2015). Uganda National Coffee Strategy 2040 Plan for 2015/16 - 2019/20. Retrieved from Kampala, Uganda:

UCDA. (2016). Annual Report. Retrieved from https://ugandacoffee.go.ug/annual-reports

UCDA. (2018). Annual Report. Retrieved from https://ugandacoffee.go.ug/annual-reports

Vaast, P., Bertrand, B., Perriot, J.-J., Guyot, B., \& Génard, M. (2006). Fruit thinning and shade improve bean characteristics and beverage quality of coffee (Coffea arabica L.) under optimal conditions. Journal of the Science of Food and Agriculture, 86(2), 197-204. doi:10.1002/jsfa.2338

van Asten, P. J. A., Wairegi, L. W. I., Mukasa, D., \& Uringi, N. O. (2011). Agronomic and economic benefits of coffee-banana intercropping in Uganda's smallholder farming systems. Agricultural Systems, 104(4), 326-334. doi:10.1016/j.agsy.2010.12.004

Willson, C. (1985a). Mineral Nutrition and Fertiliser Needs. In M. N. Clifford \& K. C. Willson (Eds.), Coffee: Botany, Biochemistry and Production of Beans and Beverage (pp. 135-156). Boston, MA: Springer US.

Willson, K. (1999). Coffee, cocoa and tea. Wallingford: CAB International.

Willson, K. C. (1985b). Climate and Soil. In M. N. Clifford \& K. C. Willson (Eds.), Coffee: Botany, Biochemistry and Production of Beans and Beverage (pp. 97-107). Boston, MA: Springer US.

Wintgens, J. N. (2004). Coffee: Growing, Processing, Sustainable Production. Weinheim, Germany: Wiley-VCH Verlag GmbH $\&$ Co. 


\section{Effect of cropping system, shade cover and altitude gradient on coffee yield components at Mt. Elgon, Uganda}

Alejandra Sarmiento-Soler ${ }^{1 *}$, Philippe Vaast ${ }^{2,3}$, Munir P. Hoffmann ${ }^{1,4}$, Laurence Jassogne ${ }^{5}$, Piet van Asten ${ }^{5,6}$, Sophie Graefe ${ }^{7,8}$ and Reimund P. Rötter ${ }^{1,9}$

${ }^{1}$ Tropical Plant Production and Agricultural Systems Modelling (TROPAGS), University of Göttingen, Göttingen, Germany 2UMR Eco\&Sols, Centre de Coopération Internationale en Recherche Agronomique pour le Développement (CIRAD), University of Montpellier, Montpellier, France

3 World Agroforestry Centre (ICRAF), Hanoi, Vietnam

${ }^{4}$ Leibniz Centre for Agricultural Landscape Research (ZALF), Müncheberg, Germany

5International Institute of Tropical Agriculture (IITA), Kampala, Uganda

${ }^{6}$ Olam International Ltd, Kampala, Uganda

7Tropical Silviculture and Forest Ecology, University of Goettingen, Göttingen, Germany

${ }^{8}$ Organic Plant Production and Agroecosystems Research in the Tropics and Subtropics (OPATS), University of Kassel, Witzenhausen, Germany

${ }^{9}$ Centre for Biodiversity and Land Use (CBL), University of Göttingen, Göttingen, Germany

*Corresponding author:

Alejandra Sarmiento-Soler

asarmie@gwdg.de

$\underline{\text { Grisebachstraße } 6}$

37077 Göttingen, Germany

\section{Published in the Journal Agriculture, Ecosystems and Environment}

Sarmiento-Soler, A., Vaast, P., Hoffmann, M. P., Jassogne, L., van Asten, P., Graefe, S., \& Rötter, R. P.(2020). Effect of cropping system, shade cover and altitudinal gradient on coffee yield components at Mt. Elgon, Uganda. Agriculture, Ecosystems \& Environment, 295. doi:10.1016/j.agee.2020.106887 


\section{Abstract}

Coffee is a key export commodity of East Africa, but average smallholders' yields are low. To guide sustainable yield improvements of smallholders' coffee systems, we investigated coffee yield components in three different types of coffee cropping systems along an altitude gradient (1100-2100 m.a.s.I.) during two production years (2015 and 2016). We selected 810 coffee trees distributed over 27 farms and monitored number of stems per tree, fruit load per branch, productive nodes per branch (on four branches of one stem per tree) and number of productive branches per stem (on one stem per selected tree) in both years. Additionally, we monitored productive stems per ha, coffee tree density and cherry weight in combination with pest and disease occurrence and management information from interviews. Coffee farms were classified as Coffee-Open (CO) $(<20 \%$ shade cover), Coffee-Banana (CB) (coffee dominantly intercropped with bananas) or Coffee-shade Tree (CT) (coffee dominantly intercropped with shade trees). Coffee-Banana had larger yield per ha (green bean kg ha $\left.{ }^{-1}\right)(1086 \pm 736$ $\left.\mathrm{kg} \mathrm{ha}^{-1}\right)$ and yield per stem (green bean $\left.\mathrm{kg} \mathrm{stem}^{-1}\right)\left(0.24 \pm 0.16 \mathrm{~kg} \mathrm{stem}^{-1}\right)$ than CO $\left(670 \pm 457 \mathrm{~kg} \mathrm{ha}^{-1}\right.$ and $\left.0.21 \pm 0.26 \mathrm{~kg} \mathrm{stem}^{-1}\right)$ and CT $\left(428 \pm 259 \mathrm{~kg} \mathrm{ha}^{-1}\right.$ and $\left.0.10 \pm 0.12 \mathrm{~kg} \mathrm{stem}^{-1}\right)$. Fruit loads, productive nodes, productive branches and cherry weight declined with shade cover, especially for shade cover $>30 \%$. Additionally, the same yield components correlated negatively with number of stems per tree. Fertilizer and fungicide use were related to more productive branches and cherry weight respectively, and stem borer was identified as the most important pest in this area. Our results suggest that yield in the region could be increased, i) by maintaining shade at an intermediate level, particularly at low and mid altitude and by reducing the number of stems per coffee tree $(<4)$, and ii) by improving soil fertility and protection against pest and disease.

Keywords: Coffea arabica, Agroforestry, Climate change, Productivity, East Africa, Yield components, Sustainable intensification, Production factors 


\section{Highlights}

- Coffee intercropped with banana had larger yield per ha than coffee under shade trees or in open conditions.

- Coffee yield components reduced when shade cover was above $30 \%$.

- $\quad$ Reducing number of stems per coffee tree can help to increase coffee yields

\section{Visual abstract}

\section{Effect of cropping system, shade cover and altitudinal gradient on coffee yield} components at Mt. Elgon, Uganda

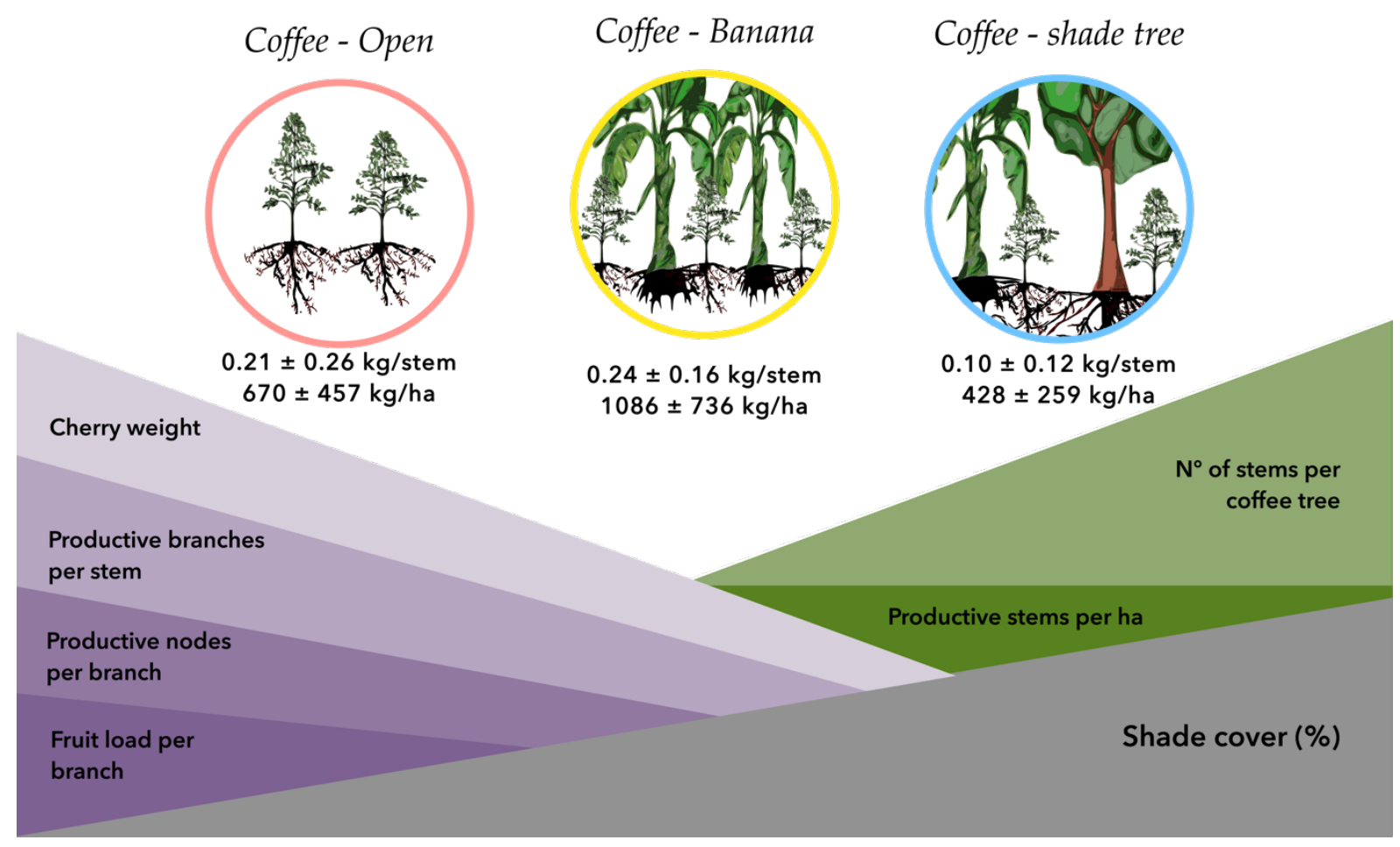




\subsection{Introduction}

Coffee is a key source of income for millions of smallholders in the developing world (ITC, 2012). However, smallholders' yields are often low ( $500 \mathrm{~kg}$ Green beans ha $\left.{ }^{-1}\right)$ (FAOSTAT, 2018) and sensitive to climate variability, extreme events and other hazards (Laderach et al., 2011; Baca et al., 2014; Vaast et al., 2016). Hence, identification of management options to improve coffee systems resilience while maintaining or enhancing coffee yield is urgently needed in the coffee sector (Laderach et al., 2011; Bunn et al., 2014; Craparo et al., 2015; Ovalle-Rivera et al., 2015; Vaast et al., 2016).

Generally, coffee is cultivated in a diverse range of cropping systems, ranging from complex agroforestry, mimicking secondary forests, to intensive monoculture with compact coffee varieties (Perfecto et al., 2005; Jha et al., 2014). The choice of a specific coffee cropping system is an important management decision, since different cropping systems will provide their set of benefits (i.e. pest control, microclimate regulation, pollination) and trade-offs (i.e. competition for water and nutrients) (Beer et al., 1998; Tscharntke et al., 2011; Jassogne et al., 2012; Jha et al., 2014; Rapidel et al., 2015; Padovan et al., 2018; Chain-Guadarrama et al., 2019). For instance, the use of shade trees has been specially recommended under sub-optimal environmental conditions (i.e. high temperatures, wind or sloping terrain) due to their proven microclimatic regulation and soil protection function (Beer et al., 1998; Vaast et al., 2016; Sarmiento-Soler et al., 2019).

Despite the fact that coffee yields might be reduced under shade due to less fruit loads (Cannell, 1985; Campanha et al., 2004; DaMatta, 2004; Franck et al., 2005; Vaast et al., 2006), several authors argued that lower fruit load in shaded systems can be counter-balanced at several levels: (i) coffee tree level by improving microclimate, reducing overbearing and die-back risk, reducing fruit drop and biennial patterns (DaMatta, 2004; Vaast et al., 2006; Vaast et al., 2008), (ii) plot level by soil nutrient provision, reduction of erosion, regulating microclimate (Cannavo et al., 2011; Souza et al., 2012; Villatoro-Sánchez et al., 2015; Meylan et al., 2017; Sarmiento-Soler et al., 2019; Sauvadet et al., 2019) and (iii) household level by diversifying income and improving food security (de Souza et al., 2011; Tscharntke et al., 2011; Lasco et al., 2014; Vaast et al., 2016). 
However, despite shaded coffee systems provide several key ecosystem services, coffee yield remains the most crucial for coffee farmers (Gobbi, 2000; Perfecto et al., 2005; Godfray \& Garnett, 2014). If coffee yields are low and not compensated by certification schemes or premium consumer prices, farmers may intensify their systems at the cost of short-term, but high-risk, gains (Perfecto et al., 2005; Vaast et al., 2006; Tscharntke et al., 2011; Jha et al., 2014). Although, high coffee yield can be achieved under open conditions and use of external chemical inputs and/or irrigation (Staver et al., 2001; Perfecto et al., 2005; DaMatta et al., 2018a), such conversion can have a detrimental effect on the environment, as well as increase the vulnerability of farmers, i.e. dependency on coffee prices, in the long run (Perfecto et al., 2005; Tscharntke et al., 2012; De Beenhouwer et al., 2013; Vaast \& Somarriba, 2014). Therefore, alternatives to increasing production are needed which adapt to local resource availability and do not harm the environment (Mbow et al., 2014a; Mbow et al., 2014b).

Within this context, this study aims to gain insights of how coffee yields could be improved under low input conditions in a smallholder context in an important Arabica coffee producing region on the footslopes of Mt. Elgon, Uganda (Liebig et al., 2016; Rahn et al., 2018a). We conducted an on-farm study to examine coffee yield components in different cropping systems along a shade cover and climate gradient (determined by altitude). We focused on the effects of shade cover and altitude have on the different coffee yield components (fruit load per branch, productive nodes per branch, productive branches per stem, cherry weight and productive stems per ha).

Specifically, we addressed the following research questions:

1. (i) What are the effects of cropping system (type and amount of shade cover) and altitude on coffee yield?

2. (ii) Which factors (cropping system and altitude) determine the different coffee yield components?

3. (iii) What are the relationships among the different yield components, and do these depend on the cropping system?

In posing these questions, we hypothesized that (a) low-shade coffee systems have higher yields in the more 'optimal' high altitude, while (b) at lower altitudes coffee systems produce comparable yield, despite their shade level. Moreover, we expect that (c) shade cover reduces branch fruit load, number of productive nodes per branch and number of productive branches, while increasing cherry weight. 
Additionally, (d) altitude positively affects yield components due to more rainfall and lower temperatures occurring at high altitude. Finally, (e) we expect a trade-off between fruit load and cherry weight, leading to heavier cherries under low fruit loads. Similarly, we expect a trade-off between fruit loads per stem and number of stems per tree and per hectare, due to an increase in self-shading with increases of stems per tree and per ha.

\subsection{Material and methods}

\subsubsection{Study site}

The study site is located on the Western slopes of Mount Elgon (peak at 4321 m a.s.I.) in Eastern Uganda. The research area covers $110 \mathrm{~km}^{2}$, between $1^{\circ} 15^{\prime} 00^{\prime \prime}-1^{\circ} 18^{\prime} 00^{\prime \prime}$ geographical latitude and $34^{\circ} 18^{\prime}-$ $34^{\circ} 24^{\prime}$ geographical longitude. It stretches along an altitudinal gradient from $1100 \mathrm{~m}$ a.s.l. to $2100 \mathrm{~m}$ a.s.I. and covers the districts of Bulambuli, Kapchorwa and Sironko. The landscape is characterized by escarpments, which divide the cultivation areas in three zones along the slope: low altitude (1100-1400 m.a.sl.), mid altitude (1400-1700 m.a.s.I.) and high altitude (1.700-2.400 m.a.sl.) (Fig. 1). These three zones were used in this study as altitude classes.

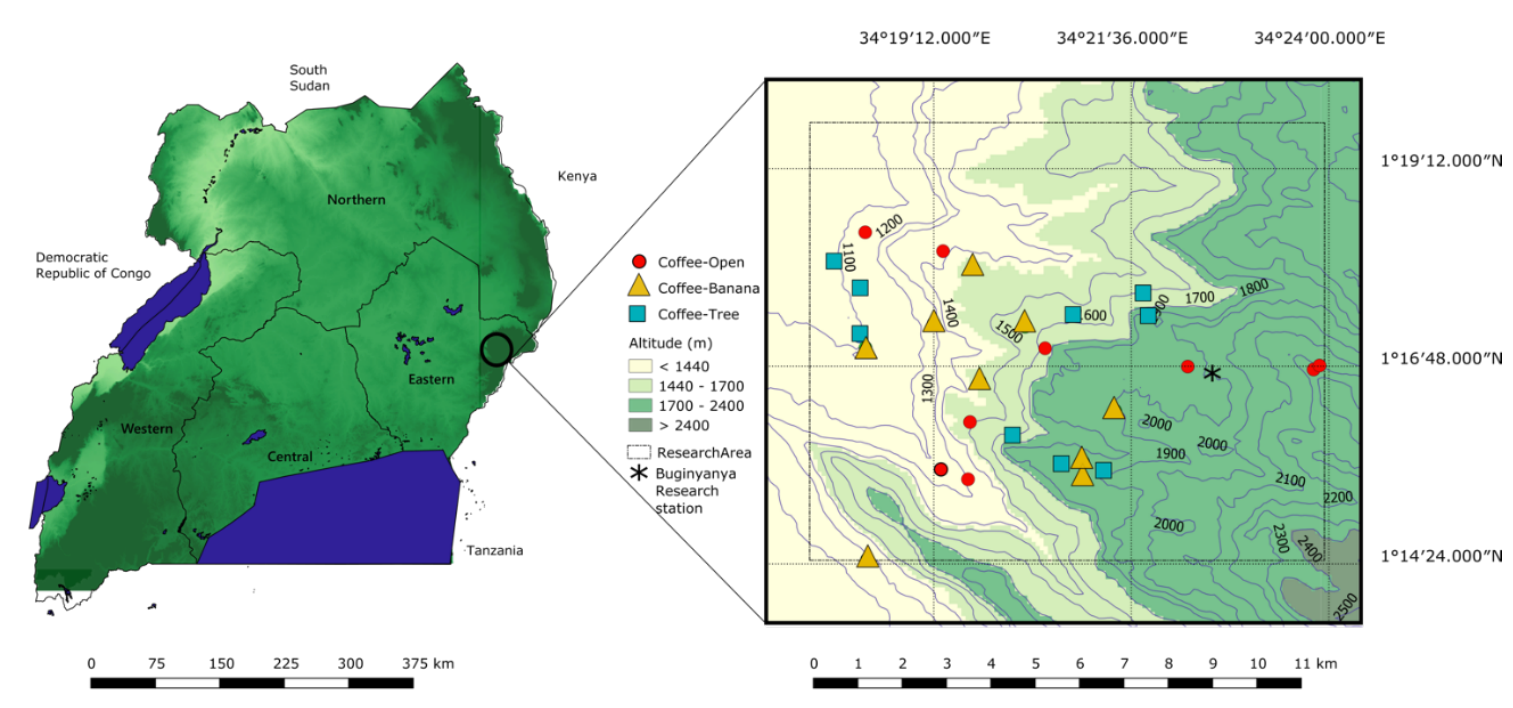

Fig. 1. Map of Uganda and research area with selected plots (27 plots) at three altitude classes: Low altitude (1100 - 1400 m.a.s.l.), mid altitude (1400 - 1700 m.a.s.l.) and high altitude $(1700-2100$ m.a.s.l). Plots belong to three different types of coffee cropping systems: 9 plots to Coffee Open = CO (Red circle), 9 plots to Coffee-Banana $=$ CB (Yellow triangle) and 9 plots to Coffee Tree $=$ CT (Blue square). Star $\left({ }^{*}\right)$ referes to Buginyianya Research Station at 1800 m.a.s.l.). 
Annual rainfall ranges from $1200 \mathrm{~mm}$ at low altitude (1200 m.a.s.l.) to $1670 \mathrm{~mm}$ at higher altitudes (2000 m.a.s.I). Rainfall is bimodal with January, February and December representing the driest months with an average $40 \mathrm{~mm} \mathrm{month}^{-1}$ at low altitude and $55 \mathrm{~mm}$ at high altitude (Fick \& Hijmans, 2017) (19702000). Mean temperature, extracted from WorldClim, is around $22 \pm 0.7^{\circ} \mathrm{C}$ at lower (1200 m.a.s.l.) and $16 \pm 0.7^{\circ} \mathrm{C}$ at higher altitudes (2000 m.a.s.l.) (Fick \& Hijmans, 2017) (Supplementary material, Figure.S1). Despite, the generalized used of the WorldClim data set, we found that in our study site, this extrapolation underestimates temperature at high altitude, since data from the closest weather station (Buginyanya, 1800 m.a.s.I., Supplementary material, Figure.S2), indicated a mean temperature of $18 \pm$ $2.5^{\circ} \mathrm{C}$ in the period between 2005 and 2015. Soils in Mt Elgon are predominantly Nitisols of volcanic origin with basalt as parent material (De Bauw et al., 2016). Soils at higher altitude are more weathered and have a lower pH (i.e. < 5.5) than at lower altitude (i.e. 7.5) (De Bauw et al., 2016).

\subsubsection{Data collection}

\subsubsection{1. $\quad$ Farmers and plot selection}

Previous studies in the area identified three main coffee systems, namely Coffee-Open (CO) (low shade), Coffee-Banana (CB) (coffee dominantly intercropped with bananas) and Coffee-shade Tree (CT) (coffee dominantly intercropped with shade trees) (Liebig et al., 2016; Rahn et al., 2018a). In this study, we aimed to have a homogenous sample of coffee plots along the three altitude classes: low altitude (1100 - 1400 ma.s.l.), mid altitude (1400 - 1700 m.a.s.I.) and high altitude (1.700 - 2100 m.a.sl.) (Nine plots per altitude class); and across the different types of systems (nine plots per system). Thus, we monitored 27 plots from a larger sample of 146 coffee farms that are part of the research project described by (Liebig et al., 2016) and (Rahn et al., 2018a). Plots were selected based on the following criteria: (i) occurrence of coffee trees in reproductive age ( $>3$ years old), (ii) active coffee management with no signs of abandonment, (iii) homogeneity of shade cover. For each coffee plot, we recorded surface area, number of coffee trees, bananas and shade trees, number of shade tree species, and shade cover at the beginning of the study period. Five replicates of composite topsoil samples $(0-30 \mathrm{~cm}$ depth) were collected in each plot and analyzed for $\mathrm{pH}$, soil organic matter (SOM \%) and macronutrients (i.e. total nitrogen (Kjeldahl), available phosphorous (Mehlich-III), and exchangeable cations (potassium (K), magnesium (Mg), calcium (Ca)) as described by (Okalebo et al., 1993). 


\subsubsection{2. $\quad$ Farmers interviews}

Each plot owner was interviewed in 2015 about management practices performed in the plot such as: coffee pruning, de-suckering, mechanical weeding, shade tree pruning, use of external inputs (fertilizer, insecticide, herbicide, fungicide) and about the presence of pest and diseases. After cleaning the data, and removing incongruent information, we remained with information from only 23 farmers.

\subsubsection{Coffee system characterization}

Coffee systems differed in density of banana stems, density of shade trees, shade cover, leaf area index (LAI) of the system, LAI of shade trees and number of stems per coffee tree (Table 1). We did not find significant differences in the density of coffee trees per ha across cropping systems. Similarly, cropping systems did not differ in surface area due to a high variability in CO and CT (Table 1). On the other hand, CT and CO had significantly more stems per tree than CB, but coffee LAI did not differ between cropping systems (Table 1). As expected, CT had the highest LAI of the shade (LAI Shade) component, followed by $\mathrm{CB}$, and $\mathrm{CO}$, which had the lowest $\mathrm{LAl}_{\text {shade. }}$. Nevertheless, we found that shade cover across cropping systems as well as LAl $\left.\right|_{\text {shade }}$ did not have well defined boundaries, and sometimes overlapped (Fig. 2.a). Therefore, in the analysis we included both cropping system and shade cover (as LAlshade) as factors, acknowledging that we might have confounding effects between them. Additionally, we did not find any significant differences in soil properties across cropping systems (Table 1). Nevertheless, pH decreased with increases in altitude and this reduction was system specific, as pH decrease with altitude was more accentuated in CB and CT than in CO (Fig. 2.b). Altitude had also a negative effect on exchangeable $\mathrm{Ca}$, but no significant cropping system effect (Supplementary material, Figure S3). 
Table 1: Plot characteristics according to coffee systems (Coffee-Open (CO), Coffee-Banana (CB) and Coffee-shade Tree (CT)).

\begin{tabular}{|lccc|}
\hline Variable & $\begin{array}{c}\text { CO } \\
(\mathbf{n}=9)\end{array}$ & $\begin{array}{c}\text { CB } \\
(\mathbf{n}=9)\end{array}$ & $\begin{array}{c}\text { CT } \\
(\mathbf{n}=9)\end{array}$ \\
\hline System characteristics & & & \\
\hline Altitude (m.a.s.l.) & $1614 \pm 378$ & $1540 \pm 314$ & $1533 \pm 343$ \\
Area (m2) & $2001 \pm 1305$ & $1126 \pm 597$ & $2062 \pm 1572$ \\
Density Coffee (Trees ha-1) & $2109 \pm 1169$ & $2085 \pm 760$ & $1758 \pm 491$ \\
Density Banana (Stems ha-1) & $148 \pm 316^{\mathrm{a}}$ & $786 \pm 426^{\mathrm{c}}$ & $370 \pm 472^{\mathrm{b}}$ \\
Density Shade Trees(Trees ha-1) & $28 \pm 27^{\mathrm{a}}$ & $36 \pm 38^{\mathrm{a}}$ & $110 \pm 82^{\mathrm{b}}$ \\
Shade cover (\%) & $16 \pm 12^{\mathrm{a}}$ & $19 \pm 12^{\mathrm{a}}$ & $46 \pm 18^{\mathrm{b}}$ \\
N $^{\circ}$ Coffee Stems Tree-1 & $3.2 \pm 1.5$ & $2.5 \pm 1.3$ & $3.7 \pm 2$ \\
LAl (System/Shade/Coffee) & $1.4 \mathrm{a} / 0.2^{\mathrm{a}} / 1.2^{\mathrm{a}}$ & $2.2^{\mathrm{b}} / 0.8^{\mathrm{b}} / 1.4^{\mathrm{a}}$ & $2.6^{\mathrm{b}} / 1.4 \mathrm{c} / 1.2^{\mathrm{a}}$ \\
Slope \% & $11 \pm 9$ & $16 \pm 8$ & $15 \pm 9$ \\
\hline Soil Properties (0-30 cm) & & & \\
\hline pH ${ }^{1}$ & $5.9 \pm 0.6$ & $5.8 \pm 0.5$ & $6.1 \pm 0.6$ \\
OM \% & $4.1 \pm 1.5$ & $4.5 \pm 2.4$ & $4.6 \pm 3$ \\
Soil N (\%) & $0.2 \pm 0.07$ & $0.27 \pm 0.05$ & $0.30 \pm 0.12$ \\
Soil P ppm & $34.1 \pm 24.5$ & $35 \pm 35$ & $56 \pm 53$ \\
Soil K (cmol kg-1) & $1.0 \pm 0.5$ & $1.08 \pm 0.6$ & $1.3 \pm 0.8$ \\
Soil Ca (cmol kg-1) & $14.7 \pm 7.8$ & $11.4 \pm 5.5$ & $15.1 \pm 4.5$ \\
Soil Mg (cmol kg-1) & $4.3 \pm 2.7$ & $3.02 \pm 4$ & $4.02 \pm 2.1$ \\
\hline
\end{tabular}

Significance levels: $()<0.1,.(*)<0.05,\left({ }^{* *}\right)<0.01$ and $\left({ }^{* *}\right)<0.001$.

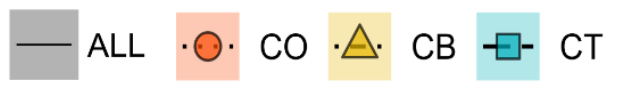

a)

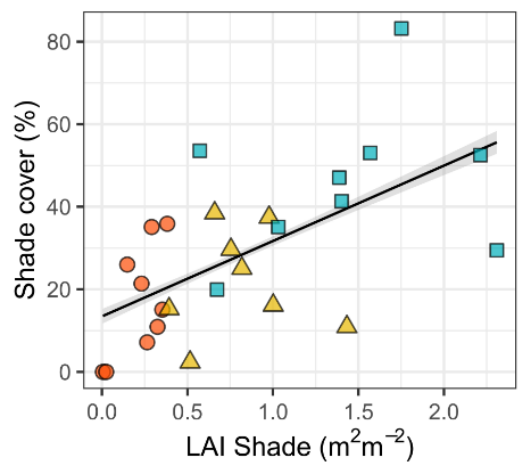

b)

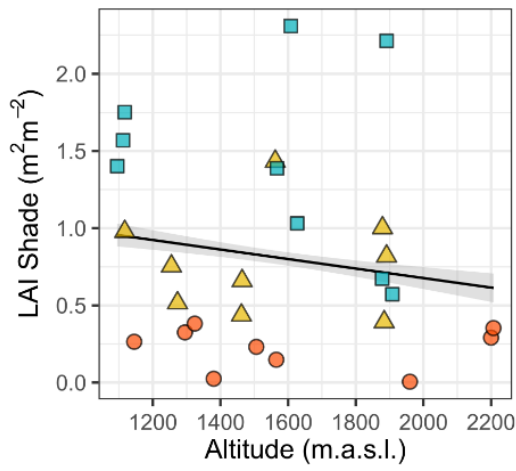

c)

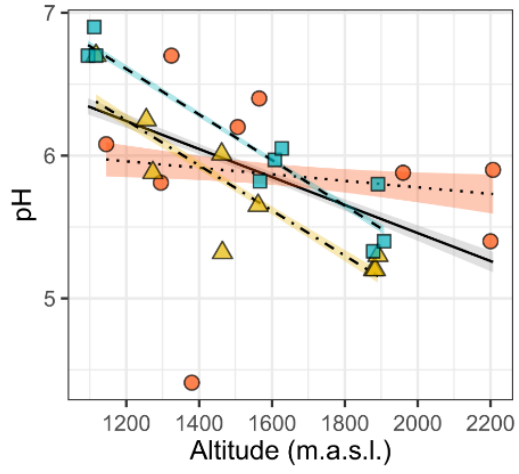

Fig. 2. a) Shade cover (\%) LAl shade $\left(m^{2} m^{-2}\right)(n=26)$, b) LAI shade $\left(m^{2} m^{-2}\right) \sim$ altitude (m.a.s.I.) ( $\left.\left.n=27\right), c\right) p H \sim$ altitude (m.a.s.I.) $(n=27)$, for three coffee systems (Coffee-Open $=$ CO (red circle), Coffee Banana = CB (yellow triangle) and Coffee -shade Tree $=C T$ (blue square) $(n=26)$. Shade cover of one CB system ( $\left(\right.$ Al shade $=0.4 \mathrm{~m}^{2} \mathrm{~m}^{-2}$ ) plot at mid altitude is missing. Line type indicates cropping system (solid $=$ all systems, dotted $=\mathrm{CO}$, dash - dotted $=\mathrm{CB}$ and dashed $=\mathrm{CT}$ ). 


\subsubsection{Coffee trees}

Coffee trees were selected following a systematic sampling in form of transects (Nath et al., 2009). Within each selected plot, 2-4 transects crossing at the center of the plot were marked. Afterwards, we selected all coffee trees along these transects, or every second tree, or every third tree until we reached a total of 30 selected coffee trees, and had approximately the same number of coffee trees per transect. On each coffee tree, variables were collected at three levels: (i) tree, (ii) stem (one stem per selected tree) and (iii) branch (four branches per selected stem distributed homogenously along the stem) (Fig. 3). Stem selection was done visually, the task was rotated within the field work team members (4-5 people) to avoid persistent bias. As principle, we selected average stems, avoiding too young ones or too old ones. These variables were monitored 12 times during the whole study period (from March 2015 to November 2016). Nevertheless, only data before the 2015 harvest season (September - November) and 2016 harvest season (September - November) are presented here as this study is focused on the final status of yield components just before harvesting time. To estimate coffee yield at stem level, we monitored yield components, fruit load per branch, productive nodes per branch and number of fruiting branches per stem before harvesting. Additionally, one hundred cherries were picked randomly in each plot during harvesting and weighted to estimate cherry weight. Harvesting occurred at different points in time depending on altitude, hence at low altitude in September, at middle altitude in October and at high altitude in November- December (Table 2). 
Table 2: Description of variables quantified and time of sampling, $F L=$ fruits load per branch, $P B=$ number of productive branches, $\mathrm{CW}=$ fresh cherry weight of 100 cherries $(\mathrm{g}), \mathrm{St}=$ number of stems in a coffee tree. ProSTha productive stems per ha, Yield per stem (Green beans kg stem ${ }^{-1}$ ), Yield per ha (Green beans kg ha ${ }^{-1}$ year $^{-1}$ ).

\begin{tabular}{|c|c|c|}
\hline Variable & Description & nation \\
\hline \multicolumn{3}{|l|}{ Measured variables } \\
\hline $\begin{array}{l}\text { Fruit load per branch } \\
\text { (FL) }\end{array}$ & Number of fruits per branch & Counted before harvesta \\
\hline $\begin{array}{l}\text { Productive node per } \\
\text { branch (PN) }\end{array}$ & Number of productive nodes per branch & Counted before harvest ${ }^{\mathrm{a}}$ \\
\hline $\begin{array}{l}\text { Productive branches } \\
\text { per stem (PB) }\end{array}$ & Number of productive branches per stem & Counted before harvest ${ }^{\mathrm{a}}$ \\
\hline $\begin{array}{l}\text { Stems per coffee tree } \\
\text { (St) }\end{array}$ & Number of stems per coffee tree & Counted before harvest ${ }^{\mathrm{a}}$ \\
\hline Cherry weight (CW) & Weight of 100 fresh cherries (g) & Weighted after harvest ${ }^{a}$ \\
\hline $\begin{array}{l}\text { Productive stems per } \\
\text { ha (ProSTha) }\end{array}$ & Productive stems per ha & Counteda \\
\hline CT density & $\begin{array}{l}\text { Density of coffee trees per hectare (Number trees ha- } \\
\text { 1) }\end{array}$ & Counted ${ }^{b}$ \\
\hline \multicolumn{3}{|l|}{ Estimated variables } \\
\hline Yield per stem & Yield of green beans (kg) per stem & YieldStem $=\mathrm{FL} \times \mathrm{PB} \times \mathrm{CW} * 0.16^{\mathrm{c}}$ \\
\hline Yield per ha & Yield of coffee green beans per ha $\left(\mathrm{kg} \mathrm{ha}^{-1} \mathrm{yr}^{-1}\right)$ & YieldHa $=$ YieldStem $\times$ ProSTha \\
\hline
\end{tabular}

a Harvest season 2015 and 2016. At Mt. Elgon occurs from September to November

b March 2014

c Conversion factor used to transform from fresh cherries to green bean

Coffee yield per hectare $\left(\mathrm{kg} \mathrm{ha}^{-1}\right)$ is a product of coffee yield per tree $\left(\mathrm{kg} \mathrm{tree}^{-1}\right)$ and density of coffee trees per hectare (number of coffee trees ha-1) (Cannell, 1985). Yield per tree is derived by fruit weight, fruit load per tree and the conversion factor from fresh cherries to green beans. Fruit load per tree is based on the fruit load per branch, productive branches per stem and number productive stems per tree (Cannell, 1985; Descroix \& Snoeck, 2008; Castro-Tanzi et al., 2014) (Fig. 3). Cannell (1985) argues that the most important components determining yield are number of productive nodes per branch and number of cherries per node. 
In this study, we included number of productive nodes and the fruit load per branch, since all cherries per branch were counted. Furthermore, based on the study of Castro-Tanzi et al. (2014), the position of the branch along the stem influenced the fruit load; we sampled four branches along the stem, to account for this variability. Moreover, coffee trees have a clear dimorphism in their reproductive and vegetative growth, in which, productive nodes are only developed on the lateral branches which grow from the nodes of the stems.

Finally, we included productive stems per ha as a yield component to be able to up-scale yield per stem to a hectare level. Furthermore, we included the variable number of stems per coffee tree to evaluate possible trade-offs between vegetative growth (represented by number of stems per coffee tree, thus resources put into formation of new wood and leaves) and reproductive growth (represented by fruit load per branch, productive nodes per branch, productive branches per stem and cherry weight). Previous studies suggest competition between vegetative and reproductive growth in coffee trees, which leads to larger vegetative growth in fruitless trees (Amaral et al., 2001; DaMatta et al., 2007). However, more stems per tree relate to more leaves, increasing self-shading and probably negatively affect other yield components.

\section{Coffee yield components}

\begin{tabular}{|c|c|}
\hline Plot level & Tree level \\
\hline $\begin{array}{l}\text { Trees per ha } \\
\quad \text { (Tha) }\end{array}$ & $\begin{array}{c}\text { Stems per tree } \\
\text { (STt) }\end{array}$ \\
\hline $\begin{array}{l}\text { Productive } \\
\text { stems per ha } \\
\text { (ProSTha) }\end{array}$ & \\
\hline
\end{tabular}

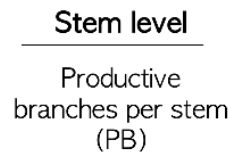

(PB)

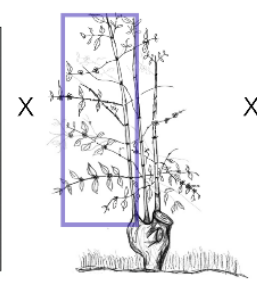

\section{Sampling design}

30 coffee trees per field, selected following transects

\begin{abstract}
One stem per coffee tree
\end{abstract}

Four branches per stem distributed homogeneously along the stem

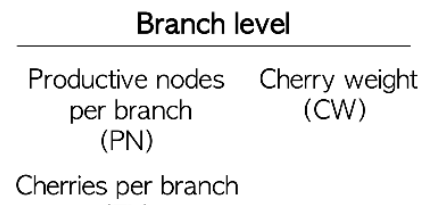

(FL)
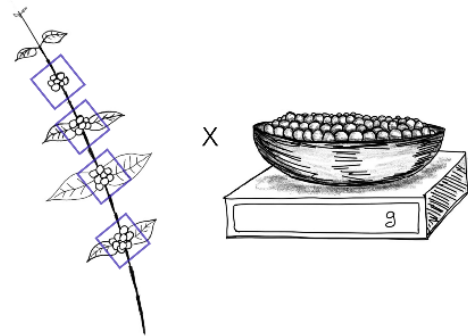
All productive nodes in the selected branch

Fig. 3. Coffee yield components and sampling design. Illustration from A. Sarmiento Soler (Visuals in Science LAB) 


\subsubsection{5. $\quad$ Shade cover and Leaf Area Index (LAI)}

Shade cover was measured once at the beginning of the study, using a Forestry Suppliers spherical crown densiometer (Lemmon, 1956). In each plot, four measurement points were taken above coffee trees and averaged to determine shade cover (\%) of the plot. Furthermore, LAI was monitored five times (July 2015, September 2015, November 2015, February 2016 and March 2016) during the study period with a LICOR 2200 C plant canopy analyzer (Model LAI-2270C, SR.NO.PCA- 3940, LICOR). LAI was measured at twenty points distributed systematically over each plot. During each measurement campaign, two different LAI measurements were collected: (a) below coffee trees, to capture LAl of the system and (b) above coffee trees to capture LAl of shade trees or banana above coffee trees. Three reference points at open areas were taken each time LAI was measured, as recommended by the manufacturer (Li-COR, 2009). In the present study, we correlated the averaged LAI (measured five times during the study period) with shade cover to extrapolate shade cover values per plot over the study period (Shade cover $(\%) \sim 18.2 \times$ LAl of shade $+13.4, p$-value $<0.00$, more details in supplementary material Table S1). For the analysis we used LAIshade, but added a figure (Fig. 2.a) to relate LAI Shade with shade cover for easier comparison with other studies, since shade cover is frequently used in agroforestry context (Soto-Pinto et al., 2000; Muschler, 2001; Romero-Alvarado et al., 2002; Perfecto et al., 2005; Boreux et al., 2016; Blaser et al., 2018).

\subsubsection{Data analysis}

\subsubsection{1. $\quad$ Models used}

We used linear mixed models ( $\mathrm{mm}$ ) and generalized linear mixed models $(\mathrm{g} / \mathrm{mm})$ to evaluate the effect of coffee systems ( $C O, C B$ and $C T$ ), shade cover (LAlshade) and altitude on coffee yield and yield components (fruit load, productive branches, cherry weight, stems per tree and productive stems per plot) averaged for 2015 and 2016 (Gbur, 2012). We introduced standardized altitude and LAl shade in the model and also accounted for interactions between these two factors. The selection of the "best model" explaining our data was done using the function dredge from the R package MuMIn, in which stepwise regression are performed and the model with the lowest Akaike Information Criterion (AIC) is selected (Bartoń 2019). PlotID was used as random effects since measurements were nested. Linear or generalized models were used depending on the nature of the response variable (continuous as cherry weight or discrete as fruit load per branch, productive nodes per branch, productive branches per stem and productive stems per ha) (Gbur, 2012). 


\subsubsection{Evaluation of other production factors}

Additionally, we performed a correlation test between yield components and other production factors (Table 3). We used Pearson correlation coefficient for continuous variables, i.e. soil characteristics. The effect of management practices and pest and disease incidence, obtained through farmers interviews, was tested separately for each yield component through glmm and simplified results: positive, negative or no effects are display in Table 3. Detailed model outputs are shown in supplementary material (Tables S2 and S3). Due to the reduced number of observations $(n=23)$, we did not include them in the global model. However, the information provided is valuable to understand the observed results and to draw conclusions later on.

Data analysis was performed using R (R core team 2017) and the packages: glmmTMB (Brooks et al., 2017), Ime4 (Bates et al., 2015), ImerTest (Kuznetsova et al., 2017), MuMIn (Bartoń 2019), car (Fox \& Wiesberg, 2019), and dplyr (Wickham et al., 2019). Graphs were produced using package ggplot2 (Wickham, 2016)(Wickham, 2016). 
Table 3: Production factors and yield components

\begin{tabular}{|c|c|c|c|c|c|c|c|c|c|c|c|}
\hline Production factors & $\begin{array}{l}\text { Type of } \\
\text { variable }\end{array}$ & & & & & $\begin{array}{l}\text { Fruit load } \\
\text { per } \\
\text { branch } \\
\text { (FL) }\end{array}$ & $\begin{array}{l}\text { Productive } \\
\text { nodes per } \\
\text { branch (PN) }\end{array}$ & $\begin{array}{l}\text { Productive } \\
\text { branches } \\
\text { per stem } \\
\text { (PB) }\end{array}$ & $\begin{array}{l}\mathrm{N}^{\circ} \text { of } \\
\text { stems } \\
\text { per } \\
\text { tree } \\
\text { (NSte } \\
\mathrm{m} \text { ) } \\
\end{array}$ & $\begin{array}{l}\mathrm{N}^{\circ} \text { of } \\
\text { productiv } \\
\text { e stems } \\
\text { per ha } \\
\text { (ProStem } \\
\mathrm{Ha} \text { ) }\end{array}$ & $\begin{array}{l}\text { Cherry } \\
\text { weigth } \\
(\mathrm{CW})\end{array}$ \\
\hline \multicolumn{12}{|l|}{$\begin{array}{l}\text { System } \\
\text { characteristics }\end{array}$} \\
\hline Altitude (m.a.s.l.) & Continuous & & & & & $(-) * * *$ & $(-) * * *$ & $(+) *$ & ns & ns & ns \\
\hline Area $\left(m^{2}\right)$ & Continuous & & & & & ns & ns & ns & ns & $(-) * * *$ & ns \\
\hline Shade cover (\%) & Continuous & & & & & $(-)^{*}$ & $(-)$ & $(-) * * *$ & $(-) * * *$ & ns & $(-)^{*}$ \\
\hline Age & Continuous & & & & & ns & ns & $(+) * *$ & $(-) * * *$ & ns & ns \\
\hline \multicolumn{12}{|c|}{ Soil Properties $(0-30 \mathrm{~cm})^{\mathrm{a}}$} \\
\hline $\mathrm{nH}^{1}$ & & & & & & & & & $(+)$ & & \\
\hline$\rho H^{2}$ & Continuous & & & & & $(-) * * *$ & $(-) * * *$ & $(-) * * *$ & $* * *$ & $(+) *$ & ns \\
\hline OM \% & Continuous & & & & & $(-) * * *$ & $(-)^{* * *}$ & $(-)^{* * *}$ & $(+) * *$ & ns & ns \\
\hline Soil N (\%) & Continuous & & & & & ns & ns & ns & ns & ns & ns \\
\hline Soil P ppm & Continuous & & & & & ns & ns & $(-) * * *$ & $(+) * *$ & ns & ns \\
\hline Soil K (cmol kg-1) & Continuous & & & & & $(-) * * *$ & $(-)^{* * *}$ & $(-)^{* * *}$ & ns & ns & ns \\
\hline Soil Ca (cmol kg-1) & Continuous & & & & & $(-) * * *$ & $(-)^{* * *}$ & $(-) * * *$ & $\begin{array}{l}(+) \\
* * *\end{array}$ & $(+)^{*}$ & ns \\
\hline Soil Mg (cmol kg-1) & Continuous & & & & & $(-)^{* * *}$ & $(-)^{* * *}$ & $(-)^{* * *}$ & $\begin{array}{l}(+) \\
* * * \\
\end{array}$ & $(+)^{*}$ & ns \\
\hline Management ${ }^{b}$ & & $\begin{array}{l}N \\
A\end{array}$ & Yes & No & $\begin{array}{c}\mathrm{CO}|\mathrm{CB}| \mathrm{C} \\
\mathrm{T}\end{array}$ & & & & & & \\
\hline Fungicide use & (Yes/No) & 5 & 5 & 17 & 1 | 1 | 3 & ns & ns & ns & ns & ns & $\begin{array}{l}+) \\
* * *\end{array}$ \\
\hline Fertilizer use & (Yes/No) & 4 & 8 & 15 & $3|3| 2$ & $\mathrm{~ns}$ & $(+)$. & $(+) *$ & ns & ns & ns \\
\hline Insecticide use & (Yes/No) & 5 & 15 & 7 & 1 | 1 | 5 & ns & ns & $(-) * *$ & ns & ns & ns \\
\hline Herbicide use & (Yes/No) & 4 & 18 & 5 & $3|0| 2$ & ns & ns & ns & ns & ns & ns \\
\hline $\begin{array}{l}\text { Manure use } \\
\text { Shade trees }\end{array}$ & (Yes/No) & 7 & 15 & 5 & $2|7| 6$ & ns & ns & ns & ns & ns & ns \\
\hline $\begin{array}{l}\text { prunning } \\
\text { Mechanical }\end{array}$ & (Yes/No) & 4 & 15 & 8 & $2|7| 6$ & ns & ns & ns & ns & ns & $(-)^{* *}$ \\
\hline weeding & (Yes/No) & 4 & 22 & 1 & $5|9| 8$ & ns & ns & ns & $(-)^{* *}$ & ns & ns \\
\hline Coffee prunning & (Yes/No) & 4 & 18 & 5 & $4|7| 7$ & ns & ns & ns & ns & ns & ns \\
\hline Desuckering & (Yes/No) & 7 & 20 & 0 & $4|8| 8$ & ns & ns & ns & ns & ns & ns \\
\hline Stumping & (Yes/No) & 4 & 8 & 15 & $1|2| 5$ & ns & ns & $\mathrm{ns}$ & ns & ns & ns \\
\hline Biotic $^{b}$ & & $\begin{array}{l}\mathrm{N} \\
\mathrm{A}\end{array}$ & Yes & No & $\begin{array}{c}\mathrm{CO}|\mathrm{CB}| \mathrm{C} \\
\mathrm{T}\end{array}$ & & & & & & \\
\hline Stemborer & (Yes/No) & 5 & 18 & 4 & $5|6| 7$ & $(-)^{*}$ & $(-)$ & $(-)$ & ns & ns & ns \\
\hline Coffee leaf rust & (Yes/No) & 5 & 14 & 8 & $5|4| 5$ & ns & ns & ns & $(-)$. & ns & ns \\
\hline Coffee berry borer & (Yes/No) & 5 & 2 & 20 & $0|0| 1$ & ns & ns & ns & ns & ns & ns \\
\hline Antesia bugs & (Yes/No) & 5 & 1 & 21 & $0|0| 1$ & ns & ns & ns & ns & $(+)^{*}$ & ns \\
\hline Scales & (Yes/No) & 5 & 3 & 19 & 1 | 1 | 1 & ns & ns & ns & ns & ns & ns \\
\hline Coffee leaf miner & (Yes/No) & 5 & 1 & 21 & $0|1| 0$ & ns & ns & ns & ns & ns & ns \\
\hline Aphids & (Yes/No) & 7 & 2 & 18 & $1|0| 1$ & ns & ns & ns & ns & ns & ns \\
\hline $\begin{array}{l}\text { Mites } \\
\text { Coffee berry }\end{array}$ & (Yes/No) & 5 & 1 & 21 & $1|0| 0$ & ns & ns & ns & ns & ns & ns \\
\hline disease & (Yes/No) & 5 & 4 & 18 & $4|7| 7$ & ns & ns & ns & $\mathrm{ns}$ & $(-)^{*}$ & ns \\
\hline
\end{tabular}

a Pearson -Correlation

b Generalized linear mixed model

Significance levels: $()<0.1,.\left({ }^{*}\right)<0.05,\left({ }^{*}\right)<0.01$ and $(* * *)<0.001$. 


\subsection{Results}

\subsubsection{Coffee yield and coffee yield componenets in the three studied systems}

Fruit load (FL) and productive branches (PB) were significantly larger in CB (17 $\pm 9 \mathrm{FL}$ and $35 \pm 10 \mathrm{~PB})$ than in CO (14 $\pm 12 \mathrm{FL}$ and $32 \pm 11 \mathrm{~PB})$ and CT (11 $\pm 9 \mathrm{FL}$ and $25 \pm 11 \mathrm{~PB})$. Coffee-Open and CB had similar number of productive nodes per branch ( $C O=5 \pm 2 \mathrm{PN}$ and $\mathrm{CB}=5 \pm 2 \mathrm{PN}$ ) and significantly larger than in CT $(4 \pm 1)$. We did not finnd any significantly differences across systems in cherry weight (CO $=212 \pm$ $26 g_{100 \text { cherries, }} C B=217 \pm 27 g_{100}$ cherries and $C T=200 \pm 23 g_{100}$ cherries $)$. Similarly, systems did not differ significantly in the number of productive stems per ha (ProSTha) ( $C O=4141 \pm 1864, C B=4540 \pm 1428$ and $\mathrm{CT}=4289 \pm 24443)$. However, $\mathrm{CT}$ had the largest number of stems per tree (St) (3.7 \pm 1.2$)$, followed by $\mathrm{CO}(3.3 \pm 0.8)$ and $\mathrm{CB}$ had the lowest $(\mathrm{St})(2.5 \pm 0.8)$.

When integrating yield components to estimate yield per stem and yield per ha, we found that $\mathrm{CB}$ and CO had significantly larger yield per stem (i.e. $0.24 \mathrm{~kg}$ and $0.20 \mathrm{~kg}$, respectively) than CT (0.10 kg) (Fig. 4.a). Consequently, $C B$ and $C O$ had larger yield per ha $(C B=1086 \mathrm{~kg}$ and $C O=670 \mathrm{~kg})$ than $C T(428 \mathrm{~kg})$, but significant differences in yield per ha across systems, only occurred between CB and CT (Fig. 4.d). Yield per stem and yield per ha reduced significantly with LAlshade increasing and this trend was consistent across altitude classes (Fig. 4.b and 4.e). We observed a threshold around LAlshade $>1 \mathrm{~m}^{2} \mathrm{~m}^{-2}$ (which matches with $30 \%$ shade cover, see Fig. 2a), below $1 \mathrm{~m}^{2} \mathrm{~m}^{-2}$ LAlshade, a wide range of yield values per stem $(0.05 \mathrm{~kg}-0.6 \mathrm{~kg})$ and ha $(250-2500 \mathrm{~kg})$ occurred. However, for LAlshade $>1 \mathrm{~m}^{2} \mathrm{~m}^{-2}$, yield did not surpass $0.2 \mathrm{~kg}$ per stem or $1200 \mathrm{~kg}$ per ha (Fig. 4.b and 4.e). Altitude effect on coffee yield (per stem and per ha) differed depending on the type of system. In CB, yield (per stem and ha) was reduced with altitude while it was the opposite in the case of yield per stem in CT, which increased with altitude (Fig. 4.c). We did not find a significant altitudinal effect on yield in CO (Fig. 4.c and 4.f). 
a)

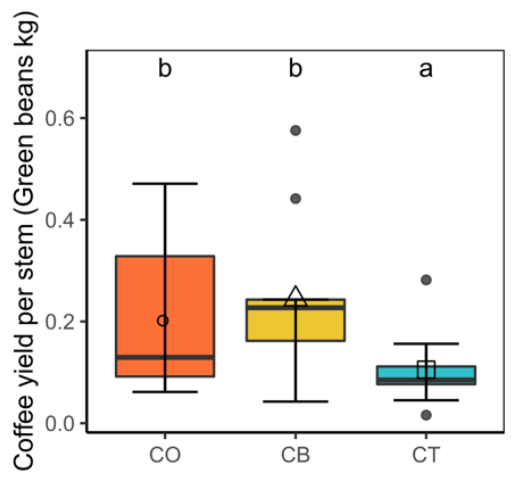

d)

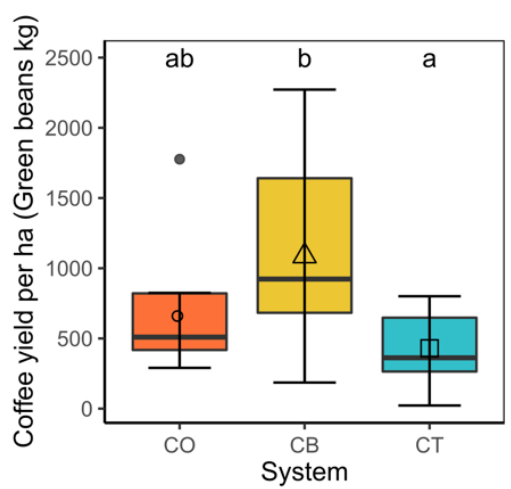

b)

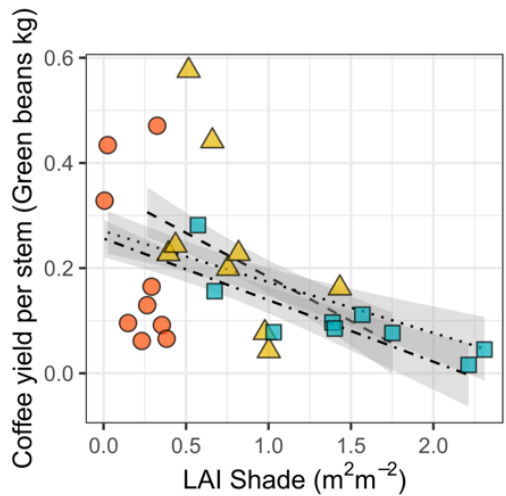

e)

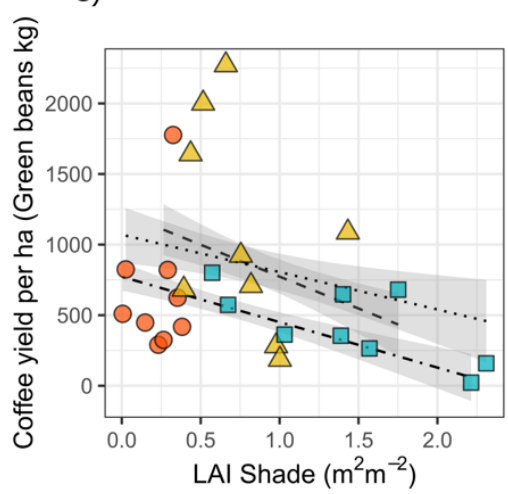

c)

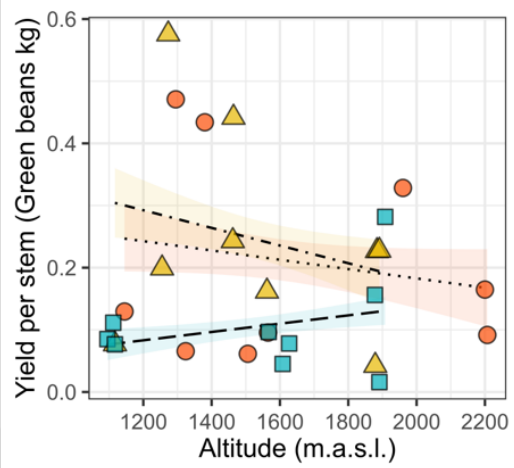

f)

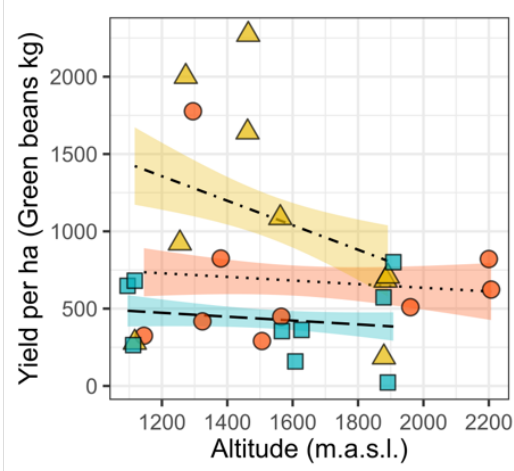

Fig. 4. a) Coffee yield per stem by cropping system, b) Coffee yield per stem $\sim$ LAI Shade $\left(\mathrm{m}^{2} \mathrm{~m}^{-2}\right)$, c) Coffee yield per stem $~$ Altitude (m.a.s.I.), (d) Coffee yield per ha by cropping system, e) Coffee yield per ha LAI Shade $\left(\mathrm{m}^{2} \mathrm{~m}^{-2}\right)$, f) Coffee yield per ha $\sim$ Altitude (m.a.s.I.). In a) and d), symbol indicates mean per cropping system and solid horizontal bar indicates median per cropping system and letters indicate significance values at $\mathrm{p}$-value $<0.05$. In b), c), e) and f), cropping systems are identified by colour and symbol, Coffee-Open = CO (red circle), Coffee-Banana = CB (yellow triangle) and Coffee -shade Tree $=$ CT (blue square). In b) and e) line type indicates altitude class: dashed = Low altitude (1100 - 1400 m.a.s.l.), dotted = mid altitude (1400 -1700 m.a.s.l.) and dash-dotted $=$ in high altitude (1700 - 2100 m.a.s.I.). In c) and f), line type indicates cropping system: dotted $=\mathrm{CO}$, dash-dotted $=\mathrm{CB}$ and dashed $=\mathrm{CT}) .{ }^{*}$ Three of the four plots with yield per ha $>1500$ Green bean kg reported use of fertilizer, the other plot did not use fertilizer. See fig. 9 for more details.

\subsubsection{Factors affecting yield components}

We found that the most complex model, a model including LAlshade; altitude and their interaction (LAI Shade $x$ altitude) was selected as the "best model" (Lowest AIC) in the case of productive nodes (Table 4), although, in this model LAlshade - altitude interaction was not significant. For the other yield components (fruit load, productive nodes per branch and cherry weight), the "best model" included either LAIshade (for PB and CW), or both LAlshade and altitude without interaction; as in the case of fruit load. Number of productive stems per ha was neither correlated with LAlshade nor with altitude (Table 4).

The studied yield components decrease with LAIshade increases. Similarly, FL and PN reduced with altitude increases (Fig. 5). 
○

a)

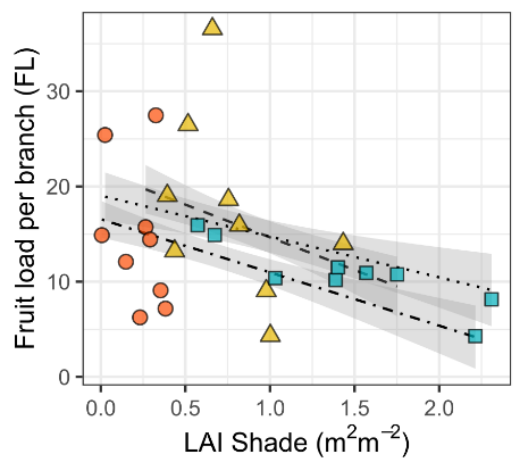

d)

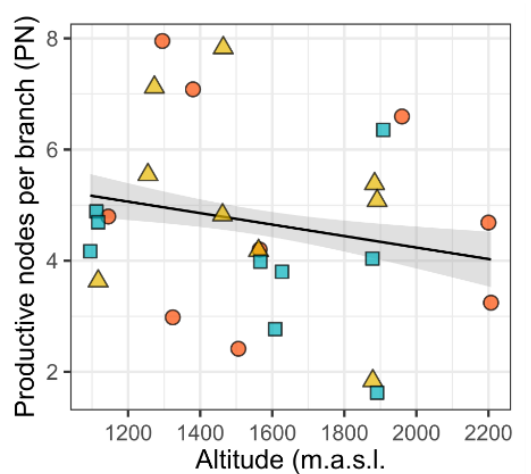

b)

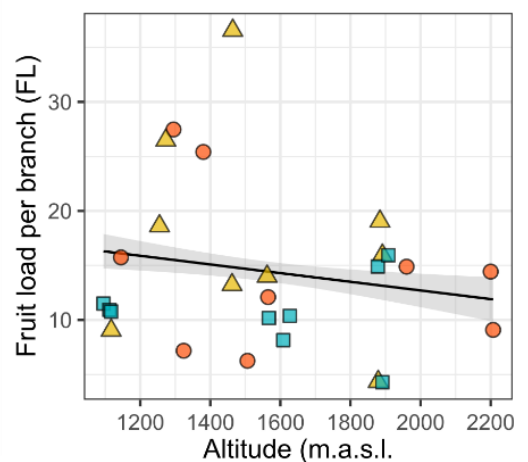

e)

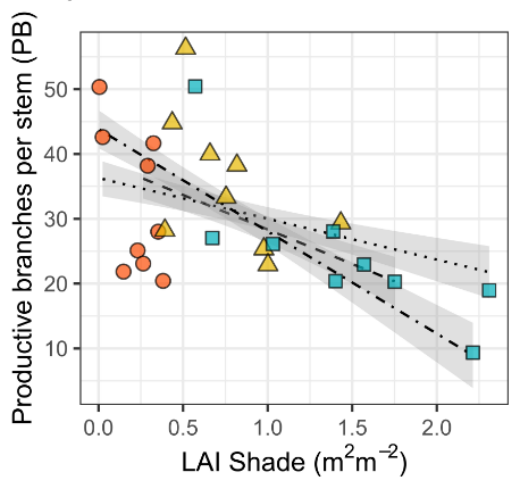

c)

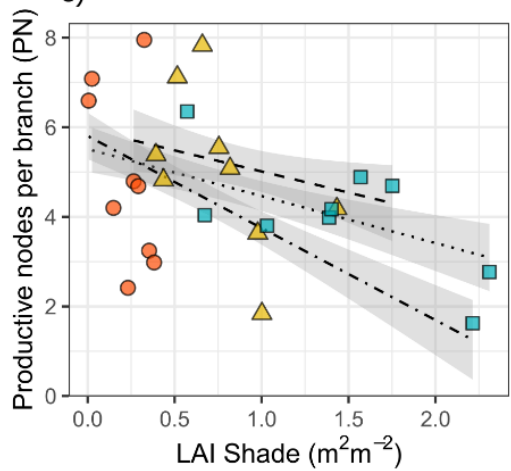

f)

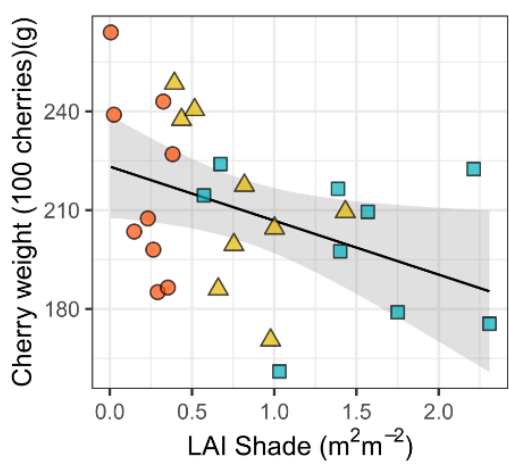

Fig. 5. a) Fruit load per branch $\sim \operatorname{LAl}$ shade $\left(\mathrm{m}^{2} \mathrm{~m}^{-2}\right)$, b) Fruit load per branch Altitude (m.a.s.l.), c) Productive nodes per branch $\sim$ LAl shade $\left(\mathrm{m}^{2} \mathrm{~m}^{-2}\right)$, d) Productive nodes per branch Altitude (m.a.s.l.), e) Productive branches per stem $\sim \operatorname{LAl}$ shade $\left.\left(\mathrm{m}^{2} \mathrm{~m}^{-2}\right), \mathrm{f}\right)$ Cherry weight $\sim \mathrm{LAl}$ shade $\left(\mathrm{m}^{2} \mathrm{~m}^{-2}\right)$. Cropping systems are identified by colour and symbol, Coffee-Open $=\mathrm{CO}$ (red circle), Coffee Banana $=$ CB (yellow triangle) and Coffee -shade Tree $=$ CT (blue square)). Line type indicates altitude class: dashed $=$ Low altitude $(1100-1400$ m.a.s.l.), dotted= mid altitude $(1400-1700$ m.a.s.l. $)$, dash-dotted $=$ in high altitude $(1700-2100$ m.a.s.l) and solid = all classes. 
Table 4: Best model for each yield component (Fruit load = FL, productive nodes per branch $=$ PN, productive branches per stem $=\mathrm{PB}$, productive stems per ha $=$ ProSTha and cherry weight $=\mathrm{CW}$ )

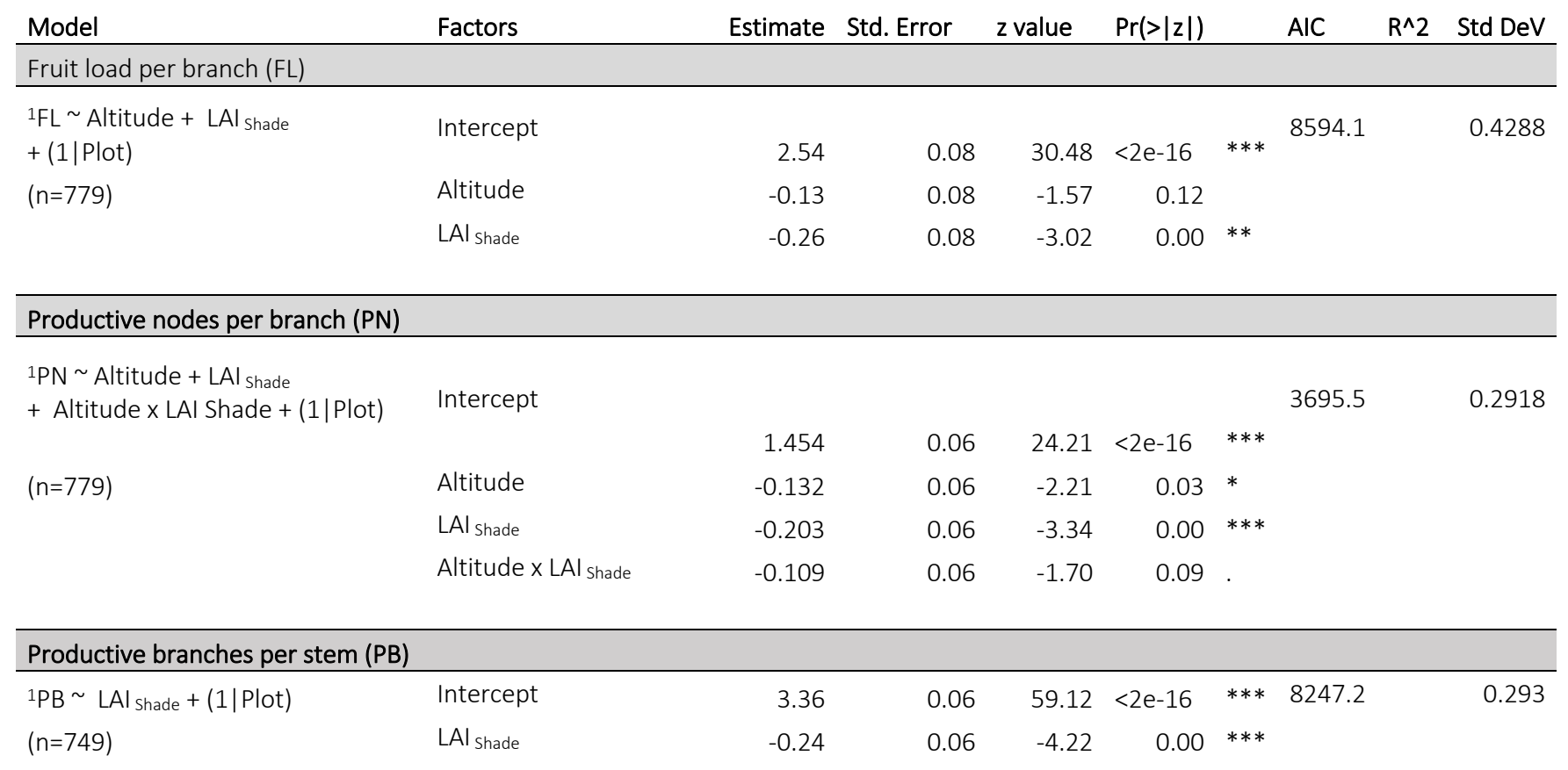

\begin{tabular}{|c|c|c|c|c|c|c|c|c|}
\hline & & Estimate & Std. Error & t value & $\operatorname{Pr}(>|t|)$ & & $\mathrm{AIC}$ & $\mathrm{R}^{\wedge} 2$ \\
\hline \multicolumn{9}{|c|}{ Productive stems per ha (ProSTha) } \\
\hline${ }^{2}$ ProStemHa $~ N A$ & - & - & - & - & - & - & - & - \\
\hline$(n=26)$ & - & - & - & - & - & - & - & - \\
\hline \multicolumn{9}{|l|}{ Cherry weight (CW) } \\
\hline${ }^{3} \mathrm{CW} \sim \mathrm{LAl}$ Shade & Intercept & 209.91 & 4.60 & 45.65 & $<2 \mathrm{e}-16$ & $* * *$ & 251.9 & 0.16 \\
\hline$(n=27)$ & LAI Shade & -10.47 & 4.69 & -2.23 & 0.03 & * & & \\
\hline
\end{tabular}

Significance levels: $()<0.1,.\left({ }^{*}\right)<0.05,\left({ }^{* *}\right)<0.01$ and $(* * *)<0.001$.

${ }^{1}$ Generalized Linear Mixed Model with log link

2 Generalized Linear Model with log link

${ }^{3}$ Linear Model

\subsubsection{Correlation between yield components}

Number of stems per tree (St) was negatively correlated with fruit load per branch (FL), productive nodes per branch (PN), productive branches per stem (PB) and cherry weight (CW) (Table 5 and Figs. 6.a, 6.b, 6.c and 6.d). Furthermore, productive stems per ha (ProSTha) was negatively correlated with FL, PN, PB and CW (Table 5 and Figs. 6.e,. $f$ and. g). Coffee tree density (Tree ha ${ }^{-1}$ ) was negatively correlated with CW (Fig. 6.h) and St (Table 5), but positively with ProSTha per ha (Table 5). 
When looking at the correlation between yield components in each system separately, we found similar trends as for the overall data set. However, in the case of $\mathrm{CB}$, negative correlations between St and the other yield components (FL, PN, PB and CW) were not significant, except for CW St (Table 5). The latter was probably due to the fact that this system had a lower number of stems per tree.

Table 5: Correlation between coffee yield components (Fruit load = FL, productive nodes per branch $=\mathrm{PN}$, productive branches per stem $=\mathrm{PB}$, cherry weight $=\mathrm{CW}$ and productive stems per ha $=$ ProSTha)

\begin{tabular}{|c|c|c|c|c|c|c|c|c|c|}
\hline & & \multicolumn{2}{|c|}{ All } & \multicolumn{2}{|l|}{$\mathrm{CO}$} & \multirow{2}{*}{\multicolumn{2}{|c|}{$\begin{array}{r}C B \\
\text { estimate }\end{array}$}} & \multicolumn{2}{|c|}{ CT } \\
\hline \multicolumn{2}{|c|}{ Yield components } & estimate & sig. & estimate & sig. & & & estimate & sig. \\
\hline $\mathrm{FL}$ & PN & 0.81 & $* * *$ & 0.84 & $* * *$ & 0.80 & $* * *$ & 0.84 & $* * *$ \\
\hline $\mathrm{FL}$ & PB & 0.38 & $* * *$ & 0.37 & $* * *$ & 0.36 & $* * *$ & 0.37 & $* * *$ \\
\hline $\mathrm{FL}$ & St & -0.16 & $* * *$ & -0.21 & $* * *$ & -0.08 & n.s. & -0.21 & $* * *$ \\
\hline $\mathrm{FL}$ & CW & 0.16 & $* * *$ & 0.26 & $* * *$ & 0.04 & n.s. & 0.26 & $* * *$ \\
\hline $\mathrm{FL}$ & ProSTHa & -0.08 & $* *$ & -0.33 & $* * *$ & -0.03 & n.s. & -0.33 & $* * *$ \\
\hline $\mathrm{FL}$ & CT density & 0.03 & n.s & -0.12 & n.s & 0.09 & n.s. & -0.12 & n.s. \\
\hline PN & PB & 0.48 & $* * *$ & 0.50 & $* * *$ & 0.46 & $* * *$ & 0.50 & $* * *$ \\
\hline PN & St & -0.18 & $* * *$ & -0.28 & $* * *$ & -0.09 & n.s. & -0.28 & $* * *$ \\
\hline PN & CW & 0.21 & $* * *$ & 0.37 & $* * *$ & 0.10 & n.s. & 0.37 & $* * *$ \\
\hline PN & ProSTHa & -0.09 & $* *$ & -0.40 & $* * *$ & -0.04 & n.s. & -0.40 & $* * *$ \\
\hline PN & CT density & -0.01 & n.s & -0.17 & $* *$ & 0.01 & n.s. & -0.17 & $* *$ \\
\hline PB & St & -0.31 & $* * *$ & -0.40 & $* * *$ & -0.24 & $* * *$ & -0.40 & $* * *$ \\
\hline PB & CW & 0.32 & $* * *$ & 0.41 & $* * *$ & 0.29 & $* * *$ & 0.41 & $* * *$ \\
\hline PB & ProsTHa & -0.13 & $* * *$ & -0.38 & $* * *$ & 0.03 & n.s. & -0.38 & $* * *$ \\
\hline PB & CT density & 0.06 & n.s. & -0.11 & n.s. & 0.14 & $* *$ & -0.11 & n.s. \\
\hline St & CW & -0.29 & $* * *$ & -0.43 & $* * *$ & -0.22 & $* * *$ & -0.43 & $* * *$ \\
\hline St & ProSTHa & 0.00 & n.s. & 0.23 & $* * *$ & -0.03 & n.s. & 0.23 & $* * *$ \\
\hline St & CT density & -0.10 & $* * *$ & 0.10 & n.s. & -0.35 & $* * *$ & 0.10 & n.s. \\
\hline$C W$ & ProSTHa & -0.40 & $* * *$ & -0.60 & $* * *$ & -0.07 & n.s. & -0.60 & $* * *$ \\
\hline$C W$ & CT density & -0.25 & $* * *$ & -0.58 & $* * *$ & 0.03 & n.s. & -0.58 & $* * *$ \\
\hline ProsTHa & CT density & 0.63 & $* * *$ & 0.68 & $* * *$ & 0.68 & $* * *$ & 0.68 & $* * *$ \\
\hline
\end{tabular}


a)

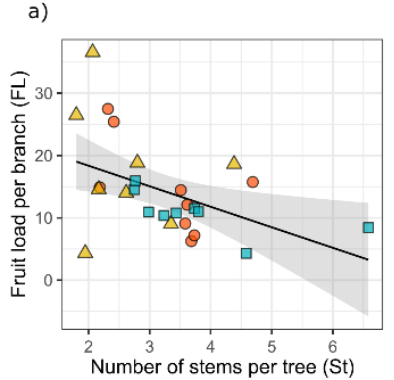

e)

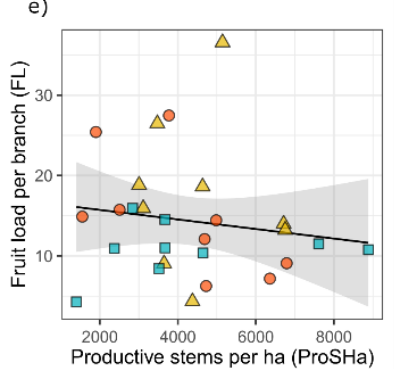

b)

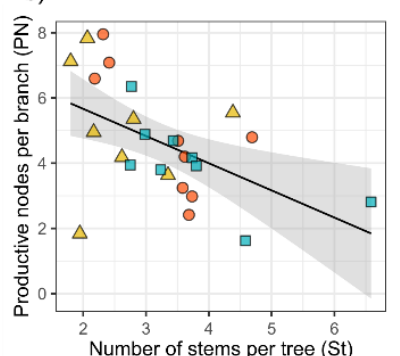

f)

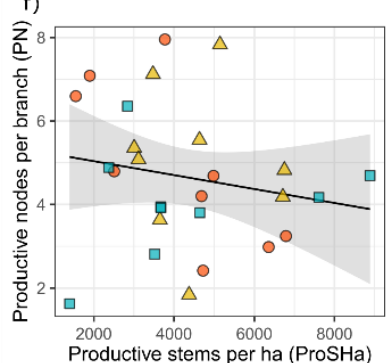

c)

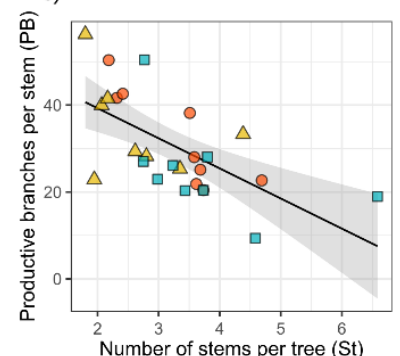

g)

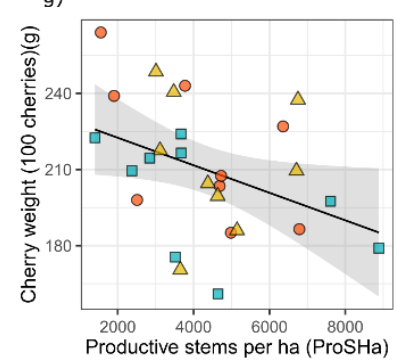

d)

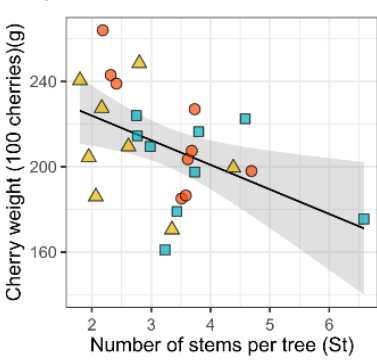

h)

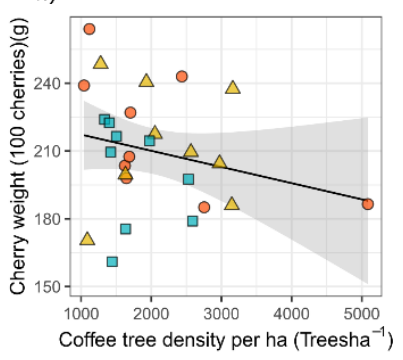

Fig. 6. a) Fruit load per branch Number of stems per tree, b) Productive nodes per branch Number of stems per tree, c) Productive branches per stem $\sim$ Number of stems per tree, d) Cherry weight $\sim$ Number of stems per tree, e) Fruit load per branch $\sim$ Productive stems per ha, f) Productive nodes per branch $\sim$ Productive stems per ha, g) Cherry weight $\sim$ Productive stems per ha and h ) Cherry weight $\sim$ coffee tree density per ha. Cropping systems are identified by colour and symbol, CoffeeOpen = CO (red circle), Coffee Banana = CB (yellow triangle) and Coffee - shade Tree = CT (blue square)). Line type indicates all systems.

\subsubsection{Management and pest and disease incidence reported by farmers}

The implementation of management practices was homogenously across cropping systems and altitudes (Table 3 and Fig. 7), although we missed data from CO systems at high altitude, which could explain why at first glance it seemed less farmers with CO systems reported management practices. Eight of twenty-three farmers (34\%) reported use of fertilizer (Table 3), however, these farms did not always achieve the highest yields. Only three of eight farmers applying fertilizers had yield per ha above $1000 \mathrm{~kg} \mathrm{ha}^{-1}$ (Fig. 7). Insecticide and herbicide use was more even, reported positively by 15 (68 \%) farmers and negatively by 18 (78\%) farmers (of total 23) (Table 3). As many as 15 out of 20 farmers (75 $\%)$ reported the use of manure, but only $5(22 \%)$ reported fungicide use. Most of the farmers performed mechanical weeding (95\%) (Table 3). In general, use of fertilizer and fungicide correlated positively with the number of productive branches per stem and cherry weight respectively (Table 3 ).

Stem borer coincided significantly with lower fruit loads. Stem borer was also related to less productive nodes per branch and less productive branches per stem (but not significantly p-value $=0.06$ and 0.08 , respectively). Surprisingly, coffee berry borer and coffee berry diseases did not have any effect on any of the yield components. Except for coffee berry disease in productive stems per ha (Table 3). 


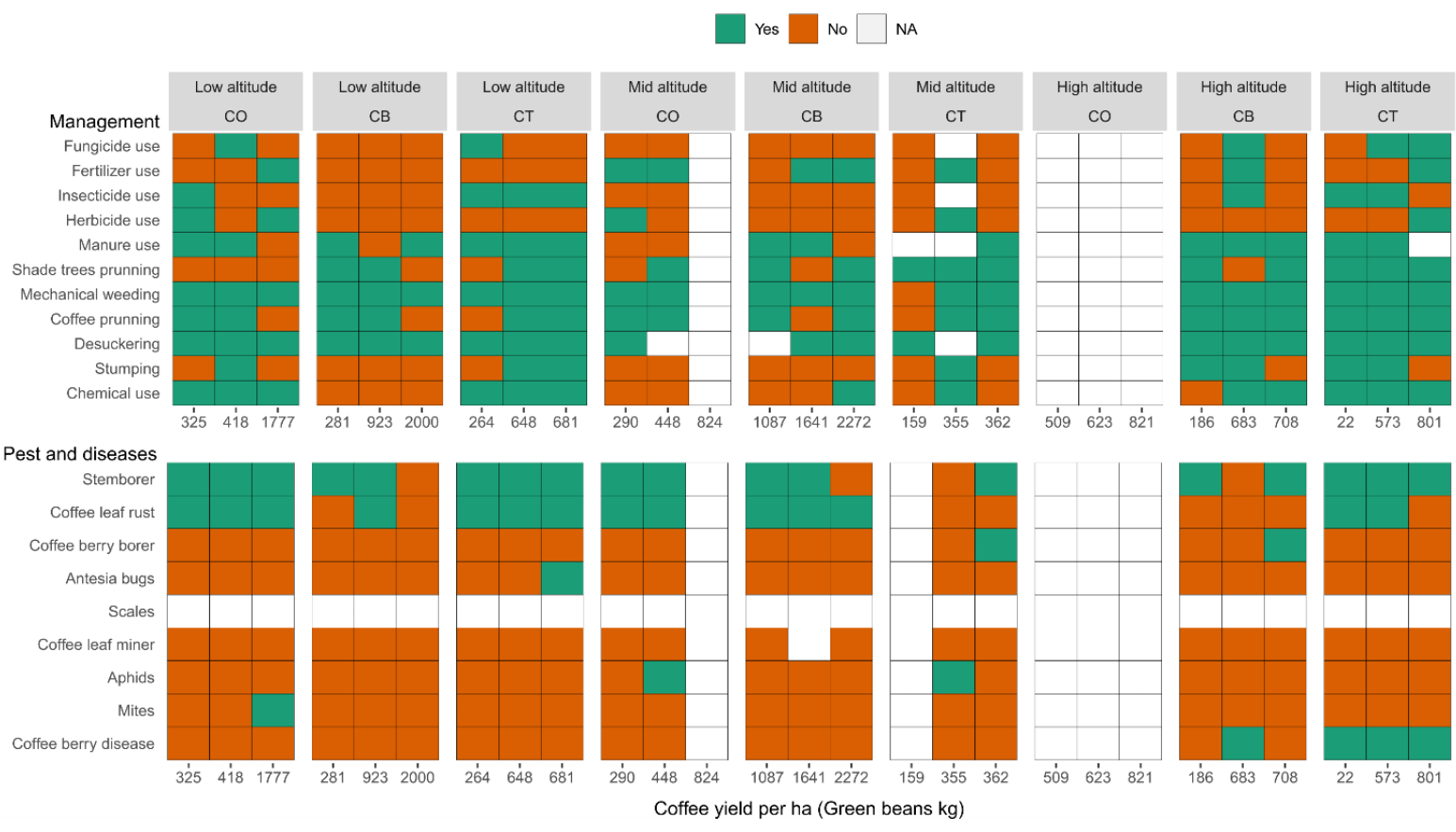

Fig. 7. Management implementation and pest and disease incidence reported by farmers. Each column refers to a plot of the study. Type of cropping system ( $C O$ = Coffee-Open, CB = Coffee-Banana and CT = Coffee-shade Tree) and altitude class are depicted on the top and coffee yield per ha (Green beans $\mathrm{kg}$ ) at the bottom, corresponding to each of the plots. Green colour indicates "Yes" to management practices implementation or to pest and disease presence. Orange colour indicates "No", that the management practices were not performed or that the specific pest or diseases were not present in the plot. White colour indicates not available information. 


\subsection{Discussion}

This study investigated coffee yield (per stem and per ha) and coffee yield components (fruit load per branch (FL), productive nodes per branch (PN), productive branches per stem (PB), stems per tree (St), cherry weight (CW) and productive stems per ha (ProSTha) in three different coffee cropping systems, along a shade cover ( $\mathrm{LAl}_{\text {shade }}$ ) and altitude gradient. We found larger fruit loads per branch, productive nodes per branch and more productive branches per stem in $\mathrm{CO}$ and $\mathrm{CB}$ systems than in the CT system and no system effect on productive stems per ha and cherry weight. This consequently resulted in larger yield per stem and per ha in CO and CB than in CT.

Fruit load per branch and productive nodes per branch were best explained by the models including LAl $\left.\right|_{\text {shade, }}$ and altitude. While, productive branches per stem and cherry weight was better explained only by $L A I_{\text {shade. }}$ Productive stems per ha did not correlate with altitude nor with $L A I_{\text {shade. }}$ LAI shade had a negative effect on all coffee yield components (except for Productive stems per ha) and altitude had either negative effect or no effect, depending on the yield component. Additionally, we found a negative correlation between St and FL, PN, PB and CW. And between CW and productive stems per ha and coffee tree density. Finally, farmers which reported use of fertilizer corresponded with larger productive branches per stem and the ones which used fungicide had larger cherry weight. As well, farmers who reported stem borer presence tend to have lower FL, PN and PB. Breaking down yields per hectare into individual yield components provides practical information for management interventions that help improving yields as discussed in detail below.

\subsubsection{Yield per ha}

Mean annual yields per ha obtained from our study (716 kg green beans ha-1) corresponded with the average $700 \mathrm{~kg} \mathrm{ha}^{-1}$ reported by Wang et al. (2015) for East Uganda and are above the average yield reported by FAOSTAT (2018) for East Africa ( $500 \mathrm{~kg} \mathrm{ha}^{-1}$ ). Coffee banana had the largest yield per ha as a result of larger fruit loads per stem, larger number of productive branches per stem and larger number of productive stems per ha. This finding agrees with van Asten et al. (2011), who reported that coffee yields in Uganda were not lower in fields intercropped with bananas compared to fields without inter- cropping. 
This study did not include information about household income or revenues from other products (food consumption, selling fruits or timber), which would provide meaningful insights for a comprehensive socio-economic evaluation of the systems (Rice, 2011; Cerda et al., 2014) (Rice, 2011; Cerda et al., 2014). In the case of Coffee-Banana system, higher banana yields have been reported when intercropped with coffee than when cultivated as a monocrop (van Asten et al., 2011). Moreover, bananas are the most important staple crop in the region and the main exported food crop of Uganda (Wairegi et al., 2010; Jassogne et al., 2012). This makes this system of particular interest in addressing multi-dimensional needs (Odoul \& Aluma, 1990; van Asten et al., 2011; Jassogne et al., 2012). Additionally, due to their architecture, bananas provide intermediate shade, reducing incoming radiation less than other shade trees (Sarmiento-Soler et al., 2019). Also, the fast growth of banana allows for easier manipulation according to farmers' needs, in regard to thinning or increasing planting density. Furthermore, it is likely that bananas herbaceous pseudo stem cannot be a host for the white stem borer, which could help to reduce infestation rate in CB compared to CT plots (Liebig et al., 2016).

Shade-tree coffee systems at Mt. Elgon have been proven to provide several ecosystem services and were used by low income farmers to reduce risks, in particular at low altitude (Rahn et al., 2018b). However, it is of relevance to quantify the contribution of those systems to farmers' livelihoods. Such analysis would allow for a more meaningful evaluation of the costs and benefits of coffee shade tree systems at low altitudes, e.g. to estimate whether the low coffee yields observed in CT compared to CO and $\mathrm{CB}$ are compensated by provision of other goods and/or by off-farm activities.

\subsubsection{Yield components as affected by shade cover and altitude in each system}

Our results confirmed our hypothesis that shade cover reduced fruit load per branch, productive nodes per stem and productive branches per stem, as this has also been demonstrated by previous studies (Campanha et al., 2004; Franck et al., 2005; Vaast et al., 2006; Bote et al., 2018). This reduction most likely results from reduced incoming radiation and reduced temperature (DaMatta, 2004; Bote et al., 2018). Nevertheless, we observed that when shade cover remained below $30 \%$ (LAl shade $<1 \mathrm{~m}^{2} \mathrm{~m}^{-2}$ ), coffee yield components were larger and similar across cropping systems (Figs. 4 and $\mathbf{5}$ ). This is in concordance with other studies of coffee under shade (Soto-Pinto et al., 2000; Staver et al., 2001; Cerda 
et al., 2017; Meylan et al., 2017) and for cacao (Blaser et al., 2018). Moreover, Bote et al. (2018) indicated no significant differences in bean yield and biomass accumulation between trees under 100 $\%$ radiation and trees under $70 \%$ radiation in an experiment carried out in Ethiopia. Thus, it appears that a maintenance of mid shade cover possibly does not limit coffee yields in this region, while it allows farmers to retain shade trees and bananas in their coffee plots and benefit from the ecosystem services they might provide (Cerda et al., 2017).

Regarding the relationship between cherry weight and shade cover, we expected heavier cherries in shaded systems, as a result of two mechanisms, (i) lower temperatures lead to a slower ripening process and larger accumulation of compounds, and (ii) less fruit loads would diminish competition for nutrients and assimilates between cherries (Beer et al., 1998; Muschler, 2001; Vaast et al., 2006; Vaast et al., 2016). Nevertheless, we found a negative relationship between cherry weight and shade cover, which requires further investigation.

The negative effect of altitude (on fruit load and productive nodes) or the lack of effect (on productive branches per stem and cherry weight), were also surprising results. We had expected a stronger positive altitudinal effect with higher values for yield components at mid and high altitude than at lower altitude due to suboptimal conditions, in particular, high temperature and high vapor pressure deficit leading to sub-optimum growing conditions (Sarmiento-Soler et al., 2019). Although temperatures at low altitude were high with respect to established temperature thresholds for coffee cultivation ((DaMatta \& Ramalho, 2006) and references therein), recent studies (Martins et al., 2016; Rodrigues et al., 2016; DaMatta et al., 2018b) question such thresholds and propose stronger resistance of coffee to higher temperatures under ample water availability supply. During the investigation period, water was not limiting as demonstrated by Sarmiento-Soler et al. (2019).

Thus, our results suggest that the observed patterns of larger fruit components at low and mid altitude probably were determined by higher (but not limiting) temperatures in conjunction with larger incoming radiation (DaMatta et al., 2007). While, at high altitude, cooler temperatures and cloudiness, reducing incoming radiation, could have limited coffee yield components. Absence of a positive altitudinal effect on coffee yield have been encountered by a similar study in smallholder farms in Costa Rica (Cerda et al., 2017). Another explanation to this altitudinal pattern could be the soil fertility gradient present in 
the area, with more fertile soils at low altitudes - as reported by De Bauw et al. (2016) and also observed in our plots by the a pH decrease (and decrease of other soil parameters) along the altitudinal gradient (Table 1 and Fig. 2.c).

Fertilizer use was positively correlated with productive branches and three of the best performing plots (yield per ha $>1500 \mathrm{~kg}$ ) reported fertilizer use, thus in the long run it appears as a good strategy to increase yields. However, here we rather concentrate on suggestions for crop management improvement that refer to other options than fertilizer application, which would require a more comprehensive investigation as pointed out by De Bauw et al. (2016) and (Wang et al., 2015). Currently it is mainly economic constraints that prevent farmers in the region from judicious fertilizer application (Jassogne et al., 2012).

Finally, presence of stem borer and coffee berry disease correlated negatively with one or more of the studied yield components and very likely influenced final yields. Although, the focus on this study was not on pest and diseases incidence, our results are in line with Liebig et al. (2016) who reported high incidence of white coffee stem borer and coffee berry diseases for this region - especially in shaded systems at low altitude. This may help to better explain the lower yields found in those systems. We acknowledge, however, that dedicated further investigation is needed to be able to couple yield losses with quantitative assessment of pests and diseases along the environmental and shade gradient.

\subsubsection{Interactions among coffee yield compoinents}

We expected a negative correlation between productive branches per stem and fruit load per branch due to a competition in resource allocation (Bote \& Vos, 2016). However, the positive correlation between these yield components suggest absence of resource competition between branches and nodes and underpins the absence of branch autonomy as has also been pointed out by other authors (Amaral et al., 2001; Chaves et al., 2012).

We found, however, that too many stems (> 4 stems) per tree might contribute to a reduction of coffee yields. Higher number of stems per coffee could occur in response to shade cover. Likewise, farmers try to compensate lower flowering, i.e. fruit load under shade, by maintaining a larger number of stems per 
tree. The negative effect of the number of stems on FL, PN and PB could result from two mechanisms, first to self-shading and reducing air circulation, and second, to resource competition between vegetative and reproductive organs. Although the latter interpretation was rejected by Chaves et al. (2012), their results indicate that fruit sink demands are stronger than vegetative ones, sometimes until the point of exhausting tree resources and leading it to die-back. However, this has been mostly tested at branch level, and it would be of interest to evaluate the effect of number of stems per tree on the other yield components under controlled conditions. This would be especially interesting, because other studies also have reported negative relationships between number of stems and other yield components similar to the ones encountered in our study (e.g. in Kenya by Njoroge et al. (1992)). Furthermore yield improvements have also been achieved through reducing the number of stems (Dufour et al., 2019).

Finally, coffee tree density was only negatively correlated with cherry weight, while it was not negatively correlated with other yield components. Based on that finding yield could potentially be improved through an increase of coffee tree density. Rahn et al. (2018a) also pointed to low coffee tree density as a factor causing low yields in the area. Nevertheless, increasing coffee tree density can negatively in uflence annual crops, as it reduces the available space as well as the incoming radiation below coffee canopies (Jassogne et al., 2012) and would increase nutrient demands on already exhausted soils (De Bauw et al., 2016).

\subsection{Conclusion}

Coffee-banana systems proved to be the best performing system in the region, by providing the highest coffee yield. Coffee yield components were mostly constrained by shade cover above $30 \%$ (LAlshade $>1$ $\mathrm{m}^{2} \mathrm{~m}^{-2}$ ), suggesting that a careful shade management below this threshold could allow farmers to benefit from reasonable coffee yields while maintaining shade trees and bananas in their plots. Reducing the stems per coffee tree $(<4)$ could improve yields by reducing their negative effect on fruit load. The partitioning of yield per stem and per ha into its yield components helped to disentangle the effects of cropping system, shade cover and altitude, and to identify management strategies that could enable smallholders to improve coffee production within the limitations of low external input use. 


\section{Declaration of Competing Interest}

The authors declare that they have no known competing nancial interests or personal relationships that could have appeared to influence the work reported in this paper.

\section{Acknowledgements}

We are very thankful to the two anonymous reviewers who through their valuable comments and suggestions help enormously improving this manuscript. Furthermore, we thank the nancial support of the German Ministry for Economic Cooperation and Development (BMZ) and GIZ (under prime agreement no. 12.1433.7-001.00). This work was implemented as part of the CGIAR Research Programs on Climate Change, Agriculture and Food Security (CCAFS) and Forest, Trees and Agroforestry (FTA) which is carried out with support from CGIAR Fund Donors and through bilateral funding agreements. For details please visit https://ccafs.cgiar.org/donors. We also received financial support from the Division of Tropical Plant Production and Agricultural Systems Modelling (TROPAGS) of the Faculty of Agricultural Sciences, University of Goettingen. The views expressed in this document cannot be taken to reflect the official opinions of these organizations. We acknowledge the support by the several other team members of the division Tropical Plant Production and Agricultural Systems Modelling (TROPAGS) at the University of Goettingen, Germany. Moreover, the support from the International Institute of Tropical Agriculture (IITA) Uganda is also fully acknowledged, especially from the field team, Medad Tamari, David Mukasa and Franco Manget. Finally, we would like to dedicate special gratitude to all farmers for allowing us under-taking measurements on their farms, answering our questions and for supporting our work.

\section{Appendix a. Supplementary data}

Supplementary data associated with this article can be found, in the online version, at https://doi.org/10.1016/j.agee.2020.106887. 


\section{References}

Amaral, J. A. T., DaMatta, F. M., \& Rena, A. B. (2001). Effects of fruiting on the growth of Arabia Coffee trees as related to carbohydrate and nitrogen status and to nitrate reductase activity. Brazilian Journal of Plant Physiology, 13(1), 66-74.

Baca, M., Laderach, P., Haggar, J., Schroth, G., \& Ovalle, O. (2014). An integrated framework for assessing vulnerability to climate change and developing adaptation strategies for coffee growing families in Mesoamerica. PLoS One, 9(2), e88463. doi:10.1371/journal.pone.0088463

Bartoń, K. (2019). MuMIn: Multi-Model Inference. Retrieved from https://CRAN.R-project.org/package=MuMIn

Bates, D., Maechler, M., Bolker, B., \& Walker, S. (2015). Fitting Linear Mixed-Effects Models Using Ime4. Journal of Statistical Software, 67(1), 1-48. doi:doi:10.18637/jss.v067.i01.

Beer, J., Muschler, R., Kass, D., \& Somarriba, E. (1998). Shade management in coffee and cacao plantations. Agroforestry Systems(38), 139-164.

Blaser, W. J., Oppong, J., Hart, S. P., Landolt, J., Yeboah, E., \& Six, J. (2018). Climate-smart sustainable agriculture in low-tointermediate shade agroforests. Nature Sustainability, 1(5), 234-239. doi:10.1038/s41893-018-0062-8

Boreux, V., Vaast, P., Madappa, L. P., Cheppudira, K. G., Garcia, C., \& Ghazoul, J. (2016). Agroforestry coffee production increased by native shade trees, irrigation, and liming. Agronomy for Sustainable Development, 36(3). doi:10.1007/s13593-016-0377-7

Bote, A. D., \& Vos, J. (2016). Branch growth dynamics, photosynthesis, yield and bean size distribution in response to fruit load manipulation in coffee trees. Trees(30), 1275-1285. doi:10.1007/s00468-016-1365-x

Bote, A. D., Zana, Z., Ocho, F. L., \& Vos, J. (2018). Analysis of coffee ( Coffea arabica L.) performance in relation to radiation level and rate of nitrogen supply II. Uptake and distribution of nitrogen, leaf photosynthesis and first bean yields. European Journal of Agronomy, 92, 107-114. doi:10.1016/j.eja.2017.10.006

Brooks, M. E., Kristensen, K., van Benthem, K. J., Magnusson, A., Berg, C. W., Nielsen, A., Skaug, H. J., Maechler, M., \& Bolker, B. M. (2017). glmmTMB Balances Speed and Flexibility Among Packages for Zero-inflated Generalized Linear Mixed Modeling. The $R$

Journal, 9(2), 378-400.

Bunn, C., Läderach, P., Ovalle Rivera, O., \& Kirschke, D. (2014). A bitter cup: climate change profile of global production of Arabica and Robusta coffee. Climatic Change, 129(1-2), 89-101. doi:10.1007/s10584-014-1306-x

Campanha, M. M., Silva Santos, R. H., De Freitas, G. B., Prieto Martinez, H. E., Ribeiro Garcia, S. L., \& Finger, F. L. (2004). Growth and yield of coffee plants in agroforestry and monoculture systems in Minas Gerais, Brazil. Agroforestry Systems, 63, 75-82.

Cannavo, P., Sansoulet, J., Harmand, J. M., Siles, P., Dreyer, E., \& Vaast, P. (2011). Agroforestry associating coffee and Inga densiflora results in complementarity for water uptake and decreases deep drainage in Costa Rica. Agriculture, Ecosystems \& Environment, 140(1-2), 1-13. doi:10.1016/j.agee.2010.11.005

Cannell, M. G. R. (1985). Physiology of the Coffee Crop. In M. N. Clifford \& K. C. Willson (Eds.), Coffee: Botany, Biochemistry and Production of Beans and Beverage (pp. 108-134). Boston, MA: Springer US.

Castro-Tanzi, S., Flores, M., Wanner, N., Dietsch, T. V., Banks, J., Ureña-Retana, N., \& Chandler, M. (2014). Evaluation of a non-destructive sampling method and a statistical model for predicting fruit load on individual coffee (Coffea arabica) trees. Scientia Horticulturae, 167, 117-126. doi:10.1016/j.scienta.2013.12.013

Cerda, R., Allinne, C., Gary, C., Tixier, P., Harvey, C. A., Krolczyk, L., Mathiot, C., Clément, E., Aubertot, J.-N., \& Avelino, J. (2017). Effects of shade, altitude and management on multiple ecosystem services in coffee agroecosystems. European Journal of Agronomy, 82, 308-319. doi:10.1016/j.eja.2016.09.019

Cerda, R., Deheuvels, O., Calvache, D., Niehaus, L., Saenz, Y., Kent, J., Vilchez, S., Villota, A., Martinez, C., \& Somarriba, E. (2014). Contribution of cocoa agroforestry systems to family income and domestic consumption: looking toward intensification. Agroforestry Systems, 88(6), 957-981. doi:10.1007/s10457-014-9691-8

Chain-Guadarrama, A., Martínez-Salinas, A., Aristizábal, N., \& Ricketts, T. H. (2019). Ecosystem services by birds and bees to coffee in a changing climate: A review of coffee berry borer control and pollination. Agriculture, Ecosystems \& Environment, 280, 53-67. doi:10.1016/j.agee.2019.04.011

Chaves, A. R. M., Martins, S. C. V., Batista, K. D., Celin, E. F., \& DaMatta, F. M. (2012). Varying leaf-to-fruit ratios affect branch growth and dieback, with little to no effect on photosynthesis, carbohydrate or mineral pools, in different canopy positions of field-grown coffee trees. Environmental and Experimental Botany, 77, 207-218. doi:10.1016/j.envexpbot.2011.11.011

Craparo, A. C. W., Van Asten, P. J. A., Läderach, P., Jassogne, L. T. P., \& Grab, S. W. (2015). Coffea arabica yields decline in Tanzania due to climate change: Global implications. Agricultural and Forest Meteorology, 207, 1-10. doi:10.1016/j.agrformet.2015.03.005

DaMatta, F. M. (2004). Ecophysiological constraints on the production of shaded and unshaded coffee: a review. Field Crops Research, 86(2-3), 99-114. doi:10.1016/j.fcr.2003.09.001

DaMatta, F. M., Avila, R. T., Cardoso, A. A., Martins, S. C. V., \& Ramalho, J. C. (2018a). Physiological and Agronomic Performance of the Coffee Crop in the Context of Climate Change and Global Warming: A Review. J Agric Food Chem, 66(21), 5264-5274. doi:10.1021/acs.jafc.7b04537 
DaMatta, F. M., Rahn, E., Läderach, P., Ghini, R., \& Ramalho, J. C. (2018b). Why could the coffee crop endure climate change and global warming to a greater extent than previously estimated? Climatic Change, 152(1), 167-178. doi:10.1007/s10584-018-2346-4

DaMatta, F. M., \& Ramalho, J. C. (2006). Impacts of drought and temperature stress on coffee physiology and production: a review. Brazilian Journal of Plant Physiology, 18(1), 55-81.

DaMatta, F. M., Ronchie, C. P., Maestri, M., \& Barros, R. S. (2007). Ecophysiology of coffee growth and production. Brazilian Journal of Plant Physiology, 19(4), 485-510.

De Bauw, P., Van Asten, P., Jassogne, L., \& Merckx, R. (2016). Soil fertility gradients and production constraints for coffee and banana on volcanic mountain slopes in the East African Rift: A case study of Mt. Elgon. Agriculture, Ecosystems \& Environment, 231, 166-175. doi:10.1016/j.agee.2016.06.036

De Beenhouwer, M., Aerts, R., \& Honnay, O. (2013). A global meta-analysis of the biodiversity and ecosystem service benefits of coffee and cacao agroforestry. Agriculture, Ecosystems \& Environment, 175, 1-7. doi:10.1016/j.agee.2013.05.003

de Souza, H. N., de Graaff, J., \& Pulleman, M. M. (2011). Strategies and economics of farming systems with coffee in the Atlantic Rainforest Biome. Agroforestry Systems, 84(2), 227-242. doi:10.1007/s10457-011-9452-x

Descroix, F., \& Snoeck, J. (2008). Environmental Factors Suitable for Coffee Cultivation. In Coffee: Growing, Processing, Sustainable Production (pp. 164-177).

Dufour, B. P., Kerana, I. W., \& Ribeyre, F. (2019). Effect of coffee tree pruning on berry production and coffee berry borer infestation in the Toba Highlands (North Sumatra). Crop Protection, 122, 151-158. doi:10.1016/j.cropro.2019.05.003

FAOSTAT. (2018). Food and Agriculture Organiaztion of the United Nations. FAOSTAT Statistics Database.

Fick, S. E., \& Hijmans, R. J. (2017). WorldClim 2: new 1-km spatial resolution climate surfaces for global land areas. International Journal of Climatology, 37(12), 4302-4315. doi:10.1002/joc.5086

Fox, J., \& Wiesberg, S. (2019). An R Companion to Applied Regression. Retrieved from https://socialsciences.mcmaster.ca/jfox/Books/Companion/

Franck, N., Vaast, P., \& Dauzat, J. (2005). Coffee a shade-adapted plant: implications on its carbon balance and consequences on coffee yield and quality in agroforestry systems. ASIC.

Gbur, E. E. (2012). Analysis of Generalized Linear Mixed Models in the Agricultural and Natural Resources Sciences. Madison, WI: American Society of Agronomy, Crop Science Society of America, Soil Science Society of America.

Gobbi, J. A. (2000). Is biodiversity-friendly coffee financially viable? An analysis

of five different coffee production systems in western $\mathrm{EI}$

Salvador. Ecological Economics, 33, 267-281.

Godfray, H. C. J., \& Garnett, T. (2014). Food security and sustainable intensification. Philosophical Transactions of the Royal Society B: Biological Sciences, 369(1639). doi:10.1098/rstb.2012.0273

ITC. (2012). The Coffee Exporters's Guide. Retrieved from Geneva:

Jassogne, L., van Asten, P. J. A., Wanyama, I., \& Baret, P. V. (2012). Perceptions and outlook on intercropping coffee with banana as an opportunity for smallholder coffee farmers in Uganda. International Journal of Agricultural Sustainability, 11(2), 144-158. doi:10.1080/14735903.2012.714576

Jha, S., Bacon, C. M., Philpott, S. M., Ernesto Méndez, V., Läderach, P., \& Rice, R. A. (2014). Shade Coffee: Update on a Disappearing Refuge for Biodiversity. BioScience, 64(5), 416-428. doi:10.1093/biosci/biu038

Kuznetsova , A., Brockhoff, P., \& Christensen, R. (2017). ImerTest Package: Tests in Linear Mixed Effects Models. Journal of Statistical

Software, 82(13), 1-26. doi:doi: 10.18637/jss.v082.i13 (URL: https://doi.org/10.18637/jss.v082.i13).

Laderach, P., Lundy, M., Jarvis, A., Ramirez, J., Portilla, E. P., Schepp, K., \& Eitzinger, A. (2011). Predicted Impact of Climate Change on Coffee Supply Chains. In The Economic, Social and Political Elements of Climate Change (pp. 703-723).

Lasco, R. D., Delfino, R. J. P., Catacutan, D. C., Simelton, E. S., \& Wilson, D. M. (2014). Climate risk adaptation by smallholder farmers: the roles of trees and agroforestry. Current Opinion in Environmental Sustainability, 6, 83-88. doi:10.1016/j.cosust.2013.11.013

Lemmon, P. E. (1956). A Spherical Densiometer For Estimating Forest Overstory Density. Forest Science, 2(4), 314-320. doi:10.1093/forestscience/2.4.314

Li-COR, I. (2009). LAI-2200 Plant Canopy Analyzer Instruction Manual. Retrieved from

Liebig, T., Jassogne, L., Rahn, E., Laderach, P., Poehling, H. M., Kucel, P., Van Asten, P., \& Avelino, J. (2016). Towards a Collaborative Research: A Case Study on Linking Science to Farmers' Perceptions and Knowledge on Arabica Coffee Pests and Diseases and Its Management. PLoS One, 11(8), e0159392. doi:10.1371/journal.pone.0159392

Martins, M. Q., Rodrigues, W. P., Fortunato, A. S., Leitao, A. E., Rodrigues, A. P., Pais, I. P., Martins, L. D., Silva, M. J., Reboredo, F. H., Partelli, F. L., Campostrini, E., Tomaz, M. A., Scotti-Campos, P., Ribeiro-Barros, A. I., Lidon, F. J., DaMatta, F. M., \& Ramalho, J. C. (2016). Protective Response Mechanisms to Heat Stress in Interaction with High [CO2] Conditions in Coffea spp. Front Plant Sci, 7, 947. doi:10.3389/fpls.2016.00947

Mbow, C., Smith, P., Skole, D., Duguma, L., \& Bustamante, M. (2014a). Achieving mitigation and adaptation to climate change through sustainable agroforestry practices in Africa. Current Opinion in Environmental Sustainability, 6, 814. doi:10.1016/j.cosust.2013.09.002

Mbow, C., Van Noordwijk, M., Luedeling, E., Neufeldt, H., Minang, P. A., \& Kowero, G. (2014b). Agroforestry solutions to address food security and climate change challenges in Africa. Current Opinion in Environmental Sustainability, 6, 61-67. doi:10.1016/j.cosust.2013.10.014 
Meylan, L., Gary, C., Allinne, C., Ortiz, J., Jackson, L., \& Rapidel, B. (2017). Evaluating the effect of shade trees on provision of ecosystem services in intensively managed coffee plantations. Agriculture, Ecosystems \& Environment, 245, 32-42. doi:10.1016/j.agee.2017.05.005

Muschler, R. G. (2001). Coffee Quality in a Sub-Optimal Coffee-Zone of Costa Rica. Agriculture, Ecosystems \& Environment., 51(2), 131-139.

Nath, C. D., Pélissier, R., \& Garcia, C. (2009). Comparative efficiency and accuracy of variable area transects versus square plots for sampling tree diversity and density. Agroforestry Systems, 79(2), 223-236. doi:10.1007/s10457-0099255-5

Njoroge, J. M., Waithaka, K., \& Chweya, J. A. (1992). The influence of tree training and plant density on growth, yield components and yield of Arabica coffee cv. Ruiru 11. Journal of Horticultural Science, 67(5), 695-702. doi:10.1080/00221589.1992.11516300

Odoul, P. A., \& Aluma, J. R. W. (1990). The banana (Musa spp.) - Coffee robusta: traditional

agroforestry system of Uganda. Agroforestry Systems, 11, 213-226.

Okalebo, J. R., Gathua, K. W., \& Woomer, P. L. (1993). Laboratory Methods of Soil and Plant Analysis: A working Manual. Retrieved from

Ovalle-Rivera, O., Laderach, P., Bunn, C., Obersteiner, M., \& Schroth, G. (2015). Projected shifts in Coffea arabica suitability among major global producing regions due to climate change. PLoS One, 10(4), e0124155. doi:10.1371/journal.pone.0124155

Padovan, M. P., Brook, R. M., Barrios, M., Cruz-Castillo, J. B., Vilchez-Mendoza, S. J., Costa, A. N., \& Rapidel, B. (2018). Water loss by transpiration and soil evaporation in coffee shaded by Tabebuia rosea Bertol . and Simarouba glauca dc. compared to unshaded coffee in sub-optimal environmental conditions. Agricultural and Forest Meteorology, 248, 1-14. doi:10.1016/j.agrformet.2017.08.036

Perfecto, I., Vandermeer, J., Mas, A., \& Pinto, L. S. (2005). Biodiversity, yield, and shade coffee certification. Ecological Economics, 54(4), 435-446. doi:10.1016/j.ecolecon.2004.10.009

Rahn, E., Liebig, T., Ghazoul, J., van Asten, P., Läderach, P., Vaast, P., Sarmiento, A., Garcia, C., \& Jassogne, L. (2018a). Opportunities for sustainable intensification of coffee agro-ecosystems along an altitudinal gradient on Mt. Elgon, Uganda. Agriculture, Ecosystems \& Environment, 263, 31-40. doi:10.1016/j.agee.2018.04.019

Rahn, E., Vaast, P., Läderach, P., van Asten, P., Jassogne, L., \& Ghazoul, J. (2018b). Exploring adaptation strategies of coffee production to climate change using a process-based model. Ecological Modelling, 371, 76-89. doi:10.1016/j.ecolmodel.2018.01.009

Rapidel, B., Ripoche, A., Allinne, C., Metay, A., Deheuvels, O., Lamanda, N., Blazy, J.-M., Valdés-Gómez, H., \& Gary, C. (2015). Analysis of ecosystem services trade-offs to design agroecosystems with perennial crops. Agronomy for Sustainable Development, 35(4), 1373-1390. doi:10.1007/s13593-015-0317-y

Rice, R. A. (2011). Fruits from shade trees in coffee: how important are they? Agroforestry Systems, 83(1), 41-49. doi:10.1007/s10457-011-9385-4

Rodrigues, W. P., Martins, M. Q., Fortunato, A. S., Rodrigues, A. P., Semedo, J. N., Simoes-Costa, M. C., Pais, I. P., Leitao, A. E., Colwell, F., Goulao, L., Maguas, C., Maia, R., Partelli, F. L., Campostrini, E., Scotti-Campos, P., Ribeiro-Barros, A. I., Lidon, F. C., DaMatta, F. M., \& Ramalho, J. C. (2016). Long-term elevated air [CO2 ] strengthens photosynthetic functioning and mitigates the impact of supra-optimal temperatures in tropical Coffea arabica and C. canephora species. Glob Chang Biol, 22(1), 415-431. doi:10.1111/gcb.13088

Romero-Alvarado, Y., Soto-Pinto, L., García-Barrios, L., \& Barrera-Gaytán, J. F. (2002). ields and Soil Nutrients under the Shades of Inga Sp. vs. Multiple Species in Chiapas, Mexico. Agroforestry Systems, 54(3), 215-224.

Sarmiento-Soler, A., Vaast, P., Hoffmann, M. P., Rötter, R. P., Jassogne, L., van Asten, P. J. A., \& Graefe, S. (2019). Water use of Coffea arabica in open versus shaded systems under smallholder's farm conditions in Eastern Uganda. Agricultural and Forest Meteorology, 266-267, 231-242. doi:10.1016/j.agrformet.2018.12.006

Sauvadet, M., den Meersche, K. V., Allinne, C., Gay, F., de Melo Virginio Filho, E., Chauvat, M., Becquer, T., Tixier, P., \& Harmand, J. M. (2019). Shade trees have higher impact on soil nutrient availability and food web in organic than conventional coffee agroforestry. Sci Total Environ, 649, 1065-1074. doi:10.1016/j.scitotenv.2018.08.291

Soto-Pinto, L., Perfecto, I., Castillo-Hernandez, J., \& Caballero-Nieto. (2000). Shade Effect on Coffee Production at the Northern Tzeltal Zone of the State of Chiapas, Mexico. Agriculture, Ecosystems \& Environment, 80((1-2)), 61-69.

Souza, H. N. d., de Goede, R. G. M., Brussaard, L., Cardoso, I. M., Duarte, E. M. G., Fernandes, R. B. A., Gomes, L. C., \& Pulleman, M. M. (2012). Protective shade, tree diversity and soil properties in coffee agroforestry systems in the Atlantic Rainforest biome. Agriculture, Ecosystems \& Environment, 146(1), 179-196. doi:10.1016/j.agee.2011.11.007

Staver, C., Guharay, F., Monterroso, D., \& Muschler, R. G. (2001). Designing pest-suppressive multistrata perennial crop systems: shade-grown coffee in Central America. Agroforestry Systems(53), 151-170.

Tscharntke, T., Clough, Y., Bhagwat, S. A., Buchori, D., Faust, H., Hertel, D., Hölscher, D., Juhrbandt, J., Kessler, M., Perfecto, I., Scherber, C., Schroth, G., Veldkamp, E., \& Wanger, T. C. (2011). Multifunctional shade-tree management in tropical agroforestry landscapes - a review. Journal of Applied Ecology, 48(3), 619-629. doi:10.1111/j.13652664.2010.01939.x

Tscharntke, T., Clough, Y., Wanger, T. C., Jackson, L., Motzke, I., Perfecto, I., Vandermeer, J., \& Whitbread, A. (2012). Global food security, biodiversity conservation and the future of agricultural intensification. Biological Conservation, 151(1), 53-59. doi:10.1016/j.biocon.2012.01.068 
Vaast, P., Bertrand, B., Perriot, J.-J., Guyot, B., \& Génard, M. (2006). Fruit thinning and shade improve bean characteristics and beverage quality of coffee (Coffea arabica L.) under optimal conditions. Journal of the Science of Food and Agriculture, 86(2), 197-204. doi:10.1002/jsfa.2338

Vaast, P., Harmand, J.-M., Rapidel, B., Jagoret, P., \& Deheuvels, O. (2016). Coffee and Cocoa Production in Agroforestry-A Climate-Smart Agriculture Model. In Climate Change and Agriculture Worldwide (pp. 209-224).

Vaast, P., \& Somarriba, E. (2014). Trade-offs between crop intensification and ecosystem services: the role of agroforestry in cocoa cultivation. Agroforestry Systems, 88(6), 947-956. doi:10.1007/s10457-014-9762-x

Vaast, P., Van Kanten, R., Siles, P., Angrands, J., \& Aguilar, A. (2008). Biophysical interactions between timber trees and Arabica coffee in suboptimal conditions of Central America. In Toward Agroforestry Design (pp. 133-146): Springer.

van Asten, P. J. A., Wairegi, L. W. I., Mukasa, D., \& Uringi, N. O. (2011). Agronomic and economic benefits of coffee-banana intercropping in Uganda's smallholder farming systems. Agricultural Systems, 104(4), 326-334. doi:10.1016/j.agsy.2010.12.004

Villatoro-Sánchez, M., Le Bissonnais, Y., Moussa, R., \& Rapidel, B. (2015). Temporal dynamics of runoff and soil loss on a plot scale under a coffee plantation on steep soil (Ultisol), Costa Rica. Journal of Hydrology, 523, 409-426. doi:10.1016/j.jhydrol.2015.01.058

Wairegi, L. W. I., van Asten, P. J. A., Tenywa, M. M., \& Bekunda, M. A. (2010). Abiotic constraints override biotic constraints in East African highland banana systems. Field Crops Research, 117(1), 146-153. doi:10.1016/j.fcr.2010.02.010

Wang, N., Jassogne, L., van Asten, P. J. A., Mukasa, D., Wanyama, I., Kagezi, G., \& Giller, K. E. (2015). Evaluating coffee yield gaps and important biotic, abiotic, and management factors limiting coffee production in Uganda. European Journal of Agronomy, 63, 1-11. doi:10.1016/j.eja.2014.11.003

Wickham, H. (2016). ggplot2: Elegant Graphics for Data Analysis: Springer-Verlag New York.

Wickham, H., François, R., Henry, L., \& Müller, K. (2019). dplyr: A Grammar of Data Manipulation. Retrieved from https://CRAN.R-project.org/package=dplyr 


\section{Water use of Coffea arabica in open versus shaded systems under smallholder's farm conditions in Eastern Uganda}

Alejandra Sarmiento-Soler ${ }^{1,5}$, Philippe Vaast ${ }^{2,3}$, Munir P. Hoffmann ${ }^{1}$, Reimund P. Rötter ${ }^{1,4}$, Laurence Jassogne ${ }^{5}$, Piet J.A. van Asten ${ }^{5,6}$ and Sophie Graefe ${ }^{7,8}$

${ }^{1}$ Tropical Plant Production and Agricultural Systems Modelling (TROPAGS), University of Goettingen, Grisebachstraße 6, 37077 Göttingen, Germany

2UMR Eco\&Sols, Centre de Coopération Internationale en Recherche Agronomique pour le Développement (CIRAD), Université Montpellier, Montpellier, France

${ }^{3}$ World Agroforestry Centre (ICRAF), Hanoi, Vietnam

${ }^{4}$ Center for Biodiversity and Land Use (CBL), University of Goettingen, Buesgenweg 1, 37077 Göttingen, Germany

5International Institute of Tropical Agriculture (IITA), Kampala, Uganda

${ }^{6}$ Olam International Ltd, Kampala, Uganda

7 Tropical Silviculture and Forest Ecology, University of Goettingen

${ }^{8}$ Organic Plant Production and Agroecosystems Research in the Tropics and Subtropics (OPATS), University of Kassel, Kassel, Germany

Corresponding author:

Alejandra Sarmiento Soler

asarmie@gwdg.de

Grisebachstraße 6

37077 Göttingen

Germany

\section{Published in the Journal Agriculture and Forest Meteorology}

Sarmiento-Soler, A., Vaast, P., Hoffmann, M. P., Rötter, R. P., Jassogne, L., van Asten, P. J. A., \& Graefe, S. (2019). Water use of Coffea arabica in open versus shaded systems under smallholder's farm conditions in Eastern Uganda. Agricultural and Forest Meteorology, 266-267, 231-242. doi:10.1016/j.agrformet.2018.12.006 


\section{Abstract}

Coffee cultivation is a major source of income in East Africa. Increasing temperatures and water scarcity related to climate change are becoming major challenges for coffee production. Therefore, there is an urgent need for sound scientific understanding of the functioning of current coffee cultivation systems and the potential of agroforestry as an adaptation strategy to climate change. In a smallholder coffee farm on Mt Elgon, Uganda, we assessed the effect of three coffee cultivation systems (i.e., Coffee-Open, Coffee-Banana and Coffee-Cordia) on (i) the coffee cultivation environment (e.g. microclimate and soil moisture), (ii) water consumption of coffee, (iii) water consumption of banana (Musa sp.) and Cordia africana and (iv) water competition or complementary use between coffee and shade tree species. To this end, we monitored sap flux density $\left(\mathrm{J}_{\mathrm{S}}\right)\left(\mathrm{g} \mathrm{cm}^{-2}\right.$ hour $\left.{ }^{-1}\right)$ of coffee, banana and $C$. africana from March 2015 to April 2016, using Granier thermal dissipation method, along with microclimate, soil moisture and rainfall. Shaded systems reduced irradiance by $70 \%$ in Coffee-Cordia system and $58 \%$ in CoffeeBanana system compared to Coffee-Open system. Maximum temperatures and daily temperature amplitude were on average reduced by $4{ }^{\circ} \mathrm{C}$ in both shaded systems compared to Coffee-Open system. Soil water content (SWC) in shaded systems was reduced by $59 \%$ in Coffee-Cordia and $6 \%$ in CoffeeBanana compared to Coffee-Open. Daily water consumption of coffee plants was $1.2 \pm 0.64 \mathrm{Id}^{-1}$ and did not differ between systems. Water use of banana was $3.1 \pm 1.8 \mathrm{Id} \mathrm{d}^{-1}$ and $42 \pm 40 \mathrm{I} \mathrm{d}^{-1}$ by $C$. africana. Coffee-Banana system had the largest daily transpiration rate, $0.9 \pm 0.4 \mathrm{~mm} \mathrm{~d}^{-1}$ per ground area and 0.6 $\pm 0.4 \mathrm{~mm} \mathrm{~d}^{-1}$ per unit leaf area, followed by Coffee-Cordia with $0.37 \pm 0.1 \mathrm{~mm} \mathrm{~d}^{-1}$ (per ground area), $0.36 \pm 0.1 \mathrm{~mm} \mathrm{~d}^{-1}$ (per leaf area) and Coffee-Open $0.24 \pm 0.1 \mathrm{~mm} \mathrm{~d}^{-1}$ (per ground area), $0.27 \pm 0.1 \mathrm{~mm}$ $\mathrm{d}^{-1}$ (per leaf area). Our results showed that differences in microclimate and SWC between cultivation systems did not influence coffee water use during the monitored year. However, water competition between coffee and shade trees could likely occur in drier years, due to the reduced SWC presently observed in shaded systems. Further research is needed to explore the performance of management practices (mulching, pruning and thinning) in interaction with seasonal weather forecast and appropriate selection of shade species (provision of extra products, reduced water use, fast growth and root zone below $80 \mathrm{~cm}$ depth) to match the systems' water requirements with expected soil water availability.

Keywords: Coffea arabica, Musa sp., agroforestry, transpiration, climate change, sap flux 
Highlights:

- Coffee water use did not differ between cultivation systems during all seasons.

- Higher system transpiration in Coffee-Banana and Coffee-Cordia than in Coffee-Open.

- Banana and C. africana buffered microclimate for coffee plants growing underneath.

- Coffee-Banana intercropping provides multiple services to smallholders at Mt. Elgon.

\section{Visual abstract}

Water use of Coffea arabica in open versus shaded systems under smallholder's farm conditions in Eastern Uganda

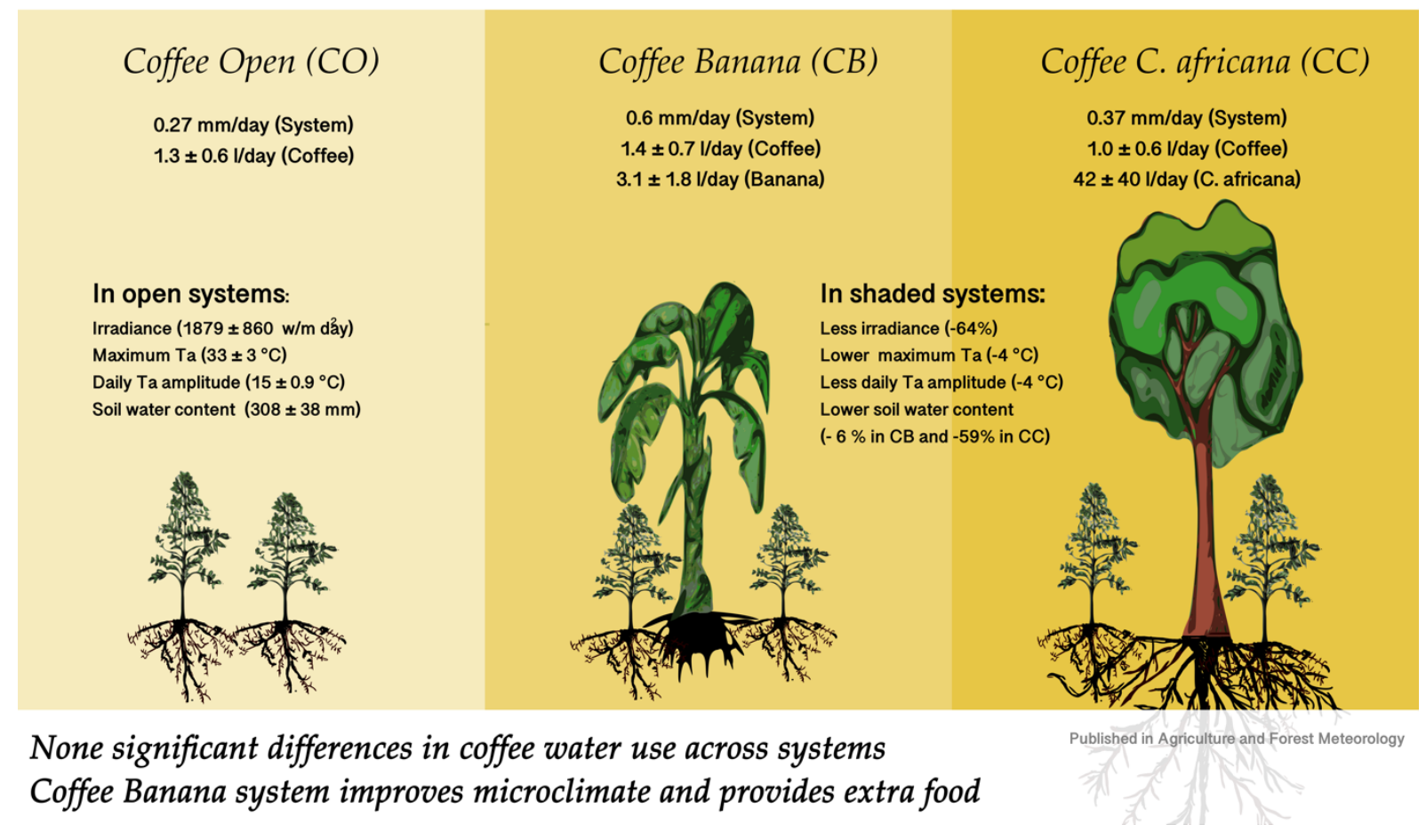





\subsection{Introduction}

African countries contribute $12 \%$ to global coffee production (FAOSTAT, 2016). Moreover, coffee constitutes up to $30 \%$ of the export revenues and foreign exchange earnings of East African countries, such as Uganda (20\%) or Ethiopia (30\%), where coffee is mostly produced by smallholders (Jassogne et al., 2013; Moat et al., 2017). Thus, coffee is an important cash crop that secures both rural livelihoods and national economy. Climate models project increasing temperatures, changes in rainfall patterns and more frequent extreme events with likely strong implications for coffee cultivation in the region (Moat et al., 2017). Coffee sensitivity to climatic variations has been reported by several studies, challenging the sustainability of the sector under climate change and demanding the development of climateresilient coffee systems (Gay et al., 2006; Zullo et al., 2011; Bunn et al., 2014; Craparo et al., 2015; Ovalle-Rivera et al., 2015; Vaast et al., 2016; Moat et al., 2017). Hence, identifying adaptation strategies, which help to increase the climate-resilience of the coffee cultivation systems in the region, is of urgent need. Finding climate-smart solutions, i.e. practices that help farmers to improve crop productivity, adapt to climate change and support mitigation of greenhouse gas emissions, should receive high priority.

Coffee intercropped with shade trees is regarded as a climate smart agricultural practice (Tscharntke et al., 2011; Vaast et al., 2016). Shade trees help to regulate microclimate by reducing incoming radiation, buffering maximum and minimum temperatures at plot level, and reducing soil evaporation rates. Ideally, this helps to protect the coffee underneath from direct sunlight, preventing temperature extremes and possibly reducing drought stress for the coffee (Barradas \& Fanjul, 1986; Muschler \& Bonnemann, 1997; Siles et al., 2009; Cannavo et al., 2011; Partelli et al., 2014). Furthermore, shade trees can help to diversify farmers' income and thereby increase food security (Rice, 2008; Mbow et al., 2014a; Vaast \& Somarriba, 2014), while capturing CO2 through biomass accumulation (Beer et al., 1998; Verchot et al., 2007; Mbow et al., 2014b). In addition, shade trees help to maintain biodiversity at landscape level (Garcia et al., 2010; Tscharntke et al., 2011).

Despite the above-mentioned potential benefits, some studies found water competition in agroforestry systems between the understory tree crop and the intercropped shade trees (Beer, 1987; Bayala et al., 2015; Abdulai et al., 2018; Padovan et al., 2018). The risk of water competition between crops and shade 
trees could pose a severe limitation to agroforestry potential as a climate adaptation strategy, particularly in extreme conditions (Abdulai et al., 2018). Shade trees affect soil water content by increasing transpiration at system level and increasing rainfall interception, potentially reducing water availability for the understory crop (Cannavo et al., 2011; Padovan et al., 2015). However, choice of species with different root architectures may allow a partitioning of soil water uptake from different soil layers, causing minimal competition and reducing water loss through deep percolation (Sanchez, 1995; Cannell et al., 1996; Meinzer et al., 2001; Cannavo et al., 2011). In addition, shade trees reduce soil evaporation as demonstrated by Padovan et al. (2018), possibly increasing water availability in the upper layers, and hence water use efficiency. Therefore, the role of shade trees in the water balance of agroforestry systems will depend on several factors such as species (rooting depth), planting density and tree size, soil physical properties, amount and pattern of rainfall, and severity of the dry season (Cannavo et al., 2011; Padovan et al., 2018). Given this complexity, designing climate-smart coffee agroforestry systems dealing with these challenges requires robust site and species-specific knowledge to guide their use when aiming to increase their climate resilience (Van Der Wolf et al., 2016).

Although coffee water use has been previously studied under controlled conditions in green-house experiments (Fanjul et al., 1985; Tausend et al., 2000) and field conditions in research stations (van Kanten \& Vaast, 2006; Cannavo et al., 2011; Padovan et al., 2018), our knowledge of coffee water use under smallholder on-farm conditions remains limited, particularly in East Africa. To contribute to closing this knowledge gap, we concentrated our study on three coffee systems (Coffee-Open, CoffeeBanana and Coffee-Tree) prevalent in the Mount Elgon region, Eastern Uganda. These systems differ in coffee tree - shade tree ratio, canopy closure and shade plant species (Liebig et al., 2016; Rahn et al., 2018). Furthermore, they are of particular interest since they provide different services to farmers, such as food and cash in the case of Coffee-Banana systems, or access to fuel wood or timber in the case of Coffee-Tree systems (Rahn et al., 2018). Within the Coffee- Tree systems, the combination of coffee with Cordia africana (Coffee-Cordia system) was selected due to the high frequency of $C$. africana, occurring in more than $25 \%$ of the agroforestry systems in this region (Rahn et al., 2018).

The main objective of this study was to assess water use patterns of coffee and associated trees under various cultivation systems. To this end, the following specific objectives were set: (i) to understand the effect of different coffee cultivation systems (Coffee-Open, Coffee-Banana and Coffee-Cordia) and a seasonal variation on microclimate and soil moisture in different seasons, (ii) to determine system and 
seasonal effects on coffee water use, (iii) to quantify water use of banana and C. africana, (iv) to estimate combined transpiration of coffee and shade tree species and $(v)$ to determine current water competition or complementary between coffee and shade tree species. We hypothesized that a) shaded systems, Coffee-Banana and Coffee-Cordia better regulate temperature extremes and have lower vapor pressure deficit (VPD) than Coffee-Open system due to reduction of incoming solar radiation, b) shaded systems have higher total transpiration due to the presence of coffee and shade trees, thus shade systems have lower soil water content than open system, and c) coffee water use is higher under shaded than under non-shaded systems due to more suitable microclimate (reduced VPD and solar radiation) in shaded systems.

\subsection{Materials and methods}

\subsubsection{Study site}

The study was carried out from March 2015 to April 2016 on a smallholder farm on the Western slopes of Mt Elgon, Uganda (1 15’ 52" N 34 19' 19" E; 1300 m.a.s.l.). The soil was classified as Mollic Nitisol (Colluvic) according to WRB system (see,(FAO, 2014)), developed from basalt rocks, with a clay texture, pH of 6.5 and organic matter content of 2.58\% (De Bauw et al., 2016). Annual mean temperature is 22.6 $\pm 0.7^{\circ} \mathrm{C}$, annual average maximum temperature $29 \pm 1.3^{\circ} \mathrm{C}$ and annual average minimum temperature $16 \pm 0.4^{\circ} \mathrm{C}$ according to Fick and Hijmans (2017)(1970-2000). Annual rainfall sums up to $1243 \mathrm{~mm}$ with January, February and December being the driest months and receiving on average $40 \mathrm{~mm} \mathrm{month}^{-1}$ (Supplementary material, figure A.1). Highest amounts of rainfall were reported in April and May, both with more than $100 \mathrm{~mm} \mathrm{month}^{-1}$ (Fick \& Hijmans, 2017) (1970-2000).

The coffee plot had a total area of $1941 \mathrm{~m}^{2}$ with a variable slope from $22 \%$ to $32 \%$. Herbicide applications (Glyphosate $48 \mathrm{E}$ ) were done three times a year $\left(\sim 10 \mathrm{l} \mathrm{ha}{ }^{-1}\right)$, no fertilizer was applied; neither pruning nor other further management was carried out during the experiment span. On the farm, three different coffee systems were distinguished according to the abundance of banana (Musa $s p$.) and shade trees (C. africana): Coffee-open (CO), Coffee-banana (CB) and Coffee- Cordia (CC) and were distributed along the slope (at the highest point CC, $\mathrm{CO}$ and $\mathrm{CB}$ at the lowest point) (Supplementary material, figure A.2). The CB system had twice as many coffee trees per hectare compared to the other two systems (Table 1). Although this high coffee tree density is atypical in the area (Rahn et al., 2018), 
the plot was selected due to its proximity to the other systems (CO and $\mathrm{CC}$ ), since sap flow sensors needed to be connected to a data logger and a power source. Cordia africana trees were only found in the CC system. Coffee stem diameter measured at $30 \mathrm{~cm}$ above the stump varied between 2.2 and 2.3 $\mathrm{cm}$ in all three systems, and the average number of stems per coffee tree was between 2.6 and 3.5. Coffee individual leaf area (based on 50 randomly selected leaves per system) was significantly higher in the CC system compared to CB and CO (Table 1). Individual leaf area was calculated by multiplying width $(\mathrm{cm})$, length $(\mathrm{cm})$ and a correction factor of 0.7243 (according to Padovan et al. (2018)).

Table 1: Characteristics of the three coffee systems studied $(C O=$ coffee-Open, $C B=$ Coffee-Banana, $C C=$ CoffeeCordia). LAI= Leaf Area Index, BA = Basal Area, SWA = Sap Wood Area.

\begin{tabular}{|c|c|c|c|}
\hline Variable & $\mathrm{CO}$ & $\mathrm{CB}$ & $\mathrm{CC}$ \\
\hline \multicolumn{4}{|l|}{ Plot characteristics } \\
\hline Area $\left(m^{2}\right)$ & $400^{a}$ & $400^{a}$ & $1000^{a}$ \\
\hline Coffee density (Trees ha-1 $\left.{ }^{-1}\right)$ & 1875 & 3900 & 1950 \\
\hline Banana mat density (mats ha-1) & - & 975 & - \\
\hline Banana stem density (stems ha-1) & - & 2450 & - \\
\hline Cordia africana density (Trees ha-1) & - & - & 50 \\
\hline $\mathrm{N}^{\circ}$ Coffee Stems per coffee plant & $3.1 \pm 0.9$ & $3.5 \pm 1.2$ & $2.6 \pm 0.9$ \\
\hline Coffee Stem Diameter $(\mathrm{cm})^{\mathrm{b}}$ & $2.20 \pm 0.4$ & $2.25 \pm 0.4$ & $2.31 \pm 0.5$ \\
\hline Individual coffee leaf Area $\left(\mathrm{cm}^{2}\right)$ & $52.1 \pm 29$ & $40.2 \pm 25$ & $87 \pm 34$ \\
\hline LAI (System/Shade/Coffee)c & $1.2 / 0.3 \mathrm{~d} / 0.9$ & $2.7 / 1.2 / 1.5$ & $2.3 / 1.5 / 0.78$ \\
\hline Coffee BA ( $\mathrm{cm}^{2}$ Tree $\left.^{-1}\right)$ & $12.5 \pm 6.5$ & $14.1 \pm 6.4$ & $10.7 \pm 5.1$ \\
\hline Coffee BA ( $\left.\mathrm{m}^{2} \mathrm{ha}^{-1}\right)$ & 2.35 & 5.5 & 2.1 \\
\hline Banana BA $\left(m^{2} h^{-1}\right)^{e}$ & - & 61.6 & - \\
\hline Cordia africana BA ( $m^{2}$ ha-1) & - & - & 25.84 \\
\hline Slope \% & 27 & 22 & 32 \\
\hline Coffee SWA $\left(\mathrm{cm}^{2} \text { stem }^{-1}\right)^{b}$ & $3.8 \pm 0.1$ & $3.9 \pm 0.1$ & $4.2 \pm 0.2$ \\
\hline Coffee SWA $\left(\mathrm{cm}^{2} \text { stem }^{-1}\right)^{f}$ & $12.7 \pm 2.5$ & $10.0 \pm 1.6$ & $10.5 \pm 3.2$ \\
\hline Musa sp. SWA $\left(\mathrm{cm}^{2}\right.$ tree $\left.^{-1}\right)$ & - & $75.9 \pm 19.8$ & - \\
\hline Cordia africana SWA ( $\mathrm{cm}^{2}$ tree $\left.^{-1}\right)$ & - & - & $1061 \pm 921$ \\
\hline \multicolumn{4}{|l|}{ Soil Properties (4 Samples per System) } \\
\hline \multicolumn{4}{|l|}{ Horizon A $(0-40 \mathrm{~cm})$} \\
\hline $\mathrm{pH}$ & $6.45 \pm 0.1$ & $6.45 \pm 0.1$ & $6.25 \pm 0.1$ \\
\hline Organic Matter \% & $4.9 \pm 3.4$ & $5.8 \pm 1.7$ & $4.6 \pm 2$ \\
\hline Sand/Clay/Silt \% & $33 / 41 / 25$ & $29 / 41 / 29$ & $30 / 49 / 20$ \\
\hline Texture Class & Clay & Clay & Clay \\
\hline Bulk Density $\left(\mathrm{g} \mathrm{cm}^{-3}\right)$ & $1.3 \pm 0.1$ & $1.1 \pm 0.1$ & $1.3 \pm 0.0$ \\
\hline Total Porosity \% & $50.6 \pm 5.0$ & $56.9 \pm 5.3$ & $49.7 \pm 2.3$ \\
\hline
\end{tabular}

\footnotetext{
${ }^{a}$ Between CO system and CC system there was a buffer area of $141 \mathrm{~m}^{2}$. Supplementary material, figure A.2

${ }^{b}$ Measured on 50 stems

c LAI measured with LiCOR 2200 C as described in section 2.3

d This LAI of shade in CO might be due to light intercepting branches of trees outside the studied plot

e Calculated based on: average BA of individual stems $(n=8) *$ banana mat density * 1.5

${ }^{f}$ Calculated based on monitored coffee stems ( $n=15,5$ stems per system)
} 


\subsubsection{Microclimate}

In each system, two sensors for measuring air temperature (Ta) and relative humidity (RH) (Thermochron iButton, Coldchain) were in- stalled inside the coffee canopy at $1.5 \mathrm{~m}$ above the ground. Temperature $(\mathrm{Ta})$ and relative humidity $(\mathrm{RH})$ were recorded every $30 \mathrm{~s}$ and averaged every $30 \mathrm{~min}$. Photosynthetic radiation was measured in every system using two quantum sensors per system (SOLEMS- PAR-CBE80, Palaiseau, France), which were placed above the coffee canopy but below the shade tree canopies. Rainfall was measured using a tipping bucket rain gauge (Model ARG, 100, Campbell Scientific Inc, Logan, UT, USA) with a resolution of $0.2 \mathrm{~mm}$, which was placed in an open area at $2 \mathrm{~m}$ above ground. All sensors (except Ta/RH sensors) were connected to a data logger (CR1000 with AM 16/31 multiplexer Campbell Scientific Inc. Logan, UT, US), values were recorded every $30 \mathrm{~s}$ and averaged every $30 \mathrm{~min}$. Photosynthetic radiation sensors were later on calibrated in the green house with LI-250A light meter. Additionally, rainfall from the last 10 years was obtained from the closest weather station (Buginyanya, $1^{\circ} 16^{\prime} 48^{\prime \prime} \mathrm{N} 34^{\circ} 22^{\prime} 16^{\prime \prime} \mathrm{E} ; 1800$ m.a.s.l), located at a distance of $5.7 \mathrm{~km}$ to the study site. Vapor pressure deficit (VPD) and reference evapotranspiration (ET $)$ was calculated via the Penman-Monteith equation (Equation A.1, supplementary material) (Allen et al., 1998). Daily radiation was derived from irradiance $\left(\mathrm{W} \mathrm{m}^{-2}\right)$ following the equation proposed by Allen et al. (1998) (Equation A.2, supplementary material). Months in which the monthly ratio rainfall/ETo was $>/=1$ were considered as wet months, whereas months in which the ratio was $<1$ were considered as dry months according to Cannavo et al. (2011).

Since it was expected that the response of water use $\left(Q_{c}\right)$ to vapor pressure deficit (VPD) and irradiance (Irr) varied with soil water content (SWC) (Carr, 2001; DaMatta \& Ramalho, 2006), we examined those responses during three distinctive periods: wet period (low VPD and high SWC), early dry period (high VPD and high SWC) and late dry period (high VPD and low SWC).

\subsubsection{Soil water content}

Soil water content (SWC) was monitored every two weeks with a Sentek soil water probe (Diviner 2000). Two access tubes of $1.60 \mathrm{~m}$ depth were installed in each system and volumetric water content $(\mathrm{mm}$ $\mathrm{cm}^{-3}$ ) was recorded at $10 \mathrm{~cm}$ intervals. The default calibration equation provided by Sentek was used to convert device readings to volumetric soil moisture content (Scaled Frequency $=0.2746 *$ (volumetric 
water content $\wedge$ 0.3314 $)+0)($ Sentek Pty Ltd, 2009). Total water content was calculated as the cumulative sum of volumetric water content across the layers and expressed in $\mathrm{mm}$.

\subsubsection{Leaf area Index}

Leaf area index (LAI) was measured with a LICOR 2200C plant canopy analyzer (Model LAI-2270C, SR.NO.PCA-3940, LICOR) five times during the study period (Jul 2015, Sep 2015, Nov 2015, Feb 2016 and Mar 2016). At each sampling time, two measurements per system were conducted. One measurement in which the sensor was placed below coffee trees for capturing system LAI (shade LAI + coffee LAI) and during the second measurement, in which the sensor was placed above coffee trees and below shade trees, to capture shade LAI. Coffee LAI was determined by subtraction of shade LAI from system LAI. Each measurement consisted of 20 points below the foliage (either below coffee or below shade), distributed systematically in the system/plot and 2 points in the open area, as recommended by Li-COR (2009).

\subsubsection{Quantifying water use}

Sap flux density was measured with thermal dissipation probes after Granier (1987). Sensors consisted of two probes with a length of $2 \mathrm{~cm}$ each. Inside each probe, a thermocouple (copper-constantan alloy) is located in the middle (at $1 \mathrm{~cm}$ ). Furthermore, one of the probes was heated by a copper filament rolled over the length of the probe, while the other remained unheated. Each probe was inserted radially into the trunk sapwood. The sensor pairs were placed at a distance of 10-15 cm from each other. In the case of coffee trees, the upper probes were place at a distance of $30 \mathrm{~cm}$ from the stump. For $C$. africana trees, probes were inserted at a height of $2 \mathrm{~m}$ from the ground. Since bananas develop a pseudostem formed by leaves which grow fast and do not have a distinct water conductive area, the sensors were inserted in the central cylinder of the corm as suggested by Lu et al. (2002). The heated probe was inserted into the upper region of the central cylinder, beneath the cambium region at a depth of $1-3 \mathrm{~cm}$ in the inner central cylinder. The unheated probe was inserted in the cortex, around $1-2 \mathrm{~cm}$ away from the heated probe. The upper probes (downstream sensor) were constantly heated by batteries recharged via a solar panel, while the lower probe (upstream sensor) remained unheated, serving as a reference. The non-flux condition was determined daily as the highest $\Delta \mathrm{V}$ recorded in the period of $24 \mathrm{~h}$ for each sensor. Each pair of sensors was connected to a data logger (Data Logger CR1000 
and AM 16/31 multiplexer Camp- bell Scientific Inc. Logan, UT, US) and values were recorded every 30 $\mathrm{s}$ and averaged every $30 \mathrm{~min}$. Five coffee plants in each system (CO, CB and $\mathrm{CC}$ ) were monitored from March-2015 to April-2016. Additionally, five banana pseudo stems (Musa sp.) and three C. africana trees (with five sensors) were monitored. Due to large size of two of the $3 \mathrm{C}$. africana individuals (DBH $>1 \mathrm{~m}$ ), we decided to place two sensors in each individual to account for possible radial variations of sap flux density (Delzon et al., 2004). Sensors were protected from rain and extreme temperatures with isolation sheets. Sap flux density (Js) ( $\mathrm{g} \mathrm{cm}^{-2}$ hour ${ }^{-1}$ ) was calculated based on the equation of Granier (1987). We did not perform any specific calibration of the equation.

$$
J_{s}\left(\mathrm{~g} \mathrm{~cm}^{-2} \text { hour }^{-1}\right)=3600 * 0.0119 *\left(\frac{\max \Delta \mathrm{V}-\Delta \mathrm{V}}{\Delta \mathrm{V}}\right)^{1.231} \text { (equation 1) }
$$

Max $\Delta V$ was determined on a daily basis as the highest value in $24 \mathrm{~h}$. For estimating mean sap flux density (mean $J_{S}$ ) only values recorded between 6:00 am (sunrise) to 7:00 pm (sunset) were considered. Hourly sap flow (Q) (I hour ${ }^{-1}$ ) was derived from the integration of sap flux density over the conductive area or sap wood area (SWA):

$$
\mathrm{Q}\left(\text { l hour }^{-1}\right)=\frac{\mathrm{Js}\left(\mathrm{g} \mathrm{cm}^{-2} \mathrm{hour}^{-1}\right) * S W A\left(\mathrm{~cm}^{2}\right)}{1000}(\text { equation 2) }
$$

Daily tree water use $\left(Q_{c}\right)\left(I d^{-1}\right)$ was calculated by summing up the obtained $Q$ values during the day (between sunrise and sunset) following the Eq. (3). To determine daily water use of coffee trees, $Q_{c}$ was multiplied by the number of stems per tree.

$$
\mathrm{Q}_{\mathrm{c}}\left(l d^{-1}\right)=\sum_{\mathrm{i}=6: 00 \mathrm{am}}^{7: 00 \mathrm{pm}} \mathrm{Qi} \text { (equation 3) }
$$

For determining conductive sapwood area of coffee, the monitored stems were cut and placed in water with methyl orange until the water was evaporated. No coloring distinction that indicated heart wood was found in monitored stems, thus the entire basal area of the coffee trees was considered to be conductive. For $C$. africana, wood cores ( $5 \mathrm{~mm}$ diameter) were extracted from the different individuals 
(4-8 cores per tree) in different directions. The sapwood had a distinguished color from the heartwood, which allowed to directly determine sapwood depth $\left(\right.$ depth $\left._{\mathrm{sw}}\right)$. Later on, measurements were confirmed through microscopic inspection of the core samples. The sapwood area of $C$. africana was calculated based on the total radius $\left(R_{t}\right)$ and the sapwood depth $\left(S W_{\text {Depth }}\right)$ using the following equation:

$$
\left.\operatorname{SWA}(\mathrm{cm})=\pi *\left(2 * \mathrm{R}_{\mathrm{t}} * \mathrm{SW}_{\mathrm{depth}}-\left(\mathrm{SW}_{\mathrm{depth}}\right)^{2}\right) \text { (equation } 4\right)
$$

For banana, the sap wood area corresponds to the area of the central cylinder, thus it can be estimated from the diameter of the central cylinder $\left(D_{c c}\right)$ (Eq. (5)). $D_{c c}$ is determined based on the relationship between the diameter of the corm $\left(D_{c}\right)$ and diameter of the central cylinder $\left(D_{c c}\right)$ as suggested by Lu et al. (2002):

$$
\begin{gathered}
\text { Banana SWA }\left(\mathrm{cm}^{2}\right)=\pi * \frac{\mathrm{Dcc}^{2}}{4} \text { (equation 5) } \\
D c c(\mathrm{~cm})=0.5973 * D c \text { (equation 6) }
\end{gathered}
$$

Transpiration per ground area $\left(\mathrm{mm} \mathrm{d}^{-1}\right)$ was estimated by multiplying water use $\left(\mathrm{Q}_{c}\right)\left(\mathrm{d} \mathrm{d}^{-1}\right)$ by the stand density (trees ha $\left.{ }^{-1}\right)$ and transpiration per unit leaf area $\left(\mathrm{mm} \mathrm{d}^{-1}\right)$ was estimated by dividing transpiration per ground area $\left(\mathrm{mm} \mathrm{d}^{-1}\right)$ by LAI (obtained as described in section 2.3) $\left(\mathrm{m}^{2} \mathrm{~m}^{-2}\right)$ (Hernández-Santana et al., 2009).

\subsubsection{Data analysis}

Statistical analysis was conducted using R version 3.3.3 (R Development Core Team, 2015). Data were analyzed using linear mixed models (Package Imer, ImerTest and multicomp) (Bates et al., 2015; Kuznetsova et al., 2017). To evaluate system effects (CO, CB and CC) on microclimatic parameters at daily and hourly resolution (mean tem- perature, max temperature, min temperature, radiation, vapor pressure deficit and soil moisture), the system was used as a fixed effect and the date as random effect (microclimate variable $\sim$ System $+(1 \mid$ Date). To evaluate system $(C O, C B$ or CC) or period (Wet, early dry or late dry) effect on coffee mean sap flux density $\left(\mathrm{J}_{s}\right)$, coffee water use $\left(\mathrm{Q}_{c}\right)$ and coffee transpiration 
per unit basal area ( $\operatorname{Tr}$ basal area) and transpiration per unit leaf area ( $\operatorname{Tr}$ per unit leaf area), system or period was used as fixed effects and coffee stem ID and date were used as random effects (mean $J_{s} \sim$ System or season $+(1 \mid I D)+(1 \mid$ Date $))$. The same model was used to evaluate period effect on $J_{s}, Q_{c}$ and $\operatorname{Tr}$ per unit LA of banana and C. africana. When significant differences were encountered, we used a post-hoc test using the "multicomp" package and "Tukey" as the multiple-comparison procedure to identify significant difference among systems and/or periods (Hothorn et al., 2008). Data were evaluated whether they fulfill the assumptions of homogeneity of variance and normality, and transformed whenever necessary. All figures were produced with package ggplot2.

\subsection{Results}

\subsubsection{Microclimate}

Daily mean temperature during the study period from 01 March 2015 to 16 April 2016 was $22.7 \pm 2.3$ ${ }^{\circ} \mathrm{C}$, and precipitation summed up to $1699 \mathrm{~mm}$. Average daily VPD was $0.9 \pm 0.7 \mathrm{kPa}$ and daily radiation $7.8 \pm 2.8 \mathrm{MJ} \mathrm{m}^{-2} \mathrm{~d}^{-1}$. Calculated daily average reference evapotranspiration $\left(E T_{0}\right)$ was $4.1( \pm 1.8) \mathrm{mm} \mathrm{d}^{-1}$. Monthly ETo was in the order of 123 ( \pm 54$) \mathrm{mm}$ per month and exceeded monthly rainfall in March, July, and August 2015, as well as during the dry period from December 2015 to March 2016 (Fig. 1A). April, May, Jun, Sep, Oct, Nov 2015, and April 2016 were considered as wet periods, (monthly rainfall > monthly ETo). Dry months (monthly rainfall < monthly ETo) were divided into early dry (July, Aug., Dec. 2015, and Jan. 2016) and late dry (March 2015, Feb. and March 2016), depending on the reduction of soil water content (Fig. 1B). 

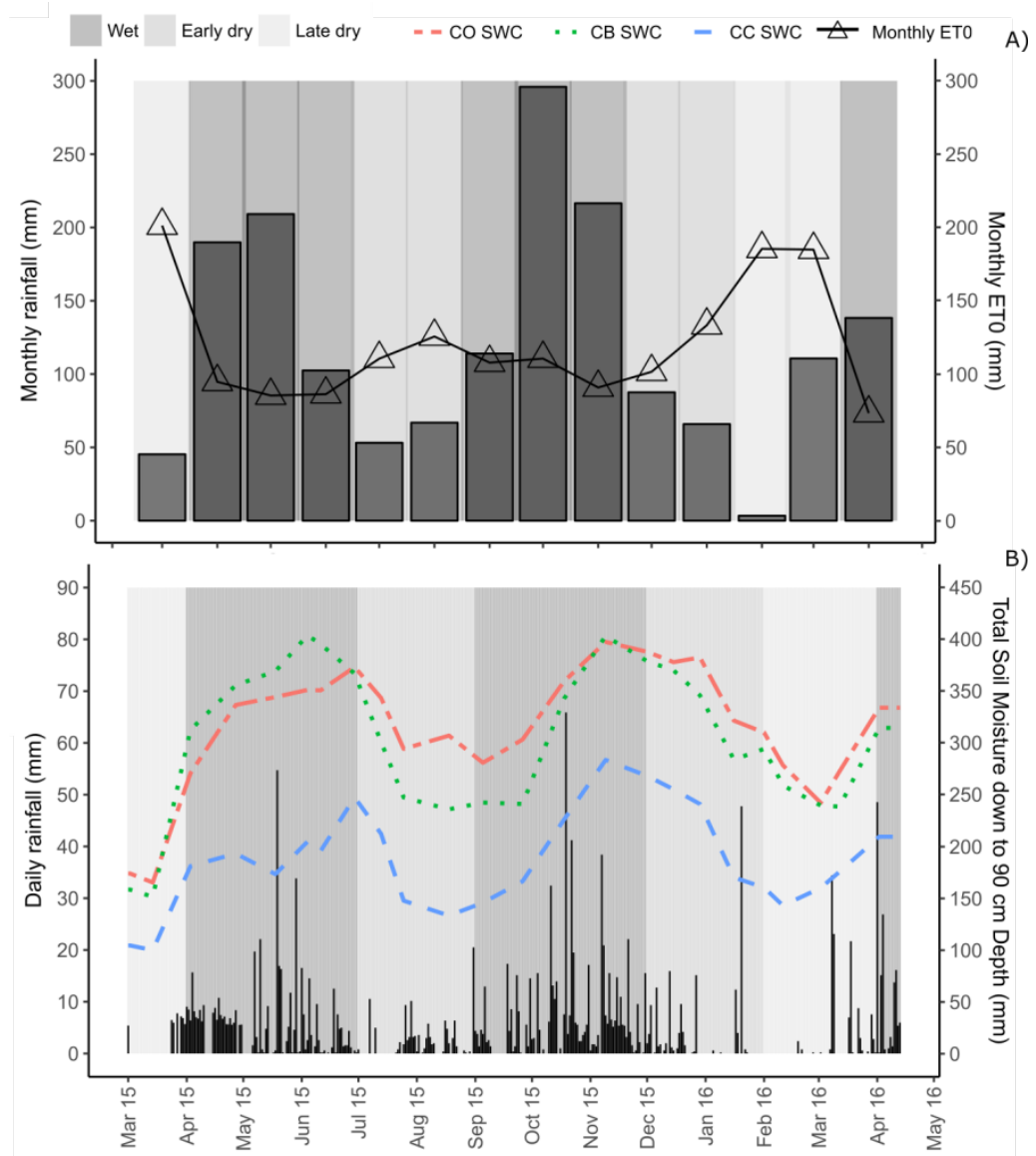

Fig. 1. A) Monthly rainfall totals ( $\mathrm{mm}$ ) (Black bars) and monthly totals of potential evapotranspiration (solid line with open triangles). B) Daily rainfall ( $\mathrm{mm} \mathrm{d}^{-1}$ ) (black bars, soil water content (SWC) in the 0 to $90 \mathrm{~cm}$ layer per system (Coffee-Open $=C O$ (Red) (- -- -), Coffee-Banana = CB (Green) (....) and Coffee-Cordia = CC (Blue) (-- -- --)) at the experimental site for the study period (March 2015 - April 2016). Background color represents the period, Wet (dark grey) (April, May, Jun, Sep, Oct and Nov 2015, Apr 2016), early dry (intermediate grey) (Jul, Aug and Dec 2015, Jan 2016) and late dry (light grey) (Mar 2015, Feb and Mar 2016).

Mean temperature, maximum temperature, irradiance and vapor pressure deficit were significantly higher in $\mathrm{CO}$ than in $\mathrm{CC}$ and $\mathrm{CB}$, averaged over the whole study period (supplementary material Table A.1) and in each period separately (Table 2). CC displayed lowest Ta max and highest Ta min, as well as the lowest amplitude (Ta max-Ta min) and lowest irradiance. CB system had the lowest daily mean VPD and Ta mean, and an intermediate irradiance (See Table 2). Temperature, vapor pressure deficit and irradiance followed a strong increase during February and March (Late dry) for all systems (Fig. 2). 
Table 2: Total soil water content down to $90 \mathrm{~cm}(\mathrm{~mm})$, mean vapor pressure deficit (VPD) (KPa), daily irradiance (Irr) $(6: 00 \mathrm{am}-7: 00 \mathrm{pm})\left(\mathrm{W} \mathrm{m}^{-2} \mathrm{~d}^{-1}\right)$, mean temperature $\left({ }^{\circ} \mathrm{C}\right)$, maximum temperature $\left({ }^{\circ} \mathrm{C}\right)$, minimum temperature $\left({ }^{\circ} \mathrm{C}\right.$ ) and temperature amplitude (T max $-\mathrm{T} \mathrm{min}$ ) for three different periods Wet (April, May, Jun, Sep, Oct and Nov 2015, Apr 2016), early dry (intermediate grey) (Jul, Aug and Dec 2015, Jan 2016) and late dry (light grey) (Mar 2015, Feb and Mar 2016).Letters refer to significant differences $(p<0.05)$ between systems in each period.

\begin{tabular}{|c|c|c|c|c|c|c|c|c|}
\hline \multicolumn{3}{|c|}{ Wet } & \multicolumn{3}{|c|}{ Early dry } & \multicolumn{3}{|c|}{ Late dry } \\
\hline $\mathrm{CO}$ & $\mathrm{CB}$ & $\mathrm{CC}$ & $\mathrm{CO}$ & $\mathrm{CB}$ & CC & $\mathrm{CO}$ & $\mathrm{CB}$ & CC \\
\hline \multicolumn{9}{|c|}{ Total Soil water content (SWC) (Down to $90 \mathrm{~cm}$ depth) } \\
\hline $340 \pm 35$ a & $340 \pm 52 b$ & $206 \pm 38^{c}$ & $335 \pm 33$ a & $298 \pm 49 b$ & $191 \pm 46^{c}$ & $249 \pm 48^{a}$ & $237 \pm 44^{b}$ & $151 \pm 29 c$ \\
\hline \multicolumn{9}{|c|}{ VPD (kPa) } \\
\hline $0.5 \pm 0.25^{a}$ & $0.3 \pm 0.2^{c}$ & $0.4 \pm 0.2^{b}$ & $0.8 \pm 0.3^{a}$ & $0.6 \pm 0.2^{c}$ & $0.7 \pm 0.3^{b}$ & $1.9 \pm 0.8^{a}$ & $1.8 \pm 1^{b}$ & $1.8 \pm 0.8^{a}$ \\
\hline \multicolumn{9}{|c|}{ Irradiance $\left(\mathrm{W} \mathrm{m}^{-2}\right)$} \\
\hline $1419 \pm 827$ a & $689 \pm 711^{b}$ & $233 \pm 253^{a}$ & $1872 \pm 582$ & $599 \pm 475 b$ & $386 \pm 186^{c}$ & $2348 \pm 1171$ & $1038 \pm 766^{b}$ & $1034 \pm 719 b$ \\
\hline \multicolumn{9}{|c|}{ Mean temperature $\left({ }^{\circ} \mathrm{C}\right)$} \\
\hline $21.5 \pm 4^{a}$ & $20.8 \pm 3.2^{c}$ & $21.1 \pm 2.6^{b}$ & $22.3 \pm 4.8^{a}$ & $21.4 \pm 3.9^{c}$ & $21.9 \pm 3.2^{b}$ & $26.1 \pm 6.2^{\text {a }}$ & $25.9 \pm 5.9^{b}$ & $25.9 \pm 5.2^{a}$ \\
\hline \multicolumn{9}{|c|}{ Max temperature $\left({ }^{\circ} \mathrm{C}\right)$} \\
\hline $30.3 \pm 3.7^{a}$ & $27.3 \pm 3.4^{b}$ & $26.1 \pm 2.6^{c}$ & $32.0 \pm 3.1^{\mathrm{a}}$ & $28.7 \pm 2.5^{b}$ & $27.7 \pm 2.2^{c}$ & $37.8 \pm 4.2^{\text {a }}$ & $36.8 \pm 4.5^{b}$ & $34.8 \pm 3.9^{c}$ \\
\hline \multicolumn{9}{|c|}{ Min temperature $\left({ }^{\circ} \mathrm{C}\right)$} \\
\hline $17.4 \pm 0.7^{a}$ & $17.5 \pm 0.7^{a}$ & $18.0 \pm 0.7^{b}$ & $17.3 \pm 0.9^{b}$ & $17.2 \pm 0.6^{c}$ & $18.1 \pm 1.0^{a}$ & $19.2 \pm 1.1^{c}$ & $19.5 \pm 1.3^{b}$ & $20.0 \pm 1.4^{\mathrm{a}}$ \\
\hline \multicolumn{9}{|c|}{ Temperature amplitude $(\Delta \mathrm{Ta})\left({ }^{\circ} \mathrm{C}\right)$} \\
\hline $12.8 \pm 3.8^{a}$ & $9.8 \pm 3.4 b$ & $8.2 \pm 2.5^{c}$ & $14.6 \pm 3.3^{a}$ & $11.5 \pm 2.5 b$ & $9.5 \pm 2.2^{c}$ & $18.6 \pm 4^{a}$ & $17.3 \pm 4.2 b$ & $14.8 \pm 3.3^{c}$ \\
\hline
\end{tabular}

Nevertheless, despite significant temperature differences between systems, differences remained below $1^{\circ} \mathrm{C}$ for Ta mean and Ta min (Table 2). Differences for Ta max were larger and reached up to $4{ }^{\circ} \mathrm{C}$ when between comparing $\mathrm{CO}$ and $\mathrm{CC}$. The temperature amplitude between systems ranged accordingly from 4 to $5{ }^{\circ} \mathrm{C}$. Daily Ta patterns revealed temperatures above $30^{\circ} \mathrm{C}$ from $10: 00$ to $18: 00 \mathrm{~h}$ in all systems during the late dry period. VPD in CO and CC did not significantly differ during late dry period, while VPD was recorded to be significantly lower in CB for all periods (Table 2). The highest VPD was recorded between 14:00 and 16:00 and remained below $2 \mathrm{kPa}$ for the wet and early dry periods. During the late dry period, however, VPD surpassed $2 \mathrm{kPa}$ already at 10:00 $\mathrm{h}$ in all systems, and reached values as high as $4.5 \mathrm{kPa}$ (Fig. 2). As reported in several studies, $2 \mathrm{kPa}$ is marked as a relevant threshold for stomata closure of coffee (> 1.6 kPa) and many other species (Butler, 1977; Fanjul et al., 1985; Gutiérrez et al., 1994; Kanechi et al., 1995; Carr, 2001; DaMatta \& Ramalho, 2006; van Kanten \& Vaast, 2006; Jung et al., 2010).

Highest irradiance was recorded in CO during all periods (Table 2). Irradiance was higher in CB than in $\mathrm{CC}$ during the wet and early dry period; however, no significant differences between these two systems were found during the late dry period (Table 2). Irradiance increase in CB had $1 \mathrm{~h}$ lag-phase compared to $\mathrm{CO}$ and $\mathrm{CC}$ in the first hours of the day, probably due to the topography of the plot (Fig. 2). 


\section{$\square \mathrm{CO} \rightarrow \mathrm{CB} \triangle \mathrm{CC}$}
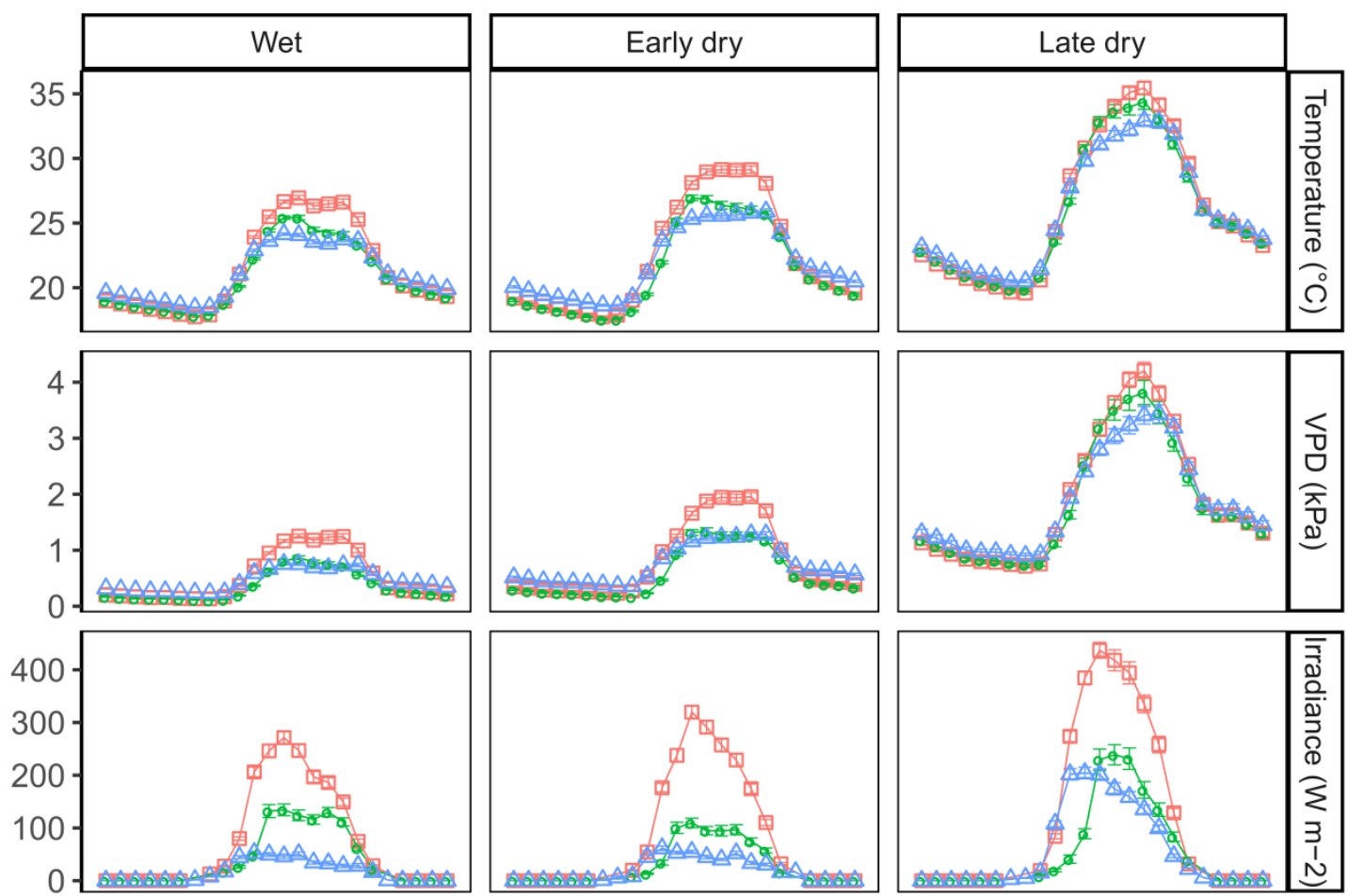

Sap flux density (Js) (cm3 cm-3 hour -1)
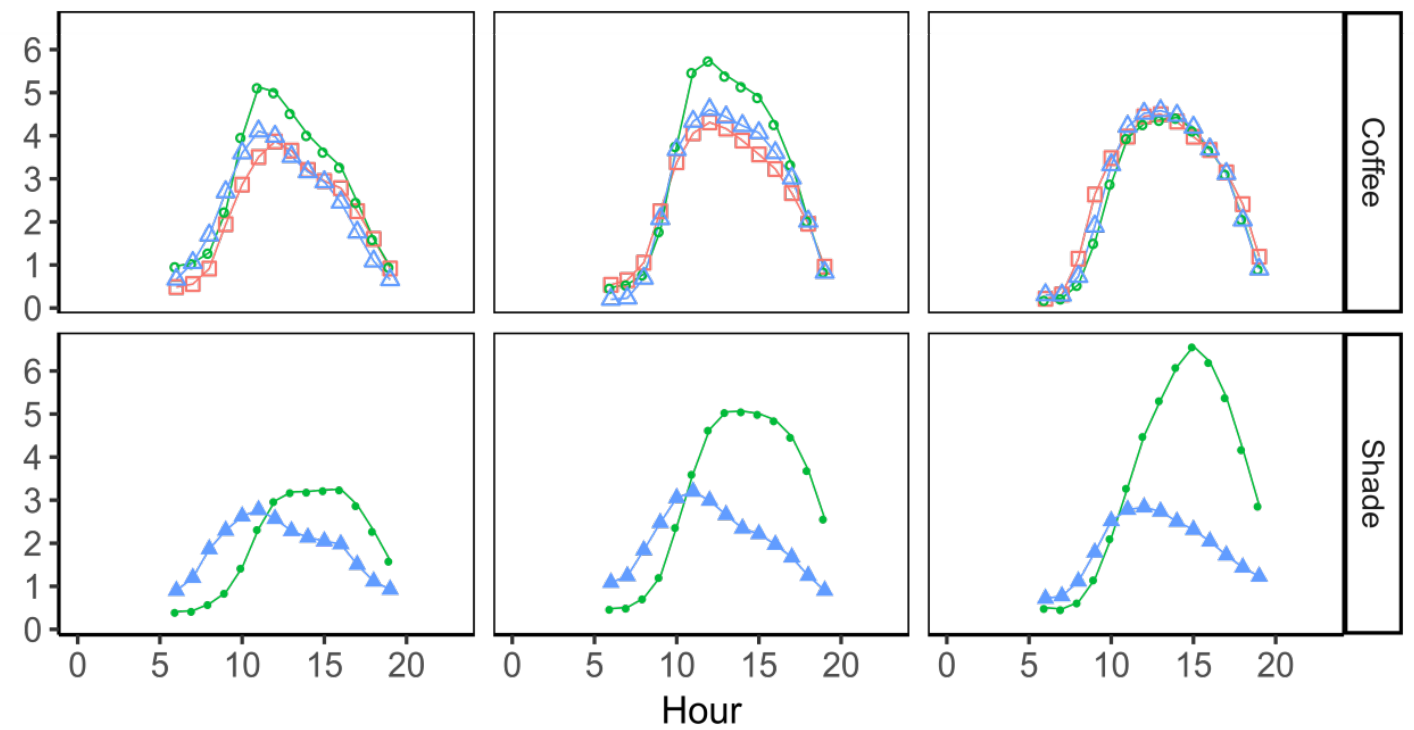

$\because$ Coffee $-\mathrm{CO} \multimap$ Coffee $-\mathrm{CB} \bumpeq$ Coffee $-\mathrm{CC} \rightarrow$ Musa sp. $\leadsto$ C. africana

Fig. 2. Daily patterns of Temperature $\left({ }^{\circ} \mathrm{C}\right)$, vapor pressure deficit (VPD) $(\mathrm{kPa})$, irradiance $\left(\mathrm{W} \mathrm{m}^{-2}\right)$ and sap flux density $\left(\mathrm{cm}^{3} \mathrm{~cm}^{-2}\right.$ hour ${ }^{-1}$ ) for three periods: Wet (April, May, Jun, Sep, Oct and Nov 2015, Apr 2016), early dry (Jul, Aug and Dec 2015, Jan 2016) and late dry (Mar 2015, Feb and Mar 2016).In three different systems (Coffee-Open = CO (Square)(Red), Coffee-Banana = CB (Circle) (Green) and Coffee-Cordia = CC (Triangle) (Blue)and coffee (Coffee-CO (Empty square) (red), Coffee-CB (empty circle)(Green), Coffee-CC (empty triangle)(Blue), Musa sp. (Fill circle)(Green) and C. africana (Fill triangle)(Blue). Line indicates mean values and error bar indicates standard error. 


\subsubsection{Soil water content}

Total soil water content (SWC) (down to $90 \mathrm{~cm}$ depth) was the highest in $\mathrm{CO}$ and varied between periods from $340 \mathrm{~mm}$ (wet) to $249 \mathrm{~mm}$ (late dry). CC had the lowest total SWC in all periods compared to CO and CB (Table 2). Water uptake by plants occurred mostly in the first $90 \mathrm{~cm}$. Between 20 to $80 \mathrm{~cm}$ depth, CO had higher SWC (30-40 mm) per depth compared to CC (10-20 mm), and this trend was consistent during the early dry period and wet period (Fig. 3). In the first $30 \mathrm{~cm}$, SWC in CB decreased during the early dry period and late dry period to $10-30 \mathrm{~mm}$ per depth and during the wet period to $20-30 \mathrm{~mm}$ per depth, while for CO such decreases were only observed during the late dry period. Below $90 \mathrm{~cm}$ depth, SWC values of the $C O$ and CC remained at similar levels (30-40 mm per depth) during the wet period, while during the dry period, $\mathrm{CC}$ dropped below $30 \mathrm{~mm}$ per depth between $100 \mathrm{~cm}$ and $130 \mathrm{~cm}$ depth

(Fig. 3). Due to technical problems, no data were available for CB below $90 \mathrm{~cm}$.
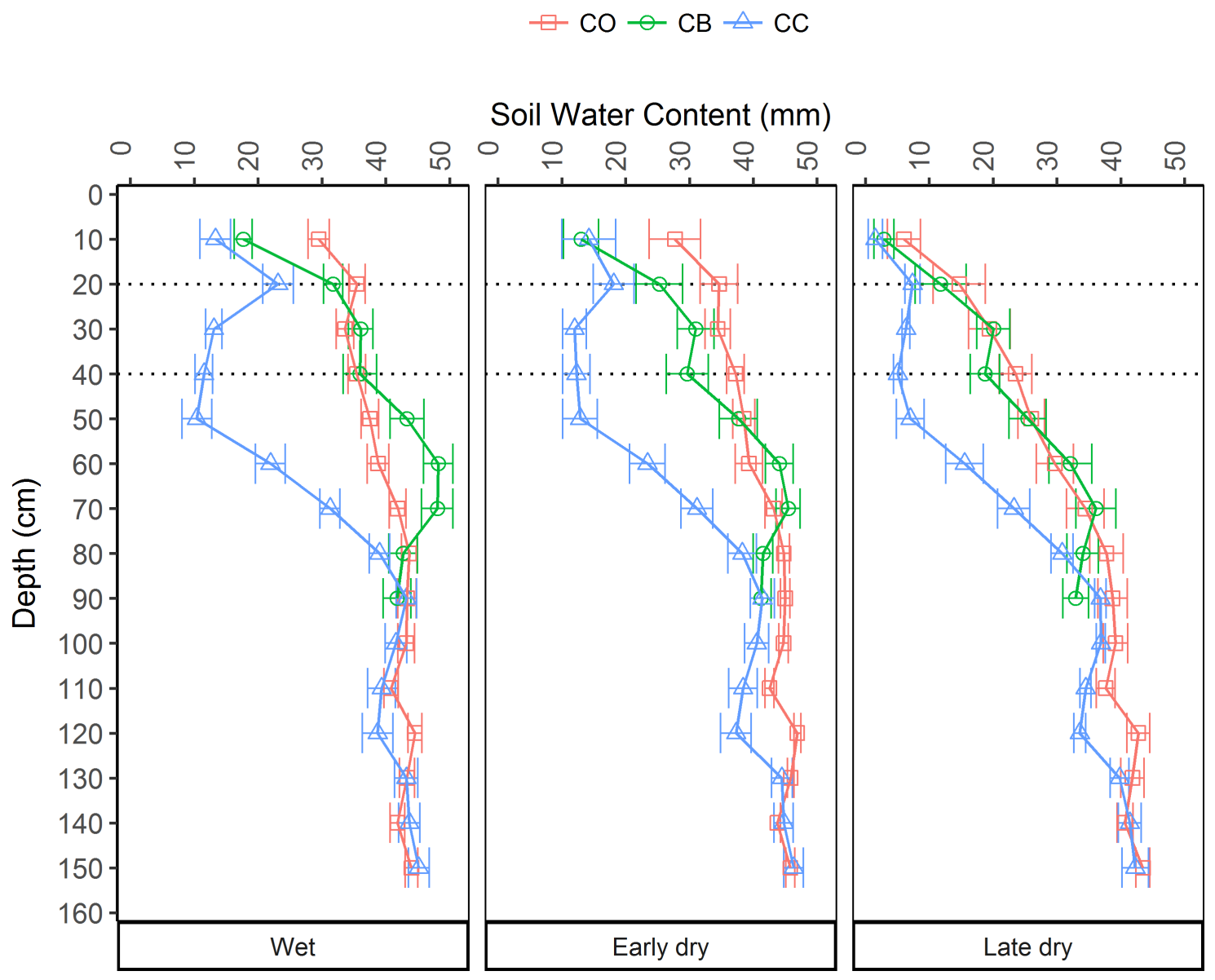

Fig. 3. Soil water content $(\mathrm{mm})$ per $10 \mathrm{~cm}$ depth interval during distinct periods (wet, early dry period and late dry period) down to $150 \mathrm{~cm}$ depth except for CB system for which measurements were only available down to $90 \mathrm{~cm}$ depth. (Coffee-Open $=\mathrm{CO}$ (Square) (Red), Coffee-Banana = CB (Circle) (Green) and Coffee-Cordia = CC (Triangle) (Blue). Line indicates mean values and error bar indicates standard error. Dotted lines indicate $20 \mathrm{~cm}$ and $40 \mathrm{~cm}$ depths. 


\subsubsection{Water use}

Coffee mean sap flux density $\left(J_{s}\right)$ averaged over the study period, was $2.6 \pm 2 \mathrm{~g} \mathrm{~cm}^{-2} \mathrm{~h}^{-1}$ in Coffee-CO, 3 $\pm 2.6 \mathrm{~g} \mathrm{~cm}^{-2} \mathrm{~h}^{-1}$ in Coffee-CB and $2.7 \pm 2.4 \mathrm{~g} \mathrm{~cm}^{-2} \mathrm{~h}^{-1}$ in Coffee-CC and did not differ significantly between systems. Coffee mean $J_{s}$ did also not differ between systems when compared for each period separately (wet, early dry, late dry, Table 3). A significant increase in coffee mean $J_{s}$ occurred in Coffee-CO during the early and late dry periods, while Coffee-CB mean $J_{s}$ increased during the early dry compared to wet period. And decreased again during the late dry period (Table 3). For Coffee-CC, highest mean $\mathrm{J}_{\mathrm{s}}$ was recorded during the early dry period, and it was significantly larger than mean $J_{s}$ during the wet period. No significant differences in mean $J_{s}$ of Coffee-CC were found between mean early period and late dry period or between late dry period and wet period. Coffee daily $Q_{c}$ per tree $\left(\mathrm{I} \mathrm{d}^{-1}\right)$ was not significantly different between systems with mean daily values of $1.3 \pm 0.55\left(\mathrm{I} \mathrm{d}^{-1}\right)$ for Coffee-CO, $1.4 \pm 0.76\left(\mathrm{I} \mathrm{d}^{-1}\right)$ for Coffee-CB and $1.0 \pm 0.63\left(\mathrm{I} \mathrm{d}^{-1}\right)$ for Coffee-CC. Furthermore, no significant system effect on $\mathrm{Q}_{c}$ was found for any of the three distinct periods (Table 3). $Q_{c}$ of Coffee-CO and Coffee-CC significantly increased during early and late dry period compared to the wet period, namely by $18 \%$ for Coffee-CO and $19 \%$ for Coffee-CC. On the other hand, $\mathrm{Q}_{c}$ of Coffee-CB increased $14 \%$ during the early dry period and decreased again during the late dry period.

Table 3: Mean $J_{s}$, daily $Q_{c}$ and transpiration per unit leaf area for coffee in each system (Coffee-CO, Coffee-CB, Coffee-CC for each of the three periods Wet (April, May, Jun, Sep, Oct and Nov 2015, Apr 2016), early dry (Jul, Aug and Dec 2015, Jan 2016) and late dry (Mar 2015, Feb and Mar 2016) . Capital letters indicate significant differences between systems for each period. Small case letters indicate significant differences across seasons for each system. Significances at $p$-value $<0.05$

$$
\text { Wet } \quad \text { Early dry Late dry }
$$

\begin{tabular}{|c|c|c|c|c|c|c|c|c|c|}
\hline & Coffee-CO & Coffee-CB & Coffee-CC & Coffee-CO & Coffee-CB & Coffee-CC & Coffee-CO & Coffee-CB & Coffee-CC \\
\hline $\begin{array}{l}\mathrm{N}^{\circ} \text { of monitoring } \\
\text { Days * }\end{array}$ & 182 & 179 & 152 & 123 & 123 & 89 & 85 & 86 & 86 \\
\hline $\begin{array}{l}\text { Mean Js } \\
\left(\mathrm{g} \mathrm{cm}^{-2} \mathrm{~h}^{-1}\right)\end{array}$ & $\begin{array}{l}2.35 \pm 1.05 \\
A, b\end{array}$ & $\begin{array}{l}3.02 \pm 1.40 \\
A, b\end{array}$ & $\begin{array}{l}2.54 \pm 1.37 \\
A, b\end{array}$ & $\begin{array}{l}2.73 \pm 1.15 \\
A, a\end{array}$ & $\begin{array}{l}3.34 \pm 1.45 \\
\text { A,a }\end{array}$ & $\begin{array}{l}2.84 \pm 1.17 \\
A, a\end{array}$ & $2.92 \pm 1.21 \mathrm{~A}$ & $\begin{array}{l}2.70 \pm 1.21 \\
A, b\end{array}$ & $\begin{array}{l}2.92 \pm 2.03 \\
A, a b\end{array}$ \\
\hline $\begin{array}{l}\text { Daily Qc } \\
\left(\mathrm{ld}^{-1}\right) \text { per stem }\end{array}$ & $\begin{array}{l}0.38 \pm 0.16 \\
A, b\end{array}$ & $\begin{array}{l}0.40 \pm 0.22 \\
A, b\end{array}$ & $\begin{array}{l}0.33 \pm 0.17 \\
A, b\end{array}$ & $\begin{array}{l}0.44 \pm 0.18 \\
A, a\end{array}$ & $\begin{array}{l}0.44 \pm 0.24 \\
A, a\end{array}$ & $\begin{array}{l}0.38 \pm 0.20 \\
A, a\end{array}$ & $\begin{array}{l}0.47 \pm 0.19 \\
A, a\end{array}$ & $\begin{array}{l}0.38 \pm 0.19 \\
A, b\end{array}$ & $\begin{array}{l}0.41 \pm 0.34 \\
A, a\end{array}$ \\
\hline $\begin{array}{l}\text { Daily Qc } \\
\left(1 d^{-1}\right) \text { per coffee } \\
\text { tree }\end{array}$ & $1.20 \pm 0.52$ & $\begin{array}{l}1.41 \pm 0.77 \\
A, b\end{array}$ & $0.86 \pm 0.45$ & $\begin{array}{l}1.38 \pm 0.56 \\
A, a\end{array}$ & $\begin{array}{l}1.57 \pm 0.84 \\
A, a\end{array}$ & $\begin{array}{l}1.00 \pm 0.54 \\
A, a\end{array}$ & $\begin{array}{l}1.47 \pm 0.58 \\
\mathrm{~A}, \mathrm{a}\end{array}$ & $\begin{array}{l}1.33 \pm 0.68 \\
A, b\end{array}$ & $\begin{array}{l}1.06 \pm 0.90 \\
\mathrm{~A}, \mathrm{a}\end{array}$ \\
\hline
\end{tabular}

* Number of days in which data is available for at least three replicates. Days with less than 2 replicates were not included in the analysis.

** SWA (Coffee-CO $=12.7 \pm 2.5 \mathrm{~cm}^{2}$, Coffee- $C B=10.0 \pm 1.6 \mathrm{~cm}^{2}$ and Coffee-CC $=10.5 \pm 3.2 \mathrm{~cm}^{2}$ )

$* * * N^{\circ}$ stems per coffee tree (Coffee-CO=3.1 \pm 0.9 , Coffee- $C B=3.5 \pm 1.2$ and Coffee- $C C=2.6 \pm 0.9$ ) 
Coffee leaf area index (LAI) increased during the early dry period when compared to the wet period in Coffee-CO by $+21 \%$ and Coffee- CC by $+25 \%$. On the other hand, LAl of Coffee-CB decreased by $-11 \%$ in the early dry period (Fig. 4). During the late dry period, LAI decreased in Coffee-CO by $-28 \%$ and Coffee-CB by $-36 \%$. Whereas, LAl of Coffee-CC increased by $+35 \%$ during the late dry season. Daily coffee transpiration per unit leaf area $\left(\mathrm{mm} \mathrm{d}^{-1}\right)$ averaged over the study period did not differ between systems. On the other hand, daily coffee transpiration per unit leaf area varied between periods differently depending on the system. In CB, coffee increased transpiration per unit leaf area by $33 \%$ during the early and late dry period compared to the wet period. In CO, coffee increased transpiration per unit leaf area during the late dry period by $70 \%$ compared to transpiration per leaf area during the wet period. On the other hand, Coffee-CC presented higher transpiration rates during the wet period, compared to the early dry and late dry periods (Fig. 4). Variations in coffee transpiration per leaf area corresponded to variations in LAI. Coffee transpiration per ground area was significantly higher in CB than in $\mathrm{CO}$ and CC, which corresponded with higher coffee tree density (Fig. 4).

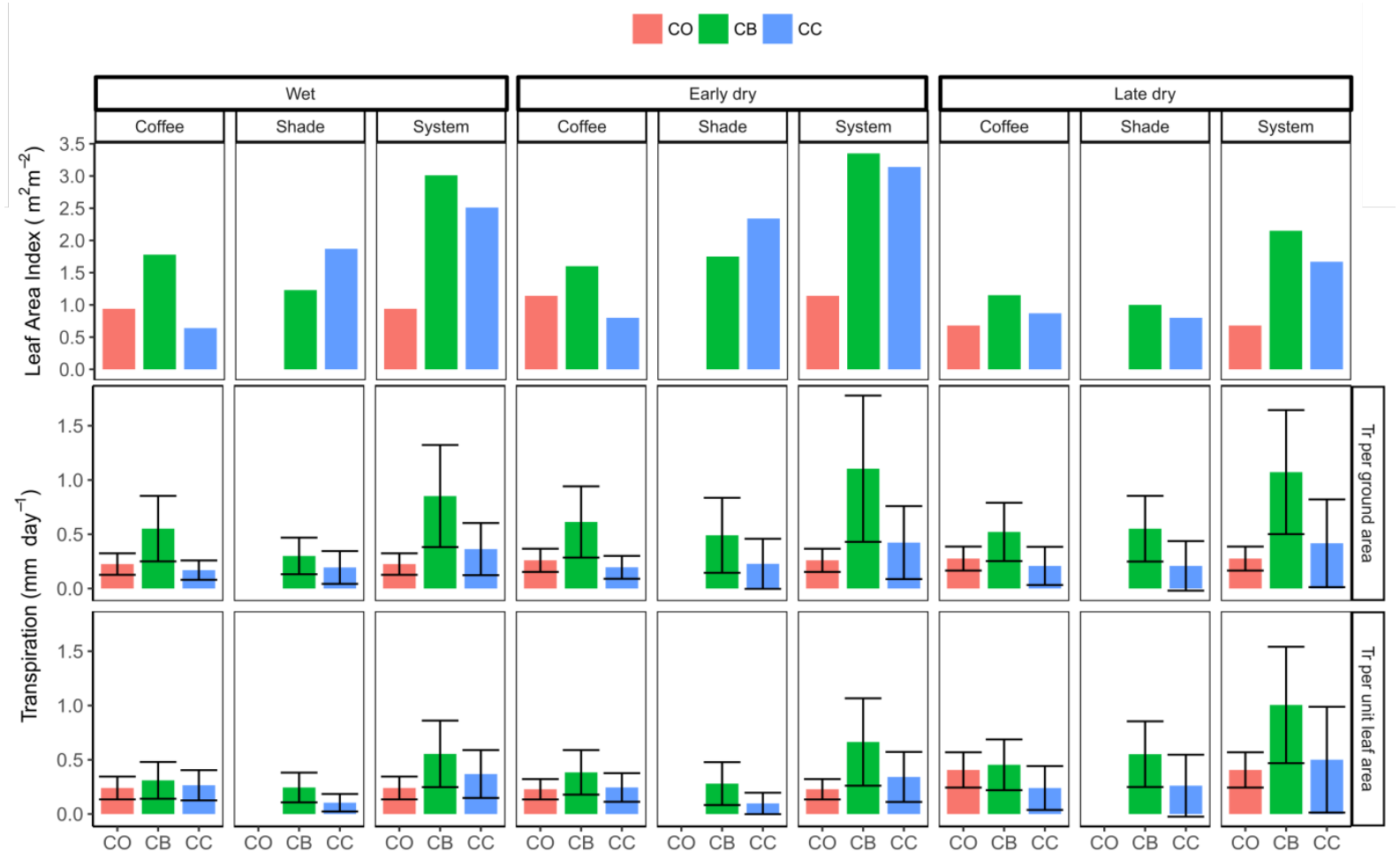

Fig. 4. Leaf area index (LAI), transpiration ( $T r)$ per ground area $\left(\mathrm{Q}_{c} *\right.$ Tree density) and transpiration $(\operatorname{Tr})$ per unit leaf area ( $\operatorname{Tr}$ per ground area/LAI) for coffee, shade (Musa sp in CB and Cordia africana in CC) system (Coffee + shade) in three systems (CoffeeOpen = CO (Red), Coffee-Banana $=$ CB (Green) and Coffee-Cordia = CC(Blue)), for three distinct periods Wet (April, May, Jun, Sep, Oct and Nov 2015, Apr 2016), early dry (Jul, Aug and Dec 2015, Jan 2016) and late dry (Mar 2015, Feb and Mar 2016) 
Daily water use $\left(Q_{c}\right)$ was significantly different between shade species ( $p$-value $\left.<0.001\right)$. The shade tree species $C$. africana had a higher daily water use rate per tree $\left(41 \pm 39 \mid \mathrm{d}^{-1}\right)$ than banana $\left(3 \pm 2 \mid \mathrm{d}^{-1}\right)$. Although, mean $J_{S}$ was lower for $C$. africana than for banana, it did not differ significantly from each other (Table 4). Banana $J_{s}$ however differed significantly across periods. Lowest values were recorded during the wet period, while highest values occurred during the late dry period (Table 4). Mean $\mathrm{J}_{\mathrm{S}}$ of $C$. africana, on the other hand increased significantly during the early dry period; and decreased during the late dry period and the wet period (Table 4). Banana transpiration per ground area was significantly larger than C. africana transpiration per ground area only for the late dry period (Fig. 4). Cordia africana transpiration per unit leaf area increased during the late dry period compared to the wet and early dry periods due to leaf senescence (Fig. 4).

Table 4: Mean Js, Daily $Q$ and Transpiration per unit leaf area transpiration for bananas and Cordia africana for Wet (April, May, Jun, Sep, Oct and Nov 2015, April 2016), early dry (July, Aug and Dec 2015, Jan 2016) and late dry (March 2015, Feb and March 2016) . Capital letters indicate significant differences between species (Banana and Cordia africana) for each period. Small case letters indicate significant differences across periods within each species at $p$-value $<0.05$
Banana
Cordia africana

\begin{tabular}{|c|c|c|c|c|c|c|}
\hline & Wet & Early dry & Late dry & Wet & Early dry & Late dry \\
\hline $\begin{array}{l}\mathrm{N}^{\circ} \text { Monitoring } \\
\text { Days }\end{array}$ & 69 & 49 & 110 & 102 & 85 & 153 \\
\hline $\begin{array}{l}\text { Mean Js } \\
\left(\mathrm{g} \mathrm{cm}^{-2} \mathrm{~h}^{-1}\right)\end{array}$ & $2.05 \pm 1.07 \mathrm{~A}, \mathrm{C}$ & $3.16 \pm 1.80^{\mathrm{A}, \mathrm{b}}$ & $3.52 \pm 1.86 \mathrm{~A}, \mathrm{a}$ & $1.96 \pm 0.86 \mathrm{~A}, \mathrm{a}$ & $2.16 \pm 1.41 \mathrm{~A}, \mathrm{a}$ & $1.95 \pm 1.25^{\mathrm{A}, \mathrm{b}}$ \\
\hline $\begin{array}{l}\text { Daily Q } \\
\left(\mathrm{d} \mathrm{d}^{-1}\right)\end{array}$ & $2 \pm 1^{B, C}$ & $3 \pm 2 B, b$ & $4 \pm 2 \mathrm{~B}, \mathrm{a}$ & $39 \pm 30^{A, b}$ & $45 \pm 46^{A, a}$ & $41 \pm 45^{A, b}$ \\
\hline
\end{tabular}

* Number of days in which data is available for at least three replicates. Days with less than 2 replicates were not included in the analysis.

** SWA (Banana $=76 \pm 20 \mathrm{~cm}^{2}$, C. africana $=1061 \pm 921 \mathrm{~cm}^{2}$

CB system had the largest system transpiration per ground area $\left(0.9 \pm 0.4 \mathrm{~mm} \mathrm{~d}^{-1}\right)$ and per unit leaf area $\left(0.6 \pm 0.4 \mathrm{~mm} \mathrm{~d}^{-1}\right)\left(p-\right.$ value $\left.=<2.26 \mathrm{e}^{-16}\right)$, which was consistent among all three periods (Fig. 4). CC transpired $0.37 \pm 0.1 \mathrm{~mm} \mathrm{~d}^{-1}$ per ground area and $0.36 \pm 0.1 \mathrm{~mm} \mathrm{~d}^{-1}$ per unit leaf area, which was significantly larger than the transpiration rates of CO that displayed values of $0.24 \pm 0.1 \mathrm{~mm} \mathrm{~d}^{-1}$ per ground area and $0.27 \pm 0.1 \mathrm{~mm} \mathrm{~d}^{-1}$ per unit leaf area. Coffee contributed on average $55 \%$ to the system transpiration per ground area in CB and $47 \%$ in the CC system, whereas bananas contributed up to $45 \%$ and Cordia africana up to $53 \%$ of the system transpiration per ground area (Fig. 4). For calculation of transpiration it was assumed that weeds were absent. 


\subsubsection{Influence of VPD on hourly sap flux density for different periods}

Bananas showed a linear increase in $J_{s}$ when VPD was increasing and higher values of $J_{s}$ were reached during the late dry period (supplementary material, figure A.4). Coffee in contrast showed initially an increase until a VPD threshold of around 2-3kPa was achieved, whereas $\mathrm{J}_{s}$ was maintained or reduced with further increases in VPD. This pattern was consistent across all systems and periods. Nevertheless, when VPD was below 2kPa, Coffee-CB and Coffee-CC reached higher values of $\mathrm{J}_{\mathrm{s}}$ compared to Coffee$\mathrm{CO}$ during the wet period (Fig. 2). $\mathrm{J}_{\mathrm{s}}$ patterns of $C$. africana showed a poor correlation with VPD for all the different periods, and $\mathrm{J}_{\mathrm{s}}$ tended to be larger at lower VPD during the early dry period (supplementary material, figure A.4).

\subsection{Discussion}

Coffee water consumption per tree, with $1.2 \pm 0.64 \mathrm{I} \mathrm{d}^{-2}$, was similar across cultivation systems with an increase during early and late dry periods, when VPD increased. Consequently, we could not observe a system effect on coffee water use, and hence hardly any signs of water competition between coffee and associated shade species. This was most likely due to the fact that rainfall amount and SWC were sufficient to meet water requirements of the studied systems. Daily water use per tree was lower in bananas than in C. africana, but daily transpiration rate per ground area and unit leaf area were larger for bananas (Fig. 4). Daily system transpiration was higher in CB than in CC and CO (Fig. 4), due to higher coffee plant densities than $\mathrm{CC}$ and $\mathrm{CO}$, and the higher banana densities than the one of $C$. africana.

Temperature during the late dry period surpassed critical thresholds of optimum temperature (Tmean between $18{ }^{\circ} \mathrm{C}$ and $22^{\circ} \mathrm{C}$ and Tmax below $30^{\circ} \mathrm{C}$ ) range for $\mathrm{C}$. arabica according to Descroix and Snoeck (2008), even under shaded systems. Compared to CO and CB, CC reduced incoming radiation and showed better buffering effects against extremes (Ta max and Ta min) and, hence had smaller daily temperature amplitude (Ta max - Ta min). Shade trees consequently protected the coffee underneath from high temperature and high radiation; and reducing coffee leaf area oscillations between seasons. $\mathrm{CC}$ on the other hand, lowered SWC in comparison to $\mathrm{CO}$ and $\mathrm{CB}$, which might result in water competition under drier conditions than experienced in our study. Detailed discussion of various factors follows below. 


\subsubsection{Microclimate differences between cultivation systems}

The microclimate regulating role of shade trees has already been described by several authors (Barradas \& Fanjul, 1986; Muschler \& Bonnemann, 1997; Siles \& Vaast, 2002; Partelli et al., 2014; Carvalho et al., 2017) and was confirmed by the present results. Nevertheless, when examining the three defined periods, it was found that the differences in VPD between systems were very low (around 0.1 K Pa), and not always significant. We attributed this to the patchiness at landscape level with a close proximity of the various systems within neighboring small farms. Our findings confirmed the importance of studying microclimate at different temporal resolutions to identify if at certain hours of the day, relevant coffee physiological thresholds such as VPD $>2 \mathrm{kPa}$, are reached and the time span that such microclimate conditions last. This is of interest since intensity, duration and speed of certain stresses will influence the plant acclimation ability, and therefore their coping capacity against stresses (DaMatta \& Ramalho, 2006).

The reduced SWC in the upper layers $(0-40 \mathrm{~cm})$ in all systems, confirmed that coffee soil water uptake occurs mostly in the top $40 \mathrm{~cm}$ of the soil profile, although it could extend down to $70 \mathrm{~cm}$. This is in congruence with Padovan et al. (2015), who reported that $56 \%$ of coffee roots were encountered in the upper $30 \mathrm{~cm}$ and was also reported in other studies (Pereira, 1957; Wallis, 1963; Van Kanten et al., 2005; van Kanten \& Vaast, 2006). Water uptake by C. africana was mainly concentrated in the top 90 $\mathrm{cm}$, extended even down to $130 \mathrm{~cm}$ depth during the dry periods (early and late dry) (Figs. 3 and 4). This indicates that the first $40 \mathrm{~cm}$ were overlapping with the active coffee root zone, which reduced soil water content of CC system compared to CB and CO. Consistent lower values of SWC in heavy shaded systems in comparison with low shaded or non-shaded systems have also been reported by Siles et al. (2009) and Padovan et al. (2015), which they explained as a result of higher combined transpiration of coffee and shade trees under high shade. This is also the case in our study (Fig. 4).

Nevertheless, despite larger transpiration in CB than in CC, we found lower SWC in CC during all seasons

(Fig. 3 and Table 3). We attributed this to a better water use efficiency in the CB system due to an effect of the intermediate shade of the bananas. It is hypothesized that banana shade reduced soil evaporation of upper layers, and intercepted less rainfall than C. africana trees, hence allowing higher soil water availability for coffee and banana transpiration. Moreover, the aspect of the plot (slope $>20 \%$ ) and distribution of systems along the slope ( $C C$ at the highest point and $C B$ at the lowest point, see 
supplementary material figure A.2) could have influenced water redistribution (runoff and lateral infiltration), increasing soil water content in CB. Nevertheless, clearly, additional data, such as soil evaporation rates, run-off, lateral infiltration and rainfall interception would be required to prove these hypotheses.

\subsubsection{Sap flux density, water use and transpiration}

Sap flux density $\left(\mathrm{J}_{\mathrm{s}}\right)$ of coffee under all systems as well as $C$. africana decreased when VPD was $>2 \mathrm{kPa}$, which can be attributed to stomatal sensitivity to high VPD. In the case of coffee, this threshold has already been reported in several studies (Butler, 1977; Fanjul et al., 1985; Gutiérrez et al., 1994; Kanechi et al., 1995; Carr, 2001; DaMatta \& Ramalho, 2006; van Kanten \& Vaast, 2006). Also in other woody species, such as Ulmus davidian, Terminalia ivorensis and Eucaliptus de- glupta, a similar VPD threshold could also be observed (van Kanten \& Vaast, 2006; Jung et al., 2010). On the contrary, banana followed a linear increase with increasing VPD without an observable threshold, thus without stomatal control. These results are in line with patterns described by Lu et al. (2002)and (Liu et al., 2008).

Daily coffee water use did not differ significantly between systems (Table 4), which can be attributed to several factors. Firstly, although significant, differences in VPD between systems were in the range of $0.2 \mathrm{kPa}$, which might be too small to generate any system-specific response in $\mathrm{J}_{\mathrm{s}}$ for coffee. Secondly, hourly VPD values frequently crossed the $2 \mathrm{kPa}$ threshold in all systems, therefore restricting increases in coffee $J_{s}$, and subsequently in coffee $Q_{c}$. Thirdly, as a shade-adapted species, coffee maintains stomatal conductance, thus photosynthetic rates, and water use (DaMatta \& Ramalho, 2006; Franck \& Vaast, 2009), even at reduced irradiance as in the case of CB and CC. Finally, a high variability in $J_{s}$ between individuals within the same system, as indicated by the high standard deviation, certainly hindered to some extent the system comparison.

Similarly, coffee transpiration per unit leaf area did not significantly differ between systems. Nevertheless, coffee transpiration per unit leaf area had different seasonal responses depending on the system. Coffee- $\mathrm{CO}$ and Coffee-CB increased transpiration per unit leaf area during the late dry period, while Coffee-CC increased during the wet period. Such variations can be attributed to the increase of $J_{s}$ 
during the late dry period combined with the reduction of the coffee LAI up to $40 \%$ and $15 \%$ in the case of Coffee-CO and Coffee-CB, respectively (Fig. 4). LAI in Coffee-CC increased during the early and late dry periods by $10 \%$ compared to the wet period. Maintenance of coffee sap flow rates despite changes in leaf area were also reported by Tausend et al. (2000).

We attributed LAI reduction in Coffee-CO to a combined effect of high irradiance and VPD, on top of large air Ta diurnal variations, which could have increased leaf damage and reduced leaf growth (Gutiérrez et al., 1994; Siles \& Vaast, 2002; DaMatta \& Ramalho, 2006). The transpiration rates per leaf area recorded during our study remained low compared to the ones reported by (Padovan et al., 2018). As well as coffee LAl and coffee tree density per hectare recorded in our study was half when compared to $4700-5000$ tree ha ${ }^{-1}$ and coffee LAI $=4.6$ in full sun reported by Cannavo et al. (2011). And 4000 trees ha ${ }^{-1}$, coffee full sun LAI $=2.39 \pm 0.10 \mathrm{SE}$ shaded coffee LAI $=3.57 \pm 0.10 \mathrm{SE}$ reported by Padovan et al. (2018).

To our knowledge, our study is the first aiming to estimate water use of $C$. africana with thermal dissipation probes. Cordia africana was found to consume 10 times more water per day than banana and 100 times more than coffee, which can be mainly attributed to its larger canopy size and sap wood area. Nevertheless, when normalized by unit leaf area, lower transpiration per unit leaf area for $C$. africana than for coffee or banana was observed. On average, C. africana consumed similar amounts of water as other deciduous shade species such as Tabebuia rosea with 60 to $170 \mathrm{I} \mathrm{d}^{-1}$ (Padovan et al., 2018). Transpiration per ground area of $C$. africana $\left(0.16 \pm 0.16 \mathrm{~mm} \mathrm{~d}^{-1}, 50\right.$ trees ha-1) was lower than transpiration per ground area reported for Inga densiflora $\left(0.49 \pm 0.5 \mathrm{~mm} \mathrm{~d}^{-1}, 277\right.$ tree ha-1) reported by Cannavo et al. (2011), Simarouba glauca (0.20 $\pm 0.02 \mathrm{SE} \mathrm{mm} \mathrm{d}^{-1}, 75$ trees ha $\left.^{-1}\right)$ and Tabebuia rosacea (from $0.24 \mathrm{~mm} \mathrm{~d}^{-1}$ to $1.05 \mathrm{~mm} \mathrm{~d}^{-1}, 113$ trees ha-1) reported by Padovan et al. (2018). Banana, on the other hand, had comparable transpiration per ground area $\left(0.34 \pm 0.20 \mathrm{~mm} \mathrm{~d}^{-1}, 975 \mathrm{mats}^{\mathrm{h}} \mathrm{a}^{-1}\right)$ to the above-mentioned species, although at higher densities per hectare.

Despite no significant differences in coffee daily water use between systems were observed and water competition appeared to be absent due to sufficient rainfall, extended periods without rain and a decrease in rainfall amount, could pose a problem for coffee when intercropped with other species. This became visible in the lower soil moisture content in shaded systems, particularly CC and is in line with 
the observations by Cannavo et al. (2011), Padovan et al. (2015), Padovan et al. (2015), and Padovan et al. (2018). Our results showed that transpiration rates of coffee and agroforestry systems appeared to be highly dependent on system structure (coffee density and shade trees density, LAI and tree size), and hence difficult to compare across regions. Therefore, we recommend the reporting of transpiration rates per ground and leaf area, accompanied with water use per tree $\left(Q_{c}\right)$, size of individuals, $L A I$ and density per ha, to provide a comprehensive description of water use in coffee agroforestry systems.

CB had the highest transpiration rates due to the high coffee tree density, in addition to a linear response of banana $J_{S}$ to vapor pressure deficit, under non soil water limiting conditions. Bananas lack a water saving mechanism under high evaporation demand, as demonstrated by the high $\mathrm{J}_{\mathrm{s}}$ rates at high VPD values of our study (Fig. 2). This could lead to faster soil water depletion and water competition between coffee and bananas. Nevertheless, we could not demonstrate this hypothesis in our study, since rainfall appeared to be enough to sustain transpiration demand of all studied systems and no water limitation was observed. Furthermore, other studies indicated that despite the fact that banana sap flux density responses linearly to VPD, bananas are very sensitive to reduced SWC ( $\mathrm{pF}>2.8$ ), thus reducing water use at low soil water content (Kissel et al., 2015).

This would mean that under soil water scarcity, bananas would reduce their water use. However, it remains to be documented if this transpiration reduction would appear early enough to avoid water competition with associated coffee and hence become an attractive climate-smart adaptation strategy. Clearly, CB systems are of particular interest since bananas are the most important staple crop in the region and provide farmers with food and extra source of income (van Asten et al., 2011). Furthermore, due to fast banana growth, coffee intercropped with banana allows for a more dynamic shade management than coffee intercropped with woody shade trees. Indeed, farmers could voluntarily cut down banana if the dry season becomes too severe and detrimental to coffee. Further research is required to assess the water dynamics of these systems under harsher conditions, namely lower annual rainfall and prolonged dry season. 


\subsubsection{Caveats of the study and future recommendations}

We acknowledge that the heterogeneity of the studied systems, in terms of structure: slope, distribution along the slope, coffee tree density and shade tree density could certainly interfere in our comparison of the systems. It has to be kept in mind, however this study was performed under on-farm conditions and high variability is inherent to research within smallholder farmers' conditions. Furthermore, water use experiments require certain compromises due to technical restrictions, namely availability of a power source and distance to the data logger. Nevertheless, we presented in this study, not only transpiration at system level, but as well at individual level and the scaling factors used in order to account for these differences in system structure. Presentation of these parameters helps understanding how system structure might influence transpiration rates of agroforestry systems. Furthermore, we strongly recommend this to become a common practice in water use studies of agroforestry systems, where, as pointed out before, systems structures can be very diverse.

Additionally, we propose for future research activities to expand the period of time, over which water use patterns are monitored to several seasons and years. Moreover, we propose to consider other shade tree species commonly used (e.g. Ficus sp., Persea americana, Grevillea robusta, Markhamia indica) at Mt Elgon (Rahn et al., 2018). Furthermore, sap flow techniques should be combined with other measurements, such as stomatal conductance, photosynthesis, and leaf water potential, to include more indicators of coffee stress. Finally, high variability in $J_{s}$ between trees should be addressed by increasing the number of monitored trees per system, as well as increasing the number of plot replicates. 


\subsection{Conclusion}

To our knowledge, this is the first study investigating jointly the water use patterns of Coffea arabica, Musa sp and Cordia africana in the context of agroforestry systems in Africa. Our results are valuable to support farmers in managing their coffee farms and inform extension services and other stakeholders aiming to adapt coffee cultivation to climate change as well as food security and livelihoods of smallholder coffee farmers in particular in Eastern Africa.

In the present study, we found no competition for water between coffee and banana, or coffee and $C$. africana, since coffee water use remained similar across systems. Shade trees modified the microclimate for coffee underneath by reducing total soil water content, incoming radiation, maximum temperatures and temperature amplitude, and by increasing minimum temperatures. Despite the fact that the microclimate-buffering effects of shade trees were reduced during the late dry period, shade trees still benefited coffee by reducing the combined, negative effect of high radiation and high VPD on leaf growth and integrity.

Nevertheless, under more extended dry seasons, water competition between coffee and banana or Cordia africana, might occur due to the higher combined transpiration of coffee and associated shade plants in agroforestry systems compared to open system. The Coffee-Banana system is an attractive cultivation system since banana reduces solar radiation, VPD and maximum temperatures for coffee underneath, while providing food and an extra cash sources to rural households. Furthermore, fast banana growth allows dynamic density management to reduce water competition with coffee in case of need, i.e. a particular prolonged dry season.

Based on this study addressing water relations, we recommend the cultivation of coffee underneath medium shade (20-40\%), the careful selection of shade species, either for its contribution to income or food security (as in the case of banana) or for its physiological characteristics (reduced water use under water limited conditions and fast growth) or morphological characteristics (rooting depth below $80 \mathrm{~cm}$ and hence below the main coffee rooting zone). Furthermore, farm management activities such as mulching, pruning and thinning should be combined with weather forecast to tailor the system water demand to the soil water availability of the season. 


\section{Acknowledgements}

The authors are thankful for the financial support of the German Ministry for Economic Cooperation and Development (BMZ) through GIZ (under prime agreement no. 12.1433.7-001.00). This work was implemented as part of the CGIAR Research Programs on Climate Change, Agriculture and Food Security (CCAFS) and Forest, Trees and Agroforestry (FTA) which are carried out with support from CGIAR Fund Donors and through bilateral funding agreements. The views expressed in this document cannot be taken to reflect the official opinions of these organizations. We acknowledge the support by the team of the division Tropical Plant Production and Agricultural Systems Modelling (TROPAGS) at the University of Gottingen, Germany. As well, the support from the International Institute of Tropical Agriculture (IITA) Uganda is also fully acknowledged, especially from the field team, Medad Tamari, David Mukasa and Franco Manget. Finally, we would like to dedicate special gratitude to Mr. Michael Lulonde for allowing us using his farm and for supporting our work. Finally, we thank two anonymous reviewers for their valuable comments.

\section{Appendix a. Supplementary data}

Supplementary material related to this article can be found, in the online version, at doi:https://doi.org/10.1016/j.agrformet.2018.12. 006. 


\section{References}

Abdulai, I., Vaast, P., Hoffmann, M. P., Asare, R., Jassogne, L., Van Asten, P., Rotter, R. P., \& Graefe, S. (2018). Cocoa agroforestry is less resilient to sub-optimal and extreme climate than cocoa in full sun. Glob Chang Biol, 24(1), 273-286. doi:10.1111/gcb.13885

Allen, R. G., Pereira, L. S., Raes, D., \& Smith, M. (1998). FAO Irrigation and Drainage Paper. Food and Agriculture Organization of the United Nations, Rome, 56, 97-156. doi:http://www.fao.org/docrep/X0490E/X0490E00.htm.

Barradas, V. L., \& Fanjul, L. (1986). Microclimate characterization of shaded and open-grown coffee (Coffea arabica L.) plantations in Mexico. Agricultural and Forest Meteorology, 38, 101-112.

Bates, D., Maechler, M., Bolker, B., \& Walker, S. (2015). Fitting Linear Mixed-Effects Models Using Ime4. Journal of Statistical Software, 67(1), 1-48. doi:doi:10.18637/jss.v067.i01.

Bayala, J., Sanou, J., Teklehaimanot, Z., Ouedraogo, S. J., Kalinganire, A., Coe, R., \& Noordwijk, M. v. (2015). Advances in knowledge of processes in soil-tree-crop interactions in parkland systems in the West African Sahel: A review. Agriculture, Ecosystems \& Environment, 205, 25-35. doi:10.1016/j.agee.2015.02.018

Beer, J. (1987). Advantages, Disadvantages and Desirable Characteristics of Shade Trees for Coffee, Cacao and Tea. Agroforestry Systems, 5(1), 3-13. doi:https://doi.org/10.1007/BF00046410

Beer, J., Muschler, R., Kass, D., \& Somarriba, E. (1998). Shade management in coffee and cacao plantations. Agroforestry Systems(38), 139-164.

Bunn, C., Läderach, P., Ovalle Rivera, O., \& Kirschke, D. (2014). A bitter cup: climate change profile of global production of Arabica and Robusta coffee. Climatic Change, 129(1-2), 89-101. doi:10.1007/s10584-014-1306-x

Butler, D. R. (1977). COFFEE LEAF TEMPERATURES IN A TROPICAL ENVIRONMENT. Acta Botanica Neerlandica, 26(2), 129140. doi:https://doi.org/10.1111/j.1438-8677.1977.tb01106.x

Cannavo, P., Sansoulet, J., Harmand, J. M., Siles, P., Dreyer, E., \& Vaast, P. (2011). Agroforestry associating coffee and Inga densiflora results in complementarity for water uptake and decreases deep drainage in Costa Rica. Agriculture, Ecosystems \& Environment, 140(1-2), 1-13. doi:10.1016/j.agee.2010.11.005

Cannell, M. G. R., Van Noordwijk, M., \& Ong, C. K. (1996). The central agroforestry hypothesis: the trees must acquire resources that the crop would not otherwise acquire. Agroforestry Systems, 34, 27-31.

Carr, M. K. V. (2001). The water relations and irrigation requirements of coffee. Experimental Agriculture, 37, 1-36.

Carvalho, L. C. C., Silva, F. M. d., Ferraz, G. A. e. S., Stracieri, J., Ferraz, P. F. P., \& Ambrosano, L. (2017). Geostatistical analysis of Arabic coffee yield in two crop seasons. Revista Brasileira de Engenharia Agrícola e Ambiental, 21(6), 410-414. doi:10.1590/1807-1929/agriambi.v21n6p410-414

Craparo, A. C. W., Van Asten, P. J. A., Läderach, P., Jassogne, L. T. P., \& Grab, S. W. (2015). Coffea arabica yields decline in Tanzania due to climate change: Global implications. Agricultural and Forest Meteorology, 207, 1-10. doi:10.1016/j.agrformet.2015.03.005

DaMatta, F. M., \& Ramalho, J. C. (2006). Impacts of drought and temperature stress on coffee physiology and production: a review. Brazilian Journal of Plant Physiology, 18(1), 55-81.

De Bauw, P., Van Asten, P., Jassogne, L., \& Merckx, R. (2016). Soil fertility gradients and production constraints for coffee and banana on volcanic mountain slopes in the East African Rift: A case study of Mt. Elgon. Agriculture, Ecosystems \& Environment, 231, 166-175. doi:10.1016/j.agee.2016.06.036

Delzon, S., Sartore, M., Granier, A., \& Loustau, D. (2004). Radial profiles of sap flow with increasing tree size in maritime pine. Tree Physiol, 24(11), 1285-1293. doi:10.1093/treephys/24.11.1285

Descroix, F., \& Snoeck, J. (2008). Environmental Factors Suitable for Coffee Cultivation. In Coffee: Growing, Processing, Sustainable Production (pp. 164-177).

Fanjul, L. R., Arreola-Rodruiguez, R., \& Mendez-Castrejon, M. P. (1985). Stomatal Responses to Environmental Variables in Shade and Sun Grown Coffee Plants in Mexico. Experimental Agriculture, 21, 249-258.

FAO. (2014). World Reference Base for Soil Resources 2014 International soil classification system for naming soils and ceating leyends for soil maps. Retrieved from Rome, Italy:

FAOSTAT. (2016). Food and Agriculture Organization of the United Nations. FAOSTAT Statistics Database.

Fick, S. E., \& Hijmans, R. J. (2017). WorldClim 2: new 1-km spatial resolution climate surfaces for global land areas. International Journal of Climatology, 37(12), 4302-4315. doi:10.1002/joc.5086

Franck, N., \& Vaast, P. (2009). Limitation of coffee leaf photosynthesis by stomatal conductance and light availability under different shade levels. Trees, 23(4), 761-769. doi:10.1007/s00468-009-0318-z

Garcia, C. A., Bhagwat, S. A., Ghazoul, J., Nath, C. D., Nanaya, K. M., Kushalappa, C. G., Raghuramulu, Y., Nasi, R., \& Vaast, P. (2010). Biodiversity conservation in agricultural landscapes: challenges and opportunities of coffee agroforests in the Western Ghats, India. Conserv Biol, 24(2), 479-488. doi:10.1111/j.1523-1739.2009.01386.x

Gay, C., Estrada, F., Conde, C., Eakin, H., \& Villers, L. (2006). Potential Impacts of Climate Change on Agriculture: A Case of Study of Coffee Production in Veracruz, Mexico. Climatic Change, 79(3-4), 259-288. doi:10.1007/s10584-0069066-x

Granier, A. (1987). Evaluation of transpiration in a Douglas-fir stand by means of sap flow measurements. Tree Physiol, 3(4), 309-320. doi:10.1093/treephys/3.4.309

Gutiérrez, M. V., Harrington, R. A., Meinzer, F. C., \& Fownes, J. H. (1994). The effect of environmentally induced stem temperature gradients on transpiration estimates from the heat balance method in two tropical woody species. Tree Physiology, 14(2), 179-190. doi:10.1093/treephys/14.2.179 
Hernández-Santana, V., Martínez-Vilalta, J., Martínez-Fernández, J., \& Williams, M. (2009). Evaluating the effect of drier and warmer conditions on water use by Quercus pyrenaica. Forest Ecology and Management, 258(7), 1719-1730. doi:10.1016/j.foreco.2009.07.038

Hothorn, T., Bretz, F., \& Westfall, P. (2008). Simultaneous inference in general parametric models. Biom J, 50(3), 346-363. doi:10.1002/bimj.200810425

Jassogne, L., Läderach, P., \& van Asten, P. (2013). The Impact of Climate Change on Coffee in Uganda: Lessons from a case study in the Rwenzori Mountains. Retrieved from http://www.ingentaconnect.com/content/oxpp/oppccr/2013/00000009/00000001/art00004

Jung, E. Y., Otieno, D., Lee, B., Lim, J. H., Kang, S. K., Schmidt, M. W. T., \& Tenhunen, J. (2010). Up-scaling to stand transpiration of an Asian temperate mixed-deciduous forest from single tree sapflow measurements. Plant Ecology, 212(3), 383-395. doi:10.1007/s11258-010-9829-3

Kanechi, M., Uchida, N. U., Yasuda, T., \& Yamaguchi, T. (1995). Water stress effects on leaf transpiration and photosyntheis of Coffea arabica L. under different irradiance conditions. Paper presented at the 16th International Scientific Colloquium on Coffee, Kyoto, Japan.

Kissel, E., van Asten, P., Swennen, R., Lorenzen, J., \& Carpentier, S. C. (2015). Transpiration efficiency versus growth: Exploring the banana biodiversity for drought tolerance. Scientia Horticulturae, 185, 175-182. doi:10.1016/j.scienta.2015.01.035

Kuznetsova , A., Brockhoff, P., \& Christensen, R. (2017). ImerTest Package: Tests in Linear Mixed Effects Models. Journal of Statistical

Software, 82(13), 1-26. doi:doi: 10.18637/jss.v082.i13 (URL: https://doi.org/10.18637/jss.v082.i13).

Li-COR, I. (2009). LAI-2200 Plant Canopy Analyzer Instruction Manual. Retrieved from

Liebig, T., Jassogne, L., Rahn, E., Laderach, P., Poehling, H. M., Kucel, P., Van Asten, P., \& Avelino, J. (2016). Towards a Collaborative Research: A Case Study on Linking Science to Farmers' Perceptions and Knowledge on Arabica Coffee Pests and Diseases and Its Management. PLoS One, 11(8), e0159392. doi:10.1371/journal.pone.0159392

Liu, H.-J., Cohen, S., Tanny, J., Lemcoff, J. H., \& Huang, G. (2008). Transpiration estimation of banana (Musa sp.) plants with the thermal dissipation method. Plant and Soil, 308(1-2), 227-238. doi:10.1007/s11104-008-9622-4

Lu, P., Woo, K. C., \& Liu, Z. T. (2002). Estimation of whole-plant transpiration of bananas using sap flow measurements. J Exp Bot, 53(375), 1771-1779. doi:10.1093/jxb/erf019

Mbow, C., Smith, P., Skole, D., Duguma, L., \& Bustamante, M. (2014a). Achieving mitigation and adaptation to climate change through sustainable agroforestry practices in Africa. Current Opinion in Environmental Sustainability, 6, 814. doi:10.1016/j.cosust.2013.09.002

Mbow, C., Van Noordwijk, M., Luedeling, E., Neufeldt, H., Minang, P. A., \& Kowero, G. (2014b). Agroforestry solutions to address food security and climate change challenges in Africa. Current Opinion in Environmental Sustainability, 6, 61-67. doi:10.1016/j.cosust.2013.10.014

Meinzer, F. C., Clearwater, M. J., \& Goldstein, G. (2001). Water transport in trees: current perspectives, new insights and some controversies. Environmental and Experimental Botany, 45, 239-262.

Moat, J., Williams, J., Baena, S., Wilkinson, T., Gole, T. W., Challa, Z. K., Demissew, S., \& Davis, A. P. (2017). Resilience potential of the Ethiopian coffee sector under climate change. Nat Plants, 3, 17081. doi:10.1038/nplants.2017.81

Muschler, R. G., \& Bonnemann, A. (1997). Potentials and limitations of agroforestry for changing land-use in the tropics: experiences from Central America. Forest Ecology and Management, 91, 61-73.

Ovalle-Rivera, O., Laderach, P., Bunn, C., Obersteiner, M., \& Schroth, G. (2015). Projected shifts in Coffea arabica suitability among major global producing regions due to climate change. PLoS One, 10(4), e0124155. doi:10.1371/journal.pone.0124155

Padovan, M. P., Brook, R. M., Barrios, M., Cruz-Castillo, J. B., Vilchez-Mendoza, S. J., Costa, A. N., \& Rapidel, B. (2018). Water loss by transpiration and soil evaporation in coffee shaded by Tabebuia rosea Bertol . and Simarouba glauca dc. compared to unshaded coffee in sub-optimal environmental conditions. Agricultural and Forest Meteorology, 248, 1-14. doi:10.1016/j.agrformet.2017.08.036

Padovan, M. P., Cortez, V. J., Navarrete, L. F., Navarrete, E. D., Deffner, A. C., Centeno, L. G., Munguía, R., Barrios, M., Vílchez-Mendoza, J. S., Vega-Jarquín, C., Costa, A. N., Brook, R. M., \& Rapidel, B. (2015). Root distribution and water use in coffee shaded with Tabebuia rosea Bertol. and Simarouba glauca DC. compared to full sun coffee in sub-optimal environmental conditions. Agroforestry Systems, 89(5), 857-868. doi:10.1007/s10457-015-9820-z

Partelli, F. L., Araújo, A. V., Vieira, H. D., Dias, J. R. M., Menezes, L. F. T. d., \& Ramalho, J. C. (2014). Microclimate and development of 'Conilon' coffee intercropped with rubber trees. Pesquisa Agropecuária Brasileira, 49(11), 872881. doi:10.1590/s0100-204×2014001100006

Pereira, H. C. (1957). Field measurements of water use for irrigation control in Kenya coffee. The Journal of Agricultural Science, 49(4), 459-466. doi:10.1017/S0021859600038466

Rahn, E., Liebig, T., Ghazoul, J., van Asten, P., Läderach, P., Vaast, P., Sarmiento, A., Garcia, C., \& Jassogne, L. (2018). Opportunities for sustainable intensification of coffee agro-ecosystems along an altitudinal gradient on Mt. Elgon, Uganda. Agriculture, Ecosystems \& Environment, 263, 31-40. doi:10.1016/j.agee.2018.04.019

Rice, R. A. (2008). Agricultural intensification within agroforestry: The case of coffee and wood products. Agriculture, Ecosystems \& Environment, 128(4), 212-218. doi:10.1016/j.agee.2008.06.007

Sanchez, P. A. (1995). Science in Agroforestry. Agroforestry Systems, 30(5), 5-55.

Sentek Pty Ltd. (2009). Diviner 2000 User Guide Version 1.5. Retrieved from Stepney South Australia 5069: 
Siles, P., Harmand, J.-M., \& Vaast, P. (2009). Effects of Inga densiflora on the microclimate of coffee (Coffea arabica L.) and overall biomass under optimal growing conditions in Costa Rica. Agroforestry Systems, 78(3), 269-286. doi:10.1007/s10457-009-9241-y

Siles, P., \& Vaast, P. (2002). Comportamiento fisiólogico del café asociado con Eucalyptus deglupta, Terminalia ivorensis o sin sombra. Agroforesteria en las Américas, 9(35-36).

Tausend, P. C., Meinzer, F. C., \& Goldstein, G. (2000). Control of transpiration in three coffee cultivars: the role of hydraulic and crown architecture. Trees, 14, 181-190.

Tscharntke, T., Clough, Y., Bhagwat, S. A., Buchori, D., Faust, H., Hertel, D., Hölscher, D., Juhrbandt, J., Kessler, M., Perfecto, I., Scherber, C., Schroth, G., Veldkamp, E., \& Wanger, T. C. (2011). Multifunctional shade-tree management in tropical agroforestry landscapes - a review. Journal of Applied Ecology, 48(3), 619-629. doi:10.1111/j.13652664.2010.01939.x

Vaast, P., Harmand, J.-M., Rapidel, B., Jagoret, P., \& Deheuvels, O. (2016). Coffee and Cocoa Production in Agroforestry-A Climate-Smart Agriculture Model. In Climate Change and Agriculture Worldwide (pp. 209-224).

Vaast, P., \& Somarriba, E. (2014). Trade-offs between crop intensification and ecosystem services: the role of agroforestry in cocoa cultivation. Agroforestry Systems, 88(6), 947-956. doi:10.1007/s10457-014-9762-x

van Asten, P. J. A., Wairegi, L. W. I., Mukasa, D., \& Uringi, N. O. (2011). Agronomic and economic benefits of coffee-banana intercropping in Uganda's smallholder farming systems. Agricultural Systems, 104(4), 326-334. doi:10.1016/j.agsy.2010.12.004

Van Der Wolf, J., Jassogne, L., Gram, G. I. L., \& Vaast, P. (2016). Turning Local Knowledge on Agroforestry into an Online Decision-Support Tool for Tree Selection in Smallholders' Farms. Experimental Agriculture, 55(S1), 50-66. doi:10.1017/s001447971600017x

Van Kanten, R., Schroth, G., Beer, J., \& Jiménez, F. (2005). Fine-root dynamics of coffee in association with two shade trees in Costa Rica. Agroforestry Forum, 63, 247-261.

van Kanten, R., \& Vaast, P. (2006). Transpiration of Arabica Coffee and Associated Shade Tree Species in Sub-optimal, Lowaltitude Conditions of Costa Rica. Agroforestry Systems, 67(2), 187-202. doi:10.1007/s10457-005-3744-y

Verchot, L. V., Van Noordwijk, M., Kandji, S., Tomich, T., Ong, C., Albrecht, A., Mackensen, J., Bantilan, C., Anupama, K. V., \& Palm, C. (2007). Climate change: linking adaptation and mitigation through agroforestry. Mitigation and Adaptation Strategies for Global Change, 12(5), 901-918. doi:10.1007/s11027-007-9105-6

Wallis, J. A. N. (1963). Water use by irrigated Arabica coffee in Kenya. The Journal of Agricultural Science, 60(3), 381-388. doi:10.1017/S0021859600011977

Zullo, J., Pinto, H. S., Assad, E. D., \& de Ávila, A. M. H. (2011). Potential for growing Arabica coffee in the extreme south of Brazil in a warmer world. Climatic Change, 109(3-4), 535-548. doi:10.1007/s10584-011-0058-0 



\section{Disentangling effects of altitude and shade cover on coffee fruit dynamics and vegetative growth in smallholder coffee systems}

Alejandra Sarmiento-Soler ${ }^{1}$, Reimund P. Rötter ${ }^{1,2}$, Munir P. Hoffmann ${ }^{1,4,11}$, Laurence Jassogne ${ }^{5}$, Piet van Asten $^{5,6}$, Sophie Graefe ${ }^{7,8}$ and Philippe Vaast ${ }^{9,10}$

${ }_{1}^{1}$ Tropical Plant Production and Agricultural Systems Modelling (TROPAGS), University of Göttingen, Grisebachstraße 6, 37077 Göttingen, Germany

${ }^{2}$ Center for Biodiversity and Land Use (CBL), University of Göttingen, Buesgenweg 1, 37077 Göttingen, Germany

${ }^{3}$ Leibniz Centre for Agricultural Landscape Research (ZALF), Müncheberg, Germany

5International Institute of Tropical Agriculture (IITA), Kampala, Uganda

${ }^{5}$ Olam International Ltd, Kampala, Uganda

${ }^{7}$ Tropical Silviculture and Forest Ecology, University of Göttingen

${ }^{8}$ Organic Plant Production and Agroecosystems Research in the Tropics and Subtropics (OPATS), University of Kassel, Kassel, Germany

9UMR ECo\&Sols, Centre de Coopération Internationale en Recherche Agronomique pour le Développement (CIRAD), Université Montpellier, Montpellier, France

10 World Agroforestry Centre (ICRAF), Hanoi, Vietnam

${ }^{11}$ AGVOLUTION GmbH, Göttingen, Germany

Corresponding author:

Alejandra Sarmiento Soler

asarmie@gwdg.de

Grisebachstraße 6

37077 Göttingen

Germany

Under review in the Journal Agriculture, Ecosystems and Environments 



\section{Abstract}

Increases in temperature and more erratic rainfall patterns due to climate change threatens the already fragile, livelihood of smallholder coffee farmers. Shaded coffee in an agroforestry system appear as a good alternative to protect coffee from extreme temperatures while providing additional ecosystem services, such as extra food and soil protection. Likewise, excessive shade might reduce coffee yields. This study analyzed the effect of shade cover (type represented by cropping system (Coffee-Open (CO), Coffee-Banana (CB), Coffee-shade tree (CT)), and amount by leaf area index of the shade cover) along an altitude gradient on: (i) microclimate, (ii) soil water content and (iii) coffee reproductive and vegetative growth. Data was collected during two fruit development cycles (2015 and 2016) in smallholder coffee farms $(n=27)$ on the west slopes of Mt. Elgon Uganda. Shade cover buffered microclimate extremes. Fruit set was not limited by temperature but reduced with shade cover increases during the second year (2016). Whilst fruit drop per stem was similar across cropping system during both studied years. Leaf set was the most important variable to ensure vegetative and reproductive growth along several production cycles. Intermediated shade cover (LAl $1 \mathrm{~m}^{2} \mathrm{~m}^{-2}$ ), as occurred in coffee intercropped with bananas showed an optimal balance between microclimate regulations, fruit set and fruit drop, and provide staple food and an extra source of income.

Keywords: Arabica coffee, fruit development cycle, fruit set, fruit drop, climate change, vegetative growth, agroforestry, piecewise structural equation modelling

\section{Highlights:}

- Maintenance of coffee leaf set is crucial to ensure coffee yield over several seasons

- Intermediate shade levels (LAI 1) buffer microclimate and reduces leaf senescence under suboptimal conditions without reducing yields

- Coffee trees withstand yield at higher temperatures than previously though 



\subsection{Introduction}

Coffee cultivation is the economic backbone of several developing countries and the main source of cash for millions of smallholder farmers across the topical belt (DaMatta et al., 2007; ITC, 2012; DaMatta et al., 2018a). As for any other agricultural product, coffee production is sensitive to climate variability. Therefore, temperature increases, more erratic rainfall patterns and increase in frequency and severity of extreme events related to climate change are expected to drastically impact coffee yield and consequently coffee producers' livelihoods (Baca et al., 2014; Bunn et al., 2014; Craparo et al., 2015; Ovalle-Rivera et al., 2015; Tavares et al., 2017).

On the other hand, recent studies report that coffee trees (referring to both commercially used species: Coffea arabica L. and Coffea canephora) are more resistant to heat than previously thought and that coffee trees can maintain photosynthetic rate up to $37^{\circ} / 30^{\circ}$ (Day/Night) (Martins et al., 2016; Rodrigues et al., 2016). Hence, these findings suggest that current projections of climate change impacts on coffee production and distribution of suitable areas for coffee cultivation (Bunn et al., 2014; Ovalle-Rivera et al., 2015) should be revaluated (DaMatta et al., 2018a; DaMatta et al., 2018b). Nonetheless, these studies (Martins et al., 2016; Rodrigues et al., 2016) focus on photosynthesis rate, but knowledge about impacts of abiotic stresses (i.e. heat and drought) on key phenological phases in the coffee cycle, such as fruit development (from flower initiation to harvest), is still insufficient and urgently needed (Drinnan \& Menzel., 1995; DaMatta et al., 2007; Rahn et al., 2018b).

Understanding the impact different environmental factors, such as radiation, temperature and water availability, have during the fruit development process might help to adapt management practices in order to improve sustainability and resilience of coffee cultivation, especially under low input farming systems. This is particularly needed as the constant and gradual increase in coffee demand over the last decades has led to coffee cultivation rises in marginal areas, according to "climate suitability thresholds" (Mean temperature, unsuitable $\leq 10^{\circ} \mathrm{C}$ and $\geq 30{ }^{\circ} \mathrm{C}$, suboptimal: $<15-16^{\circ} \mathrm{C}$ and $>23$, optimal $18-23$ ${ }^{\circ} \mathrm{C}$ (Lara Estrada et al., 2017) and maximum temperature: unsuitable $>32{ }^{\circ} \mathrm{C}$ (Descroix \& Snoeck, 2008), suboptimal: (Descroix \& Snoeck, 2008), optimal: 25-26 C (Descroix \& Snoeck, 2008).

Higher radiation and temperature conditions met in coffee full-sun or low shade systems might stimulate larger number of flowers, but excessive temperature can also cause flower deformation or even inhibit flowering. For instance, Drinnan and Menzel (1995), reported flowering failure at temperatures above $33^{\circ} / 28^{\circ} \mathrm{C}$ (Day/Night) and flower malformation at $28^{\circ} / 23^{\circ}$. Whilst Marias et al. (2017) found flowering is inhibited when coffee trees were exposed to $49^{\circ} \mathrm{C}$ for more than 45 minutes. 
Moreover, higher incoming radiation will stimulate heavy flowering and sub-sequent high fruit load in coffee trees. But heavy fruit loads have been related to die-back (death of fruiting twigs and even the whole tree), higher susceptibility to pests and diseases and biennial production patterns (high yield in current year at expenses of vegetative growth, which results in lower yields in the following year) (Cannell, 1985; Franck et al., 2005; DaMatta et al., 2007).

Therefore, cultivating coffee under shade is promoted as one management option to reduce these threats (DaMatta, 2004; Vaast et al., 2016; Rigal et al., 2020). For instance, shade has been associated with lower flower initiation and lower initial fruit set (Franck et al., 2005), which could lead to lower yield in shaded coffee systems (DaMatta, 2004; Vaast et al., 2008). However, lower fruit sets might be compensated by less fruit drop (Vaast et al., 2008; Bote \& Vos, 2016; Rigal et al., 2020). A lower fruit set would also reduce fruit carbon-sink demands and allow coffee trees to invest into vegetative growth, which will result in a more balanced development of fruiting nodes for the following year (Franck et al., 2005). This consequently reduces biennial fruiting patterns and improves cumulative yields over several years (Vaast et al., 2008; Bote \& Vos, 2016).

Most of the studies assessing the effects of shade vs. non-shade or other environmental variables on coffee yield focus mostly on coffee yield at harvest; which of course is key, since farmers ultimately depend on coffee yield to generate their livelihoods. However, disentangling the effects of environmental variables in relation to coffee reproductive vs vegetative growth processes could give insights on the role of shade during the fruit development process, and how it could be managed to potentiate its benefits, while reducing the trade-offs. To address these issues, we monitored coffee fruit development (from fruit initiation to harvest) during two production cycles (2015 and 2016) in three different coffee cropping systems (Coffee - Open (CO), Coffee - Banana (CB) and Coffee - shade tree (CT)) along an altitudinal gradient on the western slopes of Mt. Elgon Uganda. The study area is characterized by low inputs systems with pronounced shading gradients (Wang et al., 2015; Liebig et al., 2016; Rahn et al., 2018a). Specifically, we aim to answer the following questions:

(i) To what extent do shade cover (type and amount) and altitude (as a climate proxy) modify microclimate and soil water content for coffee grown underneath? We hypothesize that shade (type of system and amount of shade) improve microclimate, i.e. by reducing maximum temperature, vapor pressure deficit and temperature amplitude and increasing minimum temperature. And that this buffering effect is maintained along the altitudinal gradient. 
(ii) Do shade cover and altitude have an effect on coffee fruit development from initial fruit set to harvest? Are lower fruit initiation rates under high shade cover counterbalanced by lower fruit drop rates? Does shade cover reduce biennial bearing patterns? We expect that altitude has a positive effect on reproductive and vegetative growth, due to a reduction of extreme temperatures and an increase in effective rainfall with increasing altitude. Moreover, lower fruit initiation will occur in heavier shaded systems compared to low shaded system, but larger fruit set will lead to larger fruit drop. Thus, this will result in comparable fruit sets at harvest along the shade gradient.

(iii) Which effect do fruit set, number of leaves and number of internodes have on fruit development of a given year $(n)$ and on fruit development in the following year $(n+1)$ ? We expect that larger leaf set will lead to less fruit drop, due to larger capacity for carbon assimilation. While, larger fruit sets will inhibit branch growth, due to larger sink priority of fruits.

\subsection{Materials and methods}

\subsubsection{Study site}

The study site was located on the western slopes of Mt. Elgon, Uganda $\left(1^{\circ} 15^{\prime} 00^{\prime \prime}-1^{\circ} 18^{\prime} 00^{\prime \prime}\right.$ geographical latitude and $34^{\circ} 18^{\prime}-34^{\circ} 24^{\prime}$ geographical longitude) and covered an altitude gradient of 1100 m.a.s.l. to 2200 m.a.s.l. Annual rainfall varies from $1200 \mathrm{~mm}$ year ${ }^{-1}$ at low altitude (1200 m.a.s.l.) to around $1670 \mathrm{~mm}$ year ${ }^{1}$ at high altitude (1800 m.a.s.I.) distributed in a bi-modal rainfall pattern, with a strong dry season ( $40 \mathrm{~mm} \mathrm{month}^{-1}$ ) between December - February and a moderate dry season (110 $\mathrm{mm}$ month $^{-1}$ ) between June -July (Fick \& Hijmans, 2017). The region is characterized by coffee cultivation occurring in a mosaic of different coffee cropping systems with varied shade intensities and shade trees species (Liebig et al., 2016; Rahn et al., 2018a). Soils in the region are classified as Nitisols (FAO, 2014) with a pH reduction (from 7 to 5.5) along the altitudinal gradient (De Bauw et al., 2016; Sarmiento-Soler et al., 2020). 


\subsubsection{Data collection}

We collected data on coffee fruit development and vegetative growth on 810 coffee stems (in 810 coffee trees) in 27 coffee plots (30 trees/plot) for two years (2015 and 2016). Coffee plots were distributed along the altitudinal gradient and belonged to three different types of cropping systems ( 9 plots per type of cropping system): Coffee - Open (CO) = coffee with $16 \pm 12 \%$ shade cover; Coffee Banana $(C B)=$ coffee mostly intercropped with bananas and $19 \pm 12 \%$ shade cover; and Coffee - shade Tree $(C T)=$ coffee intercropped with varied shade tree species and with $46 \pm 18 \%$ shade cover (Fig. 1) as described in more details by (Liebig et al., 2016; Rahn et al., 2018a; Sarmiento-Soler et al., 2020).

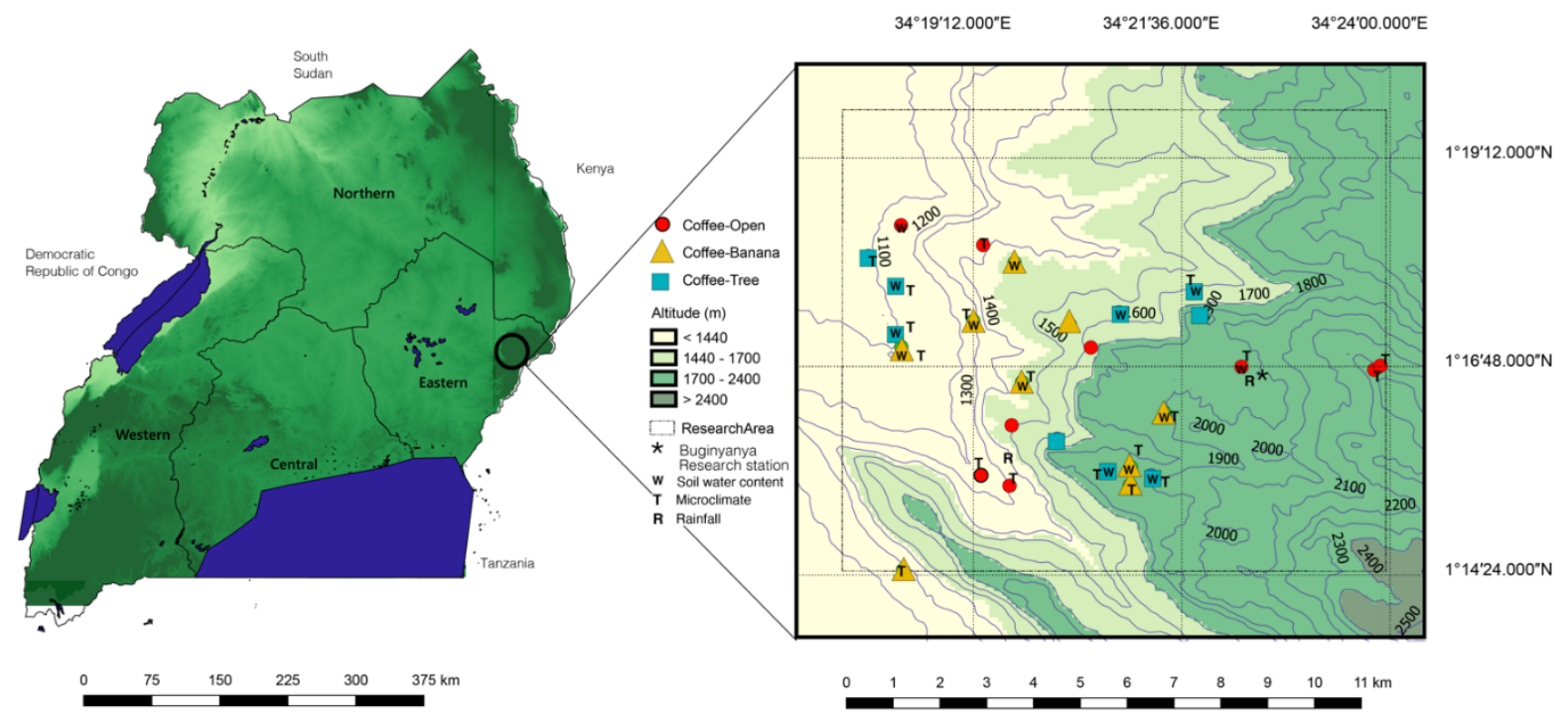

Fig. 1. Map of Uganda and research area with selected plots (27 plots) at three altitude classes: Low altitude (1100 - 1400 m.a.s.I.), mid altitude (1400 - 1700 m.a.s.I.) and high altitude $(1700-2100$ m.a.s.l).Plots belong to three different types of systems: 9 to Coffee-Open = CO (Red circle), 9 to Coffee-Banana = CB (Yellow triangle) and 9 to Coffee- shade Tree = CT (Blue square). "T" symbol indicate plots in which microclimate was monitored (18 Plots)(from January 2015 to April 2016), "W" indicates plot in which soil water content was monitored (17 Plots) (From April 2015 to April 2016); and "R" indicates where rainfall was recorded (at low altitude and high altitude).

Coffee farmers in this region tend to cultivate a mixture of different coffee varieties (Bugisu local, Catimor, KP, Ruiiru11, SL14 and SL18, (WCR, 2019)), although Bugisu local is the most prominent (Rahn et al., 2018a). For this study we did not differentiate between the different coffee varieties, except of Catimor, due to its different morphology and reduced coffee quality (WCR, 2019). Crop management information was gathered through farmers interviews. After cleaning the management data, we remined with information about 23 coffee plots from the initial 27 (Sarmiento-Soler et al., 2020). Fiveteen of 23 farmers reported use of insecticide and 18 of 23 used herbicide. However, only 8 of 23 used fertilizer and 5 of 23 usedfungicide. Finally, 18 of 23 reported to have pruned their coffee in the last year. Intensity and frequency of management activities did not follow an identifiable pattern, i.e. higher management intensity in low shaded systems, or vice versa (more details can be found in Sarmiento-Soler et al. (2020). 
We also monitored microclimate (Temperature $=$ Temp and relative humidity $=\mathrm{RH}$ ) at hourly intervals from January 2015 to April 2016 in 18 out of the 27 plots and soil water content (SWC) was measured every two weeks in 17 out of the 27 plots (Fig. 1). Leaf area index (LAI) of the cropping systems (shade and coffee trees combined) was measured five times during the study period using a LICOR 2200 C plant canopy analyzer and averaged for the study period (Model LAI-2270C, SR.NO.PCA-3940, LICOR). Type of cropping system did not have any effect of soil properties $(\mathrm{pH}$, soil organic matter and macronutrients) (Sarmiento-Soler et al., 2020) (Table 1).

Table 1: Plot characteristics according to coffee systems (Coffee-Open (CO), Coffee-Banana (CB) and Coffee-shade Tree (CT) based on Sarmiento-Soler et al. (2020)

\begin{tabular}{|c|c|c|c|}
\hline Variable & $\begin{array}{c}\mathrm{CO} \\
(n=9)\end{array}$ & $\begin{array}{c}C B \\
(n=9)\end{array}$ & $\begin{array}{c}\text { CT } \\
(n=9)\end{array}$ \\
\hline \multicolumn{4}{|l|}{ System characteristics } \\
\hline Altitude (m.a.s.l.) & $1614 \pm 378$ & $1540 \pm 314$ & $1533 \pm 343$ \\
\hline Area $(\mathrm{m} 2)$ & $2001 \pm 1305$ & $1126 \pm 597$ & $2062 \pm 1572$ \\
\hline Density Coffee (Trees ha-1) & $2109 \pm 1169$ & $2085 \pm 760$ & $1758 \pm 491$ \\
\hline Density Banana (Stems ha-1) & $148 \pm 316^{a}$ & $786 \pm 426^{c}$ & $370 \pm 472^{b}$ \\
\hline Density Shade Trees(Trees ha-1) & $28 \pm 27^{a}$ & $36 \pm 38^{a}$ & $110 \pm 82^{b}$ \\
\hline Shade cover (\%) & $16 \pm 12^{a}$ & $19 \pm 12^{a}$ & $46 \pm 18^{b}$ \\
\hline$N^{\circ}$ Coffee Stems Tree- 1 & $3.2 \pm 1.5$ & $2.5 \pm 1.3$ & $3.7 \pm 2$ \\
\hline LAI (System/Shade/Coffee) & $1.4^{\mathrm{a}} / 0.2^{\mathrm{a} / 1.2^{\mathrm{a}}}$ & $2.2^{\mathrm{b}} / 0.8^{\mathrm{b}} / 1.4^{\mathrm{a}}$ & $2.6^{\mathrm{b}} / 1.4^{\mathrm{c}} / 1.2^{\mathrm{a}}$ \\
\hline Slope \% & $11 \pm 9$ & $16 \pm 8$ & $15 \pm 9$ \\
\hline \multicolumn{4}{|l|}{ Soil Properties (0-30 cm) } \\
\hline $\mathrm{pH}^{1}$ & $5.9 \pm 0.6$ & $5.8 \pm 0.5$ & $6.1 \pm 0.6$ \\
\hline OM \% & $4.1 \pm 1.5$ & $4.5 \pm 2.4$ & $4.6 \pm 3$ \\
\hline Soil N (\%) & $0.2 \pm 0.07$ & $0.27 \pm 0.05$ & $0.30 \pm 0.12$ \\
\hline Soil P ppm & $34.1 \pm 24.5$ & $35 \pm 35$ & $56 \pm 53$ \\
\hline Soil K (cmol kg-1) & $1.0 \pm 0.5$ & $1.08 \pm 0.6$ & $1.3 \pm 0.8$ \\
\hline Soil Ca $\left(\mathrm{cmol} \mathrm{kg}^{-1) 2}\right.$ & $14.7 \pm 7.8$ & $11.4 \pm 5.5$ & $15.1 \pm 4.5$ \\
\hline Soil Mg (cmol kg-1) & $4.3 \pm 2.7$ & $3.02 \pm 4$ & $4.02 \pm 2.1$ \\
\hline
\end{tabular}

\subsubsection{Coffee reproductive and vegetative variables}

On each selected coffee tree, a stem was selected for monitoring reproductive and vegetative growth variables. We aimed to select stems with "average characteristics", meaning, not too young (not reproductively active) or too old. To avoid strong bias during the stem selection procedure, the task was rotated between team members (5 people), following the criteria described above. In each selected stem, we marked four primary branches distributed homogenously along the stem. On these branches, we monitored fruit set per branch (FS per branch), leave set per branch (LS per branch) and number of internodes per branch (INT per branch) at intervals of 6 to 8 weeks, starting after flowering (March- 
April) and finishing at harvesting (September-October) (Table 2). Fruit drop per branch (FD) was calculated from the difference in fruit set between two monitoring sessions (i.e. FD $1=100 \times$ (FS 2015 week 8- FS 2015 Week o)/ $F S_{2015}$ week o) (Table 2). Monitoring was done over production cycle in 2015 and repeated in 2016 on the same branches. Additionally, we counted total number of branches and number of productive branches in each monitored stem, at fruit initiation and at harvest for each year (2015 and 2016). Fruit set per branch was upscaled to fruit set per stem by multiplying fruit set per branch $x$ productive branches. Similarly, vegetative variables (leaf set per branch and number of internodes) were upscaled to stem level by multiplying by total number of branches (Table 2). 
Table 2: Description of monitored variables and their inclusion in the respective in piecewise structural equation models.

\begin{tabular}{|c|c|c|}
\hline & Description & $\begin{array}{l}\text { Explanatory or/and } \\
\text { Response variable }\end{array}$ \\
\hline \multicolumn{3}{|l|}{ Environmental variables } \\
\hline Altitude & & $\begin{array}{l}\text { Explanatory (Model } 1 \\
\text { and Model 2) }\end{array}$ \\
\hline Shade cover & Leaf area index of shade $(\mathrm{m} 2 \mathrm{~m}-2)$ & $\begin{array}{l}\text { Explanatory (Model } 1 \\
\text { and Model 2) }\end{array}$ \\
\hline Temperature (Temp) & Recorded every 60 minutes from January 2015 to April 2016 & $\begin{array}{l}\text { Explanatory and } \\
\text { response (Model 1) }\end{array}$ \\
\hline Relative humidity $(\mathrm{RH})$ & Recorded every 60 minutes from January 2015 to April 2016 & $\begin{array}{l}\text { Explanatory and } \\
\text { response (Model 1) }\end{array}$ \\
\hline Soil water content (SWC) & Recorded every 2 weeks from January 2015 to April 2016 & Response (Model 1) \\
\hline $\begin{array}{l}\text { Vapor pressure deficit } \\
\text { (VPD) }\end{array}$ & $\begin{array}{l}\text { Calculated based on daily temperature and daily relative humidity after Allen et al., } \\
1998\end{array}$ & $\begin{array}{l}\text { Explanatory and } \\
\text { response (Model 1) }\end{array}$ \\
\hline \multicolumn{3}{|l|}{ Reproductive growth } \\
\hline $\begin{array}{l}\text { Fruit set per branch (FS } \\
\text { per branch) }\end{array}$ & $\begin{array}{l}\text { Number of pinheads }+ \text { cherries counted in: Week } 0 \text { (after flowering), Week 4, Week } \\
8 \text {, Week } 17 \text { and at harvest }\end{array}$ & Not included \\
\hline $\begin{array}{l}\text { Productive branches per } \\
\text { stem }\end{array}$ & $\begin{array}{l}\text { Number of productive branches counted on: Week } 0 \text { (after flowering) and at } \\
\text { harvest }\end{array}$ & Not included \\
\hline $\begin{array}{l}\text { Fruit set per stem (FS per } \\
\text { stem) }\end{array}$ & $\begin{array}{l}\text { FS per branch } x \text { Productive branches per stem. Estimated for: Week } 0 \text { (after } \\
\text { flowering) and at harvest }\end{array}$ & $\begin{array}{l}\text { Explanatory and } \\
\text { response (Model 2) }\end{array}$ \\
\hline \multicolumn{3}{|l|}{ Vegetative growth } \\
\hline $\begin{array}{l}\text { Leaf set per branch (LS } \\
\text { per branch) }\end{array}$ & Number of leaves per branch on: Week 0 (after flowering), Week 17 and at harvest & Not included \\
\hline $\begin{array}{l}\text { Internodes per branch } \\
\text { (INT per branch) }\end{array}$ & $\begin{array}{l}\text { Number of internodes per branch on: Week } 0 \text { (after flowering), Week } 17 \text { and at } \\
\text { harvest }\end{array}$ & Not included \\
\hline Total branches per stem & $\begin{array}{l}\text { Total number of branches per stem counted on: Week } 0 \text { (after flowering) and at } \\
\text { harvest }\end{array}$ & Not included \\
\hline $\begin{array}{l}\text { Leaf set per stem (LS per } \\
\text { stem) }\end{array}$ & $\begin{array}{l}\text { LS per branch } x \text { total number of branches. Estimated for: Week } 0 \text { (after flowering) } \\
\text { and at harvest }\end{array}$ & $\begin{array}{l}\text { Explanatory and } \\
\text { response (Model 2) }\end{array}$ \\
\hline $\begin{array}{l}\text { Internodes per stem (INT } \\
\text { per stem) }\end{array}$ & $\begin{array}{l}\text { INT per branch } x \text { total number of branches. Estimated for: Week } 0 \text { (after flowering) } \\
\text { and at harvest }\end{array}$ & $\begin{array}{l}\text { Explanatory and } \\
\text { response (Model 2) }\end{array}$ \\
\hline \multicolumn{3}{|l|}{ Fruit drop } \\
\hline $\begin{array}{l}\text { Fruit drop per branch (FD } \\
\text { per branch) }\end{array}$ & Percentage of dropped cherries per branch $=100 \times\left(\mathrm{FS}_{\text {Session }}-\mathrm{FS}_{\text {Session -1 }}\right) / \mathrm{FS}_{\text {Session -1 }}$ & Not included \\
\hline Death branches & $\begin{array}{l}\text { Percentage of productive death branches per stem }=100 \times \text { (Productive branches per } \\
\text { stem } \mathrm{H}_{\text {Harvest }} \text { - Productive branches per stem } \text { Week o) } / \text { Productive branches per stem }_{\text {Harvest }}\end{array}$ & Not included \\
\hline $\begin{array}{l}\text { Fruit drop per stem (FD } \\
\text { per stem) }\end{array}$ & $\begin{array}{l}\text { Percentage of fruit drop per stem }=100 \times(\text { FD per stem Harvest }-F D \text { per stem week } 0) / F D \\
\text { per stem Harvest }\end{array}$ & $\begin{array}{l}\text { Explanatory and } \\
\text { response (Model 2) }\end{array}$ \\
\hline
\end{tabular}




\subsubsection{Microclimate and soil water content}

Air temperature and relative humidity were recorded at 60 minutes intervals using iButtons (DS1923 Hygrochron Temperature and Humidity Data logger). Each ibutton (2 ibuttons per plot) was placed within the canopy of a coffee tree at $1.5 \mathrm{~m}$ from the ground. Each sensor was protected by an aerated aluminum shield to avoid direct sunlight incidence. Mean daily vapour pressure deficit (VPD) was calculated from daily temperature (min Temp and max Temp) and daily relative humidity (min $\mathrm{RH}$ and max RH) following Allen et al. (1998).

Soil water content (SWC) was monitored using a Sentek soil probe (Diviner 2000). In each plot, three to five access tubes (down to $1.6 \mathrm{~m}$ ) were installed and SWC monitored every two weeks from April 2015 to April 2016. We used the default calibration recommended by the manufacturer to convert device readings to soil water content $\left(\right.$ Scaled Frequency $=0.2746 *$; volumetric water content $\left(\mathrm{mm} \mathrm{mm}^{-1}\right)$ ^ 0.3314) (Sentek Pty Ltd 2009).

\subsubsection{Data analysis}

\subsubsection{Linear mixed models and generalized mixed models}

For each day, mean temperature (mean Temp), minimum temperature (min Temp), maximum temperature (max Temp), temperature amplitude (Temp $\Delta)$, mean VPD, mean relative humidity $(\mathrm{RH})$ were calculated based on the hourly records from the Ibuttons (temperature and relative humidity sensors). For SWC, an average per plot and date was calculated. We used linear mixed models (LMM) to test the effect of cropping system, altitude and consequently interaction (cropping system $\mathrm{x}$ altitude) on microclimate and SWC. PlotID was used as a random effect to account for the non-indepency of the data due to the repeated measures (daily microclimate variables Altitude $x$ coffee cropping system + (1|PlotID)). When the cropping system effect was significant, we applied a Post-Hoc analysis (Tukey test) to determine the different groups.

Similarly, we used generalized mixed models (GLM) with PlotID as random effect, to evaluate differences in coffee reproductive variables (poisson distribution), vegetative variables (poisson distribution) and fruit drop (linear mixed models) between coffee cropping systems for each altitude class (Low altitude, mid altitude and high altitude) and for all altitude together (all) (Fig. 6, 7 and 8). Finally, when the type of cropping system had a significant effect on the studied variables, a Post Hoc test was applied to identy the different groups. 


\subsubsection{Piecewise Structural Equation Model}

Piecewise structural equation model (PiecewiseSEM) is a multivariate statistical analysis technique, which permits the evaluation of multiple predictors and multiple response variables and allows testing the direct and indirect effects within a causal network, particularly in cascade processes (Lefcheck \& Freckleton, 2016). Relationships between variables are represented with arrows, which indicate the pathways of the model, and pathways are hypothesized to be causal. Thus, applying the PiecewieseSEM models requires a prior conceptual model that indicates directions and dependences. Along the path, some variables act as explanatory (predictors) or response variables, or even both.

\subsubsection{Conceptual model}

Based on scientific literature and expert knowledge, we develop a simplified conceptual model which represents effects of environmental variables and management on coffee fruit development process (Fig. 2). We consider that environmental conditions are at first influenced by geographical location (latitude and longitude) and topography, which we divided in three elements: altitude, slope and aspect. Thus, for a given geographical location, topography influence climatic variables such as: radiation, rainfall and wind. Later on, the interaction of these climatic variables will determine temperature and relative humidity, and consequently vapor pressure deficit (Ong et al., 1991; Allen et al., 1998; Littmann, 2008; Bote et al., 2018) (Fig. 2). 


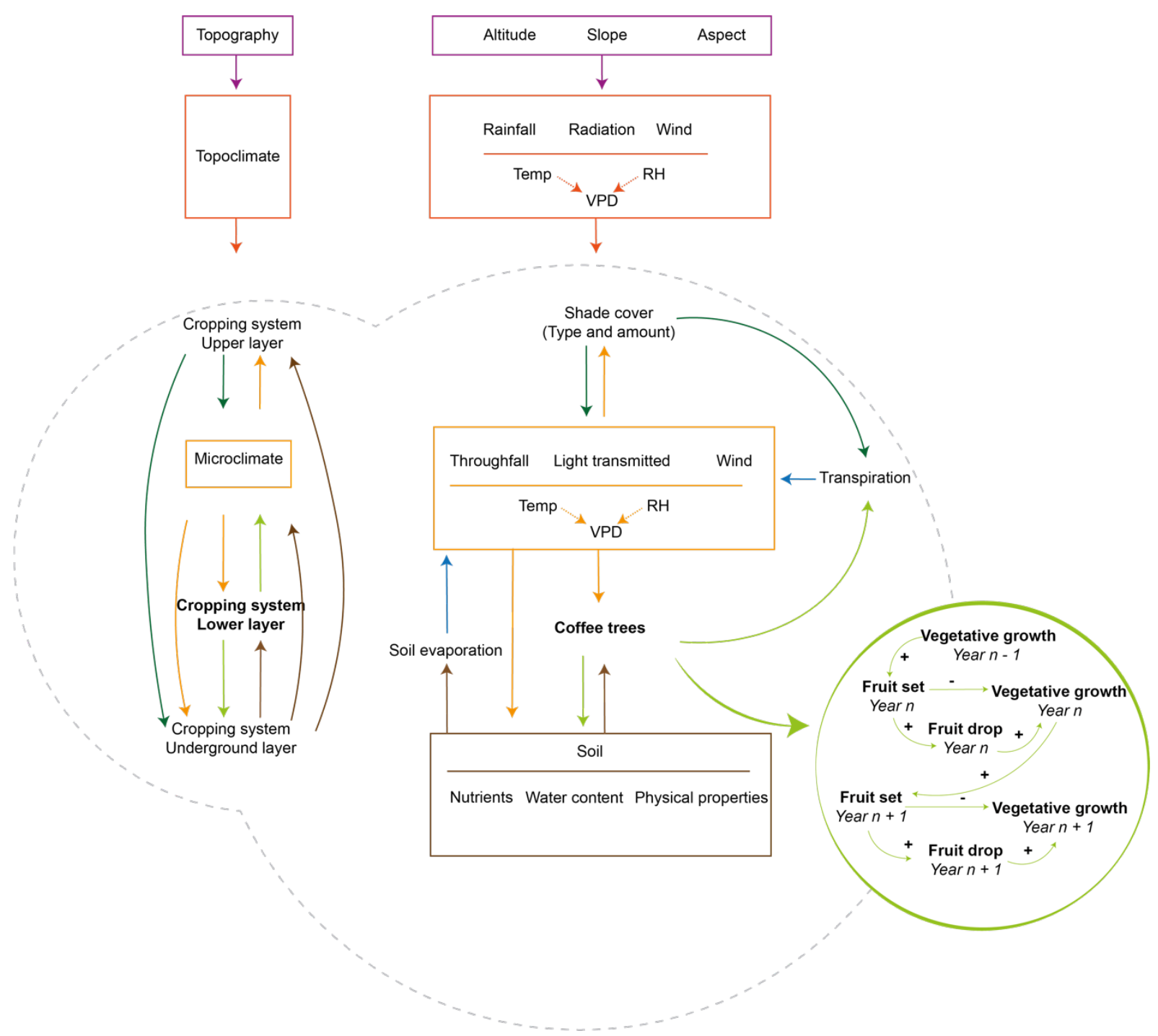

Fig. 2. Conceptual model describing relationships between geographical, environmental variables and cropping systems characteristics. Arrows indicate the direction of the relationships between the different variables or processes. Illustration by Visuals in Science LAB.

Rainfall, radiation and wind entering the coffee system are regulated by shade (amount and type), thus creating a particular microclimate to which the coffee trees are exposed (Monteith et al., 1991; Vaast et al., 2008; Siles et al., 2009). Moreover, transpiration of shade trees and of coffee trees will also influence the microclimate in which the coffee trees grow, depending on the morphologic and physiologic characteristics of the shade tree (Cannavo et al., 2011; Partelli et al., 2014; Sarmiento-Soler et al., 2019). Additionally, shade trees also influences soil properties, notably soil water holding capacity, through soil aggregate formation (Vaast et al., 2008; Padovan et al., 2015; Defrenet et al., 2016). Finally, soil water content from one hand might be reduced by larger transpiration (shade trees + coffee) and throughfall, but on the other hand soil water evaporation would reduce due to shading (Ong et al., 1991; Cannavo et al., 2011; Padovan et al., 2015; Padovan et al., 2018). 
Flower formation is stimulated by higher incoming radiation and by the number of reproductive nodes, which result from branch growth and formation of internodes during the previous year $(n-1)$ (Franck et al., 2005; Vaast et al., 2006; DaMatta et al., 2007). Higher flower set will lead to higher fruit initiation (assuming pollination success is not influenced by the shade type and amount). Higher fruit loads will lead to a higher fruit drop due to two mechanisms: (i) sink competition between fruits (sink organs) and (ii) competition between fruits (sink organs) and leaves (source organs) (Vaast et al., 2005). Eventually, if sink demand is too high exceeding source capacities, the branches will die (so called die-back). Moreover, higher fruit loads reduce available resources for new internodes formation during the same year $(n)$. This means that the following year $($ Year $n+1)$, flower formation will be hampered, since there are less nodes where flowers could develop. This will be resulting in lower fruit loads. With less fruit loads, competition between fruits, and between fruits and leaves is reduced, leading to a lower fruit drop rate and higher vegetative growth (more new internodes) which can give place to more leaves and productive nodes the following year.

\section{Explanatory and response variables}

We used altitude (as a proxy for combined influence of radiation, temperature, vapor pressure deficit and precipitation) and shade cover as explanatory variables in the model 1 and 2 (Table 2). Fruit set per stem, leave set per stem, number of internodes per stem and fruit drop per stem acted as response and explanatory variables, depending on their temporal situation along the fruit development process. For instance, at fruit initiation in 2015, number of internodes per stem acted first as a response variable, since growth is influenced by radiation and temperature (hence shade and altitude). Concurrently, number of internodes has an effect of fruit set, acting therefore as an explanatory variable (Cannell, 1985). Similarly, for 2016 we tested the effect of several coffee variables occurring during the previous year (2015) and determine the most relevant ones, affecting the fruit development during 2016. In Table 2 we specify the variables included in the model and whether they were considered as explanatory or response variables, or both. 


\subsubsection{Use of Piecewise Structural Equation Model}

\subsection{Variables and model selection}

Microclimate and soil water content data was only available for 16 plots (plots including simultaneously soil water content and microclimate data), whereas data about coffee growth was from 27 plots. Due to the different sample size of the available data sets, we decided to run two separate piecewiseSEM models. In this way, we avoided an excessive reduction of sample size (from $n=27$ to $n=16$ ) in the case all data sets would have been analyzed together. Model 1 evaluated the effect altitude and shade cover have on microclimate (temperature and vapor pressure deficit) and soil water content (16 plots) (Fig.5). Model 2 evaluated the effect of altitude and shade cover on coffee growth (fruit set per stem, leave set per stem, number of internodes per stem, and fruit drop per stem) and the effect of coffee growth during 2015 on coffee growth in 2016. Despite using separate models, insights from the two models were combined in the discussion for a better interpretation of the results.

\section{Single model selection}

For each individual path in our conceptual model, we selected the best model explaining the relationships between explanatory variables and response variables. Model selection was done stepwise using the dredge function from the R package MuMIn and selecting the model with the lowest AIC. We used linear mixed model (LMM), with plot number (PlotID) as a random effect (Hurlbert, 1984). Continuous variables were standardized and tested for normality, via visual evaluation of residual distribution. This procedure was repeated until there was one single equation representing each path of our conceptual model, this set of equations was nominated "basic set" (Lefcheck \& Freckleton, 2016).

\section{Path selection and model selection}

We introduced this basic set in the piecewise SEM function first for optimization. This was done by two procedures: (i) look for possible missing paths (non-included relationships between explanatory and response variables), which is indicated by Fisher $r$ value $<0.05$ (Shipley, 1999; Lefcheck \& Freckleton, 2016) and (ii) identify predictors with very low coefficients $(<0.001)$ or not significant. Those were removed after verifying that their removal did not lead to missing paths (as mentioned above) or to an increase of AIC of the piecewise SEM model. Accordingly, the best basic set explaining our data set was selected based on their piecewise SEM output (Lowest AIC) (Shipley, 1999; Lefcheck \& Freckleton, 2016). In the final model (lowest AIC and with the larger number of variables) good fitness was tested via chi squares statistics (Shipley, 1999; Lefcheck \& Freckleton, 2016) and are displayed in the supplementary materials as Table S1 (Model1) and Table S2 (Model 2). 
We used R (R Development Core Team, 2017) and the packages "Imer", "glmmTMB" (Brooks et al., 2017), "Ime4" (Bates et al., 2015), "ImerTest" (Kuznetsova et al., 2017), "MuMIn” (Bartoń 2019), "Car" (Fox \& Wiesberg, 2019), and "dplyr" (Wickham et al., 2019). Piecewiese SEM models were run using the function modellist (), from the package "piecewiseSEM" (Lefcheck \& Freckleton, 2016). Finally, the visualization of results was done using the R package ggplot2 (Wickham, 2016) and Adobe Illustrator (Mordy, 2010).

\subsection{Results}

\subsubsection{Effect of shade (type and amount) and altitude on microclimate and soil water content}

In the study area, precipitation (from $1^{\text {st }}$ January 2015 to $30^{\text {th }}$ April 2016) amounted to $1733 \mathrm{~mm}$ at 1300 m.a.s.I. (low altitude) and $2252 \mathrm{~mm}$ at 1800 m.a.s.l. (high altitude). Mean temperature (mean Temp) from $1^{\text {st }}$ January 2015 to $30^{\text {th }}$ April 2016 under open conditions was $22.6 \pm 1.7^{\circ} \mathrm{C}$ at low altitude, $21.6 \pm$ $1.8^{\circ} \mathrm{C}$ at mid altitude, and $19.2 \pm 2.2^{\circ} \mathrm{C}$ at high altitude. All temperature related variables (mean min temperature, mean temperature, mean max temperature, mean temperature amplitude), vapor pressure deficit (VPD) and soil water content decreased significantly with altitude (Table 3 and Fig.3). Differences between cropping systems were significant for mean temp, max temp and temp amplitude (Table 3). Coffee-Open had the largest max temp, mean temp and temp amplitude (Table 3). An interaction effect between altitude and cropping system was significant for min temp, max temp, temp amplitude, VPD and SWC. In the case of min temp and SWC the negative effect of altitude was more pronounced in CO than in CB and CT (Fig.3.a and Fig.3.g). While in CO, max temp decrease with altitude was less pronounced than in the other systems (CB and CT) (Fig.3.c). On the contrary, temp amplitude and VPD increased along altitude in CO, but not in CB and CT (Fig.3.d and Fig.3.e). 
a)

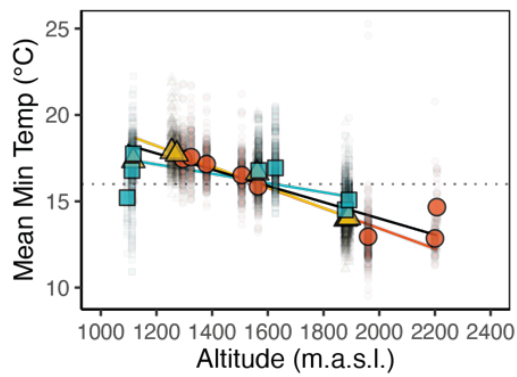

d)

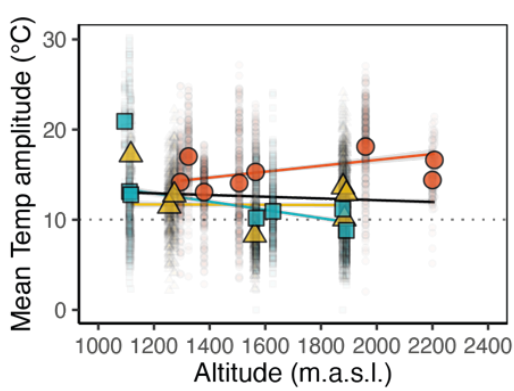

g)

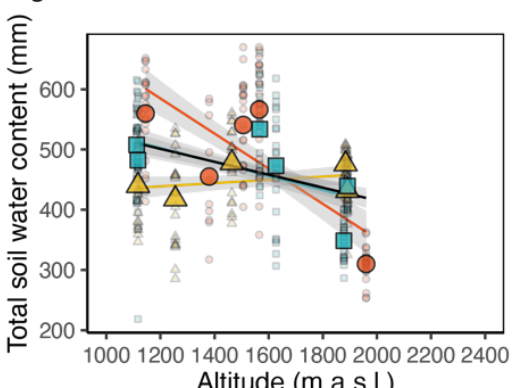

b)

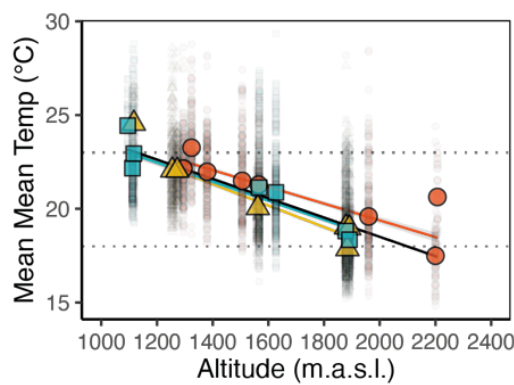

e) $\quad$ f)

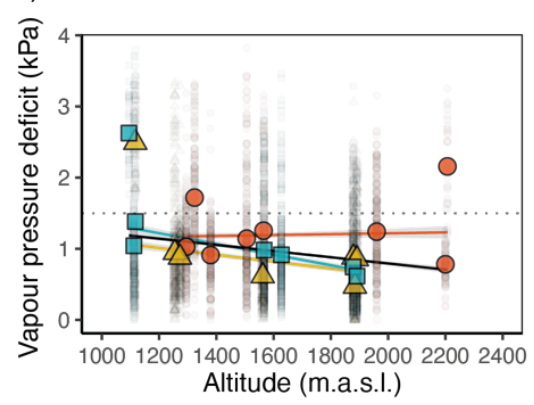

c)

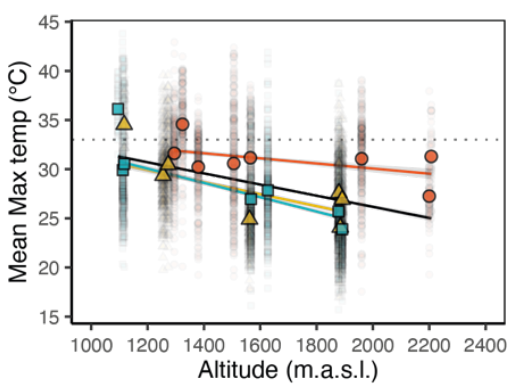

f)

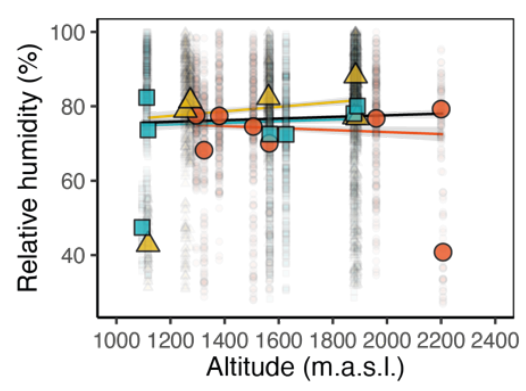

Fig. 4. Scatterplots of microclimate variables and soil water content vs altitude for three coffee cropping systems, a) Mean minimum temperature $\left({ }^{\circ} \mathrm{C}\right)$, b) Mean mean temperature $\left({ }^{\circ} \mathrm{C}\right)$, c) Mean maximum temperature $\left({ }^{\circ} \mathrm{C}\right)$, d) Mean temperature amplitude $\left({ }^{\circ} \mathrm{C}\right)$, e) Vapour pressure deficit $\left.(\mathrm{kPa}), \mathrm{f}\right)$ Relative humidity (\%) and g) Soil water content (mm). Colour and symbol indicate coffee cropping system (Coffee-Open = CO (Red circle), Coffee - Banana $=$ CB (Yellow triangle), Coffee- shade tree $=$ CT (Blue square). Black line indicates all systems together. Dotted line indicates environmental coffee thresholds. 
Table 3: Results from linear mixed models to evaluate the effect of cropping system and altitude on microclimate and soil water content

\begin{tabular}{|c|c|c|c|c|c|c|c|}
\hline \multicolumn{8}{|c|}{ Minimum temperature } \\
\hline & Sum & Sq Mean & Sq NumDF & DenDF & F-value & $\operatorname{Pr}(>\mathrm{F})$ & Sig \\
\hline System & 0.709 & 0.354 & 2.000 & 21.082 & 0.274 & 0.763 & \\
\hline Altitude & 87.322 & 87.322 & 1.000 & 21.554 & 67.471 & 0.000 & $* * *$ \\
\hline \multirow[t]{2}{*}{ System:Altitude } & 12.150 & 6.075 & 2.000 & 21.563 & 4.694 & 0.020 & $*$ \\
\hline & Estimate & Std.Error & df & t-value & $\operatorname{Pr}(>|t|)$ & sig & \\
\hline (Intercept) & 16.052 & 0.269 & 21.142 & 59.626 & $<$ & $2.00 \mathrm{E}-16$ & $* * *$ \\
\hline CB & -0.285 & 0.388 & 21.150 & -0.734 & 0.471 & & \\
\hline CT & -0.103 & 0.399 & 21.041 & -0.258 & 0.799 & & \\
\hline Altitude & -1.358 & 0.215 & 21.810 & -6.314 & 0.000 & $* * *$ & \\
\hline CB:Altitude & -0.200 & 0.340 & 21.657 & -0.587 & 0.563 & & \\
\hline CT:Altitude & 0.818 & 0.328 & 21.554 & 2.493 & 0.021 & $*$ & \\
\hline \multicolumn{8}{|c|}{ Mean temperature } \\
\hline & Sum & Sq Mean & Sq NumDF & DenDF & F-value & $\operatorname{Pr}(>\mathrm{F})$ & Sig \\
\hline System & 23.630 & 11.810 & 2.000 & 19.439 & 3.642 & 0.045 & $*$ \\
\hline Altitude & 450.430 & 450.430 & 1.000 & 20.547 & 138.870 & 0.000 & $* * *$ \\
\hline \multirow[t]{2}{*}{ System:Altitude } & 17.610 & 8.810 & 2.000 & 20.569 & 2.715 & 0.090 & . \\
\hline & Estimate & Std.Error & df & t-value & $\operatorname{Pr}(>|t|)$ & sig & \\
\hline (Intercept) & 21.341 & 0.257 & 19.608 & 83.101 & $<2 \mathrm{e}-16$ & $* * *$ & \\
\hline$C B$ & -0.935 & 0.371 & 19.605 & -2.523 & 0.020 & $*$ & \\
\hline CT & -0.770 & 0.380 & 19.348 & -2.030 & 0.056 & . & \\
\hline Altitude & -1.185 & 0.208 & 21.232 & -5.698 & 0.000 & $* * *$ & \\
\hline CB:Altitude & -0.734 & 0.327 & 20.799 & -2.240 & 0.036 & $*$ & \\
\hline CT:Altitude & -0.480 & 0.316 & 20.569 & -1.520 & 0.144 & & \\
\hline \multicolumn{8}{|c|}{ Maximum temperature } \\
\hline & Sum & Sq Mean & Sq NumDF & DenDF & F-value & $\operatorname{Pr}(>\mathrm{F})$ & Sig \\
\hline System & 253.320 & 126.660 & 2.000 & 20.703 & 9.313 & 0.001 & $* *$ \\
\hline Altitude & 489.950 & 489.950 & 1.000 & 21.521 & 36.026 & 0.000 & $* * *$ \\
\hline \multirow[t]{2}{*}{ System:Altitude } & 93.280 & 46.640 & 2.000 & 21.536 & 3.430 & 0.051 & . \\
\hline & Estimate & Std.Error & df & t-value & $\operatorname{Pr}(>|t|)$ & sig & \\
\hline (Intercept) & 31.235 & 0.645 & 20.817 & 48.446 & $<2 \mathrm{e}-16$ & $* * *$ & \\
\hline $\mathrm{CB}$ & -3.292 & 0.930 & 20.823 & -3.539 & 0.002 & $* *$ & \\
\hline CT & -3.663 & 0.954 & 20.634 & -3.840 & 0.001 & $* * *$ & \\
\hline Altitude & -0.866 & 0.518 & 21.993 & -1.670 & 0.109 & & \\
\hline CB:Altitude & -1.558 & 0.818 & 21.703 & -1.904 & 0.070 & . & \\
\hline CT:Altitude & -1.916 & 0.789 & 21.528 & -2.428 & 0.024 & $*$ & \\
\hline \multicolumn{8}{|c|}{ Temperature amplitude } \\
\hline & Sum & Sq Mean & Sq NumDF & DenDF & F-value & $\operatorname{Pr}(>\mathrm{F})$ & Sig \\
\hline System & 155.260 & 77.630 & 2.000 & 20.976 & 5.571 & 0.011 & $*$ \\
\hline Altitude & 63.380 & 63.380 & 1.000 & 21.557 & 4.549 & 0.045 & $*$ \\
\hline \multirow[t]{2}{*}{ System:Altitude } & 114.400 & 57.200 & 2.000 & 21.567 & 4.105 & 0.031 & $*$ \\
\hline & Estimate & Std.Error & df & t-value & $\operatorname{Pr}(>|t|)$ & sig & \\
\hline (Intercept) & 15.187 & 0.789 & 21.051 & 19.238 & 0.000 & $* * *$ & \\
\hline CB & -3.003 & 1.139 & 21.059 & -2.636 & 0.015 & $*$ & \\
\hline CT & -3.557 & 1.169 & 20.925 & -3.043 & 0.006 & $* *$ & \\
\hline Altitude & 0.499 & 0.632 & 21.878 & 0.790 & 0.438 & & \\
\hline CB:Altitude & -1.378 & 0.998 & 21.684 & -1.380 & 0.182 & & \\
\hline CT:Altitude & -2.754 & 0.964 & 21.558 & -2.857 & 0.009 & $* *$ & \\
\hline \multicolumn{8}{|c|}{ Vapor pressure deficit } \\
\hline & Sum & Sq Mean & Sq NumDF & DenDF & F-value & $\operatorname{Pr}(>\mathrm{F})$ & Sig \\
\hline
\end{tabular}




\begin{tabular}{|c|c|c|c|c|c|c|c|}
\hline System & 0.596 & 0.298 & 2.000 & 21.041 & 0.843 & 0.444 & \\
\hline Altitude & 2.665 & 2.665 & 1.000 & 21.413 & 7.542 & 0.012 & $*$ \\
\hline \multirow[t]{2}{*}{ System:Altitude } & 2.640 & 1.320 & 2.000 & 21.419 & 3.736 & 0.041 & $*$ \\
\hline & Estimate & Std.Error & df & t-value & $\operatorname{Pr}(>|t|)$ & sig & \\
\hline (Intercept) & 1.252 & 0.159 & 21.087 & 7.867 & 0.000 & $* * *$ & \\
\hline$C B$ & -0.281 & 0.230 & 21.094 & -1.224 & 0.235 & & \\
\hline СТ & -0.225 & 0.236 & 21.008 & -0.956 & 0.350 & & \\
\hline Altitude & 0.074 & 0.127 & 21.610 & 0.581 & 0.567 & & \\
\hline CB:Altitude & -0.438 & 0.201 & 21.493 & -2.182 & 0.040 & * & \\
\hline CT:Altitude & -0.466 & 0.194 & 21.411 & -2.403 & 0.025 & $*$ & \\
\hline \multicolumn{8}{|l|}{ Relative humidity } \\
\hline & Sum & Sq Mean & Sq NumDF & DenDF & F-value & $\operatorname{Pr}(>\mathrm{F})$ & Sig \\
\hline System & 137.440 & 68.720 & 2.000 & 20.932 & 0.319 & 0.730 & \\
\hline Altitude & 313.930 & 313.930 & 1.000 & 21.323 & 1.459 & 0.240 & \\
\hline \multirow[t]{2}{*}{ System:Altitude } & 1254.400 & 627.200 & 2.000 & 21.330 & 2.914 & 0.076 & . \\
\hline & Estimate & Std.Error & $d f$ & t-value & $\operatorname{Pr}(>|t|)$ & sig & \\
\hline (Intercept) & 71.924 & 3.815 & 20.981 & 18.851 & 0.000 & $* * *$ & \\
\hline $\mathrm{CB}$ & 4.399 & 5.505 & 20.988 & 0.799 & 0.433 & & \\
\hline СТ & 2.156 & 5.652 & 20.898 & 0.381 & 0.707 & & \\
\hline Altitude & -3.870 & 3.044 & 21.532 & -1.271 & 0.217 & & \\
\hline CB:Altitude & 10.891 & 4.812 & 21.408 & 2.263 & 0.034 & $*$ & \\
\hline CT:Altitude & 7.913 & 4.648 & 21.322 & 1.702 & 0.103 & & \\
\hline \multicolumn{8}{|c|}{ Soil Water Content } \\
\hline & Sum & Sq Mean & Sq NumDF & DenDF & F-value & $\operatorname{Pr}(>\mathrm{F})$ & Sig \\
\hline System & 8382.000 & 4191.000 & 2.000 & 16.773 & 0.997 & 0.390 & \\
\hline Altitude & 43182.000 & 43182.000 & 1.000 & 16.597 & 10.270 & 0.005 & $* *$ \\
\hline \multirow[t]{2}{*}{ System:Altitude } & 40834.000 & 20417.000 & 2.000 & 16.585 & 4.856 & 0.022 & $*$ \\
\hline & Estimate & Std.Error & $d f$ & t-value & $\operatorname{Pr}(>|t|)$ & sig & \\
\hline (Intercept) & 484.460 & 20.410 & 17.200 & 23.734 & 0.000 & $* * *$ & \\
\hline $\mathrm{CB}$ & -38.760 & 27.510 & 16.910 & -1.409 & 0.177 & & \\
\hline CT & -19.320 & 27.500 & 16.890 & -0.703 & 0.492 & & \\
\hline Altitude & -83.470 & 22.780 & 16.710 & -3.664 & 0.002 & $* *$ & \\
\hline CB:Altitude & 92.060 & 29.650 & 16.620 & 3.105 & 0.007 & $* *$ & \\
\hline CT:Altitude & 48.230 & 28.650 & 16.640 & 1.683 & 0.111 & & \\
\hline
\end{tabular}

We found that microclimate and soil water content oscillations followed the seasonal patterns described for the region, with a strong dry season from December to February and a rainy season from April to June (Fig. 4). This latter period coincides with the fruit developing period (Fig. 6). From June to September there is another short dry season, which affects SWC at low and middle altitudes, while at high altitude rainfall reduction was moderated. Soil water content was lower at higher altitude (Fig. 4.b) and also less variable along the year, where SWC values did not reach the amplitude observed at low and mid altitude (Fig. 4.b). Maximum temperatures surpassed $30^{\circ} \mathrm{C}$ frequently at low altitudes in all systems (Fig. 4.a). At mid and high altitudes, $30^{\circ} \mathrm{C}$ threshold was exceeded predominantly in $\mathrm{CO}$ and in the other systems only during the dry season (Fig. 4.a). From October 2015 to January 2016, maximum temperatures in $\mathrm{CO}$ coincided with a decrease in soil water content in the same system, suggesting higher evapotranspiration demand in CO compared to CB for this altitude. Vapor pressure deficit (VPD) was above $1.5 \mathrm{kPa}$ during dry periods regardless of altitude and system (Fig 4.c). 
$\neg \mathrm{CO} \triangle \mathrm{CB} \rightleftarrows \mathrm{CT}$

a)

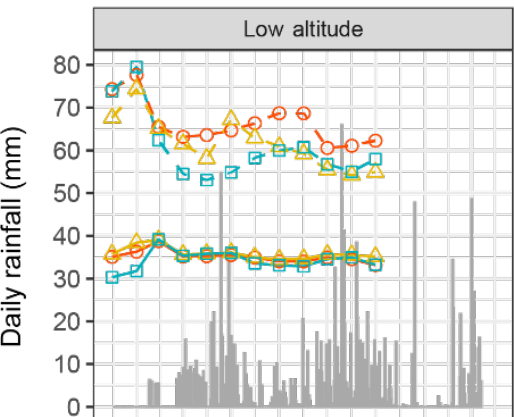

b)
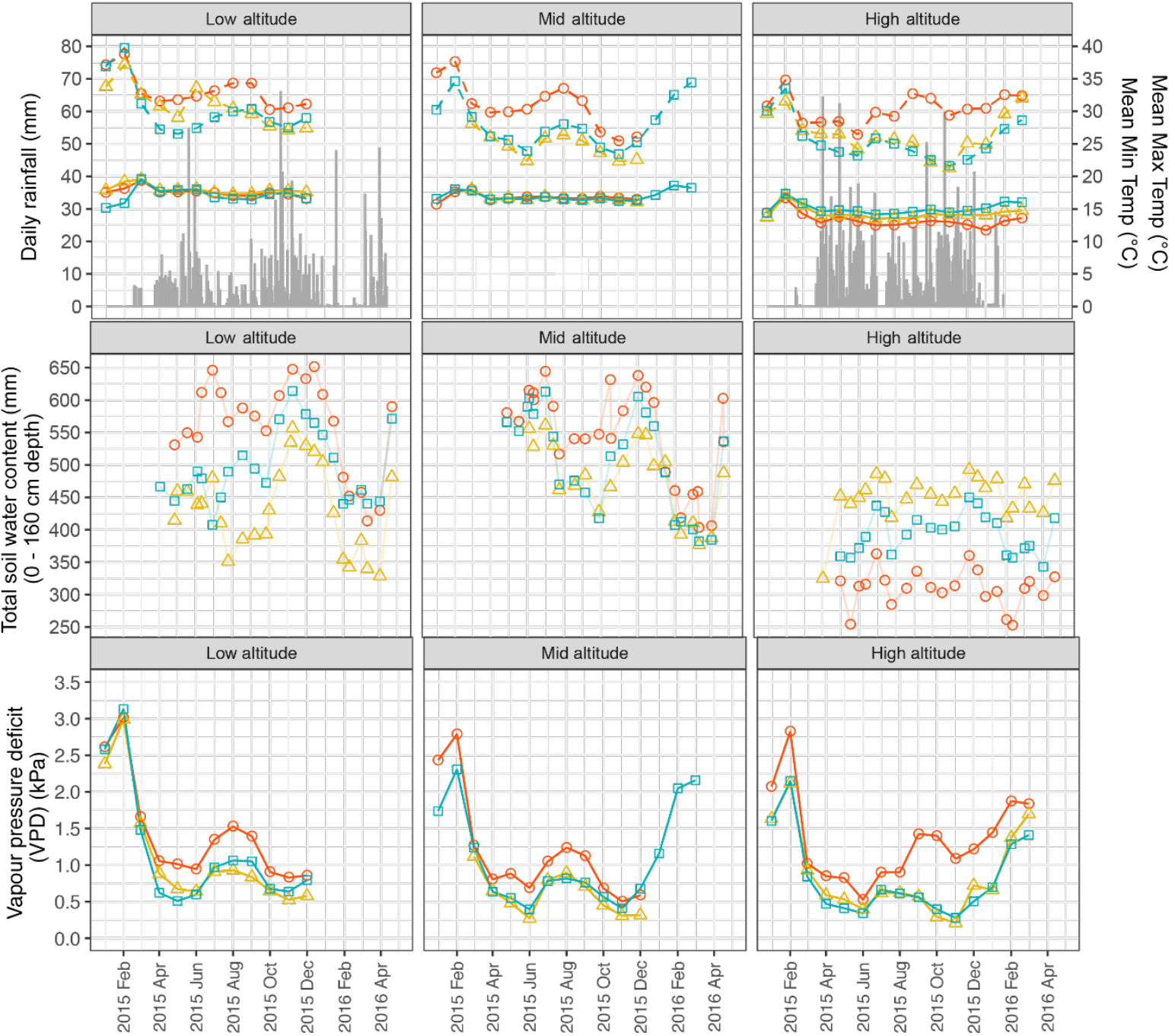

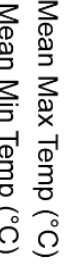
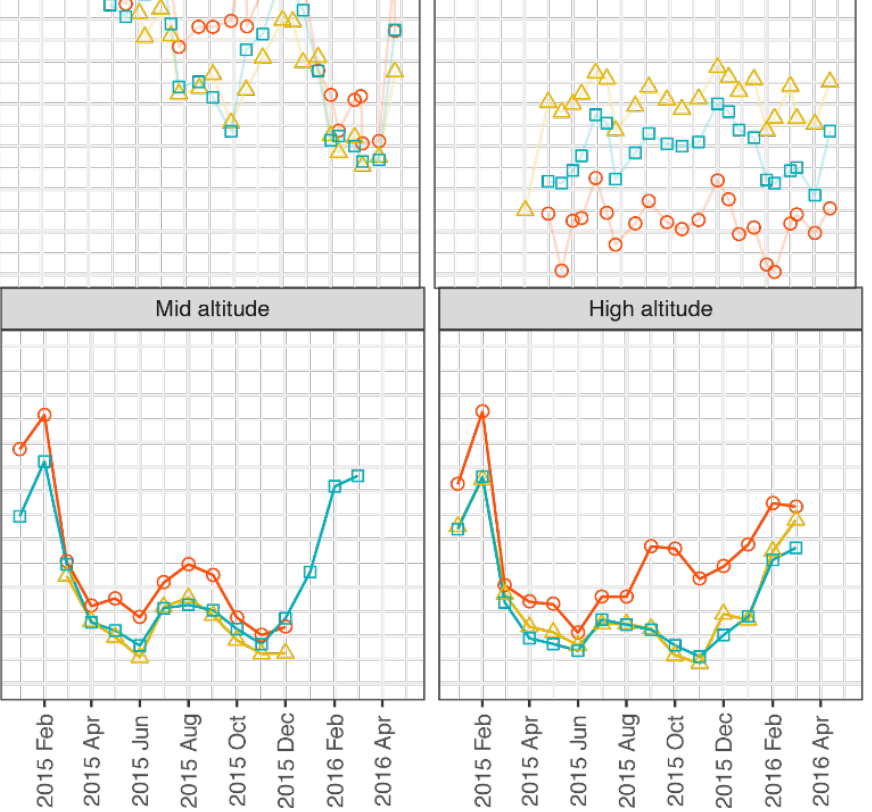

Fig. 4. Timeline of total soil water content and microclimate variables during the study period in different coffee cropping systems (January 2015 - April 2016) along the altitude gradient. a) Daily rainfall and Mean monthly minimum temperature (Min Temp $\mathrm{C}^{\circ}$ ) and mean monthly maximum temperature (Max Temp $\mathrm{C}^{\circ}$ ), b) Soil water content $(\mathrm{mm})$ from 0 to $160 \mathrm{~cm}$ depth, c), d) Vapour pressure deficit (VPD kPa). Altitude classes: Low altitude (1100 - 1400 m.a.s.I.), mid altitude (1400 - 1700 m.a.s.I.) and high altitude (1700 - 2100 m.a.s.I). Symbol and colour indicate type of coffee cropping system: Coffee-Open = CO (Red circle), Coffee-Banana = CB (Yellow triangle) and Coffee- shade Tree = CT (Blue square). 
The path model (piecewise SEM) confirmed that altitude and shade reduced mean and maximum temperature, as well as VPD (Fig. 5). Minimum temperature reduced along with altitude increases while it was positively affected by shade. Finally, we found a negative effect of VPD and min temp on soil water content (Fig. 5) (Detail model results can be found in supplementary material Table S1).

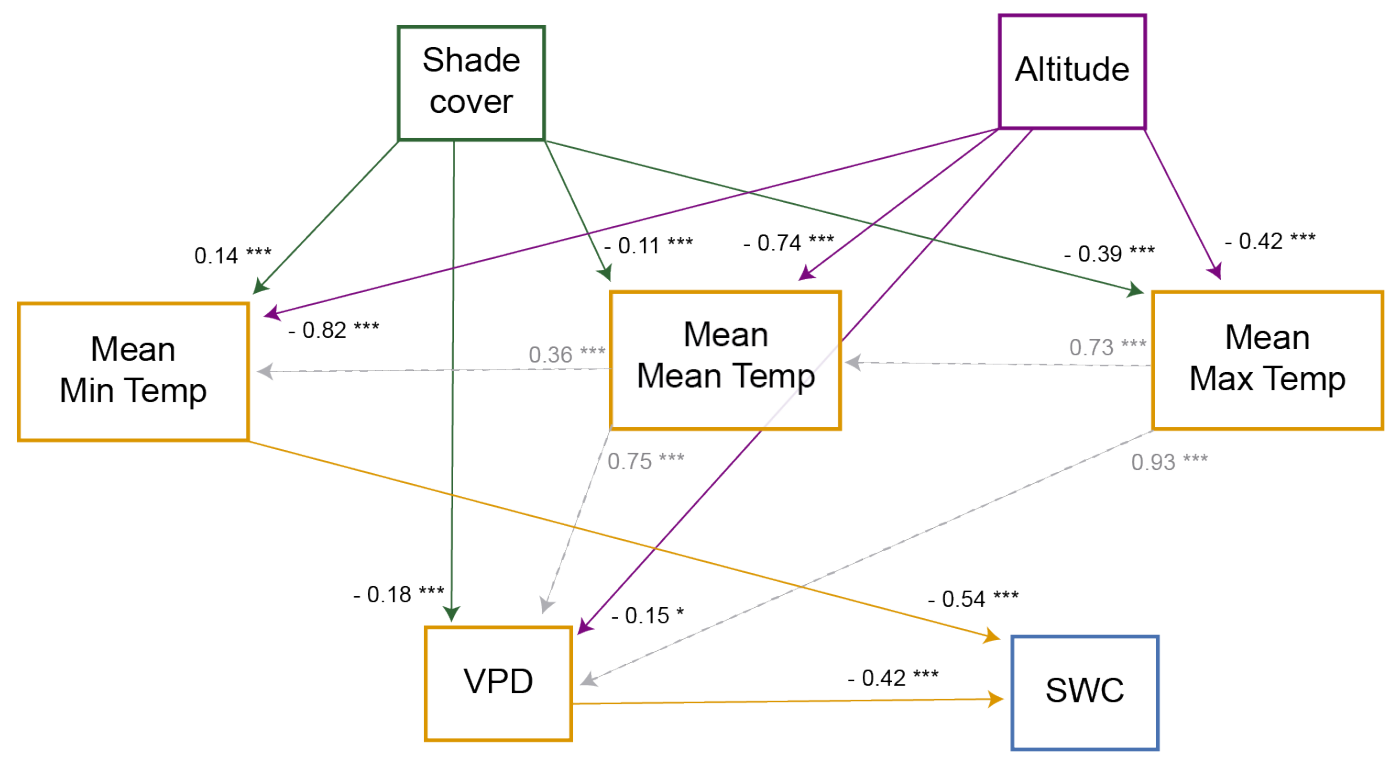

Fig 5. Piecewise structural equation model for the effect of shade cover (LAl $\mathrm{m}^{2} \mathrm{~m}^{-2}$ and altitude (m.a.s.l.) on microclimate parameters (Mean minimum temperature ${ }^{\circ} \mathrm{C}$ (Mean Min Temp), mean mean temperature ${ }^{\circ} \mathrm{C}$ (Mean Mean Temp), mean maximum temperature ${ }^{\circ} \mathrm{C}$ (Mean Max Temp) and vapor pressure deficit $\mathrm{kPa}$ (VPD) and total soil water content $(\mathrm{mm})(0-160$ $\mathrm{cm}$ depth) (SWC). The arrows indicate unidirectional relationship between variables ( $p$-value $<0.05)$. Standardized regression coefficients accompanying the arrows indicate the magnitude of the relationship between variables. Negative relations are indicated by "-"symbol before the corresponding coefficient. Grey arrows and coefficients indicate previously defined relationships among variable introduced in the model.

\subsubsection{Fruit set, leaf set and branch growth}

\section{Fruit set per branch}

Differences in fruit set per branch between cropping systems varied from one year (2015) to the next one (2016). In 2015, fruit set was similar across cropping systems along the fruit development process for low and high altitude (Fig. 6.a (Low and high altitude)). On the other hand, at mid altitude, CB had larger fruit initiation ( $F S_{2015}$ week o) than CO and CT ( $C O=26 \pm 31, C B=54 \pm 39, C T=31 \pm 34$ ) (Fig. 6.a Mid altitude). Those differences decreased towards the end of fruit development cycle. Thus, at harvest 2015, CB had larger fruit set than $C O$, while $C T$ was situated in between $(C O=7 \pm 9, C B=13 \pm 12, C T=$ $9 \pm 7$ ) (Fig. 6.a Mid altitude). When pooling all altitude classes together, fruit set differences between cropping systems occurred only at week 8, when CT had lower fruit set than CO and CB (Fig. 6.a (all). However, at harvest, these differences were no longer significant (Fig. 7.a (all)). 
Fruit initiation in 2016 (FS 2016 week o) was delayed by one month, starting in April 2016, compared to 2015. When pooling altitude classes, Coffee in CT systems had the lowest fruit set (10 \pm 15$)$ at fruit initiation ( $C O=29 \pm 12$ and $C B=22 \pm 32)$. And, this pattern was repeated in week 8 of $2016(C O=28 \pm 43$, $\mathrm{CB}=19 \pm 28, \mathrm{CT}=9 \pm 13)$ and week 17 of $2016(\mathrm{CO}=20 \pm 27, \mathrm{CB}=15 \pm 23, \mathrm{CT}=8 \pm 11)$. However, at harvest we did not see any differences in fruit set between systems $(C O=3 \pm 8, C B=1 \pm 3, C T=0.6 \pm 2.3)$

(Fig. 6.a. (all)). Lower fruit set in $\mathrm{CT}$ than in $\mathrm{CO}$ and $\mathrm{CB}$ occurred at low and mi altitude, while there were no systems differences in fruit set along the fruit development process at high altitude (Fig. 6.a).

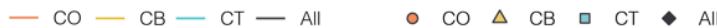

a)
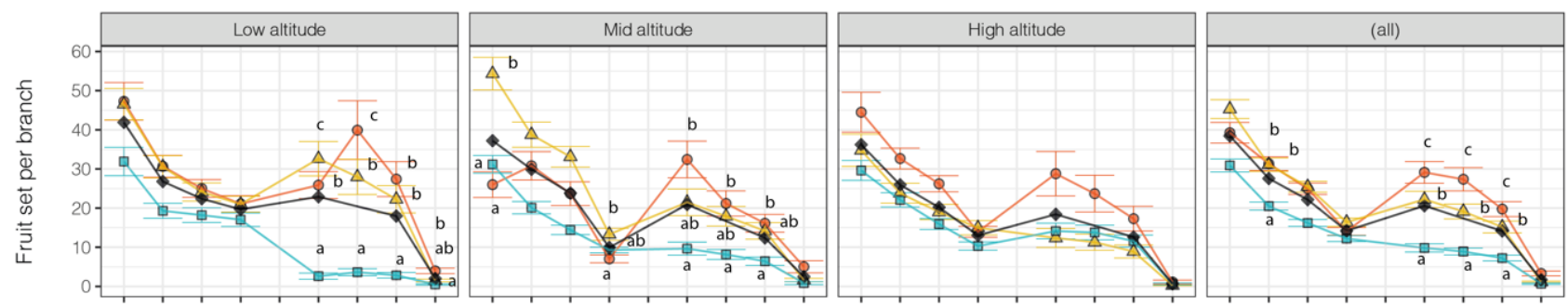

b)
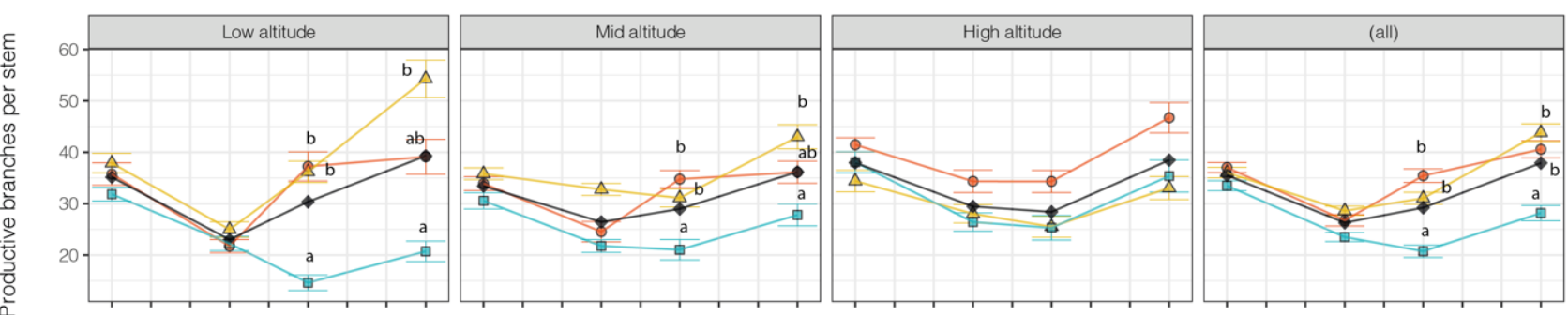

c)
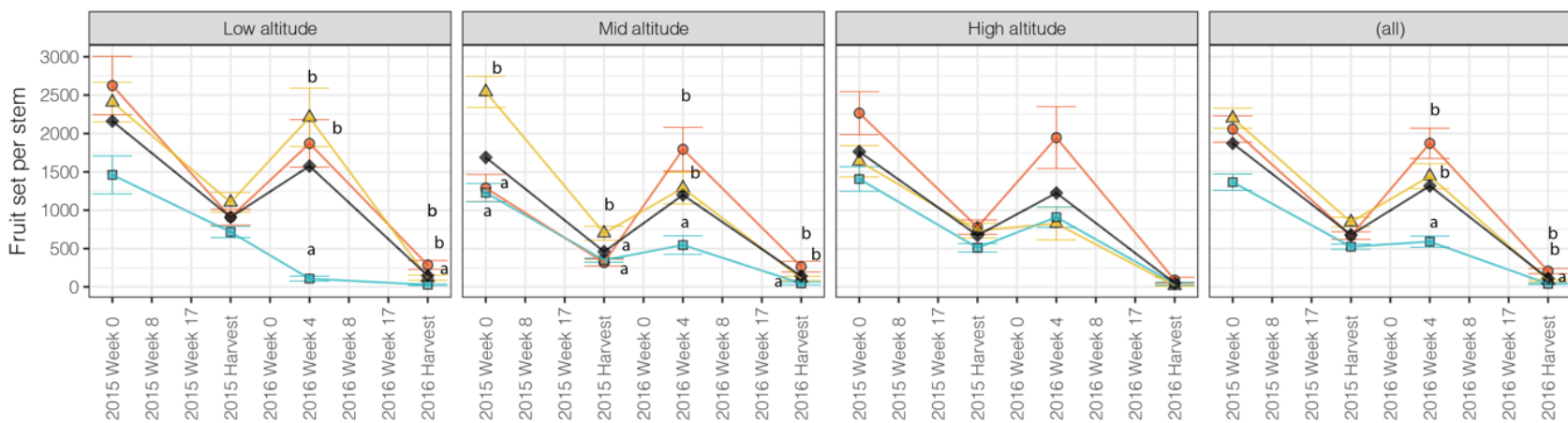

Fig.6. Timeline of coffee reproductive variables, (a) Fruit set per branch, (b) productive branches per stem, (c) fruit set per stem. Colour and symbol indicates coffee cropping system (Coffee-Open = CO (Red circle), Coffee - Banana = CB (Yellow triangle), Coffee- shade tree $=\mathrm{CT}$ (Blu square) and all systems = All (Black diamond) in three altitude classes altitude classes (Low altitude (1100 - 1400 m.a.s.I.), mid altitude (1400 - 1700 m.a.s.I.) and high altitude (1700 - 2100 m.a.s.l) during the study period (from April 2015 to December 2016). Letters indicate significant differences across systems in the specified point in time ( $p$-value $>0.05$, generalized mixed models). Absence of letters indicate no significant differences across systems. 


\section{Productive branches per stem}

Mean number of productive branches per stem was $36 \pm 16$ at fruit initiation in 2015 and $29 \pm 20$ in 2016 (Fig. 6.b, (All)). At harvest, number of productive branches decreased by $28 \%$ (26 \pm 15 ) in 2015 but increased by $27 \%(37 \pm 25)$ in 2016 compared to the same variable at fruit initiation (Fig. 6.b, (all)). In 2015, there were no differences in number of productive branches (at fruit initiation and at harvest) across systems (Fig. 6.b). On the contrary, in 2016 coffee trees in CT systems had a smaller number of productive branches at low and mid altitude at fruit initiation and at harvest (Fig. 6.b). This pattern also occurred when pooling all altitude classes together (Fruit initiation: $\mathrm{CO}=35 \pm 20, \mathrm{CB}=31 \pm 18$ and $\mathrm{CT}=$ $21 \pm 18$ and harvest: $C O=41 \pm 25, C B=44 \pm 26$ and $C T=28 \pm 21$ ) (Fig. 6.b (all)). Finally, no differences in productive branches across systems occurred at high altitude (Fig. 6.b, High altitude).

\section{Fruit set per stem}

Similarly, as with number of productive branches, differences in fruit set per stem across cropping systems occurred only at mid altitude in 2015 and at low and mid altitude in 2016 (Fig. 6.c). In 2015, mean fruit set per stem at fruit initiation (2015 Week 0) was $1871 \pm 2283$ and at harvest fruit set per stem was $679 \pm 816$ (-63\%). In this year, at mid altitude coffee in CB system had larger FS Stem than the other systems at fruit initiation $(C O=1289 \pm 1671, C B=2543 \pm 1932$ and $C T=1228 \pm 1127$ and at harvest ( $C O=317 \pm 410, C B=700 \pm 886$ and $C T=349 \pm 253$ ) (Fig. 6.C ,Mid altitude). The following year (2016), mean FS Stem at fruit initiation (Week 4) was $1317 \pm 2370$ and at harvest $110 \pm 314$ (- $92 \%$ ). Coffee in CT systems had consistently smaller FS Stem at fruit initiation and at harvest in low and mid altitude classes (Fig. 6.c Low altitude, Mid altitude and all).

\section{Fruit drop per branch}

In 2015, fruit drop per branch in the first 8 weeks (Week 8 ) averaged $30 \pm 26 \%$ for all systems. At week $17^{\text {th }}$ (FD 2015 Week 17 ) averaged $41 \pm 27 \%$ and at harvest cumulated $57 \pm 27 \%$ (Fig. 7.a (all)). We did not find differences in fruit drop per branch across systems in any of the altitude classes nor in all data pooled together (Fig. 7.a (all)). The largest fruit drop per branch occurred at Mid altitude (67 $\pm 24 \%)$ (Low altitude $=49 \pm 27 \%$, High altitude $=55 \pm 29 \%$ ) (Fig. 7.a). In 2016, the fruit drop per branch in the first eight weeks averaged $19 \pm 27 \%$; after $17^{\text {th }}$ week, fruit drop per branch was $30 \pm 30 \%$ and at harvest it accumulated up to $76 \pm 38 \%$. Coffee - Banana had the largest fruit drop (83 $\pm 33 \%)$ and CT the smallest $(65 \pm 45 \%)$ when altitude classes are pooled together (Fig. 7.a (all)). At low altitude, CT had also the smallest fruit drop (44 $\pm 48 \%)$ compared to $C O(75 \pm 33 \%)$ and to CB (86 $\pm 27 \%)$ (Fig. 7.a (Low altitude)). 


\section{Productive branch death}

At harvest in 2015, there were $30 \%$ less productive branches than at fruit initiation of the same year. We did not find any differences between cropping systems or along the altitude gradient. In the following year, 2016, there were $10 \%$ less productive branches at harvest compared to fruit initiation. As in the previous year, we did not find any significant differences in branch death across systems and altitude (Fig. 7.b).

\section{Fruit drop per stem}

In 2015, mean fruit drop per stem was $55 \pm 29 \%$ and in 2016 fruit drop per stem was $74 \pm 50 \%$. Fruit drop per stem did not differ between cropping systems, probably due to the high variability between trees of the same plot, as it is indicated by the standard deviation and the lower number of plots sampled in relation to the number of trees per plots (Fig. 7.c). 
a)

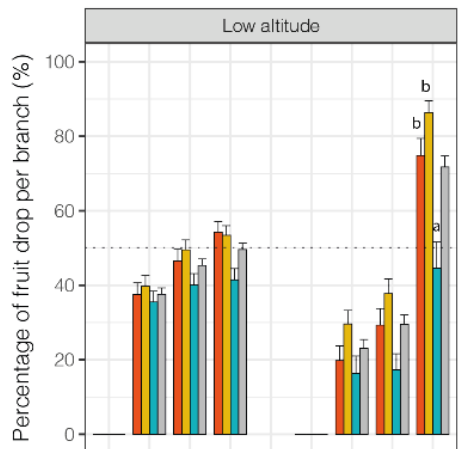

b)

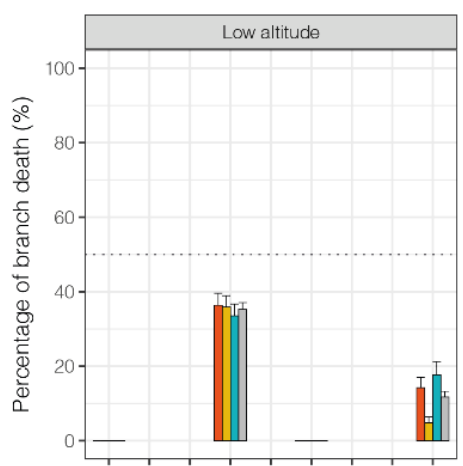

c)

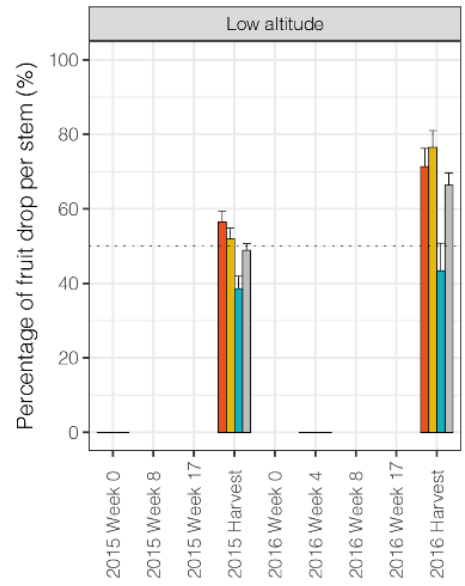

$\mathrm{CO} \square$ CB $\square$ CT $\square$ All
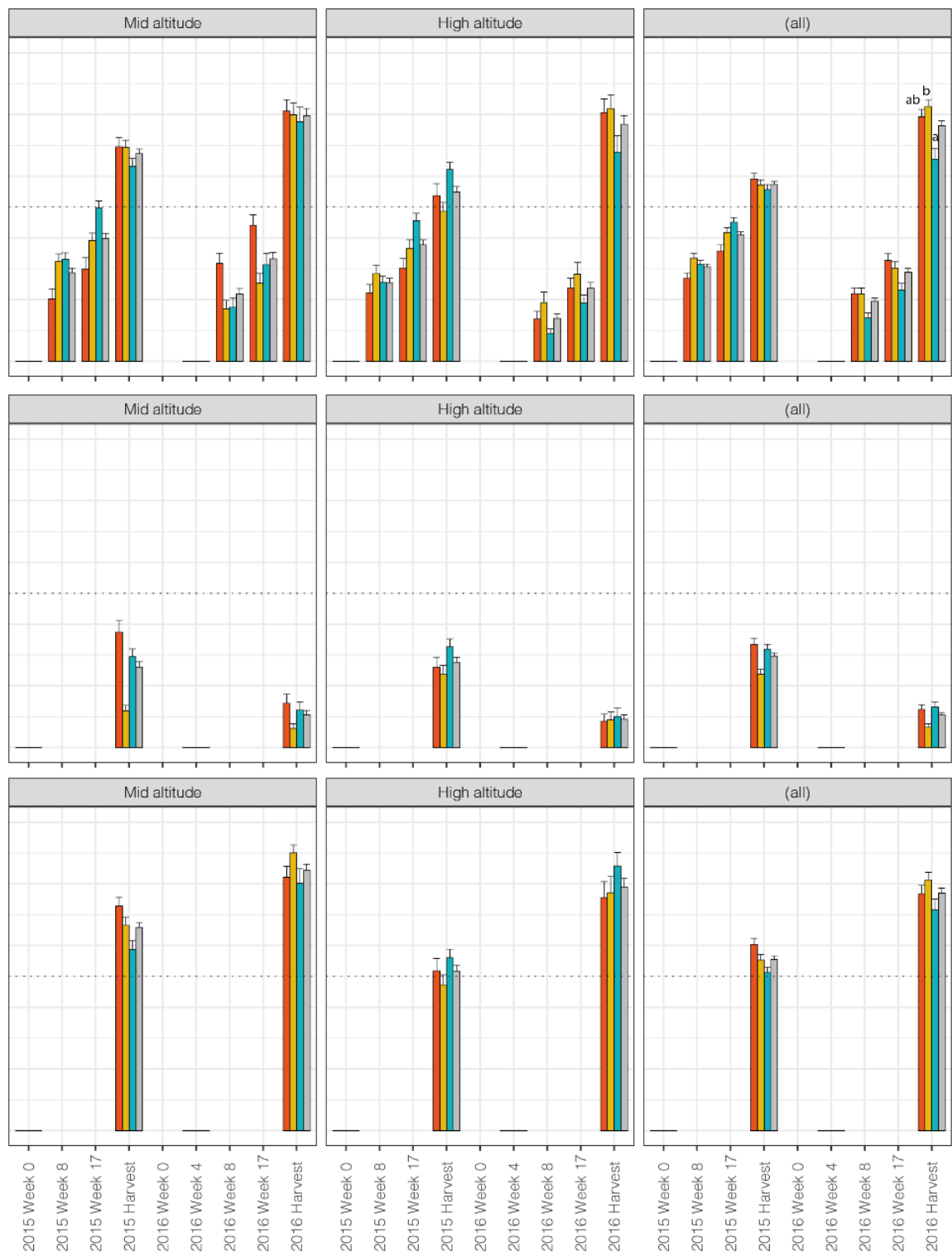

Fig. 7. (a)Percentage of fruit drop per branch, (b) percentage of branch death, (c)percentage of fruit drop per stem. Colour indicates coffee cropping system (Coffee-Open $=$ CO (Red), Coffee - Banana $=C B$ (Yellow), Coffee- shade tree $=$ CT (Blue) and all systems $=$ All (Grey) in three altitude classes altitude classes (Low altitude (1100 - 1400 m.a.s.l.), mid altitude $(1400-1700$ m.a.s.I.) and high altitude (1700 - 2100 m.a.s.I) during the study period (from April 2015 to December 2016). Letters indicate significant differences across systems in the specified point in time ( $p$-value $>0.05$, generalized mixed models). Absence of letters indicate no significant differences.

\section{Leaf set}

For both years (2015 and 2016), mean number of leaves per branch increased in the first 17 weeks after fruit initiation, while in the last weeks of fruit development, leaf set per branch stagnated in 2015 or even reduced in 2016 (Fig. 8.a). Differences in leaf set across systems were more pronounced in 2015 than in 2016 and varied depending on the altitude class. At low altitude, coffee in CO systems had less leaves per branch than CT and CB. On the contrary, at mid and high altitude, CT had less leaves per branch than the other systems (Fig. 8.a). 


\section{Number of internodes per branch}

Similarly, as with leaf set per branch, number of internodes per branch increased more pronounced in the initial weeks of fruit development and stagnated towards the harvest. At low altitude, coffee in CT had more internodes per branch than in the other cropping systems, but only during 2015. In 2016, at mid altitude and high altitude, CT had less internodes per branch than $\mathrm{CO}$ and CB (Fig. 8.b).

\section{Total number of branches per stem}

In 2015, total number of branches per stem was similar across systems, except for CT at mid altitude where coffee trees had less branches at fruit initiation. In 2016, CB had more branches at low and mid altitude, while at high altitude, $\mathrm{CO}$ had higher number of branches (Fig. 8.c).

\section{Total number of leaves per stem}

In 2015, leaf set per stem was $508 \pm 467$ at fruit initiation and at harvest $874 \pm 735$. We did not find any significant differences between cropping systems when altitude classes were pooled together, neither when analyzed by altitude class. In 2016, CT had less leaves per stem at mid, high altitude and when pooling all altitude classes together. On the other hand, at low altitude, CT had less leaves at fruit initiation than $\mathrm{CO}$ and $\mathrm{CB}$, but at harvest $\mathrm{CO}$ had the smallest leaf set per stem (Fig. 8.d).

\section{Total number of internodes per stem}

Mean number of internodes constantly increased along the study. In 2015, all systems had similar number of internodes per stem. While the following year, CT system had less internodes per stem at low and mid altitude at fruit initiation and at high altitude at harvest. When pooling all data together, CT had a smaller number of internodes per stem than CO and CB (Fig. 8.e) 


\section{a)}

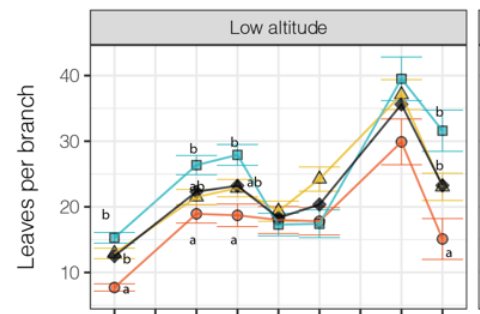

b)

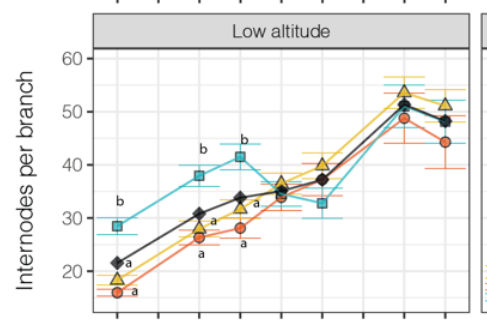

c)

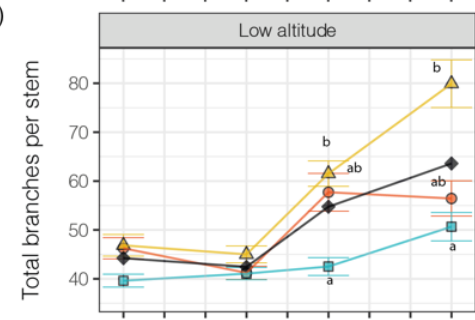

d)
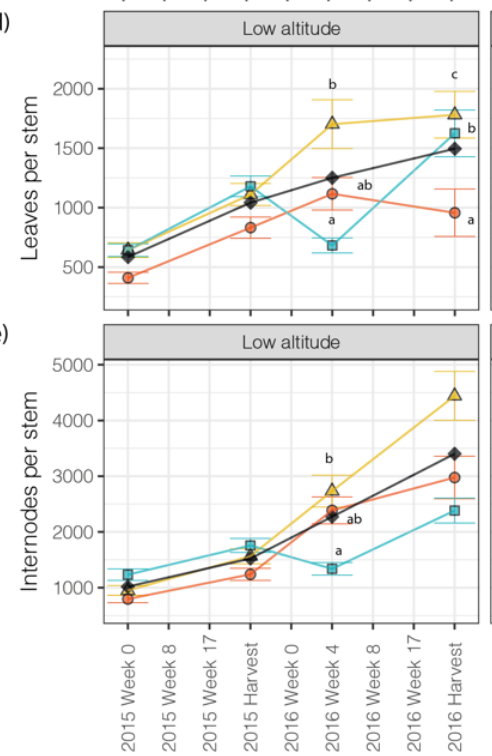

- $\mathrm{CO}-\mathrm{CB}-\mathrm{CT}-\mathrm{All}$
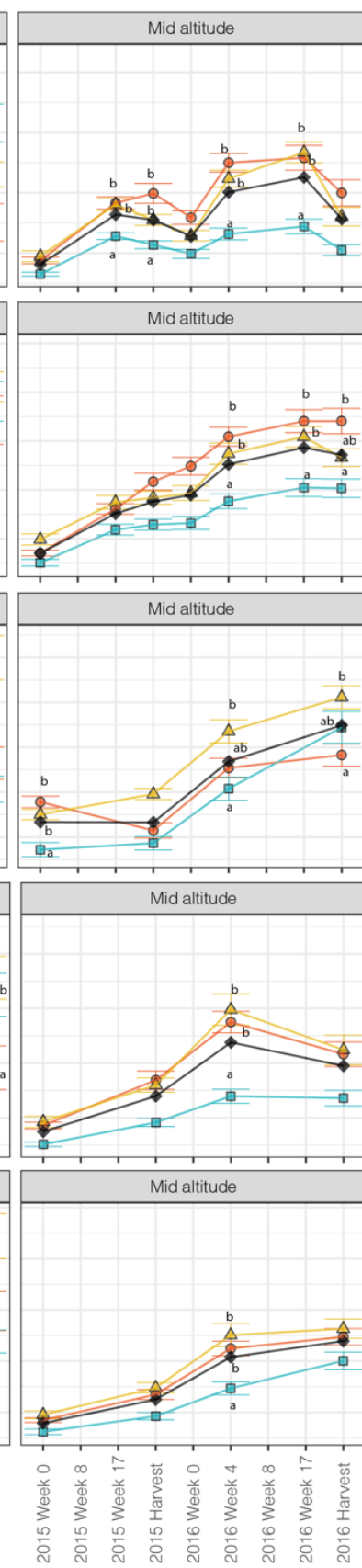

$\mathrm{CO} \triangle \mathrm{CB}$ 口 $\mathrm{CT} \bullet \mathrm{All}$
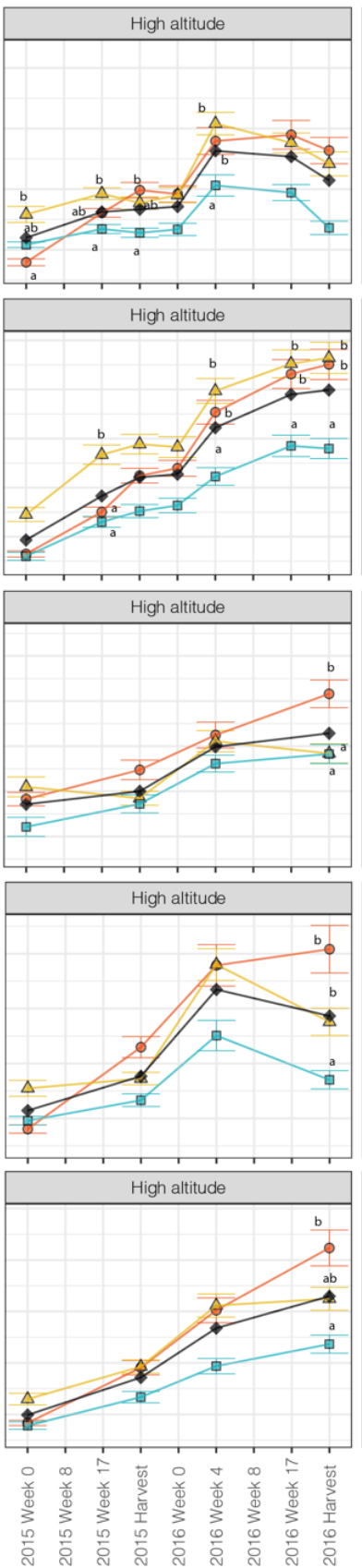

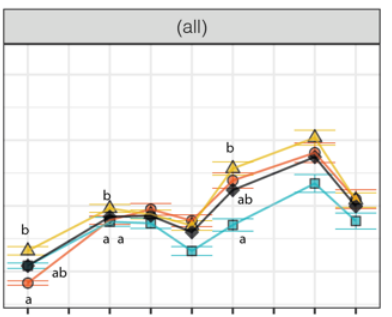

(all)
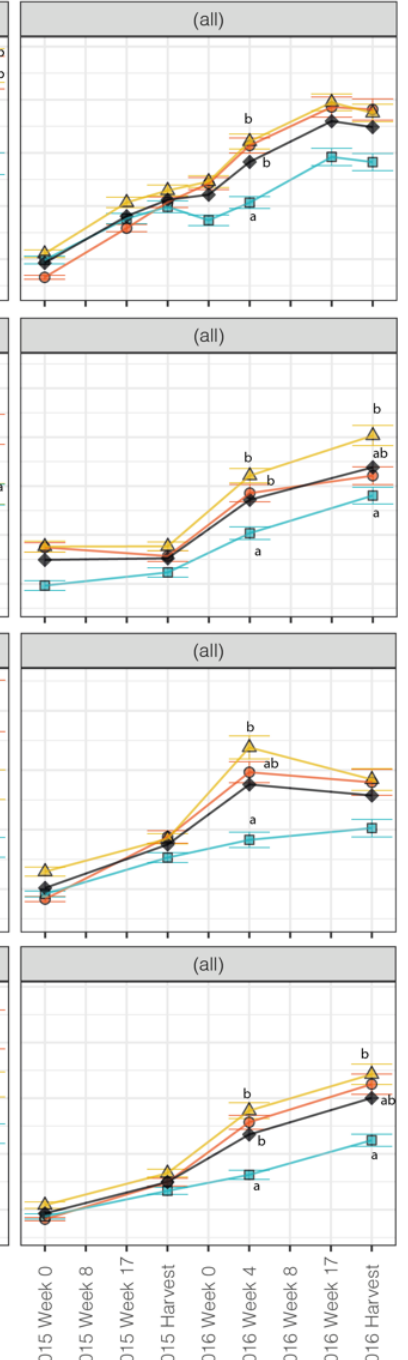

Fig. 8. (a) Leaf set per branch, (b) internodes per branch, (c) total branches per stem, (d) leaf set per stem and e) internodes per stem. Colour indicates coffee cropping system (Coffee-Open = CO (Red), Coffee - Banana = CB (Yellow), Coffee- shade tree $=\mathrm{CT}$ (Blue) and all systems = All (Grey) in three altitude classes altitude classes (Low altitude (1100 - 1400 m.a.s.l.), mid altitude (1400 - 1700 m.a.s.I.) and high altitude (1700 - 2100 m.a.s.I) during the study period (from April 2015 to December 2016$)$. Letters indicate significant differences across systems in the specified point in time ( $p$-value $<0.05$, generalized mixed models). Absence of letters indicate no significant differences. 


\subsubsection{Piecewise Structural Equation Model (SEM)}

According to the piecewise SEM , altitude had a direct and positive effect on total number of internodes at harvest in 2015 (Int 2015 Harvest) (Table 4 and Fig. 9.a) but a negative effect on total number of leaves also at harvest in 2015 (LS 2015 Harvest) (Table 4 and Fig. 9.b). Altitude had no significant effect on the other variables or was excluded by the piecewise SEM (Table 4). On the other hand, shade reduced fruit drop in the first year (2015) (FD 2015) (Table 4 and Fig. 9.c), while in the second year (2016) fruit set at fruit initiation (FS 2016 Week 0 ) and at harvest (FS 2016 Harvest) was negatively affected by shade (Table 4 and Fig. 9.d and Fig. 9.e). For the other variables the path model indicated non-significant effect of shade or shade was excluded from the model (Table 4). Finally, the path model indicated a negative interactive effect of altitude and shade on total number of leaves at harvest for both years ( LS $_{2015}$ Week 17) and LS 2016 Week 17) (Table 4, Fig. 9.f and Fig. 9.g).

Table 4: Summarized results from piecewiseSEM (Model 2). Effect of shade cover and altitude on coffee reproductive and vegetative growth in 2015 and 2016 (Alt $=$ Altitude (m.a.s.l.), Shade $=$ Sahde cover $\left(\mathrm{m}^{2} \mathrm{~m}^{-2}\right)$, Int $=$ Internodes per stem, $\mathrm{LS}=$ leaf set per stem, FS = fruit set per stem and FD = fruit drop).

\begin{tabular}{|c|c|c|c|c|c|c|c|c|c|c|c|c|c|c|c|c|c|}
\hline & & & & & & & 2015 & & & & & & & 016 & & & \\
\hline & Alt & Shade & $\begin{array}{c}\text { Alt X } \\
\text { Shade }\end{array}$ & \begin{tabular}{|c} 
Int \\
Week 0
\end{tabular} & $\begin{array}{c}\mathrm{LS} \\
\text { Week }\end{array}$ & $\begin{array}{c}\text { FS } \\
\text { Week } 0\end{array}$ & FD & Int & LS & $\begin{array}{c}\text { FS } \\
\text { Harvest }\end{array}$ & $\begin{array}{c}\text { Int } \\
\text { Week }\end{array}$ & $\begin{array}{c}\text { LS } \\
\text { week } 0\end{array}$ & $\begin{array}{c}\text { FS } \\
\text { Week } 0\end{array}$ & FD & $\begin{array}{c}\text { Int } \\
\text { Harvest }\end{array}$ & LS & $\begin{array}{c}\text { FS } \\
\text { Harvest }\end{array}$ \\
\hline $\begin{array}{l}\text { Alt } \\
\text { Shade }\end{array}$ & & & & & & & & & & & & & & & & & \\
\hline 2015 & & & & & & & & & & & & & & & & & \\
\hline $\begin{array}{l}\text { Int } \\
\text { Week } 0\end{array}$ & n.s. & n.s. & n.s. & & & & & & & & & & & & & & \\
\hline $\begin{array}{l}\text { LS } \\
\text { Week } 0\end{array}$ & n.s. & // & // & $\begin{array}{l}0.63 \\
* * *\end{array}$ & & & & & & & & & & & & & \\
\hline $\begin{array}{l}\text { FS } \\
\text { Week o }\end{array}$ & $/ /$ & n.s. & // & $\begin{array}{l}0.27 \\
* * *\end{array}$ & $\begin{array}{l}0.33 \\
* * *\end{array}$ & & & & & & & & & & & & \\
\hline FD & // & $\begin{array}{c}-0.22 \\
* *\end{array}$ & // & $\begin{array}{c}0.22 \\
* *\end{array}$ & $\begin{array}{c}-0.11 \\
*\end{array}$ & $\begin{array}{c}0.16 \\
* *\end{array}$ & & & & & & & & & & & \\
\hline $\begin{array}{l}\text { Int } \\
\text { Harvest }\end{array}$ & $\begin{array}{c}0.16 \\
*\end{array}$ & // & /I & $\begin{array}{l}(+) \\
* * *\end{array}$ & $\begin{array}{l}0.52 \\
* * *\end{array}$ & $\begin{array}{l}0.13 \\
* * *\end{array}$ & n.s. & & & & & & & & & & \\
\hline $\begin{array}{l}\text { LS } \\
\text { Harvest }\end{array}$ & $\begin{array}{c}- \\
0.20 \\
* *\end{array}$ & n.s. & $\begin{array}{c}0.16 \\
*\end{array}$ & \begin{tabular}{|c}
-0.32 \\
$* * *$
\end{tabular} & $\begin{array}{l}(+) \\
* * *\end{array}$ & n.s. & // & $\begin{array}{l}0.79 \\
* * *\end{array}$ & & & & & & & & & \\
\hline $\begin{array}{l}\text { FS } \\
\text { Harvest }\end{array}$ & // & // & // & \begin{tabular}{|c}
-0.37 \\
$* * *$
\end{tabular} & $\begin{array}{c}0.34 \\
* * *\end{array}$ & $\begin{array}{l}(+) \\
* * *\end{array}$ & $\begin{array}{l}(-) \\
* * *\end{array}$ & $\begin{array}{l}0.40 \\
* * *\end{array}$ & $\begin{array}{c}0.10 \\
*\end{array}$ & & & & & & & & \\
\hline 2016 & & & & & & & & & & & & & & & & & \\
\hline $\begin{array}{l}\text { Int } \\
\text { Week } 0\end{array}$ & n.s. & // & // & $\begin{array}{l}+(+) \\
* * *\end{array}$ & $\begin{array}{l}0.55 \\
* * *\end{array}$ & n.s. & $\begin{array}{c}0.09 \\
* *\end{array}$ & $\begin{array}{l}(+) \\
* * *\end{array}$ & // & // & & & & & & & \\
\hline $\begin{array}{l}\text { LS } \\
\text { Week } 0\end{array}$ & // & n.s. & // & \begin{tabular}{|l}
-0.46 \\
$* * *$
\end{tabular} & $\begin{array}{l}(+) \\
* * *\end{array}$ & $\begin{array}{l}0.17 \\
* * *\end{array}$ & // & // & $\begin{array}{l}(+) \\
* * *\end{array}$ & // & \begin{tabular}{|l}
0.83 \\
$* * *$
\end{tabular} & & & & & & \\
\hline $\begin{array}{l}\text { FS } \\
\text { Week } 0\end{array}$ & $/ /$ & $\begin{array}{c}-0.15 \\
* *\end{array}$ & // & $\begin{array}{c}0.19 \\
* *\end{array}$ & $\begin{array}{c}-0.26 \\
* * *\end{array}$ & n.s. & // & $\begin{array}{c}-0.49 \\
* * *\end{array}$ & $\begin{array}{l}0.61 \\
* * *\end{array}$ & // & $\begin{array}{l}0.35 \\
* * *\end{array}$ & $\begin{array}{l}0.20 \\
* * *\end{array}$ & & & & & \\
\hline FD & n.s. & // & // & \begin{tabular}{|c|}
-0.23 \\
$* *$
\end{tabular} & n.s. & $\begin{array}{c}-0.16 \\
*\end{array}$ & $\begin{array}{l}0.69 \\
* * *\end{array}$ & $\begin{array}{l}0.20 \\
* * *\end{array}$ & $\begin{array}{c}-0.20 \\
*\end{array}$ & $\begin{array}{l}0.26 \\
* * *\end{array}$ & // & n.s. & $\begin{array}{l}0.23 \\
* * *\end{array}$ & & & & \\
\hline
\end{tabular}




\begin{tabular}{|c|c|c|c|c|c|c|c|c|c|c|c|c|c|c|c|c|}
\hline $\begin{array}{l}\text { Int } \\
\text { Harvest }\end{array}$ & $/ /$ & // & $/ /$ & $\begin{array}{l}(+) \\
* * *\end{array}$ & $\begin{array}{l}0.39 \\
* * *\end{array}$ & n.s. & // & $\begin{array}{l}(+) \\
* * *\end{array}$ & n.s. & n.s. & $\begin{array}{c}(+) \\
* * *\end{array}$ & $0.11^{* *}$ & $\begin{array}{c}0.10 \\
* *\end{array}$ & // & & \\
\hline $\begin{array}{l}\text { LS } \\
\text { Harvest }\end{array}$ & n.s. & n.s. & $\begin{array}{c}-0.25 \\
*\end{array}$ & $\begin{array}{c}-0.16 \\
* *\end{array}$ & $\begin{array}{l}(+) \\
* * *\end{array}$ & // & n.s. & $/ /$ & $\begin{array}{l}(+) \\
* * *\end{array}$ & $\begin{array}{l}0.26 \\
* * *\end{array}$ & n.s. & $(+) * *$ & $\begin{array}{c}0.09 \\
*\end{array}$ & $\begin{array}{l}0.14 \\
* * *\end{array}$ & $\begin{array}{c}0.52 \\
* *\end{array}$ & \\
\hline $\begin{array}{l}\text { FS } \\
\text { Harvest }\end{array}$ & $/ /$ & $\begin{array}{c}-0.18 \\
*\end{array}$ & // & $/ /$ & $/ /$ & $/ /$ & $\begin{array}{c}-0.10 \\
*\end{array}$ & $\begin{array}{c}-0.26 \\
* *\end{array}$ & $\begin{array}{l}0.34 \\
* * *\end{array}$ & $\begin{array}{c}-0.10 \\
*\end{array}$ & $\begin{array}{c}0.21 \\
* *\end{array}$ & // & $(+) *$ & $\begin{array}{l}(-) \\
* * *\end{array}$ & $/ /$ & 0.1 * \\
\hline
\end{tabular}

Sig

// Excluded by the path model

n.s. Non- significant ( $p$-value $>0.05$ )

Values in grey indicate obvious relationships between variables

In general, total number of leaves had a positive effect on both vegetative growth (total number of internodes) and fruit set and a negative effect on fruit drop (Table 4). This pattern was consistent for both years (2015 and 2016). More intricate is the effect of total number of internodes, since it varied depending on the point of the fruit development cycle. A higher total number of internodes corresponded with higher fruit initiation in 2015 and larger number of leaves (Table 4). The opposite trend occurred at harvest, were initial large number of internodes had a negative effect on fruit set (FS 2015 Harvest) and leaf set (LS 2015 Harvest) (Table 4). Nevertheless, more internodes at harvest (Int 2015 Harvest) corresponded with higher fruit set (FS 2015 Harvest) and leaf set (LS 2015 Harvest) (Table 4). Similarly, total number of internodes at harvest in 2015 had a negative effect on initial fruit set (FS 2016 week o) and at harvest (FS 2016 Harvest) in 2016. While a larger number of internodes at fruit initiation in 2016 corresponded with larger fruit initiation (FS 2016 Week o) and fruit set at harvest (FS 2016 Harvest) (Table 4). 
a)

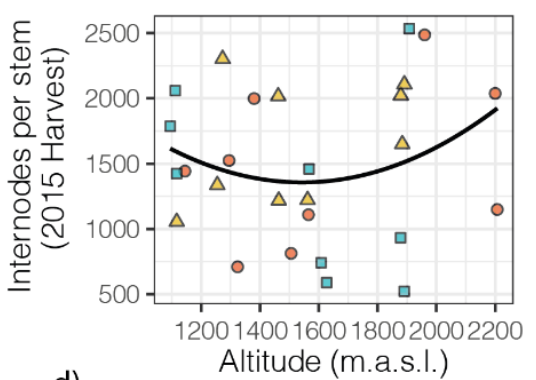

d)

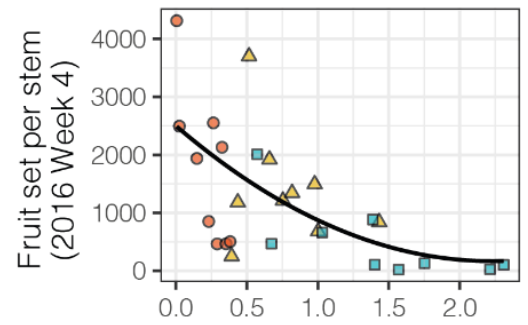

$\mathrm{LAl}$ of the shade cover $\left(\mathrm{m} \mathrm{m}^{-1}\right.$

g)

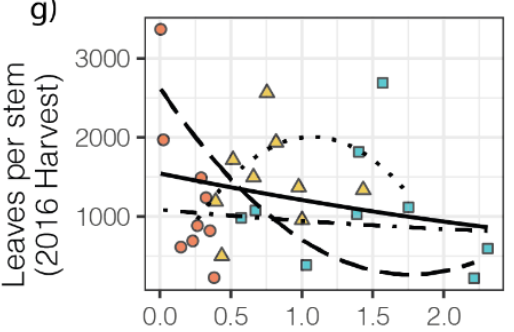

LAI of the shade cover $\left(\mathrm{m} \mathrm{m}^{-1}\right.$ b)

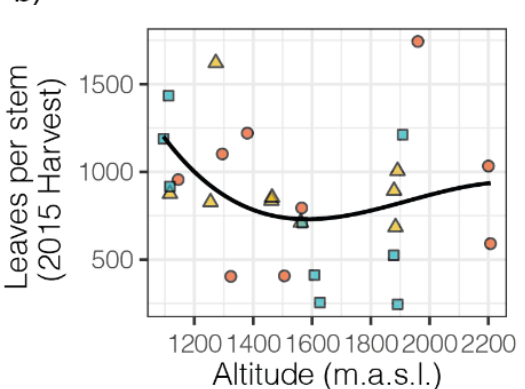

e)

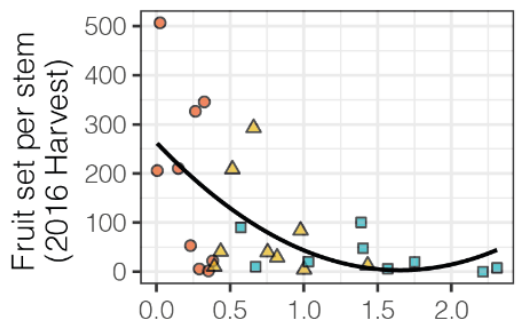

$\mathrm{LAl}$ of the shade cover $\left(\mathrm{m} \mathrm{m}^{-1}\right)$ c)

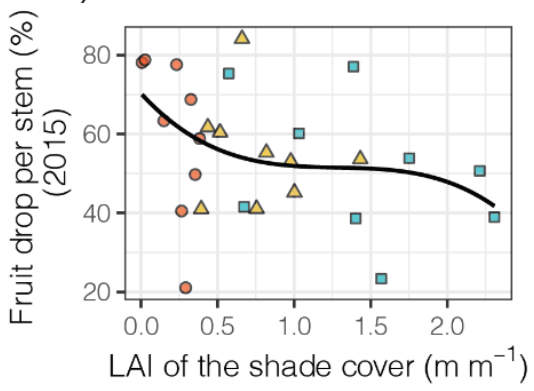

f)

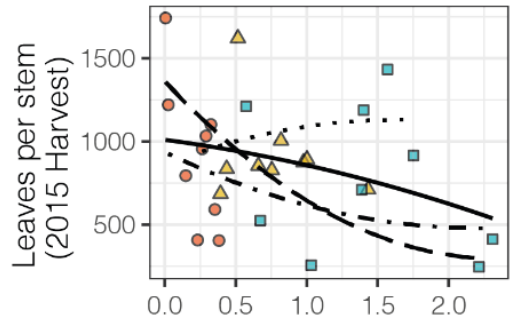

$\mathrm{LAl}$ of the shade cover $\left(\mathrm{m} \mathrm{m}^{-1}\right.$

Fig. 9. a) Internodes per stem 2015 Harvest vs altitude (m.a.s.l.), b) leaf set per stem 2015 Harvest vs altitude (m.a.s.l.), c) fruit drop per stem 2015 vs shade cover $\left(\mathrm{m}^{2} \mathrm{~m}^{-2}\right)$, d) fruit set per stem 2016 Week 4 vs shade cover $\left(\mathrm{m}^{2} \mathrm{~m}^{-2}\right)$, e) fruit set per stem 2016 Harvest vs shade cover $\left(m^{2} m^{-2}\right)$, f) leaf set per stem 2015 Harvest vs shade cover $\left(m^{2} m^{-2}\right)$ and g) leaf set per stem 2016 Harvest vs shade cover $\left(m^{2} m^{-2}\right)$. Colour indicates coffee cropping system (Coffee-Open = CO (Red), Coffee - Banana = CB (Yellow), Coffee- shade tree = CT (Blue) and all systems = All (Grey) in three altitude classes altitude classes (Low altitude (1100 - 1400 m.a.s.l.), mid altitude (1400 1700 m.a.s.l.) and high altitude (1700 - 2100 m.a.s.l) during the study period (from April 2015 to December 2016).

Higher fruit set at fruit initiation in 2015 lead to larger fruit drop in the same year (FD 2015) but had a negative effect on fruit drop the following year (FD 2016). On the other hand, larger fruit set at harvest stimulated larger fruit drop the following year, resulting in less fruit set at harvest in 2016, but more leaves. Initial fruit set in 2016 was also related to larger fruit drop (FD 2016), larger number of internodes and number of leaves at harvest (Table 4). Finally, fruit drop in 2016 (FD 2016) had a negative effect on the following total number of leaves and internodes (Table 4) (The complete piecewise SEM can be found in supplementary materials in Table S2.). 


\subsection{Discussion}

Microclimatic differences across coffee cropping systems were noticeable regarding mean temperature (mean Temp), maximum temperature (max Temp) and temperature amplitude ( $\Delta$ Temp). A more extreme microclimate occurred in low shaded systems along the altitudinal gradient. Finally, differences in soil water content (SWC) across coffee cropping systems varied depending on altitude and, contrary to our expectations, SWC decreased with altitude, probably due to different soil characteristics along the altitudinal gradient.

Shade (represented by type of cropping system and shade cover) had an effect on fruit set only during the second year and at low and mid altitude, with CT systems presenting smaller fruit set per stem. On the contrary, differences in vegetative growth across systems were pronounced during the first year, when coffee in $\mathrm{CT}$ systems tend to have more leaves and internodes at low altitude. Whereas the opposite occurred at mid and high altitude. Fruit drop did not differ across systems, except for the low altitude in 2016, and it was directly correlated with initial fruit set. Finally, fruit set in 2016 was lower than in 2015 irrespective of cropping system.

In general, larger leaf set had a positive effect on vegetative and reproductive growth along the fruit development process in both years. More internodes are positively related with larger fruit set in each specific point of the fruit development process. However, previous larger number of internodes have a negative effect on following fruit set. On other hand, the piecewieseSEM did not show a negative significant effect of fruit set on following internode development. Further details are discussed below.

\subsubsection{Microclimate and soil water content}

Shaded systems buffered coffee from extreme microclimate conditions in comparison to open systems and reduced soil evaporation. These findings agree with Sarmiento-Soler et al. (2019) for the same area and microclimate studies from other coffee regions (Campanha et al., 2004; Lin, 2007; Partelli et al., 2014; Oliosi et al., 2016; Rigal et al., 2020). Despite the microclimate buffering effect provided by shaded systems, maximum temperatures still surpassed recommend thresholds for coffee cultivation (Maximum temperature: unsuitable $>32^{\circ} \mathrm{C}$ (Nunes et al., 1968; Descroix \& Snoeck, 2008), suboptimal: (Descroix \& Snoeck, 2008), optimal: 25-26 (Descroix \& Snoeck, 2008)).

However, despite the high temperatures, we could not observe any detrimental effects of high temperature on initial fruit set, as expected following Drinnan and Menzel. (1995). Our results concur with field observations of other coffee regions, in which coffee trees maintain their production despite 
high temperatures whenever rainfall and hence water supply are sufficient (Verhage et al., 2017). This was certainly the case during the period from January 2015 and April 2016, as reported by SarmientoSoler et al. (2019). Thus, these findings support the statement of DaMatta et al. (2018b) that coffee tree could endure temperature rise better than previously projected and encourage to focus on the importance of sufficient water supply to ensure coffee yields during current and future climate change scenarios. The importance of sufficient water supply has also been addressed by Rahn et al. (2018b) and Verhage et al. (2017), who predicted through a modelling exercise that $\mathrm{CO}_{2}$ fertilization effect can offset negative impacts of heat given water supply is not limiting.

It is interesting to notice that soil water content was unexpectedly lower at high altitude compared to low and mid altitudes, despite higher rainfall. One reason for this could be differences in soil characteristics, as demonstrated by De Bauw et al. (2016), which might have not been sensitive to the soil water content measurement method we used (Sentek Device with default equation). Another explanation could be that despite VPD reduces with altitude, VPD values were high enough to stimulate transpiration, but not high enough to trigger stomata closure as a water protection mechanism. Thus, a constant transpiration at this altitude class in addition to higher exposure to winds could also be a reason behind lower soil water content found at high altitude, although more data would be necessary to test this hypothesis.

\subsubsection{Fruit development process}

The use of piecewise SEM analysis allowed to confirm certain relationships between fruit set, fruit drop and environmental variables addressed in previous studies (Franck et al., 2005; Bote \& Vos, 2016; Cerda et al., 2017). It also allowed us to disentangle the effects of environmental conditions on coffee growth vegetative and reproductive in a specific year, from the effects of coffee growth (vegetative and reproductive) of one year on coffee growth during the following year.

Based on our hypothesis, we expected that shade reduced directly fruit initiation, by reducing radiation and temperature (Cannell, 1985; Franck et al., 2005; Franck \& Vaast, 2009; Rigal et al., 2020). This was confirmed by our study, however not consistently across years. Our results indicated different responses of fruit set and fruit drop to shade and cropping system depending on the year. In the first year (2015), shade cover or cropping system did not have any significant effect on fruit set. However, fruit drop reduced with shade cover as indicated by the piecewise SEM (Table 4 and Fig. 9.c). We attributed the effect of shade cover on fruit drop in 2015 as a result of the microclimate buffering effect, higher leaf set in shaded systems, especially at low altitude and a slightly lower initial fruit set. Thus, our results 
highlight the importance of maintaining a adequate leaf area/fruit ratio with an estimated optimal range around $15-20 \mathrm{~cm}^{2}$ of leaf per fruit (Vaast et al., 2006).

In the second year (2016), fruit set was significantly reduced by shade cover, which was also visible in the differences in fruit set across cropping systems, in particular at low and mid altitude (Fig. 6.a., Fig. 9.d and Fig. 9.e). Moreover, fruit drop remained similar across cropping systems and along the shade cover gradient. Therefore, a lower fruit initiation in shaded systems was not compensated by a smaller fruit drop rate, contradicting our fruit drop-shade hypothesis. Yet, fruit drop was positively correlated with initial fruit set as confirmed by the piesewiese SEM, which was also reported by Bote and Vos (2016) in their fruit thinning experiment in Ethiopia and by others (Vaast et al., 2005; Vaast et al., 2006).

Additionally, we did not find a consistent pattern in fruit drop phases. While in the first year, most of the fruit drop (30\% of $50 \%$ ) occurred within the first 8 weeks and was therefore related to fecundation failure according to DaMatta et al. (2007). In the second year, most of the fruit drop occurred during the last weeks, which points towards high competition between fruits, which is also indicated by the piesewiese SEM through the highest estimate and significance level (Table 4). The fact that during the second year, fruit drop per branch and per stem was stronger than in the first year, despite higher leaf set in the second year and smaller initial fruit sets, suggest that fruit drop cannot only be attributed to fruit/leaf ratios, but also other mechanisms take place which require further investigation.

We also did not find a clear altitudinal pattern, when focusing exclusively on altitude. This contradicts our hypothesis of a positive altitudinal effect on coffee reproductive and vegetative growth due to better growing conditions with increasing altitude. However, altitude interacted with shade and had a negative effect on vegetative growth, as, evidenced by the piecewise SEM (Table 4, Fig. 9.f and Fig. 9.g). We observed, that shade had a positive effect on leaf set at low altitude, probably as a result of reduced radiation and VPD (reducing heat and drought stress). But with increasing altitude (mid and high altitude), CT systems had a lower number of internodes and consequently less leaves, probably due to the combined effect of lower temperatures from altitude increases, and the buffering effect from the shade. This agrees with the observations of Drinnan and Menzel. (1995), that vegetative growth is related to temperature, and that at highest temperature more growth occurs both in elongation and in number of nodes. 
Nevertheless, despite a decrease of vegetative growth as a result of the interaction of altitude and shade, this did not affect fruit set at high altitude, which was comparable across cropping systems for the two years of the study (Fig. 6.a.). We also did not observe a negative effect of fruit set on leaf set, as it was expected from the strong competition between reproductive and vegetative growth reported by other authors (Vaast et al., 2005; Bote \& Vos, 2016; Charbonnier et al., 2017). Which reinforces the need to study further mechanisms controlling fruit drop, beyond fruit/leaf area ratios and competition (Vaast et al., 2005).

We observed contradictory effects of the number of internodes per stem with fruit set along the fruit development process. Number of internodes at fruit initiation was positively related with initial fruit set in the same year (i.e. FS 2015 Week o (+) Int 2015 Week o and FS 2015 Week o (+) Int 2015 Week o), merely more internodes, more places were flower buds can develop. However, number of internodes at harvest had a negative effect on initial fruit set of the following year (FS 2016 Week $0 ~(+)$ Int 2015 Harvest), which was contrary to our expectation, that a higher vegetative growth in 2015, would lead to higher fruit set in the following year (Vaast et al., 2005). Hence, this suggests that shoot growth allows the development of more flowers (providing more nodes where flowers can develop), but also on the other side competes with flower development. Thus, as suggested by (Bote \& Vos, 2016) biennial patterns could not only be explained by reduced number of potential flowering nodes, but also by less or no flower formation on those nodes. This would need further studies and a closer monitoring of hormonal growth control.

Finally, number of leaves demonstrated to be the most important variable determining fruit set, further vegetative growth and reducing fruit drop. This is rational since carbon assimilation in coffee trees occurs mostly on the leaves, although it has been demonstrated that green coffee fruits perform photosynthesis (Vaast et al., 2005). Initial leaf set in 2015 (LS 2015 Week 0$)$ was one of the most determinant variables for fruit set and growth in 2015 and 2016, which could be explained by the fact that mature leaves are more resistant to heat and other stress (Marias et al., 2017), thus reducing leaf senescence and ensuring carbon assimilation through the fruit development process.

The relevance of leaf set in determining yields has also been demonstrated by Cerda et al. (2017), who pointed out that defoliation due to pest incidence, was one of the main determinants for yield losses, in particular during the second year. DaMatta et al. (2007) also pointed out that leaf maintenance is associated with improved vegetative growth. Hence, our study highlights the importance to maintain leaf area in coffee trees and reduce early leaf senescence. 


\subsubsection{Caveats of the study}

Firstly, our data presented a high standard deviation, high differences in reproductive and vegetative growth between trees belonging to the same plots. This made it difficult to clearly distinguish cropping systems effects. However, high variability is typical for small holder systems and should be also addressed as a strategy to improve yields, e.g. to bring all coffee trees in a plot to similar growth levels. Secondly, our study covered only two years of coffee fruit development. Three or more years would have been ideal to confirm biennial patterns and to better address and disentangle environmental effects from growth effects on those biennial patterns. Finally, the soil water content probe was used (Sentek deviner) with the default equation which allowed to explicitly compare soil water content across similar soil profiles. However, when soil properties change (as was the case due to the altitudinal gradient), those comparisons turn difficult and less accurate. Hence, for further studies, soil type of each profile should be determined to derive the appropriate equation to allow more confident comparisons.

\subsection{Conclusion}

This study remarks the importance of maintaining a shade cover in coffee cropping systems to buffer coffee cultivated underneath from microclimate extremes. However, shade cover has to be managed, to allow for optimal vegetative growth and leaf area maintenance, without hampering fruit set. Moreover, leaf set proved to be a crucial variable to maintain vegetative and reproductive growth throughout several seasons. Further studies are needed to explain high fruit drop causes beyond unbalanced fruit/leaf area ratios. Intermediated shade cover (LAI $1 \mathrm{~m}^{2} \mathrm{~m}^{-2}$ ), as occurred in coffee intercropped with bananas showed an optimal balance between microclimate regulations, fruit set and fruit drop, a part of provide an important staple food and an extra source of income. 


\section{Acknowledgements}

The authors are thankful for the financial support of the German Ministry for Economic Cooperation and Development (BMZ) through GIZ (under prime agreement no. 12.1433.7-001.00). This work was implemented as part of the CGIAR Research Programs on Climate Change, Agriculture and Food Security (CCAFS) and Forest, Trees and Agroforestry (FTA) which are carried out with support from CGIAR Fund Donors and through bilateral funding agreements. The views expressed in this document cannot be taken to reflect the official opinions of these organizations. We acknowledge the support by the team of the division Tropical Plant Production and Agricultural Systems Modelling (TROPAGS) at the University of Gottingen, Germany. As well, the support from the International Institute of Tropical Agriculture (IITA) Uganda is also fully acknowledged, especially from the plot team, Medad Tamari, David Mukasa and Franco Manget. Finally, we would like to dedicate special gratitude to all farmers for allowing us working on their farms, answering our questions and for supporting our work. 


\section{References}

Allen, R. G., Pereira, L. S., \& Smith, M. (1998). FAO Irrigation and Drainage Paper. Retrieved from Rome: http://www.fao.org/docrep/X0490E/X0490E00.htm

Baca, M., Laderach, P., Haggar, J., Schroth, G., \& Ovalle, O. (2014). An integrated framework for assessing vulnerability to climate change and developing adaptation strategies for coffee growing families in Mesoamerica. PLoS One, 9(2), e88463. doi:10.1371/journal.pone.0088463

Bartoń , K. (2019). MuMIn: Multi-Model Inference. Retrieved from https://CRAN.R-project.org/package=MuMIn

Bates, D., Maechler, M., Bolker, B., \& Walker, S. (2015). Fitting Linear Mixed-Effects Models Using Ime4. Journal of Statistical Software, 67(1), 1-48. doi:doi:10.18637/jss.v067.i01.

Bote, A. D., Ayalew, B., Ocho, F. L., Anten, N. P. R., \& Vos, J. (2018). Analysis of coffee ( Coffea arabica L.) performance in relation to radiation levels and rates of nitrogen supply I. Vegetative growth, production and distribution of biomass and radiation use efficiency. European Journal of Agronomy, 92, 115-122. doi:10.1016/j.eja.2017.10.007

Bote, A. D., \& Vos, J. (2016). Branch growth dynamics, photosynthesis, yield and bean size distribution in response to fruit load manipulation in coffee trees. Trees(30), 1275-1285. doi:10.1007/s00468-016-1365-x

Brooks, M. E., Kristensen, K., van Benthem, K. J., Magnusson, A., Berg, C. W., Nielsen, A., Skaug, H. J., Maechler, M., \& Bolker, B. M. (2017). glmmTMB Balances Speed and Flexibility Among Packages for Zero-inflated Generalized Linear Mixed Modeling. The $R$

Journal, 9(2), 378-400.

Bunn, C., Läderach, P., Ovalle Rivera, O., \& Kirschke, D. (2014). A bitter cup: climate change profile of global production of Arabica and Robusta coffee. Climatic Change, 129(1-2), 89-101. doi:10.1007/s10584-014-1306-x

Campanha, M. M., Silva Santos, R. H., De Freitas, G. B., Prieto Martinez, H. E., Ribeiro Garcia, S. L., \& Finger, F. L. (2004). Growth and yield of coffee plants in agroforestry and monoculture systems in Minas Gerais, Brazil. Agroforestry Systems, 63, 75-82.

Cannavo, P., Sansoulet, J., Harmand, J. M., Siles, P., Dreyer, E., \& Vaast, P. (2011). Agroforestry associating coffee and Inga densiflora results in complementarity for water uptake and decreases deep drainage in Costa Rica. Agriculture, Ecosystems \& Environment, 140(1-2), 1-13. doi:10.1016/j.agee.2010.11.005

Cannell, M. G. R. (1985). Physiology of the Coffee Crop. In M. N. Clifford \& K. C. Willson (Eds.), Coffee: Botany, Biochemistry and Production of Beans and Beverage (pp. 108-134). Boston, MA: Springer US.

Cerda, R., Avelino, J., Gary, C., Tixier, P., Lechevallier, E., \& Allinne, C. (2017). Primary and Secondary Yield Losses Caused by Pests and Diseases: Assessment and Modeling in Coffee. PLoS One, 12(1), e0169133. doi:10.1371/journal.pone.0169133

Charbonnier, F., Roupsard, O., le Maire, G., Guillemot, J., Casanoves, F., Lacointe, A., Vaast, P., Allinne, C., Audebert, L., Cambou, A., Clement-Vidal, A., Defrenet, E., Duursma, R. A., Jarri, L., Jourdan, C., Khac, E., Leandro, P., Medlyn, B. E., Saint-Andre, L., Thaler, P., Van Den Meersche, K., Barquero Aguilar, A., Lehner, P., \& Dreyer, E. (2017). Increased light-use efficiency sustains net primary productivity of shaded coffee plants in agroforestry system. Plant Cell Environ, 40(8), 1592-1608. doi:10.1111/pce.12964

Craparo, A. C. W., Van Asten, P. J. A., Läderach, P., Jassogne, L. T. P., \& Grab, S. W. (2015). Coffea arabica yields decline in Tanzania due to climate change: Global implications. Agricultural and Forest Meteorology, 207, 1-10. doi:10.1016/j.agrformet.2015.03.005

DaMatta, F. M. (2004). Ecophysiological constraints on the production of shaded and unshaded coffee: a review. Field Crops Research, 86(2-3), 99-114. doi:10.1016/j.fcr.2003.09.001

DaMatta, F. M., Avila, R. T., Cardoso, A. A., Martins, S. C. V., \& Ramalho, J. C. (2018a). Physiological and Agronomic Performance of the Coffee Crop in the Context of Climate Change and Global Warming: A Review. J Agric Food Chem, 66(21), 5264-5274. doi:10.1021/acs.jafc.7b04537

DaMatta, F. M., Rahn, E., Läderach, P., Ghini, R., \& Ramalho, J. C. (2018b). Why could the coffee crop endure climate change and global warming to a greater extent than previously estimated? Climatic Change, 152(1), 167-178. doi:10.1007/s10584-018-2346-4

DaMatta, F. M., Ronchie, C. P., Maestri, M., \& Barros, R. S. (2007). Ecophysiology of coffee growth and production. Brazilian Journal of Plant Physiology, 19(4), 485-510.

De Bauw, P., Van Asten, P., Jassogne, L., \& Merckx, R. (2016). Soil fertility gradients and production constraints for coffee and banana on volcanic mountain slopes in the East African Rift: A case study of Mt. Elgon. Agriculture, Ecosystems \& Environment, 231, 166-175. doi:10.1016/j.agee.2016.06.036

Defrenet, E., Roupsard, O., Van den Meersche, K., Charbonnier, F., Pastor Perez-Molina, J., Khac, E., Prieto, I., Stokes, A., Roumet, C., Rapidel, B., de Melo Virginio Filho, E., Vargas, V. J., Robelo, D., Barquero, A., \& Jourdan, C. (2016). Root biomass, turnover and net primary productivity of a coffee agroforestry system in Costa Rica: effects of soil depth, shade trees, distance to row and coffee age. Ann Bot, 118(4), 833-851. doi:10.1093/aob/mcw153

Descroix, F., \& Snoeck, J. (2008). Environmental Factors Suitable for Coffee Cultivation. In Coffee: Growing, Processing, Sustainable Production (pp. 164-177).

Drinnan, J. E., \& Menzel., C. M. (1995). Temperature affects vegetative growth and flowering of coffee (Coffea arabica L.). Journal of Horticultural Science, 70(1), 25-34. 
Fick, S. E., \& Hijmans, R. J. (2017). WorldClim 2: new 1-km spatial resolution climate surfaces for global land areas. International Journal of Climatology, 37(12), 4302-4315. doi:10.1002/joc.5086

Fox, J., \& Wiesberg, S. (2019). An R Companion to Applied Regression. Retrieved from https://socialsciences.mcmaster.ca/jfox/Books/Companion/

Franck, N., \& Vaast, P. (2009). Limitation of coffee leaf photosynthesis by stomatal conductance and light availability under different shade levels. Trees, 23(4), 761-769. doi:10.1007/s00468-009-0318-z

Franck, N., Vaast, P., \& Dauzat, J. (2005). Coffee a shade-adapted plant: implications on its carbon balance and consequences on coffee yield and quality in agroforestry systems. ASIC.

Hurlbert, S. H. (1984). Pseudoreplication and the Design of Ecological Field Experiments. Ecological Monographs, 54(2), 187211.

ITC. (2012). The Coffee Exporters's Guide. Retrieved from Geneva:

Kuznetsova , A., Brockhoff, P., \& Christensen, R. (2017). ImerTest Package: Tests in Linear Mixed Effects Models. Journal of Statistical

Software, 82(13), 1-26. doi:doi: 10.18637/jss.v082.i13 (URL: https://doi.org/10.18637/jss.v082.i13).

Lara Estrada, L., Rasche, L., \& Schneider, U. A. (2017). Modeling land suitability for Coffea arabica L. in Central America. Environmental Modelling \& Software, 95, 196-209. doi:10.1016/j.envsoft.2017.06.028

Lefcheck, J. S., \& Freckleton, R. (2016). piecewiseSEM: Piecewise structural equation modelling inr for ecology, evolution, and systematics. Methods in Ecology and Evolution, 7(5), 573-579. doi:10.1111/2041-210x.12512

Liebig, T., Jassogne, L., Rahn, E., Laderach, P., Poehling, H. M., Kucel, P., Van Asten, P., \& Avelino, J. (2016). Towards a Collaborative Research: A Case Study on Linking Science to Farmers' Perceptions and Knowledge on Arabica Coffee Pests and Diseases and Its Management. PLoS One, 11(8), e0159392. doi:10.1371/journal.pone.0159392

Lin, B. B. (2007). Agroforestry management as an adaptive strategy against potential microclimate extremes in coffee agriculture. Agricultural and Forest Meteorology, 144(1-2), 85-94. doi:10.1016/j.agrformet.2006.12.009

Littmann, T. (2008). Topoclimate and Microclimate. In S.-W. Breckle, A. Yair, \& M. Veste (Eds.), Arid Dune Ecosystems: The Nizzana Sands in the Negev Desert (pp. 175-182). Berlin, Heidelberg: Springer Berlin Heidelberg.

Marias, D. E., Meinzer, F. C., \& Still, C. (2017). Impacts of leaf age and heat stress duration on photosynthetic gas exchange and foliar nonstructural carbohydrates in Coffea arabica. Ecol Evol, 7(4), 1297-1310. doi:10.1002/ece3.2681

Martins, M. Q., Rodrigues, W. P., Fortunato, A. S., Leitao, A. E., Rodrigues, A. P., Pais, I. P., Martins, L. D., Silva, M. J., Reboredo, F. H., Partelli, F. L., Campostrini, E., Tomaz, M. A., Scotti-Campos, P., Ribeiro-Barros, A. I., Lidon, F. J., DaMatta, F. M., \& Ramalho, J. C. (2016). Protective Response Mechanisms to Heat Stress in Interaction with High [CO2] Conditions in Coffea spp. Front Plant Sci, 7, 947. doi:10.3389/fpls.2016.00947

Monteith, J. L., Ong, C. K., \& Corlett, J. E. (1991). Microclimatic interactions in agroforestry systems. Forest Ecology and Management, 45, 31-44.

Mordy, G. (2010). Adobe Illustrator CS5 : for web and interactive design: Ventura, CA : Lynda.com, [2010] @2010. Retrieved from https://search.library.wisc.edu/catalog/9910101663502121

Nunes, M. A., Bierhuizen, J. F., \& Ploegman, C. (1968). STUDIES ON PRODUCTIVITY OF COFFEE: I. EFFECT OF LIGHT, TEMPERATURE AND CO2 CONCENTRATION ON PHOTOSYNTHESIS OF COFFEA ARABICA. Acta Botanica Neerlandica, 17(2), 93-102. doi:10.1111/j.1438-8677.1968.tb00109.x

Oliosi, G., Giles, J. A. D., Rodrigues, W. P., Ramalho, J. C., \& Partelli, F. L. (2016). Microclimate and development of Coffea canephora cv. Conilon under different shading levels promoted by Australian cedar (Toona ciliata M. Roem. var. Australis). Australian Journal of Crop Science, 10(04), 528-538. doi:10.21475/ajcs.2016.10.04.p7295x

Ong, C. K., Corlett, J. E., Singh, R. P., \& Black, C. R. (1991). Abobe and below ground interactions on agroforestry systems. Forest Ecology and Management, 45, 45-57.

Ovalle-Rivera, O., Laderach, P., Bunn, C., Obersteiner, M., \& Schroth, G. (2015). Projected shifts in Coffea arabica suitability among major global producing regions due to climate change. PLoS One, 10(4), e0124155. doi:10.1371/journal.pone.0124155

Padovan, M. P., Brook, R. M., Barrios, M., Cruz-Castillo, J. B., Vilchez-Mendoza, S. J., Costa, A. N., \& Rapidel, B. (2018). Water loss by transpiration and soil evaporation in coffee shaded by Tabebuia rosea Bertol . and Simarouba glauca dc. compared to unshaded coffee in sub-optimal environmental conditions. Agricultural and Forest Meteorology, 248, 1-14. doi:10.1016/j.agrformet.2017.08.036

Padovan, M. P., Cortez, V. J., Navarrete, L. F., Navarrete, E. D., Deffner, A. C., Centeno, L. G., Munguía, R., Barrios, M., Vílchez-Mendoza, J. S., Vega-Jarquín, C., Costa, A. N., Brook, R. M., \& Rapidel, B. (2015). Root distribution and water use in coffee shaded with Tabebuia rosea Bertol. and Simarouba glauca DC. compared to full sun coffee in sub-optimal environmental conditions. Agroforestry Systems, 89(5), 857-868. doi:10.1007/s10457-015-9820-z

Partelli, F. L., Araújo, A. V., Vieira, H. D., Dias, J. R. M., Menezes, L. F. T. d., \& Ramalho, J. C. (2014). Microclimate and development of 'Conilon' coffee intercropped with rubber trees. Pesquisa Agropecuária Brasileira, 49(11), 872881. doi:10.1590/s0100-204×2014001100006

Rahn, E., Liebig, T., Ghazoul, J., van Asten, P., Läderach, P., Vaast, P., Sarmiento, A., Garcia, C., \& Jassogne, L. (2018a). Opportunities for sustainable intensification of coffee agro-ecosystems along an altitudinal gradient on Mt. Elgon, Uganda. Agriculture, Ecosystems \& Environment, 263, 31-40. doi:10.1016/j.agee.2018.04.019

Rahn, E., Vaast, P., Läderach, P., van Asten, P., Jassogne, L., \& Ghazoul, J. (2018b). Exploring adaptation strategies of coffee production to climate change using a process-based model. Ecological Modelling, 371, 76-89. doi:10.1016/j.ecolmodel.2018.01.009 
Rigal, C., Xu, J., Hu, G., Qiu, M., \& Vaast, P. (2020). Coffee production during the transition period from monoculture to agroforestry systems in near optimal growing conditions, in Yunnan Province. Agricultural Systems, 177. doi:10.1016/j.agsy.2019.102696

Rodrigues, W. P., Martins, M. Q., Fortunato, A. S., Rodrigues, A. P., Semedo, J. N., Simoes-Costa, M. C., Pais, I. P., Leitao, A. E., Colwell, F., Goulao, L., Maguas, C., Maia, R., Partelli, F. L., Campostrini, E., Scotti-Campos, P., Ribeiro-Barros, A. I., Lidon, F. C., DaMatta, F. M., \& Ramalho, J. C. (2016). Long-term elevated air [CO2 ] strengthens photosynthetic functioning and mitigates the impact of supra-optimal temperatures in tropical Coffea arabica and C. canephora species. Glob Chang Biol, 22(1), 415-431. doi:10.1111/gcb.13088

Sarmiento-Soler, A., Vaast, P., Hoffmann, M. P., Jassogne, L., van Asten, P., Graefe, S., \& Rötter, R. P. (2020). Effect of cropping system, shade cover and altitudinal gradient on coffee yield components at Mt. Elgon, Uganda. Agriculture, Ecosystems \& Environment, 295. doi:10.1016/j.agee.2020.106887

Sarmiento-Soler, A., Vaast, P., Hoffmann, M. P., Rötter, R. P., Jassogne, L., van Asten, P. J. A., \& Graefe, S. (2019). Water use of Coffea arabica in open versus shaded systems under smallholder's farm conditions in Eastern Uganda. Agricultural and Forest Meteorology, 266-267, 231-242. doi:10.1016/j.agrformet.2018.12.006

Shipley, B. (1999). Testing Causal Explanations in Organismal Biology: Causation, Correlation and Structural Equation Modelling. Oikos, 86, 374-382.

Siles, P., Harmand, J.-M., \& Vaast, P. (2009). Effects of Inga densiflora on the microclimate of coffee (Coffea arabica L.) and overall biomass under optimal growing conditions in Costa Rica. Agroforestry Systems, 78(3), 269-286. doi:10.1007/s10457-009-9241-y

Tavares, P. d. S., Giarolla, A., Chou, S. C., Silva, A. J. d. P., \& Lyra, A. d. A. (2017). Climate change impact on the potential yield of Arabica coffee in southeast Brazil. Regional Environmental Change, 18(3), 873-883. doi:10.1007/s10113017-1236-z

Vaast, P., Angrand, J., Franck, N., Dauzat, J., \& Génard, M. (2005). Fruit Load and branch ring-barking affect carbon allocation and photosynthesis of leaf and fruit of Coffea arabica in the field. Tree Physiology(25), 753-760.

Vaast, P., Bertrand, B., Perriot, J.-J., Guyot, B., \& Génard, M. (2006). Fruit thinning and shade improve bean characteristics and beverage quality of coffee (Coffea arabica L.) under optimal conditions. Journal of the Science of Food and Agriculture, 86(2), 197-204. doi:10.1002/jsfa.2338

Vaast, P., Harmand, J.-M., Rapidel, B., Jagoret, P., \& Deheuvels, O. (2016). Coffee and Cocoa Production in Agroforestry-A Climate-Smart Agriculture Model. In Climate Change and Agriculture Worldwide (pp. 209-224).

Vaast, P., Van Kanten, R., Siles, P., Angrands, J., \& Aguilar, A. (2008). Biophysical interactions between timber trees and Arabica coffee in suboptimal conditions of Central America. In Toward Agroforestry Design (pp. 133-146): Springer.

Verhage, F. Y. F., Anten, N. P. R., \& Sentelhas, P. C. (2017). Carbon dioxide fertilization offsets negative impacts of climate change on Arabica coffee yield in Brazil. Climatic Change, 144(4), 671-685. doi:10.1007/s10584-017-2068-z

Wang, N., Jassogne, L., van Asten, P. J. A., Mukasa, D., Wanyama, I., Kagezi, G., \& Giller, K. E. (2015). Evaluating coffee yield gaps and important biotic, abiotic, and management factors limiting coffee production in Uganda. European Journal of Agronomy, 63, 1-11. doi:10.1016/j.eja.2014.11.003

WCR. (2019). Arabica Coffee Varieties. Retrieved from Portland, USA:

Wickham, H. (2016). ggplot2: Elegant Graphics for Data Analysis: Springer-Verlag New York.

Wickham, H., François, R., Henry, L., \& Müller, K. (2019). dplyr: A Grammar of Data Manipulation. Retrieved from https://CRAN.R-project.org/package $=$ dplyr 


\section{Discussion}

This research took place in an important coffee Arabica region in Eastern Africa (Mt. Elgon) dominated by smallholder farmers (with farms smaller than 2 ha). Rising of temperatures and increase of rainfall variability as consequences of climate change impose serious challenges on the coffee sector, particularly for smallholder famers, as the ones located on Mt. Elgon. Whithin this context, better understanding of agronomic performance and ecological functioning of coffee cropping systems can guide climate change adaptation measures in this region. The overall goals of this study were to identify major benefits and limitations of the current coffee cropping systems along a climatic gradient (imposed by an altitudinal gradient) and identify management strategies which could improve yield performance and increase household resilience within sustainable intensification bounds (Godfray 2015).

To achieve this, we studied two types of ecosystem services: i.e. provisioning (coffee yield) and regulating (microclimate buffering and water balance) services, in different coffee cropping systems (coffee low shade (Coffee-Open), coffee intercropped with bananas (Coffee-Banana) and coffee intercropped with shade trees (Coffee-Shade Tree) on the slopes (1100 - 2100 m.a.s.l.) of Mt Elgon in Uganda. And addressed the following questions, (i) How does coffee yield ( $\mathrm{kg} \mathrm{ha}^{-1}$ ) and coffee yield components vary along the shade and altitudinal gradient? (ii) How do coffee cultivation conditions vary as a funtions the the type of cropping system and seasonal climate variation? Do these differences affect coffee water use and how? (iii) How do shade and altitudinal gradient affect coffee fruit development, coffee fruit drop and coffee reproductive/vegetative growth dynamics?

We found that coffee-Banana (CB) had larger coffee yields than coffee-Open (CO) and coffee-shade Tree (CT), while CT had the lowest coffee yields. This partially supports our first hypothesis, in which shade cover increases has a detrimental effect on yield. However, significant variation of yield along the altitudinal gradient was not observed, which contradicted our expectations. Concerning our second hypothesis, we found that indeed, shaded systems, CB and CT better regulated microclimate for the coffee planted underneath than CO. For instance, CB systems reduced by $30 \%$ incoming radiation and CT by $60 \%$, this incoming radiation decrease was associated with a reduction of maximum temperatures and temperature amplitude by $4^{\circ} \mathrm{C}$. Shaded systems had lower soil water content than $\mathrm{CO}(\mathrm{CB}-6 \%$ and CC $-54 \%)$ at low altitude. However, despite microclimate and soil water content differences across systems, coffee water use did not differ significantly across cultivation systems. 
Furthermore, we found that lower fruit inititation in shaded CT systems was not compensated by less fruit drop, since all cropping systems had similar fruit drop rates. On the other hand, shade cover helps to maintain leaf set, which is a key variable to ensure reproductive and vegetative growth. Therefore, shade cover should be carefully managed to allow for optimal reproductive growth and leaf maintainance. Finally, maximum temperature was above $30^{\circ} \mathrm{C}$ for several consecutive days in all systems studied during the dry season, but this did not have a dramatic effect on fruit development, suggesting that coffee trees might stand higher temperatures than previously thought.

Overall, we did not find the expected coffee yield increases with increasing altitude. This may be attributed to lower temperatures that may have been sub-optimal for various processes affecting flower formation, dry matter accumulation and coffee yield and or to the soil characteistics gradient found in the study area. This lacking effect of altitudinal gradient on coffee yield requires further investigation in the research area and comparison compared with similar and differing mountainous coffee growing regions.

\subsection{Merits and caveats of the study}

This is a unique dataset on coffee performance (vegetative and reproductive growth), microclimate and soil water content under smallholder conditions along an environmental gradient. Moreover, to our knowledge, this is the first study that explicitly investigates microclimates and coffee water use in coffee intercropped with bananas. This coffee-banana cropping system is of particular interest due to importance of both species to Ugandan livelihoods and diets (van Asten et al., 2011).

We acknowledge that research conducted under on-farm smallholder conditions implies higher variability and confounding factors than with using the more classical, controlled experimental set-up. This is visible in our large standard deviation across several monitored parameters. We found large intraand inter-plot variability, which, combined with various spatial and temporal scales, increases data complexity. This study was based on the detailed monitoring of twenty-seven coffee plots along an altitudinal and management gradient. In each coffee plot, 30 coffee trees were monitored in detail. We found that for further research of this kind, it could be of major interest to increase the number of plots as much as possible (given financial and labour constraints). High intra-plot variability requires more measurements within the plot in order to fully understand the drivers behind variability and find potential management practices to focus on. However, the high intra-plot variability provides valuable insights into the realities of smallholder livelihoods in the region and valuable quantitative information as well. 
In the following sections it is discussed in more detail how the results are related to the objectives and hypotheses presented in the introduction and what their impact are, e.g. how the findings contribute to the needs of Mt. Elgon farmers, other relevant resource managers in the region and the Ugandan coffee industry more generally.

\subsection{Coffee yield implications for livelihoods in the region}

As mentioned before, while agroforestry systems provide many ecosystem services, their provisioning services (yield) remain key for social and economic sustainability, at least in current economic and market scenarios (Gobbi, 2000; Perfecto et al., 2005; Godfray \& Garnett, 2014). If the cropping system provides low yields, which are not compensated by premium consumer prices, for instance, as is the case of certified production; farmers may look into intensifying their systems for potentially short-term and high-risk gains. Such conversion can, however, have a detrimental effect on the environment such as biodiversity loss and increasing $\mathrm{CO}_{2}$ emission. It also may lead to increased vulnerability of the smallholder farmers in the long run (Perfecto et al., 2005; Tscharntke et al., 2012).

In our study, we found yields ranging from $0 \mathrm{~kg} \mathrm{ha}^{-1}$ to $2300 \mathrm{~kg} \mathrm{ha}^{-1}$ with a mean value of $716 \mathrm{~kg} \mathrm{ha}{ }^{-1}$. Similar average farmer's yields and yield ranges have been reported by Wang et al. (2015) for the same region. Same authors suggest there is a yield gap of $57 \%$, which is the difference between the average observed and the attainable yield (defined as the maximum observed yield in the same area by Wang et al. (2015)). Our results indicate an even larger yield gap (68\%) which suggests that yields could be increased, at least, up to the currently observed maximum yield in the region, by using more appropriate management practices (e.g. regulating amount of shade, maintaining a maximum number of 3 stems per coffee tree) (Chapter 3). Coffee cultivation at Mt Elgon is characterized by low intensification levels (De Bauw et al., 2016; Liebig et al., 2016; Rahn et al., 2018a). This was also reflected in our results by the low coffee tree density and low LAI (Chapter 3, Table 1). Despite low coffee yields in the region, when compared to the attainable yield, or to yield levels achieved in so-called high yielding countries such as Colombia, Costa Rica or Vietnam ${ }^{13}$ (average yields above $1000 \mathrm{~kg} \mathrm{ha}^{-1}$, from 2014 to 2016), observed yields in our study area during the given study period (2015-16) are still above the average yields reported by FAOSTAT for East Africa ${ }^{1}$ ( $566 \mathrm{~kg} \mathrm{ha}^{-1}$, from 2014 to 2016).

\footnotetext{
12 Estimated from the maximum observed yield (2300 kg ha-1) and the average observed yield (716 $\left.\mathrm{kg} \mathrm{ha}^{-1}\right)$

${ }^{13}$ Colombia $\left(945 \mathrm{~kg} \mathrm{ha}^{-1}\right)$, Vietnam (945 kg ha-1), Burundi (848 kg ha-1), Costa Rica (1099 kg ha-1), Kenya (408 kg ha-1), Rwanda (570 kg ha-1), Ethiopia (705 kg ha-1) according the data provided by FAOSTAT (2018-11-28) average yield (kg ha-1) from 2014 to 2016 .
} 
We found that the observed yields at stem level $(\sim 0.2 \mathrm{~kg})$ and fruit loads per stem $(\sim 1500)$ were comparable to the results of other studies, including those run under experimental conditions in Costa Rica and Ethiopia (Bote \& Vos, 2016; Cerda et al., 2017b). Comparable yield (and fruit load values) between our study (under on-farm conditions) and other studies (under experimental controlled conditions) supports that coffee trees at Mt: Elgon could have better yields if management is improved. For instance, a key result from chapter 3 was the negative correlation between several coffee yield components and number of stems per coffee tree. Frequent coffee pruning, maintaining a maximum of three stems per tree could help increase coffee yield per stem on Mt. Elgon. Furthermore, we found that low coffee tree density also maintains low coffee yield per ha in this area. This agrees with Wang et al. (2015) and Rahn et al. (2018a), who reported that coffee yields per ha could be improved through an increase in coffee planting density which currently at Mt Elgon is approx. 2000 coffee trees ha ${ }^{-1}$.

Increasing coffee tree density might have negative knock-on effects that should be considered carefully. For instance, Jassogne et al. (2013) warns that increasing coffee tree density can negatively influence the intercropping with annual food crops (cultivated in between the coffee trees), as it reduces the space, soil water, and nutrients available, as well as the incoming radiation below coffee canopies. In addition, an increased density of coffee trees can also increase competition for water and nutrients among coffee trees. From our water use study (Chapter 4), we learned that during our measurement campaign at Mt Elgon, available water had been sufficient to support shaded systems, even for high density coffee stands (4000 coffee trees ha-1).

However, we cannot claim the same for soil nutrients, as we did not investigate this in detail, nor did we find significant differences between soil properties across systems. However, other studies warn of the poor soil fertility in the area (van Asten et al., 2011; Wang et al., 2015; De Bauw et al., 2016). For Mt. Elgon, De Bauw et al. (2016) indicated soil fertility decreased along the altitudinal gradient. Moreover, same authors indicated that nutrients deficiencies also varied along the altitudinal gradient, nitrogen being a limiting factor at low altitude and sulfur at high altitude, which is to be expected based on temperature and rainfall gradients for the Nitisols developed from the volcanic substrate of Mt. Elgon (Sombroek \& van de Weg, 1980; Jones et al., 2013). Nonetheless, De Bauw et al. (2016) was not able to relate soil nutrients gradient with coffee nutrient deficiency gradients. Thus, further studies on the soil nutrient status combined with analyses of nutrient uptake (at least of macro-nutrients NPK) and their concetrations in various plant organs will help to better understand nutrient deficiencies in the region (see, Janssen et al. (1990)). 
Capa et al. (2015), suggested through their experiment that moderate applications of fertilizers could help to increase yields in full-sun systems without considerable increasing $\mathrm{N}_{2} \mathrm{O}$ emissions and $\mathrm{NO}_{3}$ leaching. We suggest that an improvement in soil nutrition could help to improve coffee productivity on Mt. Elgon, since due to the low intensification of the systems, nutrient replenishment might be insufficient ${ }^{14}$. If poor soil fertility is one of the main reasons behind the current yield gap this problem is likely to become more serious in the future. Before fertilizer recommendations can be made, it is important to locally test practices that improve nutrient recycling for their performance in the various cultivation systems present in the region.

Our hypothesis, that higher shade cover reduces yields was confirmed by our results (Chapter 3), in which fruit load per branch and productive branches per stem reduced with shade cover in all cultivation systems. For this region, the negative relationship between shade cover (or shade tree density) and yields was also reported by Wang et al. (2015) and by several other studies in other coffee regions (Campanha et al., 2004; DaMatta, 2004; Morais et al., 2006; López-Bravo et al., 2012). Nevertheless, we also found that intermediate shade level systems (below $40 \%$ and above $20 \%$ ), such as CB can provide higher or equal yields than low $(<20 \%)$ shaded systems. Similar findings were also reported for Uganda by van van Asten et al. (2011) and for other coffee regions (Soto-Pinto et al., 2000; Cerda et al., 2017a; Meylan et al., 2017). Higher maximum temperatures and higher temperature amplitude combined with higher radiation in low shaded systems might be one of the reasons for limited yields under open conditions in our study. Furthermore, low shaded systems were more exposed to heavy rains that could have caused of fruit drop. On the other hand, under heavier shaded systems (CT), yields were also reduced. This was due to lower fruit initiation as demonstrated in chapter 5.

As we observed in chapter 5 , the yield differences across systems were initially determined by reduced fruit initiation in CT, which was not fully counterbalanced by reduced fruit drop in the same system. Contrary to our expectations, that shaded systems, CB and CT, would have significantly lower fruit drop rates than $\mathrm{CO}$, especially under suboptimal conditions, we found all systems had similar fruit drop rates. These results are surprising, since based on other studies (Vaast et al., 2008; Bote \& Vos, 2016; Rigal et al., 2020) we expected loss fruit drop in shaded systems due to two mechanismus, (i) lower fruit load reduces competition between fruits and (ii) improved microclimate reduce leaf senecensce and plant stress. These findings conflicting with some previous work also call for further investigation.

\footnotetext{
${ }^{14}$ Muschler (2000) reported the following nutrient extraction (in $1500 \mathrm{~kg}$ green coffee ha ${ }^{-1}$ ): $27 \mathrm{~kg} \mathrm{ha}^{-1}$ of Nitrogen, $1.5 \mathrm{~kg} \mathrm{ha}^{-1}$ of Phosporous, $3.6 \mathrm{~kg} \mathrm{ha}^{-1}$ of Potassium and $1.4 \mathrm{~kg} \mathrm{ha}^{-1}$ of Calcium.
} 
Although we did not focus on pests and diseases in this work, we have to acknowledge that they play a significant role in terms of yield losses, as has been demonstrated by (López-Bravo et al., 2012), (Cerda et al., 2017b) and (Garedew et al., 2017). Furthermore, Liebig et al. (2016) already points out bidirectional effects of shade and altitude on different coffee pest and diseases in this region, thus further increasing complexity of the relationship between coffee yields and altitudinal gradient. For example, shaded systems at low altitude experienced larger white stem borer infestation rates, while coffee berry disease was more prominent at high altitudes in open systems (Liebig et al., 2016). Similarly, López-Bravo et al. (2012) suggest a direct and indirect effect of shade on leaf rust infections on coffee. While infestation rates were related to fruit load, i.e. larger infestations in open conditions, shaded conditions (more relative humidity) offered more appropriate conditions for leaf rust development (López-Bravo et al., 2012). These scenarios could cause similar fruit drop levels at low shade and high shade. Combining our results with knowledge on pest and diseases is certainly key for the further development of our understanding of the mechanisms behind yield losses - as found in our study.

\subsection{Microclimate regulation}

Our results showed that in shaded systems, coffee intercropped with shade trees and with bananas, reduce maximum temperatures and temperature amplitude (Tmax -Tmin) up to $4{ }^{\circ} \mathrm{C}$ along the altitudinal gradient. Microclimate regulation by agroforestry systems has already been studied by several authors in the context of coffee agroforestry systems and also in forest (Partelli et al., 2014; Araújo et al., 2016; de Carvalho et al., 2020). Nevertheless, such studies have taken place mostly in Latin America or Asia, whereas microclimate studies in African agroforestry systems are rather scarce, thus this work provides valuable dataset and evidence to add. Furthermore, we found that despite $C B$ systems intercept less light than CT systems (Chapter 4) relative humidity is higher in this system than in coffee intercropped with other shade trees species. We attributed this to the linear response of bananas' transpiration to vapor pressure deficit increases. And this is of highly importance, due to coffee stomata sensitivity to atmospheric drought (VPD >1.5 - $2 \mathrm{kPa}$ ). Despite, we did not find significant differences in coffee water use across systems due to high variability; nevertheless, we observed high $J_{s}$ values in $\mathrm{CB}$, which could indicate better microclimatic conditions for coffee in those systems.

To our knowledge, this is the first study that explicitly investigates microclimate in coffee intercropped with bananas. These cultivation systems are of particular interest due to importance of both species to the livelihood and diet in Uganda (van Asten et al., 2011). Although, some constrains could occurs in coffee-bananas intercrop, for instance a faster depletion of soil water content under drought conditions, if bananas do not show a stomatal control mechanism for saving water. A contrary argument to this, is 
the study of Kissel et al. (2015), which reports banana transpiration decreases when soil water content $(\mathrm{pF})$ falls below 2.8. Hence, this suggests that banana water saving mechanism is related to edaphic drough more than to atmospheric drought. Certainly, more research of water dynamics in CB systems needs to be done, to explore longer hotter and dryer conditions. This would allow answering the following questions: (i) Do bananas deplete faster soil water content than other shade trees (ii) do bananas reduce transpiration due to low soil water content before coffee trees reduce transpiration? (iii) Until which extent banana morphology influences rainfall partition and how does that benefits coffee underneath?

As mentioned before, mean temperature during our study period ranged within coffee optimum thresholds $\left(18^{\circ} \mathrm{C}-23^{\circ} \mathrm{C}\right)$ along the altitudinal gradient (Descroix \& Snoeck, 2008). However, maximum temperature exceeded $30^{\circ} \mathrm{C}$ at low altitude in all systems and in $\mathrm{CO}$ at higher altitude. With these temperatures we expected less fruit initiation at low altitude than at middle and high altitude, since Camargo (1985) and Drinnan and Menzel. (1995) 15 suggested flower abortion with high temperature. Furthermore, according to Liebig et al. (2016), farmers at low altitude stated poor flowering as the main reason for low yields. However, from our results (chapter 5 ) we could not relate temperatures above $30{ }^{\circ} \mathrm{C}$ with flower abortion, since fruit initiation had not a clear pattern along altitude and varied from system to system. From this point, we question the validity of previous climatic thresholds proposed for coffee and suggest coffee plants are more heat resistant than expected. This argument is supported by recent findings from Martins et al. (2016) and Rodrigues et al. (2016), who suggested a higher coffee tolerance to heat stress under the conditions of high water availability (and VPD $<1.5-2 \mathrm{kPa}$ ). These authors proposed that coffee can maintain photosynthesis rates up to $34^{\circ} \mathrm{C}$ degrees. And even at higher temperatures $\left(42 / 34^{\circ} \mathrm{C}\right.$, day/night) under enhanced atmospheric $\mathrm{CO}_{2}$ concentrations (i.e. $700 \mu \mathrm{l} \mathrm{CO} \mathrm{I}^{-1}$ ) ppmv).

In the light of these results, water appeared to be a crucial factor determining coffee tolerance of heat. From Martins et al. (2016) and Rodrigues et al. (2016) we learnt that we might have to reconsider the already "institutionalized" coffee temperature thresholds. Nevertheless, in their experiments, relative humidity was controlled to maintain stable evaporative demand. Yet, as stated before and shown in our study (chapter 4), coffee stomata are sensitive to high VPD and under field conditions relevant thresholds were crossed even under shade (chapter 4). Thus, designing agroforestry systems for improving climate resilience of coffee should consider not only to reduce temperature, but also to maintain optimal relative humidity conditions, and consequently VPD. Nonetheless, it is important to

15 Camargo (1985) Camargo 1985 said $30^{\circ} \mathrm{C}$ and Drinnan and Menzel. (1995) $28^{\circ} \mathrm{C}$ 
note that such microclimatic conditions (high temperature combined with high relative humidity) could be conducive to pest and disease development. Such relationships, therefore, should be investigated and quantitatively described before implementing respective management advice.

Turning to soil moisture, our results on chapter 4 indicated lower soil moisture in shaded systems, CB ($6 \%)$ and CC (-59\%), compared with CO. Under sufficient rainfall, as it was the case of our study, shaded coffee has a more efficient water use, since it is used in coffee and shaded species, rather than been loss by evaporation and/or infiltration, as it is more likely to occur in the open system (Chapter 5 and Lin (2010)). On the other hand, under water limited conditions, the larger transpiration rate of shaded coffee (due to the combination of coffee and shade trees transpiration) can lead to water competition between coffee and shade trees. This has been already suggested by other studies in coffee (Cannavo et al., 2011; Padovan et al., 2018) and has been observed during an extreme drought event in shadedcocoa systems by (Abdulai et al., 2018).

On the other hand, our results from chapter 5 indicated similar water content across cropping system for similar microclimatic conditions (same altitude class) as the experiment carried out in chapter 4 . We attributed these contrasting results to the effect slope might have had on soil water content. The CT system used in the experimental plot of chapter 4 had a slope of $32 \%$, while monitored fields in chapter 5 had an averaged slope of $7 \%$, which could be one of the reasons behind the differences in soil water content among cropping systems in both studies. However, this discrepancy highlights the importance of considering topography when designing agroforestry systems to increase climate resilience. This, ads to other several factors that should be considered, e.g. species, use, phenology, morphology (size and root depth) and physiology, plot arrangement and tree management and spatial arrangement and position in the landscape (Vaast et al., 2008; Vaast et al., 2016; Van Der Wolf et al., 2016; Rahn et al., 2018a; Rahn et al., 2018b). 


\subsection{Shaded systems for sustainable intensification and climate smart agriculture}

Coffee farmers at Mt. Elgon practice agriculture at low intensity and intercrop their coffee with other species, at diverse densities. Thus, there is hardly any farmer that only specializes in coffee cultivation. With this scenario in mind, it appears more reasonable to improve local practices and reduce the tradeoffs occurring in the current systems, rather than to promote a costly and risk prone innovation toolbox such as intensified coffee monocultures with high yielding compact varieties (Tscharntke et al., 2011). The observed yields, despite being low compared with other regions, in conjunction with estimated yield gaps, indicate that coffee productivity in the region could be improved with better management, such as improved pruning. Nevertheless, it is clear that interventions aiming to improve yield will usually require an increment of labour input and of growers' commitment and will likely not work if such interventions do not show larger economic return than current practices. Moreover, beyond the improvement of agronomic practices, it is also important to strengthen post-harvest processing and facilities and improve marketing opportunities.

Even though the functioning of $\mathrm{CT}$ at low altitude requires further investigation since coffee yields of these systems were inconsistent at that altitude; shade trees and bananas demonstrated an important microclimate regulation function at field level, and their intercropping with coffee trees should be maintained and promoted. Moreover, the role trees play in regulating water and climate for larger areas (e.g. landscape and regional) should not be underestimated. Trees and forest have shown to modify meso-climatic conditions, especially rainfall and wind circulation parterns at landscape and larger scales (Lawton et al., 2001; van Noordwijk et al., 2014). Trees also significantly contribute towards the potential of farm income diversification (Rice, 2008; Mbow et al., 2014; Vaast \& Somarriba, 2014; Cerda et al., 2017a) and soil erosion protection (Kimmins et al., 2008).

Based on our study, and to ensure shade tree maintenance at field level, we propose dynamic shade management, in which shade components are pruned or thinned according to the forecasted severity of the dry season. For instance, if the dry season is rather short, and not too hot, shade should be pruned to allow for more access to light. If the dry season is short and very hot, shade should be maintained (no pruning performed) to protect lower coffee canopies. If the dry season is forecasted to be long but not very hot, shade trees should be pruned, and more mulching provided to reduce water evaporation from the soil as well as water transpired by shade trees as much as possible. Finally, if it is a very severe dry season (long and hot) shade should be maintained until certain soil water content thresholds are 
reached. Afterwards, shade tree water use should be reduced as much as possible through pruning to guarantee water competition does not impact coffee production. To our knowledge, this type of dynamic shade management has not been proposed yet, and would need to have extensive testing before being promoted as a management tool. Furthermore, within the above-mentioned options, coffee is the main actor, and measures are taken to favour its survival under extreme drought events. While such measures may not guarantee high yields under extreme drought, coffee tree survival can be ensured, as well as a functional shade canopy. However, this should be combined with other strategies that increase resilience at a household level, such as fostering money saving strategies and/or crop insurances in case of extreme events.

\subsection{Outlook}

In the various discussion sections, we have mentioned a number of opportunities for further research, as summarized in the following:

1. To explore water-use patterns of other species used in the area (including bananas) under normal and also harsher conditions (longer and hotter dry periods). For instance, with shade trees that reduce water use before coffee does (temporal complementarity) or shade trees that obtain water from different soil layers than coffee (morphologic complementarity).

2. To focus not only on coffee performance, but explore smallholder farms from a systemic perspective, in which yield (or growth), their role in the farmer's livelihood, and role in the farm ecosystem of other intercropped species is addressed.

3. To streamline coffee phenology combinations with microclimates, flower initiation, flower abortion, fruit initiation and fruit development.

4. To investgate the role of soil nutrients /nutrient recycling and the investigation of various local species and their nutrient provision to the soil.

5. To explore the genetic diversity and genotypic performance of coffee under typical coffee cultivation environments.

6. To ensure that all field experiments should help to generate datasets that can be used for the parametrization and improvement of (process-based) ecopysiological models, which allow studying genotype $x$ environment $x$ management (GxExM) interactions and are especially useful to guide management recommendations under different current climatic conditions, as well as under climate change scenarios as proposed by Bayala et al. (2015) and Rahn et al. (2018b). 


\section{References}

Abdulai, I., Vaast, P., Hoffmann, M. P., Asare, R., Jassogne, L., Van Asten, P., Rotter, R. P., \& Graefe, S. (2018). Cocoa agroforestry is less resilient to sub-optimal and extreme climate than cocoa in full sun. Glob Chang Biol, 24(1), 273-286. doi:10.1111/gcb.13885

Araújo, A. V., Partelli, F. L., Oliosi, G., \& Pezzopane, J. R. M. (2016). Microclimate, development and productivity of robusta coffee shaded by rubber trees and at full sun. Revista CiÊncia AgronÔmica, 47. doi:10.5935/1806-6690.20160084

Bayala, J., Sanou, J., Teklehaimanot, Z., Ouedraogo, S. J., Kalinganire, A., Coe, R., \& Noordwijk, M. v. (2015). Advances in knowledge of processes in soil-tree-crop interactions in parkland systems in the West African Sahel: A review. Agriculture, Ecosystems \& Environment, 205, 25-35. doi:10.1016/j.agee.2015.02.018

Bote, A. D., \& Vos, J. (2016). Branch growth dynamics, photosynthesis, yield and bean size distribution in response to fruit load manipulation in coffee trees. Trees(30), 1275-1285. doi:10.1007/s00468-016-1365-x

Camargo, A. P. (1985). O clima e a cafeicultura no Brasil. Agropec, 11, 13-26.

Campanha, M. M., Silva Santos, R. H., De Freitas, G. B., Prieto Martinez, H. E., Ribeiro Garcia, S. L., \& Finger, F. L. (2004). Growth and yield of coffee plants in agroforestry and monoculture systems in Minas Gerais, Brazil. Agroforestry Systems, 63, 75-82.

Cannavo, P., Sansoulet, J., Harmand, J. M., Siles, P., Dreyer, E., \& Vaast, P. (2011). Agroforestry associating coffee and Inga densiflora results in complementarity for water uptake and decreases deep drainage in Costa Rica. Agriculture, Ecosystems \& Environment, 140(1-2), 1-13. doi:10.1016/j.agee.2010.11.005

Capa, D., Pérez-Esteban, J., \& Masaguer, A. (2015). Unsustainability of recommended fertilization rates for coffee monoculture due to high N2O emissions. Agronomy for Sustainable Development, 35(4), 1551-1559. doi:10.1007/s13593-015-0316-z

Cerda, R., Allinne, C., Gary, C., Tixier, P., Harvey, C. A., Krolczyk, L., Mathiot, C., Clément, E., Aubertot, J.-N., \& Avelino, J. (2017a). Effects of shade, altitude and management on multiple ecosystem services in coffee agroecosystems. European Journal of Agronomy, 82, 308-319. doi:10.1016/j.eja.2016.09.019

Cerda, R., Avelino, J., Gary, C., Tixier, P., Lechevallier, E., \& Allinne, C. (2017b). Primary and Secondary Yield Losses Caused by Pests and Diseases: Assessment and Modeling in Coffee. PLoS One, 12(1), e0169133. doi:10.1371/journal.pone.0169133

DaMatta, F. M. (2004). Ecophysiological constraints on the production of shaded and unshaded coffee: a review. Field Crops Research, 86(2-3), 99-114. doi:10.1016/j.fcr.2003.09.001

De Bauw, P., Van Asten, P., Jassogne, L., \& Merckx, R. (2016). Soil fertility gradients and production constraints for coffee and banana on volcanic mountain slopes in the East African Rift: A case study of Mt. Elgon. Agriculture, Ecosystems \& Environment, 231, 166-175. doi:10.1016/j.agee.2016.06.036

de Carvalho, A. F., Fernandes-Filho, E. I., Daher, M., Gomes, L. d. C., Cardoso, I. M., Fernandes, R. B. A., \& Schaefer, C. E. G. R. (2020). Microclimate and soil and water loss in shaded and unshaded agroforestry coffee systems. Agroforestry Systems. doi:10.1007/s10457-020-00567-6

Descroix, F., \& Snoeck, J. (2008). Environmental Factors Suitable for Coffee Cultivation. In Coffee: Growing, Processing, Sustainable Production (pp. 164-177).

Drinnan, J. E., \& Menzel., C. M. (1995). Temperature affects vegetative growth and flowering of coffee (Coffea arabica L.). Journal of Horticultural Science, 70(1), 25-34.

Garedew, W., Lemessa, F., \& Pinard, F. (2017). Assessment of berry drop due to coffee berry disease and non-CBD factors in Arabica coffee under farmers fields of Southwestern Ethiopia. Crop Protection, 98, 276-282. doi:10.1016/j.cropro.2017.04.012

Gobbi, J. A. (2000). Is biodiversity-friendly coffee financially viable? An analysis

of five different coffee production systems in western EI

Salvador. Ecological Economics, 33, 267-281.

Godfray, H. C. J., \& Garnett, T. (2014). Food security and sustainable intensification. Philosophical Transactions of the Royal Society B: Biological Sciences, 369(1639). doi:10.1098/rstb.2012.0273

Janssen, B. H., Guiking, F. C. T., van der Eijk, D., Smaling, E. M. A., Wolf, J., \& van Reuler, H. (1990). A system for quantitative evaluation of the fertility of tropical soils (QUEFTS). Geoderma, 46(4), 299-318. doi:https://doi.org/10.1016/00167061(90)90021-Z

Jassogne, L., Läderach, P., \& van Asten, P. (2013). The Impact of Climate Change on Coffee in Uganda: Lessons from a case study in the Rwenzori Mountains. Retrieved from http://www.ingentaconnect.com/content/oxpp/oppccr/2013/00000009/00000001/art00004

Jones, A., Breuning-Madsen, H., Brossard, M., Dampha, A., Deckers, J., Dewitte, O., Gallali, T., Hallett, S., Jones, R., Kilasara, M., Le Roux, P., Micheli, E., Montanarella, L., Spaargaren, O., Thombiano, L., Van Ranst, E., Yemefack, M., \& Zougmoré, R. (Eds.). (2013). Soil atlas of Africa. Luxembourg: Union Européenne.

Kimmins, J. P., Welham, C., Cao, F., Wangpakapattanawong, P., \& Christanty, L. (2008). The Role of Ecosystem-level Models in the Design of Agroforestry Systems for Future Environmental Conditions and Social Needs. In S. Jose \& A. M. Gordon (Eds.), Toward Agroforestry Design: An Ecological Approach (pp. 231-248). Dordrecht: Springer Netherlands. 
Kissel, E., van Asten, P., Swennen, R., Lorenzen, J., \& Carpentier, S. C. (2015). Transpiration efficiency versus growth: Exploring the banana biodiversity for drought tolerance. Scientia Horticulturae, 185, 175-182. doi:10.1016/j.scienta.2015.01.035

Lawton, R. O., Nair, U. S., Pielke Sr, R. A., \& Welch, R. M. (2001). Climatic Impact of Tropical

Lowland Deforestation on

Nearby Montane Cloud Forests. Science, 294(5542), 584-587.

Liebig, T., Jassogne, L., Rahn, E., Laderach, P., Poehling, H. M., Kucel, P., Van Asten, P., \& Avelino, J. (2016). Towards a Collaborative Research: A Case Study on Linking Science to Farmers' Perceptions and Knowledge on Arabica Coffee Pests and Diseases and Its Management. PLoS One, 11(8), e0159392. doi:10.1371/journal.pone.0159392

Lin, B. B. (2010). The role of agroforestry in reducing water loss through soil evaporation and crop transpiration in coffee agroecosystems. Agricultural and Forest Meteorology, 150(4), 510-518. doi:10.1016/j.agrformet.2009.11.010

López-Bravo, D. F., Virginio-Filho, E. d. M., \& Avelino, J. (2012). Shade is conducive to coffee rust as compared to full sun exposure under standardized fruit load conditions. Crop Protection, 38, 21-29. doi:10.1016/j.cropro.2012.03.011

Martins, M. Q., Rodrigues, W. P., Fortunato, A. S., Leitao, A. E., Rodrigues, A. P., Pais, I. P., Martins, L. D., Silva, M. J., Reboredo, F. H., Partelli, F. L., Campostrini, E., Tomaz, M. A., Scotti-Campos, P., Ribeiro-Barros, A. I., Lidon, F. J., DaMatta, F. M., \& Ramalho, J. C. (2016). Protective Response Mechanisms to Heat Stress in Interaction with High [CO2] Conditions in Coffea spp. Front Plant Sci, 7, 947. doi:10.3389/fpls.2016.00947

Mbow, C., Van Noordwijk, M., Luedeling, E., Neufeldt, H., Minang, P. A., \& Kowero, G. (2014). Agroforestry solutions to address food security and climate change challenges in Africa. Current Opinion in Environmental Sustainability, 6, 61-67. doi:10.1016/j.cosust.2013.10.014

Meylan, L., Gary, C., Allinne, C., Ortiz, J., Jackson, L., \& Rapidel, B. (2017). Evaluating the effect of shade trees on provision of ecosystem services in intensively managed coffee plantations. Agriculture, Ecosystems \& Environment, 245, 32-42. doi:10.1016/j.agee.2017.05.005

Morais, H., Caramori, P. H., de Arruda Ribeiro, A. M., Gomes, J. C., \& Sei Koguishi, M. (2006). Microclimatic characterization and productivity of coffee plants grown under shade of pigeon pea in Southern Brazil. Pesquisa Agropecuária Brasileira, 41, 763-770.

Muschler, R. (2000). Tree-crop compatibility in agroforestry : production and quality of coffee grown under managed tree shade in Costa Rica.

Padovan, M. P., Brook, R. M., Barrios, M., Cruz-Castillo, J. B., Vilchez-Mendoza, S. J., Costa, A. N., \& Rapidel, B. (2018). Water loss by transpiration and soil evaporation in coffee shaded by Tabebuia rosea Bertol . and Simarouba glauca dc. compared to unshaded coffee in sub-optimal environmental conditions. Agricultural and Forest Meteorology, 248, 1-14. doi:10.1016/j.agrformet.2017.08.036

Partelli, F. L., Araújo, A. V., Vieira, H. D., Dias, J. R. M., Menezes, L. F. T. d., \& Ramalho, J. C. (2014). Microclimate and development of 'Conilon' coffee intercropped with rubber trees. Pesquisa Agropecuária Brasileira, 49(11), 872881. doi:10.1590/s0100-204x2014001100006

Perfecto, I., Vandermeer, J., Mas, A., \& Pinto, L. S. (2005). Biodiversity, yield, and shade coffee certification. Ecological Economics, 54(4), 435-446. doi:10.1016/j.ecolecon.2004.10.009

Rahn, E., Liebig, T., Ghazoul, J., van Asten, P., Läderach, P., Vaast, P., Sarmiento, A., Garcia, C., \& Jassogne, L. (2018a). Opportunities for sustainable intensification of coffee agro-ecosystems along an altitudinal gradient on Mt. Elgon, Uganda. Agriculture, Ecosystems \& Environment, 263, 31-40. doi:10.1016/j.agee.2018.04.019

Rahn, E., Vaast, P., Läderach, P., van Asten, P., Jassogne, L., \& Ghazoul, J. (2018b). Exploring adaptation strategies of coffee production to climate change using a process-based model. Ecological Modelling, 371, 76-89. doi:10.1016/j.ecolmodel.2018.01.009

Rice, R. A. (2008). Agricultural intensification within agroforestry: The case of coffee and wood products. Agriculture, Ecosystems \& Environment, 128(4), 212-218. doi:10.1016/j.agee.2008.06.007

Rigal, C., Xu, J., Hu, G., Qiu, M., \& Vaast, P. (2020). Coffee production during the transition period from monoculture to agroforestry systems in near optimal growing conditions, in Yunnan Province. Agricultural Systems, 177. doi:10.1016/j.agsy.2019.102696

Rodrigues, W. P., Martins, M. Q., Fortunato, A. S., Rodrigues, A. P., Semedo, J. N., Simoes-Costa, M. C., Pais, I. P., Leitao, A. E., Colwell, F., Goulao, L., Maguas, C., Maia, R., Partelli, F. L., Campostrini, E., Scotti-Campos, P., Ribeiro-Barros, A. I., Lidon, F. C., DaMatta, F. M., \& Ramalho, J. C. (2016). Long-term elevated air [CO2 ] strengthens photosynthetic functioning and mitigates the impact of supra-optimal temperatures in tropical Coffea arabica and C. canephora species. Glob Chang Biol, 22(1), 415-431. doi:10.1111/gcb.13088

Sombroek, W. G., \& van de Weg, R. F. (1980). Some considerations on quality and readability of soil maps and their legends. Retrieved from Amsterdam, Netherlands:

Soto-Pinto, L., Perfecto, I., Castillo-Hernandez, J., \& Caballero-Nieto. (2000). Shade Effect on Coffee Production at the Northern Tzeltal Zone of the State of Chiapas, Mexico. Agriculture, Ecosystems \& Environment, 80((1-2)), 61-69.

Tscharntke, T., Clough, Y., Bhagwat, S. A., Buchori, D., Faust, H., Hertel, D., Hölscher, D., Juhrbandt, J., Kessler, M., Perfecto, I., Scherber, C., Schroth, G., Veldkamp, E., \& Wanger, T. C. (2011). Multifunctional shade-tree management in tropical agroforestry landscapes - a review. Journal of Applied Ecology, 48(3), 619-629. doi:10.1111/j.13652664.2010.01939.x

Tscharntke, T., Clough, Y., Wanger, T. C., Jackson, L., Motzke, I., Perfecto, I., Vandermeer, J., \& Whitbread, A. (2012). Global food security, biodiversity conservation and the future of agricultural intensification. Biological Conservation, 151(1), 53-59. doi:10.1016/j.biocon.2012.01.068 
Vaast, P., Harmand, J.-M., Rapidel, B., Jagoret, P., \& Deheuvels, O. (2016). Coffee and Cocoa Production in Agroforestry-A Climate-Smart Agriculture Model. In Climate Change and Agriculture Worldwide (pp. 209-224).

Vaast, P., \& Somarriba, E. (2014). Trade-offs between crop intensification and ecosystem services: the role of agroforestry in cocoa cultivation. Agroforestry Systems, 88(6), 947-956. doi:10.1007/s10457-014-9762-x

Vaast, P., Van Kanten, R., Siles, P., Angrands, J., \& Aguilar, A. (2008). Biophysical interactions between timber trees and Arabica coffee in suboptimal conditions of Central America. In Toward Agroforestry Design (pp. 133-146): Springer.

van Asten, P. J. A., Wairegi, L. W. I., Mukasa, D., \& Uringi, N. O. (2011). Agronomic and economic benefits of coffee-banana intercropping in Uganda's smallholder farming systems. Agricultural Systems, 104(4), 326-334. doi:10.1016/j.agsy.2010.12.004

Van Der Wolf, J., Jassogne, L., Gram, G. I. L., \& Vaast, P. (2016). Turning Local Knowledge on Agroforestry into an Online Decision-Support Tool for Tree Selection in Smallholders' Farms. Experimental Agriculture, 55(S1), 50-66. doi:10.1017/s001447971600017x

van Noordwijk, M., Namirembe, S., Catacutan, D., Williamson, D., \& Gebrekirstos, A. (2014). Pricing rainbow, green, blue and grey water: tree cover and geopolitics of climatic teleconnections. Current Opinion in Environmental Sustainability, 6, 41-47. doi:10.1016/j.cosust.2013.10.008

Wang, N., Jassogne, L., van Asten, P. J. A., Mukasa, D., Wanyama, I., Kagezi, G., \& Giller, K. E. (2015). Evaluating coffee yield gaps and important biotic, abiotic, and management factors limiting coffee production in Uganda. European Journal of Agronomy, 63, 1-11. doi:10.1016/j.eja.2014.11.003 



\section{Conclusion}

This research took place in an important coffee region dominated by smallholder farmers (farms smaller than 2 ha) in Eastern Africa (Mt. Elgon, Uganda). Two types of ecosystem services were studied: provisioning (coffee yield) and regulating (microclimate and water balance) in different coffee cropping systems (coffee low shade (Coffee-Open, CO), coffee intercropped with bananas (Coffee-Banana, CB) and coffee intercropped with shade trees (Coffee-Shade Tree, CT).

Coffee-Banana systems had larger yields than Coffee-Open and Coffee-Shade Tree. This was due to better fruit initiation/fruit drop ratio in $\mathrm{CB}$ compared to the other two systems. Fruit load per branch and number of productive branches were the most important yield components determining yield per ha and were negatively correlated with the number of stems per coffee tree. Shaded systems (CB and CT) improved the microclimate for coffee trees beneath through reducing incoming radiation, maximum temperature, and temperature amplitude along the altitudinal gradient. We found higher transpiration rates in shaded systems (CB and CT) compared to CO. Water availability during our study period was sufficient to main shaded systems without water competition between coffee and shade trees.

We found that coffee yields on Mt. Elgon are low compared to other high yielding regions around the world. However, yields were within the average range of smallholder coffee yields for Eastern Africa. Yields could be improved by reducing the number of stems per coffee tree (pruning) and increasing coffee tree density. However, this last recommendation needs to be combined with a sustainable soil nutrient replenishment strategy. Also, opportunities for intercropping coffee with annual crops should, wherever meaningful, not be reduced. Furthermore, we found that coffee trees benefit from the microclimates provided by shade trees, which emphasizes the notion that a certain level of shade should be maintained throughout such cultivation systems. We observed maximum temperatures above a recognized optimal coffee threshold temperature, which confirms the recommendation on shade maintenance.

Finally, species choice and spatial arrangement should be in line with seasonal climate forecasts and also consider future conditions as indicated by climate change projections for the region. The inconsistent altitudinal pattern observed in this study, highlights the complexity of management $x$ environment $x$ pests and diseases $x$ genotype interactions, and calls for more comprehensive interdisciplinary research efforts 



\section{Supplementary material}

\subsection{Chapter 2: Background information about coffee and coffee in Uganda}

\subsubsection{Climate data}

In this study we use an altitude gradient (from 1100 m.a.s.I. to 2100 m.s.I.) as a climate proxy to evaluate the performance of coffee cultivation systems under different climatic conditions. Although long term data sets as AgMerra or Worldclim could be suitable for reflecting the climate trends and patterns. They perform poorly for capturing climate variations in a very low spatial resolution and a large altitudinal gradient, as in the case of our study area (10 $\mathrm{km}^{2}$ and $1000 \mathrm{~m}$. gradient). Therefore, to capture the climatic variation along the altitudinal gradient, we use the correlation of altitude and the different parameters (Rainfall, Tmean, Tmax and Tmin). As data input, we used the weather data collected from our experimental site at low altitude (from March 2015 to April 2016, 1300 m.a.s.I.) (Fig. 1, microclimate (Ta and relative humidity) collected in different fields along the altitudinal gradient (see chapter 5), climate data obtained from the closest weather station (from 2005 to 2015, 1800 m.a.s.I.) and annual rainfall amounts reported by Mbogga (2012) at different altitudes for other locations at Mt Elgon.
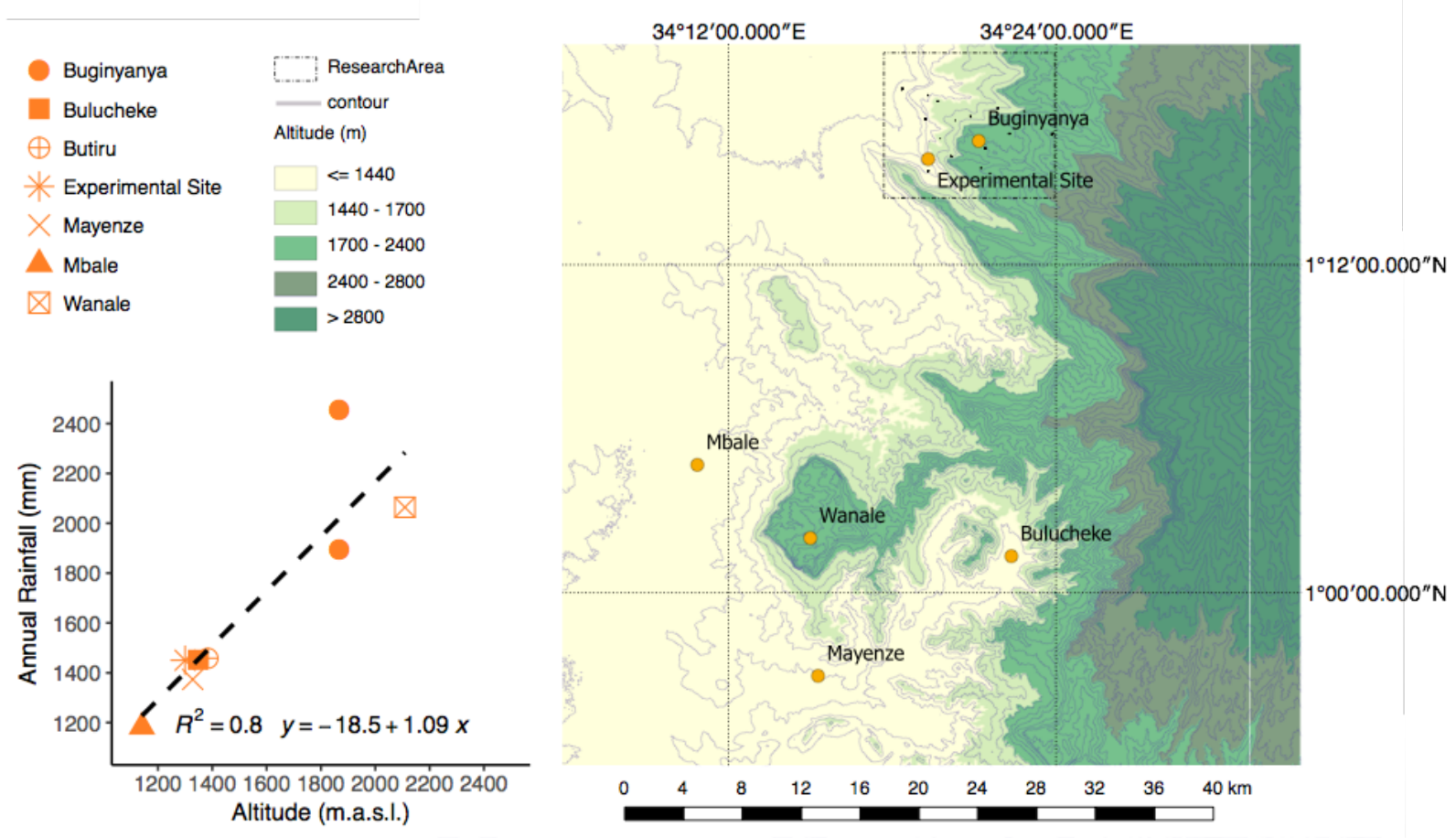

Fig. 1. A) Correlation of anual rainfall and altitude B) Location of annual rainfall records

Long term data for the area were obtained from AgMERRA database (Ruane et al., 2015), with a horizontal resolution of approximately $25 \mathrm{~km}$ and a time spam from 1980 to 2010. Daily mean temperature is $22.5 \pm 1.5{ }^{\circ} \mathrm{C}$, mean minimum temperature is $16.4 \pm 1.2{ }^{\circ} \mathrm{C}$ and mean maximum 
temperature is $29.6 \pm 2.8^{\circ} \mathrm{C}$. Annual precipitation is around $1262 \mathrm{~mm}$. January, February and December are the driest months and receive on average $40 \mathrm{~mm}$ month, while April and May are the wettest months, with an average of $180 \mathrm{~mm}$ per month.

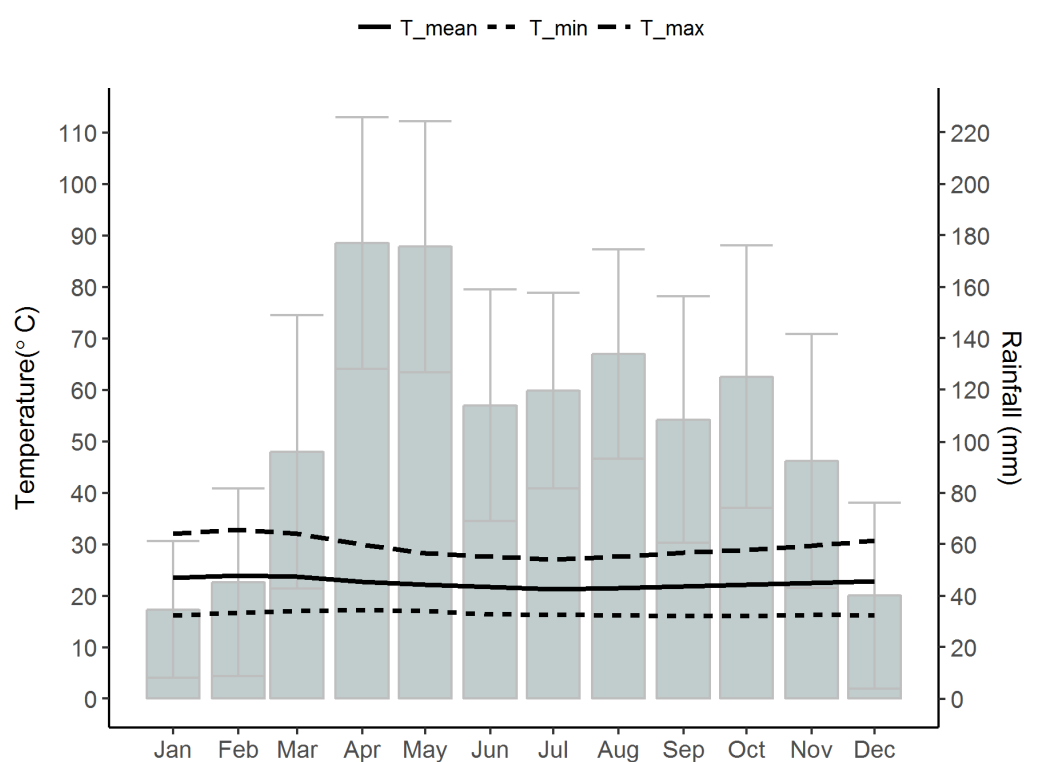

Fig. 2. Climate at the research area from 1980 to 2010 from AgMERRA (Ruane et al., 2015)

\subsubsection{Development of the coffee sector in Uganda}

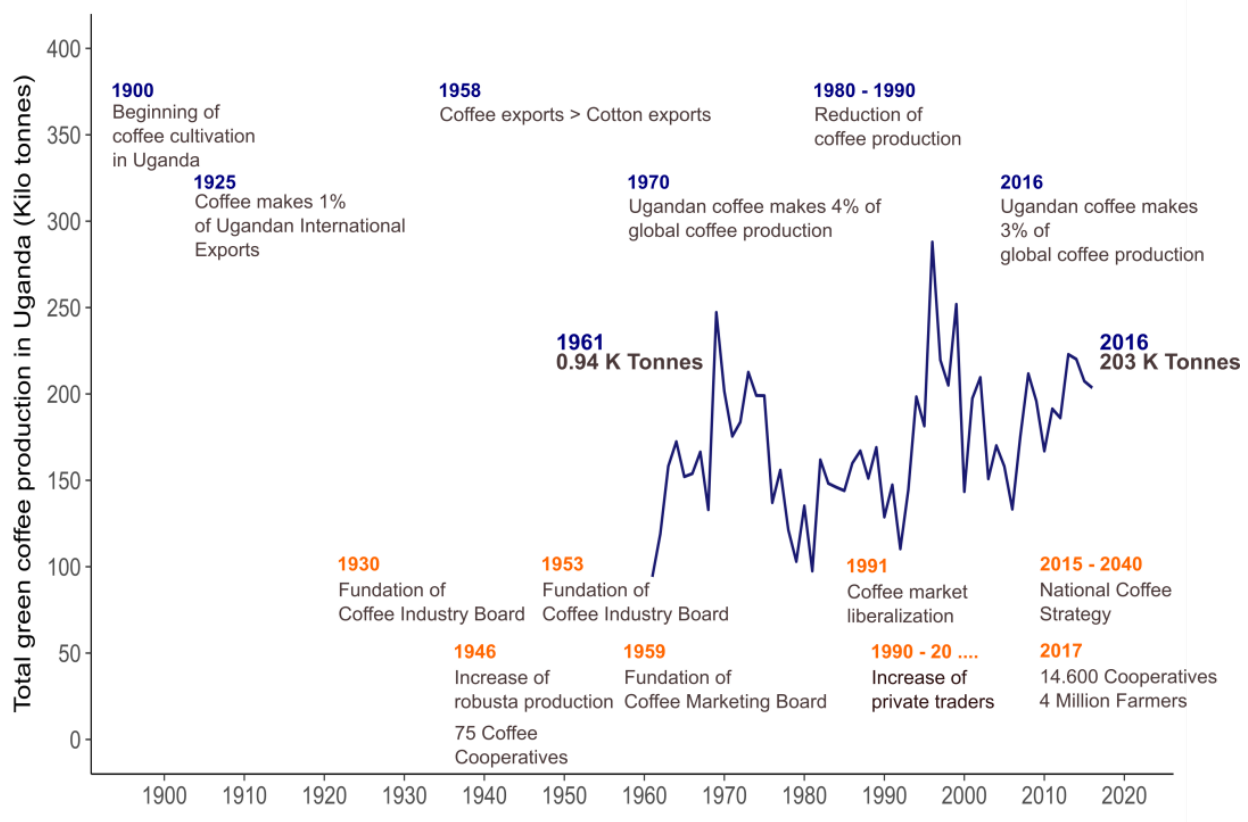

Fig.3. Timeline of the coffee sector in Uganda. Line represents total green coffee production in Uganda from 1961 to 2016 based on data provided by FAOSTAT accessed April 2018.

\subsubsection{Group discussions with farmers at Mt. Elgon}


We carried out group discussions about coffee and climate change with the coffee farmers that participate in the project on September 2015. During these group discussions, we aimed: (i) to get an understanding of farmers perception about climate change and climate change impacts on coffee cultivation, (ii) to share and discuss project objectives and methodologies and finally (iii) to understand farmers expectations and concerns. The meetings were carried out following a participatory dynamic, in which farmers were first asked to give their own definitions and answers to questions such as:

- What is climate?

- What is climate change?

- Which are the effects of climate change?

- Which are the effects of climate change on coffee?

- Do farmers care about coffee quality? Why?

And later on, farmers' answers were contrasted with definitions provided by the International Panel for Climate Change (IPCC, 2014). Thereby, we also discussed about the farmers' perception on the role of different cultivation systems and which preferences farmers have regarding systems management. Farmers were informed about the objectives of the research and instructed in the different methodologies used for collecting data. Finally, a list of farmers' concerns, and expectations was completed.

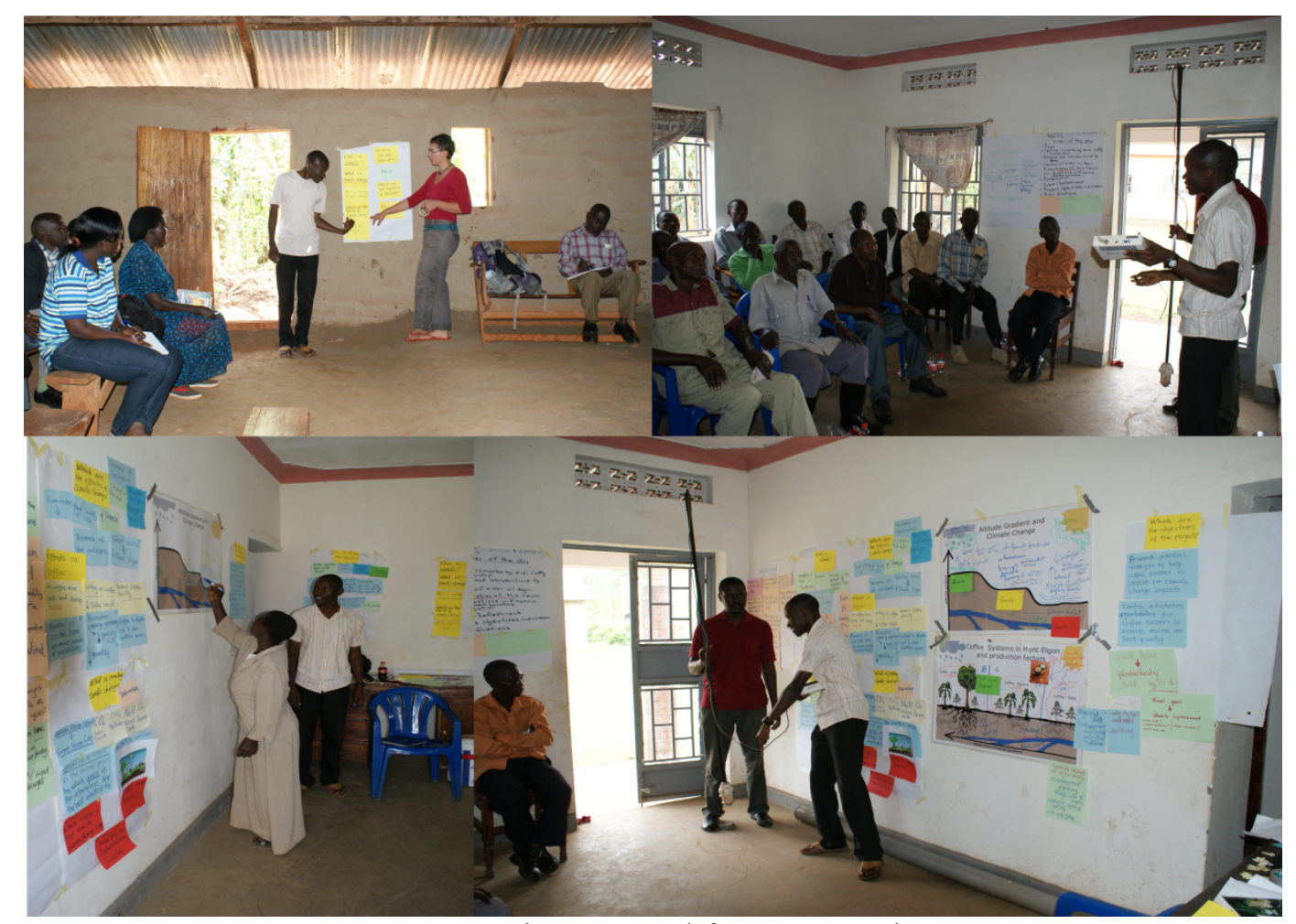

Fig. 4: Group discussions with farmers at Mt. Elgon 
Farmers demonstrated a broad understanding of climate, climate change and its implications for coffee. Farmers defined the Mt. Elgon climate as - "in the past there was two rainy seasons, one light from March to May and another stronger from August to October, but this is not predictable anymore"-. Furthermore, they defined climate change as -"variation in the amount of rain and increase of temperatures"-, and many agreed that would represent a change in planting dates and a more unreliable starting date of the rains, which would imply shorter rainy seasons and longer dry season, with less food and poor crop performance. Regarding specifically to climate change impacts on coffee, farmers at all altitudes mentioned their concern about pest and diseases increases and a reduction of coffee quality. At lower altitudes, farmers also mention water stress, coffee reaching wilting point and threads to food security. While at middle and higher altitudes, farmers were more concern about crop damages occasioned by heavy storms and landslides. Finally, farmers recognized coffee plays an important role in their economies, as well, farmers mentioned coffee importance for Uganda's foreign exchange earnings.

\subsubsection{Data management}

We followed the data life cycle suggested by German Federation for Biological Data (gfbio) for the research data collected in this study.

Plan: during the planning it was decided which variables are crucial to answer the objectives descried before and could they be recorded. We had data collected automatically through data loggers and sensors, while other type of data collected manually. For the last type, a field data collection manual was written, in which it was specified which variables needed to be monitored and the procedure to do so. Furthermore, the field manual was tested by team members and improved before data collection started. Empty data set with variables names and description were created with the objective to facilitate the data collection in the field and ensure consistency on measurements taking at several points on time.

Data collection: depending on the data loggers and sensors capacity, data were downloaded into a computer in the field from every 2 weeks with a maximum span of two months. Manual data were collected every two- or three-months using tablets (Samsung Galaxy Tab Pro 8.4). All raw data were uploaded to the GWDG cloud after each field workday in order to have more than one backup.

Assure: for manual data, each data set was double checked for typing mistakes and formatting errors. The new version was saved as a new file to ensure the existence of primary raw data and avoid 
information lost. Furthermore, data were analyzed for impossible values and outliers. In the case automatized data, original files were arranged to facilitate data analysis and saved in a new version. Data were subject to quality check to identify correct functioning of the sensors during the data collection period. All quality check procedures were performed by a script based program, R Core Team (2017), to ensure reproducibility of data cleaning and analysis procedures.

Describe: for each data set or data set group a metadata was written in which it is described the context of the data set. Location and time frame in which data were collected, as well as data collection procedures and meaning of the variables.

Submit: data sets were (will be) submitted to Dataverse in different Dataverse Objects depending on the research article there were linked with. Data were (will be) submitted in comma separated value (csv) format to ensure readability in the long term.

Data analysis: Microsoft Excel (2010) and R Core Team (2017) were used for data manipulation and cleaning, while data analysis was performed using the program R Core Team (2017) and several packages within it (dplyr, Imer, lubridate, ggplot, multicomp, Imertest). Most of the data analysis presented in this work consisted in comparison of different coffee variables (water use, production, growth) across different management systems, altitude classes and/or seasons. Therefore, we use linear mixed models or generalized linear mixed models (depending on the characteristics of the variable of interest) to determine the effect of the independent variables.

Linear mixed models were used when the dependent variable was continuous, meaning that between to values can be infinite numbers, as in the case of weight $(\mathrm{g})$, yield $(\mathrm{Kg})$, water use $\left(\mathrm{L} \mathrm{tree}^{-1}\right)$. To fulfil the assumptions of linearity, homoskedasticity and normality of residuals linear models, visual assessment of residual plots and as and histogram was done, and transformations (most of the cases $\log ()$ transformation) were used when necessary. Significance levels were determined at $p$-value < 0.005. On the other hand, we used generalized mixed models for the analysis when dependent variables had different distribution from normal (Poisson, binomial), as in the case of number of cherries, number of productive branches. Furthermore, since the experimental design involved repeated measures in time and as well as nested effects (trees inside plots), we used random effects to accounts for the pseudo replication of some data points (Hurlbert, 1984). 


\section{References}

Hurlbert, S. H. (1984). Pseudoreplication and the Design of Ecological Field Experiments. Ecological Monographs, 54(2), 187211.

IPCC. (2014). Climate Change 2014 Synthesis Report. Fifth Assessment Report of the Intergovernmental Panel on Climate Change, 151.

Mbogga, M. (2012). Climate Profiles and Climate Change Vulnerability Assessment for the Mbale Region of Uganda. Retrieved from

Ruane, A. C., Goldberg, R., \& Chryssanthacopoulos, J. (2015). Climate forcing datasets for agricultural modeling: Merged products for gap-filling and historical climate series estimation. Agricultural and Forest Meteorology, 200, 233248. doi:https://doi.org/10.1016/i.agrformet.2014.09.016 


\subsection{Chapter 3: Effect of cropping system, shade cover and altitude gradient on coffee yield components at Mt. Elgon, Uganda}

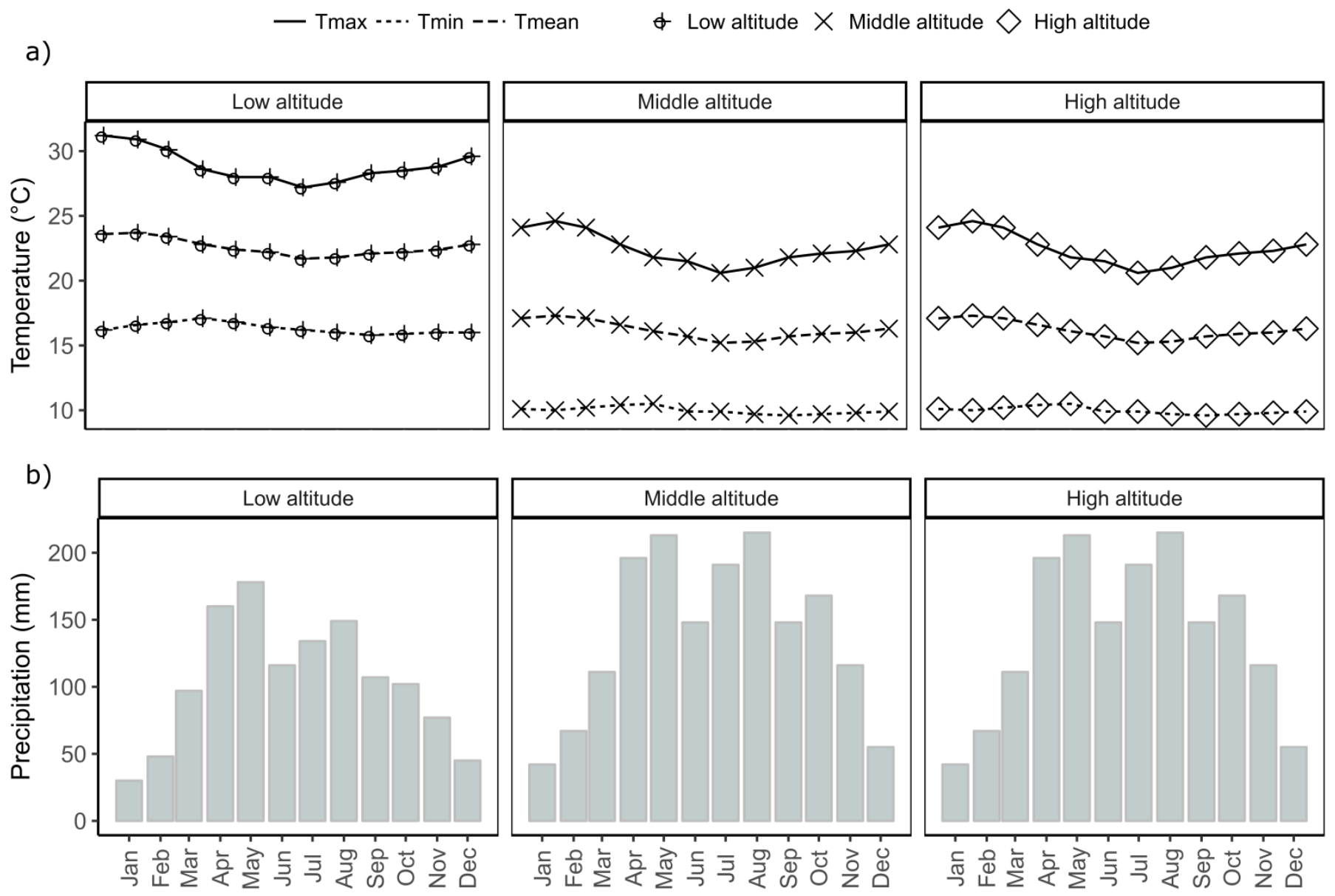

Fig.S.2. a) Monthly temperature (max (solid line), mean (dotted line) and min (dashed line) and b) Monthly precipitation at low altitude $\left(34^{\circ} 30^{\prime} 87^{\prime \prime}-1^{\circ} 30^{\prime} 16^{\prime \prime}, 1200 \mathrm{~m}\right.$ a.s.I.), middle altitude $\left(34^{\circ} 34^{\prime} 11^{\prime \prime}-1^{\circ} 28^{\prime} 40^{\prime \prime}, 1600\right.$ $m$ a.s.l.) and high altitude ( $34^{\circ} 37^{\prime} 63^{\prime \prime}-1^{\circ} 26^{\prime} 29^{\prime \prime}, 2000 \mathrm{~m}$ a.s.l) from WorldClim (1980 -2010) (Fick and Hijmans 2017). 


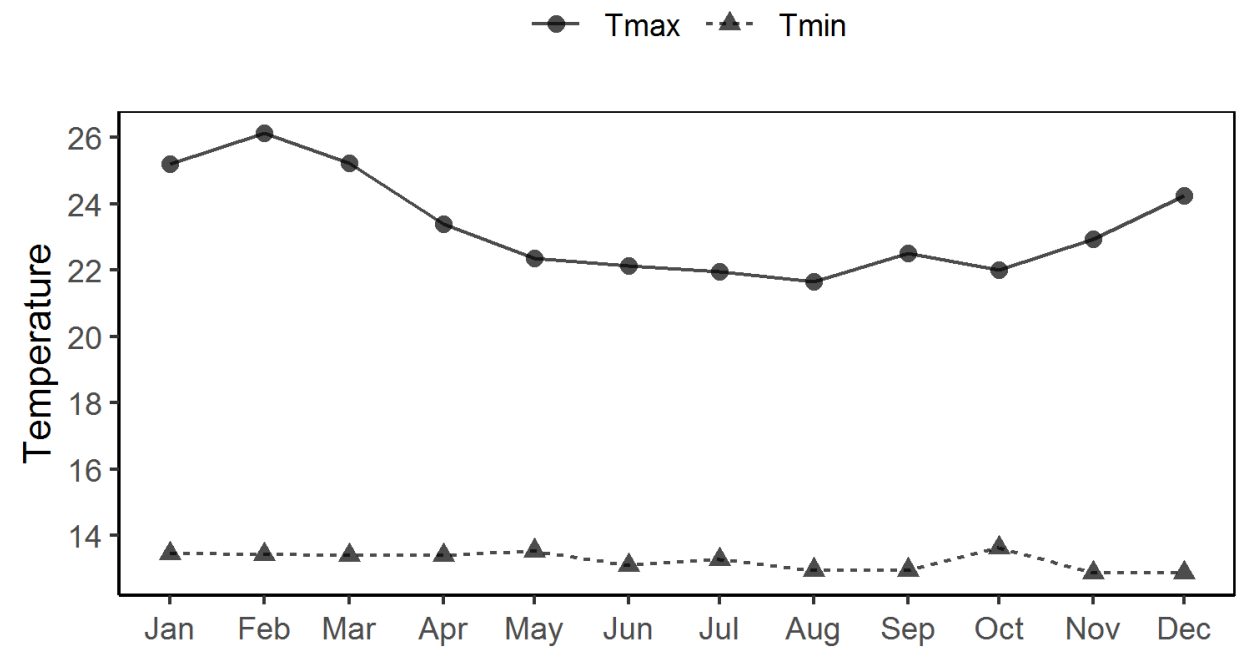

Fig.S.2. a) Monthly temperature (Tmax (solid line) and Tmin (dashed line) at the Buginyanya research station (1800 m.s.l.) from 2005 to 2015.

\section{ALL $-\odot-C O \cdot \triangle \mathrm{CB} \cdot €-\mathrm{CT}$}
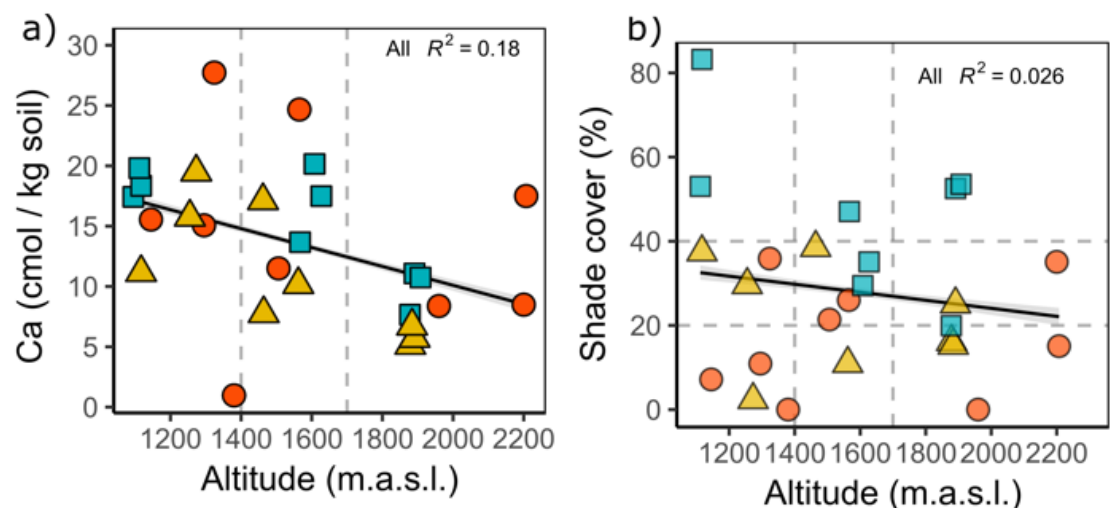

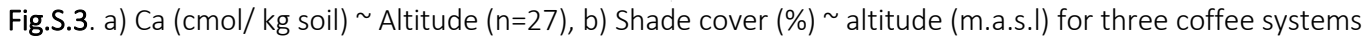
(Coffee-Open = CO (red circle), Coffee Banana = CB (yellow triangle) and Coffee -shade Tree = CT (blue square) $(n=26)$. * Shade cover of one CB plot at mid altitude is missing.

Table S1: Linear regression Shade cover (\%) LAI Shade $\left(\mathrm{m}^{2} \mathrm{~m}^{-2}\right)$

Residuals:

\begin{tabular}{llllll}
\hline Min & $1 \mathrm{Q}$ & Median & $3 \mathrm{Q}$ & Max \\
-28.687 & -11.105 & 0.477 & 9.849 & 37.775 & \\
& & & & & \\
Coefficients: & & & & $\operatorname{Pr}(>|\mathrm{t}|)$ & \\
\hline & Estimate & Std. Error & t value & 0.01569 & $*$ \\
(Intercept) & 13.445 & 5.171 & 2.6 & 0.00118 & $* *$ \\
LAl Shade & 18.261 & 4.964 & 3.679 & & $*$
\end{tabular}

$---$

Signif. codes: $0^{\prime * * * \prime} 0.001^{* * \prime} 0.01^{\prime * \prime} 0.05$ '. $0.1^{\prime \prime} 1$ 
Residual standard error: 16.05 on 24 degrees of freedom

(1 observation deleted due to missingness)

Multiple R-squared: 0.3606, Adjusted R-squared: 0.3339

F-statistic: 13.53 on 1 and 24 DF, p-value: 0.001182

a)

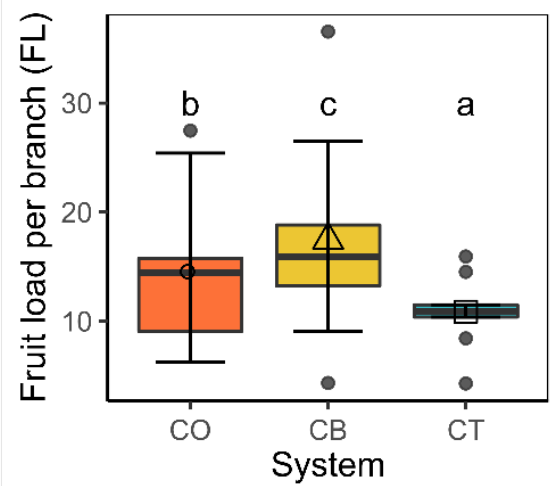

d)

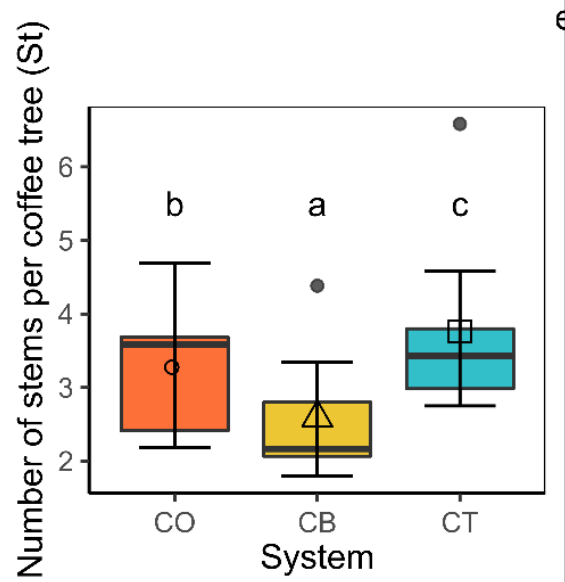

b) $\widehat{z}$

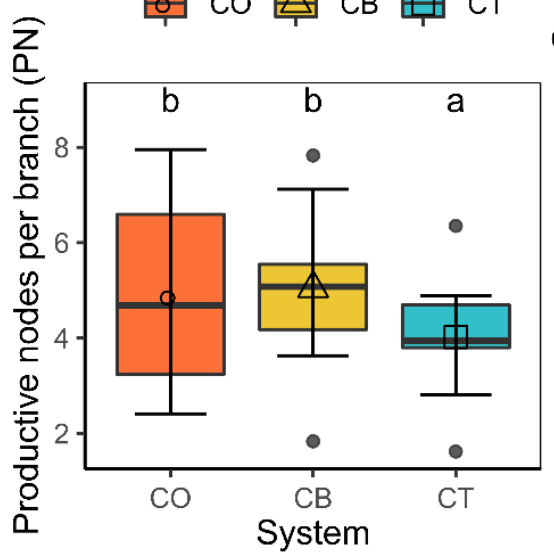

e)

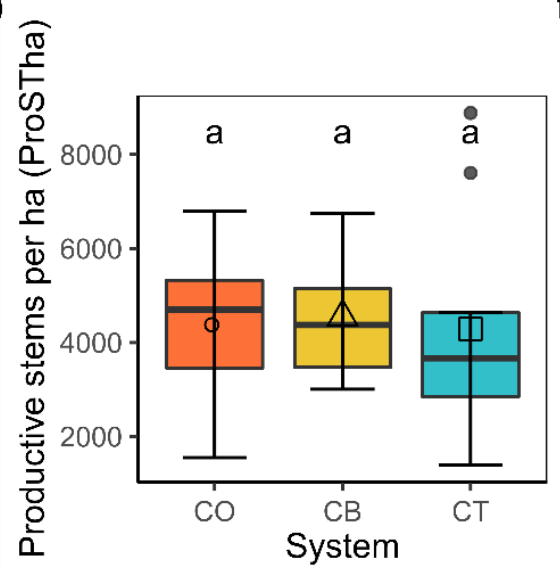

c) $\overparen{0}$

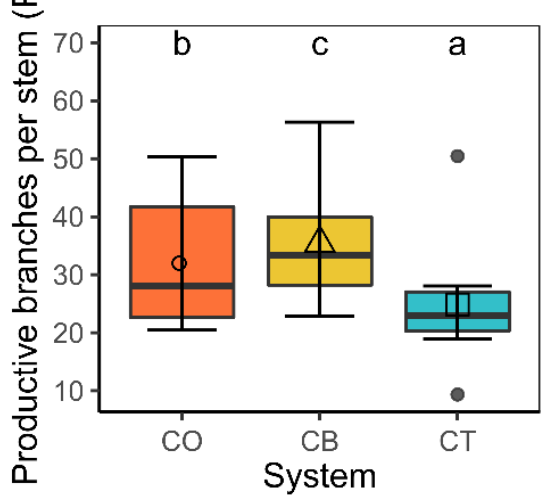

f)

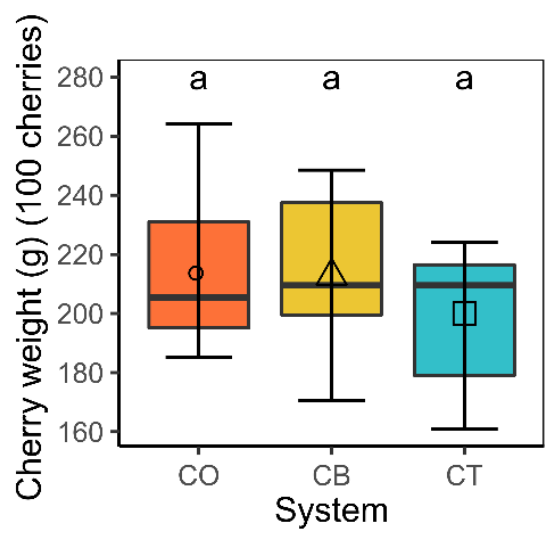

Fig.S4: a) Fruit load per branch, b) productive nodes per branch, c) productive branches per stems, d) number of stems per coffee tree, productive stems per ha, f) cherry weight (g) of 100 fresh cherries. Symbol indicates mean per system and solid horizontal bar indicates median per system. Systems are identified by colour and symbol, CoffeeOpen $=$ CO (circle), Coffee Banana $=$ CB (triangle) and Coffee - shade Tree $=C T$ (square)). Letters indicate significance values at $p$-value $<0.05$. 
Table 2: Model results from management practices

\begin{tabular}{|c|c|c|c|c|c|}
\hline \multicolumn{6}{|l|}{ Fruit load (FL) } \\
\hline & Estimate & Std.Error & $z$ value & $\operatorname{Pr}(>|z|)$ & \\
\hline (Intercept) & 2.46 & 0.04 & 55.58 & $<2 \mathrm{e}-16$ & $* * *$ \\
\hline Stumped (YES) & -0.47 & 0.08 & -6.20 & 0.00 & $* * *$ \\
\hline (Intercept) & 2.31 & 0.04 & 52.67 & $<2 \mathrm{e}-16$ & $* * *$ \\
\hline Fungicide use (Yes) & -0.03 & 0.09 & -0.35 & 0.72 & \\
\hline (Intercept) & 2.14 & 0.05 & 46.97 & $<2 \mathrm{e}-16$ & \\
\hline Fertilizer use (Yes) & 0.45 & 0.07 & 6.00 & 0.00 & $* * *$ \\
\hline (Intercept) & 2.70 & 0.08 & 34.39 & $<2 \mathrm{e}-16$ & $* * *$ \\
\hline Manure use (Yes) & -0.54 & 0.09 & -5.89 & 0.00 & $* * *$ \\
\hline (Intercept) & 2.37 & 0.05 & 51.50 & $<2 \mathrm{e}-16$ & $* * *$ \\
\hline Insecticide use (Yes) & -0.23 & 0.08 & -2.79 & 0.01 & $* *$ \\
\hline (Intercept) & 2.40 & 0.06 & 37.87 & $<2 \mathrm{e}-16$ & $* * *$ \\
\hline Shade tree prunning (Yes) & -0.15 & 0.08 & -1.96 & 0.05 & $*$ \\
\hline (Intercept) & 1.89 & 0.18 & 10.47 & $<2 \mathrm{e}-16$ & $* * *$ \\
\hline Mechanical weeding (Yes) & 0.42 & 0.18 & 2.27 & 0.02 & $*$ \\
\hline (Intercept) & 2.25 & 0.04 & 53.57 & $<2 \mathrm{e}-16$ & $* * *$ \\
\hline Herbicide use (Yes) & 0.19 & 0.09 & 2.15 & 0.03 & $*$ \\
\hline (Intercept) & 2.49 & 0.08 & 32.04 & $<2 \mathrm{e}-16$ & $* * *$ \\
\hline Coffee prunning (Yes) & -0.24 & 0.09 & -2.78 & 0.01 & $* *$ \\
\hline (Intercept) & 2.17 & 0.06 & 38.46 & $<2 \mathrm{e}-16$ & $* * *$ \\
\hline Chemicaluse (Yes) & 0.22 & 0.07 & 2.95 & 0.00 & $* *$ \\
\hline \multicolumn{6}{|l|}{ Productive branches (PB) } \\
\hline & Estimate & Std.Error & $z$ value & $\operatorname{Pr}(>|z|)$ & \\
\hline (Intercept) & 3.38 & 0.03 & 123.51 & $<2 \mathrm{e}-16$ & $* * *$ \\
\hline Stumped (YES) & -0.43 & 0.05 & -8.99 & $<2 \mathrm{e}-16$ & $* * *$ \\
\hline (Intercept) & 3.22 & 0.03 & 115.47 & $<2 \mathrm{e}-16$ & $* * *$ \\
\hline Fungicide use (Yes) & 0.04 & 0.06 & 0.73 & 0.47 & \\
\hline (Intercept) & 3.11 & 0.03 & 108.91 & $<2 \mathrm{e}-16$ & $* * *$ \\
\hline Fertilizer use (Yes) & 0.34 & 0.05 & 7.15 & 0.00 & $* * *$ \\
\hline
\end{tabular}




\begin{tabular}{|c|c|c|c|c|c|}
\hline (Intercept) & 3.37 & 0.05 & 67.72 & $<2 \mathrm{e}-16$ & $* * *$ \\
\hline Manure use (Yes) & -0.21 & 0.06 & -3.66 & 0.00 & $* * *$ \\
\hline (Intercept) & 3.38 & 0.03 & 122.95 & $<2 \mathrm{e}-16$ & $* * *$ \\
\hline Insecticide use (Yes) & -0.47 & 0.05 & -9.49 & $<2 \mathrm{e}-16$ & $* * *$ \\
\hline (Intercept) & 3.35 & 0.04 & 83.90 & $<2 \mathrm{e}-16$ & $* * *$ \\
\hline Shade tree prunning (Yes) & -0.18 & 0.05 & -3.70 & 0.00 & $* * *$ \\
\hline (Intercept) & 2.81 & 0.12 & 23.83 & $<2 \mathrm{e}-16$ & $* * *$ \\
\hline Mechanical weeding (Yes) & 0.44 & 0.12 & 3.69 & 0.00 & $* * *$ \\
\hline (Intercept) & 3.19 & 0.03 & 119.81 & $<2 \mathrm{e}-16$ & $* * *$ \\
\hline Herbicide use (Yes) & 0.21 & 0.06 & 3.66 & 0.00 & $* * *$ \\
\hline (Intercept) & 3.46 & 0.05 & 70.92 & 0.00 & $* * *$ \\
\hline Coffee prunning (Yes) & -0.30 & 0.06 & -5.33 & 0.00 & $* * *$ \\
\hline (Intercept) & 3.28 & 0.04 & 91.60 & $<2 \mathrm{e}-16$ & $* * *$ \\
\hline Chemicaluse (Yes) & -0.09 & 0.05 & -1.93 & 0.05 & . \\
\hline \multicolumn{6}{|l|}{ Productive nodes (PN) } \\
\hline & Estimate & Std.Error & $z$ value & $\operatorname{Pr}(>|z|)$ & \\
\hline (Intercept) & 1.53 & 0.03 & 48.73 & $<2 \mathrm{e}-16$ & $* * *$ \\
\hline Stumped (YES) & -0.35 & 0.05 & -6.37 & 0.00 & $* * *$ \\
\hline (Intercept) & 1.40 & 0.03 & 44.39 & $<2 \mathrm{e}-16$ & $* * *$ \\
\hline Fungicide use (Yes) & 0.04 & 0.06 & 0.56 & 0.58 & \\
\hline (Intercept) & 1.30 & 0.03 & 38.60 & $<2 \mathrm{e}-16$ & $* * *$ \\
\hline Fertilizer use (Yes) & 0.30 & 0.05 & 5.76 & 0.00 & $* * *$ \\
\hline (Intercept) & 1.64 & 0.05 & 30.71 & $<2 \mathrm{e}-16$ & $* * *$ \\
\hline Manure use (Yes) & -0.31 & 0.06 & -5.07 & 0.00 & $* * *$ \\
\hline (Intercept) & 1.46 & 0.03 & 44.21 & $<2 \mathrm{e}-16$ & $* * *$ \\
\hline Insecticide use (Yes) & -0.14 & 0.06 & -2.43 & 0.02 & $*$ \\
\hline (Intercept) & 1.52 & 0.04 & 34.70 & $<2 \mathrm{e}-16$ & $* * *$ \\
\hline Shade tree prunning (Yes) & -0.17 & 0.05 & -3.18 & 0.00 & $* *$ \\
\hline (Intercept) & 0.95 & 0.14 & 6.75 & 0.00 & $* * *$ \\
\hline Mechanical weeding (Yes) & 0.48 & 0.14 & 3.34 & 0.00 & $* * *$ \\
\hline (Intercept) & 1.37 & 0.03 & 44.68 & $<2 \mathrm{e}-16$ & $* * *$ \\
\hline
\end{tabular}




\begin{tabular}{|c|c|c|c|c|c|}
\hline Herbicide use (Yes) & 0.18 & 0.06 & 2.95 & 0.00 & $* *$ \\
\hline (Intercept) & 1.60 & 0.05 & 30.33 & $<2 \mathrm{e}-16$ & $* * *$ \\
\hline Coffee prunning (Yes) & -0.24 & 0.06 & -4.07 & 0.00 & $* * *$ \\
\hline (Intercept) & 1.30 & 0.04 & 31.76 & $<2 \mathrm{e}-16$ & $* * *$ \\
\hline Chemicaluse (Yes) & 0.18 & 0.05 & 3.53 & 0.00 & $* * *$ \\
\hline \multicolumn{6}{|l|}{$N^{\circ}$ of Stems per tree $(\mathrm{St})$} \\
\hline & Estimate & Std.Error & $z$ value & $\operatorname{Pr}(>|z|)$ & \\
\hline (Intercept) & 1.172 & 0.026 & 44.670 & $<2 \mathrm{e}-16$ & $* * *$ \\
\hline Stumped (YES) & 0.040 & 0.044 & 0.900 & 0.366 & \\
\hline (Intercept) & 1.200 & 0.024 & 49.300 & $<2 \mathrm{e}-16$ & $* * *$ \\
\hline Fungicide use (Yes) & -0.099 & 0.053 & -1.880 & 0.061 & . \\
\hline (Intercept) & 1.245 & 0.025 & 49.100 & $<2 \mathrm{e}-16$ & $* * *$ \\
\hline Fertilizer use (Yes) & -0.179 & 0.046 & -3.940 & 0.000 & $* * *$ \\
\hline (Intercept) & 1.167 & 0.046 & 25.628 & $<2 \mathrm{e}-16$ & $* * *$ \\
\hline Manure use (Yes) & -0.045 & 0.053 & -0.858 & 0.391 & \\
\hline (Intercept) & 1.132 & 0.027 & 42.170 & $<2 e-16$ & $* * *$ \\
\hline Insecticide use (Yes) & 0.140 & 0.045 & 3.100 & 0.002 & $* *$ \\
\hline (Intercept) & 1.106 & 0.037 & 29.777 & $<2 \mathrm{e}-16$ & $* * *$ \\
\hline Shade tree prunning (Yes) & 0.121 & 0.045 & 2.672 & 0.008 & $* *$ \\
\hline (Intercept) & 1.885 & 0.071 & 26.480 & $<2 \mathrm{e}-16$ & $* * *$ \\
\hline MechanicalWeeding Yes & -0.746 & 0.075 & -10.010 & $<2 \mathrm{e}-16$ & $* * *$ \\
\hline (Intercept) & 1.171 & 0.024 & 48.750 & $<2 \mathrm{e}-16$ & $* * *$ \\
\hline Herbicide use (Yes) & 0.068 & 0.050 & 1.360 & 0.174 & \\
\hline (Intercept) & 1.154 & 0.046 & 25.158 & $<2 \mathrm{e}-16$ & $* * *$ \\
\hline Coffee prunning (Yes) & 0.041 & 0.052 & 0.792 & 0.428 & \\
\hline (Intercept) & 1.208 & 0.032 & 38.160 & $<2 \mathrm{e}-16$ & $* * *$ \\
\hline Chemicaluse (Yes) & -0.040 & 0.042 & -0.940 & 0.350 & \\
\hline \multicolumn{6}{|c|}{$\mathrm{N}^{\circ}$ of productive stems per ha (ProStemHa) } \\
\hline & Estimate & Std.Error & $z$ value & $\operatorname{Pr}(>|z|)$ & \\
\hline (Intercept) & 8.288 & 0.019 & 429.100 & $<2 \mathrm{e}-16$ & $* * *$ \\
\hline
\end{tabular}




\begin{tabular}{|c|c|c|c|c|c|}
\hline Stumped (YES) & 0.067 & 0.033 & 2.000 & 0.041 & $*$ \\
\hline (Intercept) & 8.368 & 0.018 & 462.600 & $<2 \mathrm{e}-16$ & $* * *$ \\
\hline Fungicide use (Yes) & -0.229 & 0.038 & -6.000 & 0.000 & $* * *$ \\
\hline (Intercept) & 8.299 & 0.019 & 428.700 & $<2 \mathrm{e}-16$ & $* * *$ \\
\hline Fertilizer use (Yes) & 0.036 & 0.033 & 1.100 & 0.271 & \\
\hline (Intercept) & 8.427 & 0.035 & 241.390 & $<2 \mathrm{e}-16$ & $* * *$ \\
\hline Manure use (Yes) & -0.113 & 0.040 & -2.810 & 0.005 & $* *$ \\
\hline (Intercept) & 8.391 & 0.019 & 439.400 & $<2 \mathrm{e}-16$ & $* * *$ \\
\hline Insecticide use (Yes) & -0.235 & 0.034 & -6.900 & 0.000 & $* * *$ \\
\hline (Intercept) & 8.254 & 0.026 & 312.750 & $<2 \mathrm{e}-16$ & $* * *$ \\
\hline Shade tree prunning (Yes) & 0.088 & 0.033 & 2.690 & 0.007 & $* *$ \\
\hline (Intercept) & 8.165 & 0.075 & 109.100 & $<2 \mathrm{e}-16$ & $* * *$ \\
\hline Mechanical weeding (Yes) & 0.153 & 0.077 & 2.000 & 0.045 & $*$ \\
\hline (Intercept) & 8.360 & 0.017 & 485.100 & $<2 \mathrm{e}-16$ & $* * *$ \\
\hline Herbicide use & -0.223 & 0.037 & -6.000 & 0.000 & $* * *$ \\
\hline (Intercept) & 8.229 & 0.033 & 246.600 & $<2 \mathrm{e}-16$ & $* * *$ \\
\hline Coffee prunning (Yes) & 0.106 & 0.038 & 2.810 & 0.005 & $* *$ \\
\hline (Intercept) & 8.433 & 0.023 & 368.000 & $<2 \mathrm{e}-16$ & $* * *$ \\
\hline Chemicaluse (Yes) & -0.215 & 0.030 & -7.100 & 0.000 & $* * *$ \\
\hline \multicolumn{6}{|l|}{ Cherry weigth (CW) } \\
\hline & Estimate & Std.Error & $\mathrm{t}$ value & $\operatorname{Pr}(>|t|)$ & \\
\hline (Intercept) & 204.9 & 6.071 & 33.749 & $<2 \mathrm{e}-16$ & $* * *$ \\
\hline Stumped (YES) & 10.037 & 10.294 & 0.975 & 0.341 & \\
\hline (Intercept) & 203.118 & 5.495 & 36.961 & $<2 \mathrm{e}-16$ & $* * *$ \\
\hline Fungicide use (Yes) & 21.582 & 11.527 & 1.872 & 0.0759 & . \\
\hline (Intercept) & 202.4 & 5.798 & 34.91 & $<2 e-16$ & $* * *$ \\
\hline Fertilizer use (Yes) & 17.225 & 9.831 & 1.752 & 0.0943 & . \\
\hline (Intercept) & 207.9 & 11.02 & 18.874 & $2.61 \mathrm{E}-13$ & $* * *$ \\
\hline Manure use (Yes) & 1.9 & 12.72 & 0.149 & 0.883 & \\
\hline (Intercept) & 206.5 & 6.314 & 32.707 & $<2 \mathrm{e}-16$ & $* * *$ \\
\hline Insecticide use (Yes) & 4.786 & 11.193 & 0.428 & 0.674 & \\
\hline
\end{tabular}


(Intercept)

Shade tree prunning (Yes)

(Intercept)

Mechanical weeding (Yes)

(Intercept)

Herbicide use

(Intercept)

Coffee prunning (Yes)

(Intercept)

Chemicaluse (Yes)
226.438

$-27.671$

175.5

34.39

22.89

23.41

206.306

9.594

221.2

$-16.37$

200.95

13.165

6.961

8.62

5.582

11.971

7.289

9.695
$32.53<2 \mathrm{e}-16$

$-3.21$

0.0042

$36.962<2 \mathrm{e}-16$

0.801

0.432

10.28

21.525

$8.58 \mathrm{E}-16 \quad * * *$

11.62

$-1.409$

0.173

$27.569<2 \mathrm{e}-16$

1.358

0.189 
Table 3: Model results from Pest and diseases (Stemborer, $\mathrm{CLR}=$ coffee leaf rust, $\mathrm{CBB}=$ coffee berry borer, antesia bugs, scales, $C L M=$ coffee leaf miner, aphids, mites, $C B D=$ coffee berry disease)

\begin{tabular}{|c|c|c|c|c|c|}
\hline \multicolumn{6}{|l|}{ Fruit load (FL) } \\
\hline & Estimate & Std.Error & $z$ value & $\operatorname{Pr}(>|z|)$ & \\
\hline (Intercept) & 2.88 & 0.08 & 35.57 & 0 & $* * *$ \\
\hline Stemborer (Yes) & -0.70 & 0.09 & -7.7 & $1 E-14$ & $* * *$ \\
\hline (Intercept) & 2.32 & 0.06 & 37.10 & $<2 \mathrm{e}-16$ & $* * *$ \\
\hline CLR (Yes) & -0.01 & 0.08 & -0.14 & 0.886 & \\
\hline (Intercept) & 2.31 & 0.04 & 57.06 & $<2 \mathrm{e}-16$ & $* * *$ \\
\hline CBB (Yes) & 0.05 & 0.13 & 0.36 & 0.719 & \\
\hline (Intercept) & 2.32 & 0.04 & 59.19 & $<2 \mathrm{e}-16$ & $* * *$ \\
\hline Antesia bugs (Yes) & -0.26 & 0.18 & -1.41 & 0.16 & \\
\hline (Intercept) & 2.27 & 0.04 & 55.29 & $<2 e-16$ & $* * *$ \\
\hline Scales (Yes) & 0.31 & 0.11 & 2.88 & 0.00397 & $* *$ \\
\hline (Intercept) & 2.31 & 0.04 & 58.64 & $<2 \mathrm{e}-16$ & $* * *$ \\
\hline CLM (Yes) & 0.04 & 0.18 & 0.21 & 0.836 & \\
\hline (Intercept) & 2.32 & 0.04 & 57.68 & $<2 \mathrm{e}-16$ & $* * *$ \\
\hline AphidsYes & -0.13 & 0.13 & -1.01 & 0.311 & \\
\hline (Intercept) & 2.27 & 0.04 & 58.83 & $<2 \mathrm{e}-16$ & $* * *$ \\
\hline Mites (Yes) & 0.89 & 0.17 & 5.27 & $1 \mathrm{E}-07$ & $* * *$ \\
\hline (Intercept) & 2.31 & 0.04 & 54.28 & $<2 \mathrm{e}-16$ & $* * *$ \\
\hline CBD (Yes) & 0.00 & 0.10 & 0.02 & 0.987 & \\
\hline \multicolumn{6}{|c|}{ Productive branches (PB) } \\
\hline & Estimate & Std.Error & $z$ value & $\operatorname{Pr}(>|z|)$ & \\
\hline (Intercept) & 3.55 & 0.05 & 66.05 & $<2 \mathrm{e}-16$ & $* * *$ \\
\hline Stemborer (Yes) & -0.36 & 0.06 & -6.06 & 0.00 & $* * *$ \\
\hline (Intercept) & 3.42 & 0.04 & 89.39 & $<2 \mathrm{e}-16$ & $* * *$ \\
\hline CLR (Yes) & -0.28 & 0.05 & -5.71 & 0.00 & $* * *$ \\
\hline (Intercept) & 3.24 & 0.03 & 127.70 & $<2 \mathrm{e}-16$ & $* * *$ \\
\hline CBB (Yes) & 0.14 & 0.08 & 1.67 & 0.10 & . \\
\hline (Intercept) & 3.27 & 0.02 & 133.68 & $<2 \mathrm{e}-16$ & $* * *$ \\
\hline
\end{tabular}




\begin{tabular}{|c|c|c|c|c|c|}
\hline Antesia bugs (Yes) & -0.40 & 0.12 & -3.48 & 0.00 & $* * *$ \\
\hline (Intercept) & 3.24 & 0.03 & 124.83 & $<2 \mathrm{e}-16$ & $* * *$ \\
\hline Scales (Yes) & 0.06 & 0.07 & 0.85 & 0.40 & \\
\hline (Intercept) & 3.23 & 0.02 & 132.60 & $<2 \mathrm{e}-16$ & $* * *$ \\
\hline CLM (Yes) & 0.51 & 0.11 & 4.69 & 0.00 & $* * *$ \\
\hline (Intercept) & 3.27 & 0.03 & 129.72 & $<2 \mathrm{e}-16$ & $* * *$ \\
\hline Aphids (Yes) & -0.18 & 0.08 & -2.16 & 0.03 & $*$ \\
\hline (Intercept) & 3.23 & 0.02 & 132.00 & $<2 \mathrm{e}-16$ & $* * *$ \\
\hline Mites (Yes) & 0.43 & 0.11 & 3.88 & 0.00 & $* * *$ \\
\hline (Intercept) & 3.27 & 0.03 & 122.84 & $<2 \mathrm{e}-16$ & $* * *$ \\
\hline CBD (Yes) & -0.10 & 0.06 & -1.64 & 0.10 & \\
\hline \multicolumn{6}{|c|}{ Productive nodes per branch (PN) } \\
\hline & Estimate & Std.Error & $z$ value & $\operatorname{Pr}(>|z|)$ & \\
\hline (Intercept) & 1.72 & 0.06 & 30.66 & $<2 \mathrm{e}-16$ & $* * *$ \\
\hline Stemborer (Yes) & -0.36 & 0.06 & -5.70 & 0.00 & $* * *$ \\
\hline (Intercept) & 1.44 & 0.04 & 32.69 & $<2 \mathrm{e}-16$ & $* * *$ \\
\hline CLR (Yes) & -0.02 & 0.05 & -0.35 & 0.72 & \\
\hline (Intercept) & 1.43 & 0.03 & 49.01 & $<2 \mathrm{e}-16$ & $* * *$ \\
\hline CBB (Yes) & -0.02 & 0.09 & -0.21 & 0.83 & \\
\hline (Intercept) & 2.32 & 0.04 & 59.19 & $<2 \mathrm{e}-16$ & $* * *$ \\
\hline Antesia bugs (Yes) & -0.26 & 0.18 & -1.41 & 0.16 & \\
\hline (Intercept) & 1.38 & 0.03 & 46.96 & $<2 \mathrm{e}-16$ & $* * *$ \\
\hline Scales (Yes) & 0.30 & 0.07 & 4.29 & 0.00 & $* * *$ \\
\hline (Intercept) & 1.42 & 0.03 & 49.93 & $<2 \mathrm{e}-16$ & $* * *$ \\
\hline CLM (Yes) & 0.07 & 0.12 & 0.58 & 0.56 & \\
\hline (Intercept) & 1.44 & 0.03 & 49.64 & $<2 \mathrm{e}-16$ & $* * *$ \\
\hline Aphids (Yes) & -0.13 & 0.09 & -1.38 & 0.17 & \\
\hline (Intercept) & 1.40 & 0.03 & 49.83 & $<2 \mathrm{e}-16$ & $* * *$ \\
\hline Mites (Yes) & 0.61 & 0.11 & 5.68 & 0.00 & $* * *$ \\
\hline (Intercept) & 1.44 & 0.03 & 47.34 & $<2 \mathrm{e}-16$ & $* * *$ \\
\hline CBD (Yes) & -0.08 & 0.07 & -1.12 & 0.26 & \\
\hline
\end{tabular}


Number of stems per tree (St)

\begin{tabular}{|c|c|c|c|c|c|}
\hline & Estimate & Std.Error & $z$ value & $\operatorname{Pr}(>|z|)$ & \\
\hline (Intercept) & 0.96 & 0.06 & 17.05 & $<2 \mathrm{e}-16$ & $* * *$ \\
\hline Stemborer (Yes) & 0.21 & 0.06 & 3.46 & 0.00 & $* * *$ \\
\hline (Intercept) & 1.01 & 0.04 & 25.73 & $<2 \mathrm{e}-16$ & $* * *$ \\
\hline CLR (Yes) & 0.20 & 0.05 & 4.18 & 0.00 & $* * *$ \\
\hline (Intercept) & 1.15 & 0.02 & 50.12 & $<2 \mathrm{e}-16$ & $* * *$ \\
\hline CBB (Yes) & -0.16 & 0.08 & -1.94 & 0.05 & . \\
\hline (Intercept) & 1.13 & 0.02 & 50.09 & $<2 \mathrm{e}-16$ & $* * *$ \\
\hline Antesia bugs (Yes) & 0.10 & 0.10 & 0.99 & 0.32 & \\
\hline (Intercept) & 1.16 & 0.02 & 49.37 & $<2 \mathrm{e}-16$ & $* * *$ \\
\hline Scales (Yes) & -0.17 & 0.07 & -2.44 & 0.01 & $*$ \\
\hline (Intercept) & 1.15 & 0.02 & 51.44 & $<2 \mathrm{e}-16$ & $* * *$ \\
\hline CLM (Yes) & -0.38 & 0.13 & -3.01 & 0.00 & $* *$ \\
\hline (Intercept) & 1.12 & 0.02 & 47.93 & $<2 \mathrm{e}-16$ & $* * *$ \\
\hline Aphids (Yes) & 0.19 & 0.07 & 2.69 & 0.01 & $* *$ \\
\hline (Intercept) & 1.15 & 0.02 & 51.28 & $<2 \mathrm{e}-16$ & $* * *$ \\
\hline Mites (Yes) & -0.31 & 0.12 & -2.55 & 0.01 & $*$ \\
\hline (Intercept) & 1.131 & 0.024 & 46.200 & $<2 \mathrm{e}-16$ & $* * *$ \\
\hline CBD (Yes) & 0.040 & 0.056 & 0.700 & 0.483 & \\
\hline \multicolumn{6}{|c|}{ Number of productive stems per ha (ProStHa) } \\
\hline & Estimate & Std.Error & $z$ value & $\operatorname{Pr}(>|z|)$ & \\
\hline (Intercept) & 8.23 & 0.04 & 216.22 & $<2 \mathrm{e}-16$ & $* * *$ \\
\hline Stemborer (Yes) & 0.11 & 0.04 & 2.59 & 0.01 & $* *$ \\
\hline (Intercept) & 8.17 & 0.03 & 312.99 & $<2 \mathrm{e}-16$ & $* * *$ \\
\hline CLR (Yes) & 0.23 & 0.03 & 6.91 & 0.00 & $* * *$ \\
\hline (Intercept) & 8.33 & 0.02 & 487.50 & $<2 \mathrm{e}-16$ & $* * *$ \\
\hline CBB (Yes) & -0.08 & 0.06 & -1.50 & 0.15 & \\
\hline (Intercept) & 8.28 & 0.02 & 542.20 & $<2 \mathrm{e}-16$ & $* * *$ \\
\hline Antesia bugs (Yes) & 0.81 & 0.07 & 11.30 & $<2 \mathrm{e}-16$ & $* * *$ \\
\hline (Intercept) & 8.37 & 0.02 & 499.30 & $<2 \mathrm{e}-16$ & $* * *$ \\
\hline
\end{tabular}




\begin{tabular}{|c|c|c|c|c|c|}
\hline Scales (Yes) & -0.36 & 0.05 & -8.00 & 0.00 & $* * *$ \\
\hline (Intercept) & 8.29 & 0.02 & 514.60 & $<2 \mathrm{e}-16$ & $* * *$ \\
\hline CLM (Yes) & 0.52 & 0.08 & 6.90 & 0.00 & $* * *$ \\
\hline (Intercept) & 8.32 & 0.02 & 486.20 & $<2 \mathrm{e}-16$ & $* * *$ \\
\hline Aphids (Yes) & 0.01 & 0.06 & 0.20 & 0.81 & \\
\hline (Intercept) & 8.32 & 0.02 & 499.00 & $<2 \mathrm{e}-16$ & $* * *$ \\
\hline Mites (Yes) & -0.09 & 0.08 & -1.10 & 0.27 & \\
\hline (Intercept) & 8.422 & 0.015 & 547.900 & $<2 \mathrm{e}-16$ & $* * *$ \\
\hline CBD (Yes) & -0.568 & 0.036 & -15.800 & $<2 \mathrm{e}-16$ & $* * *$ \\
\hline \multicolumn{6}{|l|}{ Cherry weigth (CW) } \\
\hline & Estimate & Std.Error & $\mathrm{t}$ value & $\operatorname{Pr}(>|t|)$ & \\
\hline (Intercept) & 222.87 & 11.28 & 19.76 & 0.00 & $* * *$ \\
\hline Stemborer (Yes) & -15.87 & 12.47 & -1.27 & 0.22 & \\
\hline (Intercept) & 209.19 & 8.29 & 25.23 & $<2 \mathrm{e}-16$ & $* * *$ \\
\hline CLR (Yes) & 1.10 & 10.39 & 0.11 & 0.92 & \\
\hline (Intercept) & 211.95 & 5.02 & 42.25 & $<2 \mathrm{e}-16$ & $* * *$ \\
\hline CBB (Yes) & -22.70 & 16.64 & -1.36 & 0.19 & \\
\hline (Intercept) & 211.36 & 4.88 & 43.30 & $<2 \mathrm{e}-16$ & $* * *$ \\
\hline Antesia bugs (Yes) & -32.36 & 22.89 & -1.41 & 0.17 & \\
\hline (Intercept) & 206.13 & 4.88 & 42.26 & $<2 \mathrm{e}-16$ & $* * *$ \\
\hline Scales (Yes) & 27.54 & 13.21 & 2.09 & 0.05 & . \\
\hline (Intercept) & 208.57 & 4.93 & 42.31 & $<2 \mathrm{e}-16$ & $* * *$ \\
\hline CLM (Yes) & 28.93 & 23.12 & 1.25 & 0.23 & \\
\hline (Intercept) & 209.88 & 5.25 & 40.01 & $<2 \mathrm{e}-16$ & $* * *$ \\
\hline Aphids (Yes) & 0.13 & 17.40 & 0.01 & 0.99 & \\
\hline (Intercept) & 208.31 & 4.84 & 43.00 & $<2 \mathrm{e}-16$ & $* * *$ \\
\hline Mites (Yes) & 34.69 & 22.72 & 1.53 & 0.14 & \\
\hline (Intercept) & 206.00 & 5.14 & 40.08 & $<2 \mathrm{e}-16$ & $* * *$ \\
\hline CBD (Yes) & 21.38 & 12.05 & 1.77 & 0.09 & . \\
\hline
\end{tabular}




\subsection{Chapter 4: Water use of Coffea arabica in open versus shaded systems under smallholder's farm conditions in Eastern Uganda}

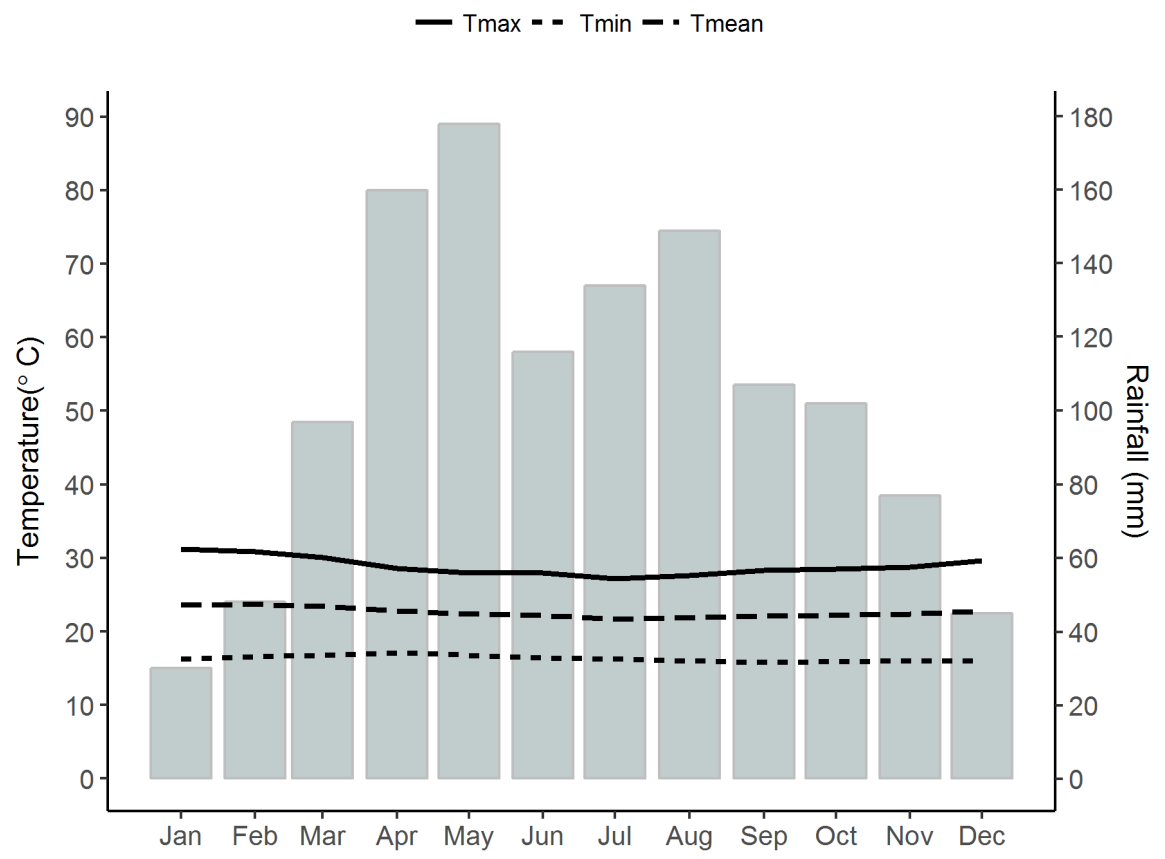

Fig.1 Annual temperature and rainfall patterns according to WorldClim (1970-2010) for the farm location (1ํ $15^{\prime} 52^{\prime \prime} \mathrm{N} 34^{\circ} 19^{\prime}$ 19" E)

a)

b)

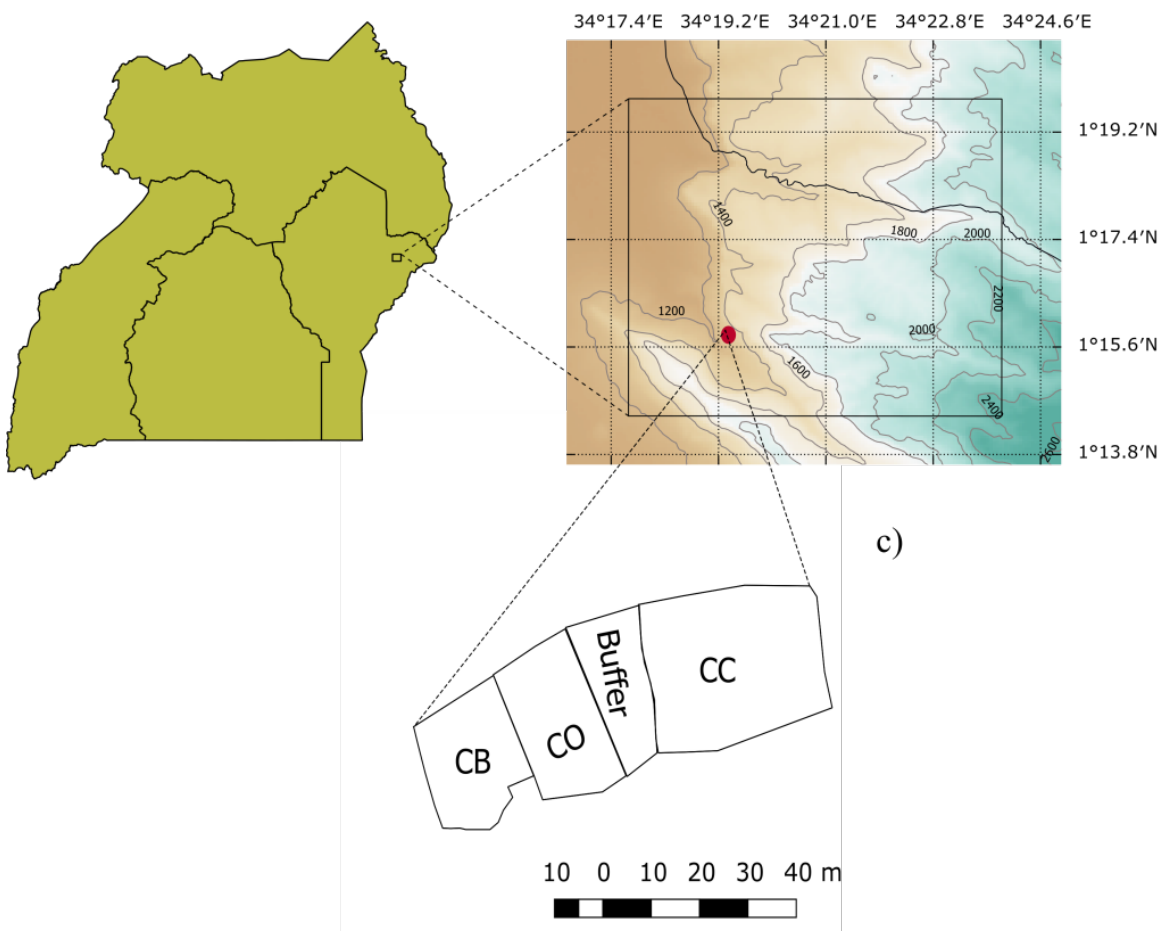

Fig A.2: a) Map of Uganda and location of research area, b) Topographic map of research area with plot location (red point) at 1.300 m.a.s.I c) Map of the research plot with three systems (Coffee-Open = CO, Coffee-Banana = CB and Coffee-Cordia = CC and a buffer area). 
Equation A.1:

$$
E T_{0}=\frac{0.408 \Delta\left(R_{n}-G\right)+\gamma \frac{900}{T+273} u_{2}\left(e_{s}-e_{a}\right)}{\Delta+\gamma\left(1+0.34 u_{2}\right)}
$$

ETO $=$ reference evapotranspiration $\left(\mathrm{mm} \mathrm{d}^{-1}\right)$

$R_{n}=$ net radiation at the crop surface $\left(\mathrm{MJ} \mathrm{m}^{-2} \mathrm{~d}^{-1}\right)$

$\mathrm{G}=$ soil heat flux density

$\mathrm{T}=$ mean daily air temperature at $2 \mathrm{~m}$ height $\left({ }^{\circ} \mathrm{C}\right)$

$\mathrm{u}_{2}=$ wind speed at $2 \mathrm{~m}$ height $\left(\mathrm{m} \mathrm{s}^{-1}\right)$

$\mathrm{e}_{\mathrm{s}}=$ saturation vapour pressure $(\mathrm{kPa})$

$\mathrm{e}_{\mathrm{a}}=$ actual vapur pressure $(\mathrm{kPa})$

es - ea $=$ vapour pressure deficit $(\mathrm{VPD})(\mathrm{kPa})$

$\Delta=$ slope vapour pressure curve $\left(\mathrm{kPa}^{\circ} \mathrm{C}^{-1}\right)$

$\mathrm{v}=$ psychrometric constant $\mathrm{kPa}{ }^{\circ} \mathrm{C}^{-1}$

(Allen et al. 1998)

Equation A.2:

$$
1 \text { watt per } m^{2}\left(W m^{-2}\right)=0.0864 M J m^{-2} \text { day }^{-1}
$$

(Allen et al., 1998)

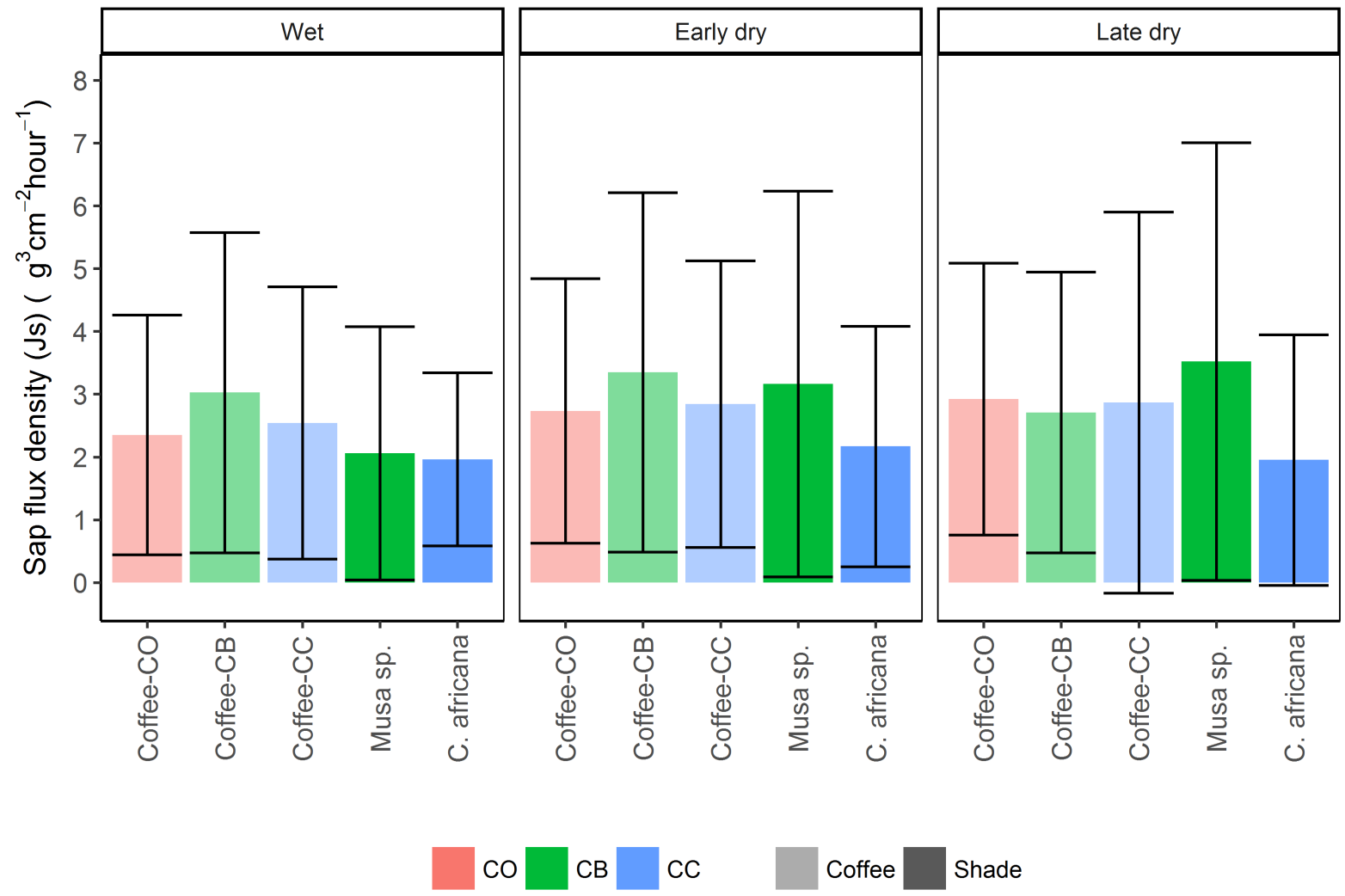

Fig.3: Mean Js of Coffee in different systems (Coffee-CO, Coffee-CB and Coffee-CC), of Banana and Cordia africana during distinct three periods: wet (April, May, Jun, Sep, Oct and Nov 2015, Apr 2016), early dry (Jul, Aug and Dec 2015, Jan 2016) and late dry (Mar 2015, Feb and Mar 2016). 

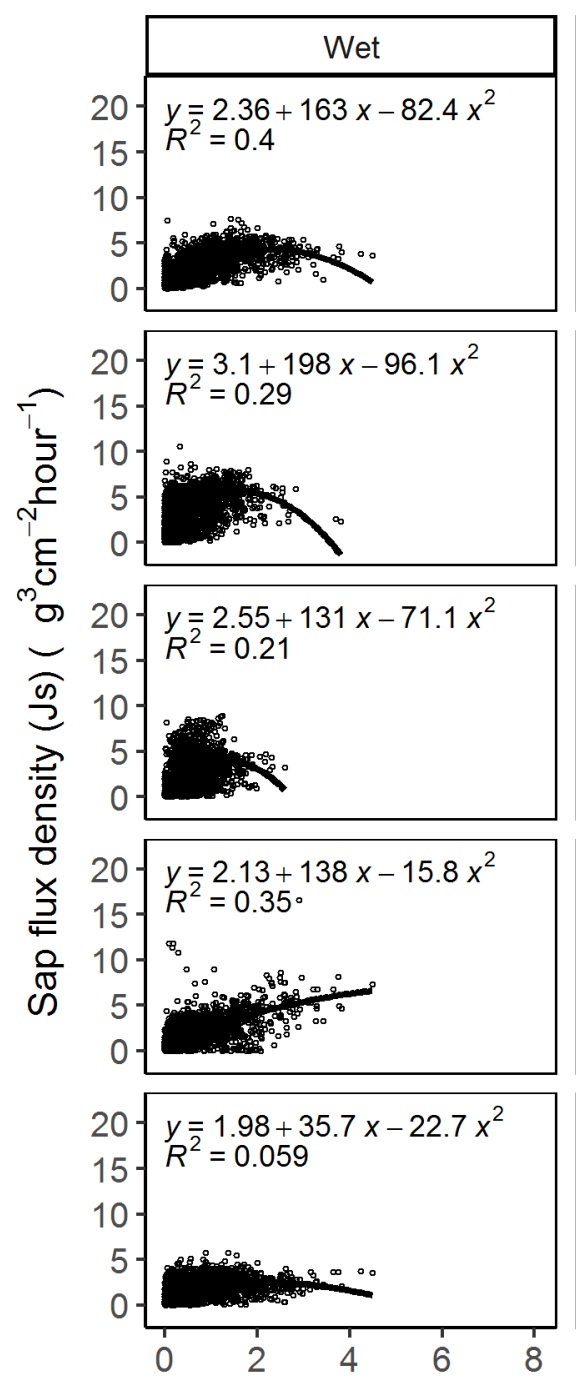
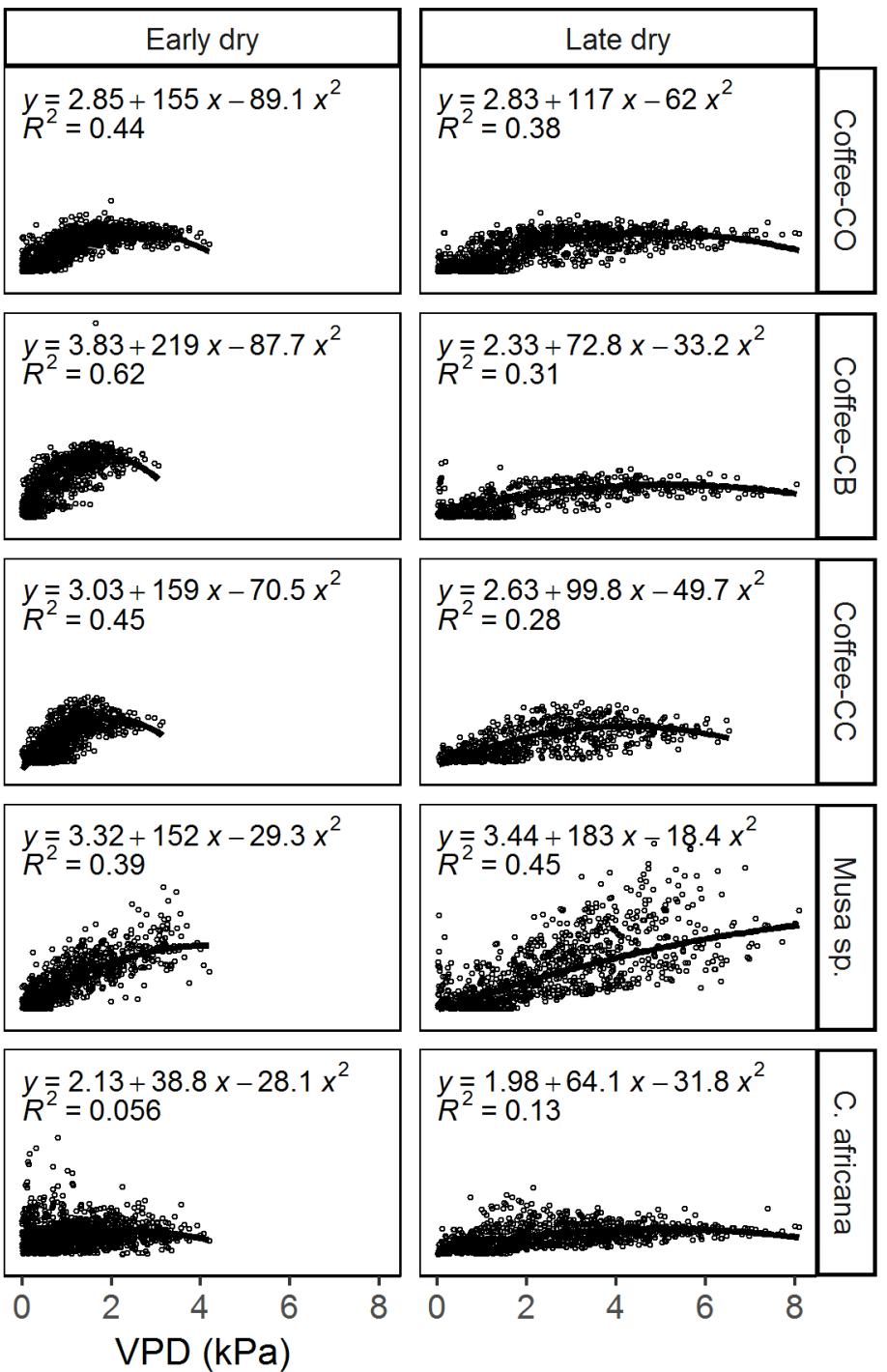

Fig.A.4. Regression Js VPD during for coffee under different systems (Coffee-CO, Coffee-CB and Coffee-CC), Banana and Cordia africana during distinct three periods: wet (April, May, Jun, Sep, Oct and Nov 2015, Apr 2016), early dry (Jul, Aug and Dec 2015, Jan 2016) and late dry (Mar 2015, Feb and Mar 2016).

Table A.1: Differences in mean microclimatic daily data between systems ((Coffee-Open = CO, Coffee-Banana = CB and Coffee-Cordia = CC) during the study period (Mar 2015 - Apr 2016); values with different letters were significantly different at $\mathrm{p}<0.05$.

\begin{tabular}{llll} 
Variable & CO & CB & CC \\
\hline Ta max $\left({ }^{\circ} \mathrm{C}\right)$ & $32.8 \pm 4.7^{\mathrm{a}}$ & $29.7 \pm 4.8^{\mathrm{b}}$ & $28.4 \pm 4.1^{\mathrm{c}}$ \\
Ta min $\left({ }^{\circ} \mathrm{C}\right)$ & $17.8 \pm 1.2^{\mathrm{c}}$ & $17.9 \pm 1.1^{\mathrm{b}}$ & $18.5 \pm 1.2^{\mathrm{a}}$ \\
Ta mean $\left({ }^{\circ} \mathrm{C}\right)$ & $22.8 \pm 2.3^{\mathrm{a}}$ & $22.1 \pm 2.4^{\mathrm{c}}$ & $22.3 \pm 2.3^{\mathrm{b}}$ \\
$\Delta \mathrm{T}(\mathrm{Ta} \max -\mathrm{Ta} \min )\left({ }^{\circ} \mathrm{C}\right)$ & $14.6 \pm 4.3^{\mathrm{a}}$ & $11.9 \pm 4.3^{\mathrm{b}}$ & $10 \pm 3.6^{\mathrm{c}}$ \\
$\operatorname{VPD}(\mathrm{KPa})$ & $0.9 \pm 0.7^{\mathrm{a}}$ & $0.7 \pm 0.7^{\mathrm{c}}$ & $0.8 \pm 0.6^{\mathrm{b}}$ \\
Radiation $\left(\mathrm{Mj} \mathrm{m}^{-2} \mathrm{~d}^{-1}\right)$ & $7.8 \pm 2.8^{\mathrm{a}}$ & $3.5 \pm 2.8^{\mathrm{b}}$ & $2.2 \pm 2^{\mathrm{c}}$ \\
\hline
\end{tabular}


Table A.2: Mean soil water content per depth $(\mathrm{mm})$ by system (Coffee Open = CO, Coffee Banana $=\mathrm{CB}$ and CoffeeCordia $=$ CC) and soil depth every $10 \mathrm{~cm}$ for three periods Wet (April, May, Jun, Sep, Oct and Nov 2015, April 2016), early dry (intermediate grey) (July, Aug. and Dec. 2015, Jan 2016) and late dry (light grey) (March 2015, Feb. and March 2016). (2 access tubes per system)

\begin{tabular}{|c|c|c|c|c|c|c|c|c|c|}
\hline \multirow[b]{2}{*}{ Depth } & \multicolumn{3}{|c|}{ Wet } & \multicolumn{3}{|l|}{ Early dry } & \multicolumn{3}{|l|}{ Late dry } \\
\hline & $\mathrm{CO}$ & $\mathrm{CB}$ & $\mathrm{CC}$ & $\mathrm{CO}$ & $\mathrm{CB}$ & $\mathrm{CC}$ & $\mathrm{CO}$ & $\mathrm{CB}$ & $\mathrm{CC}$ \\
\hline 10 & $29 \pm 5$ & $18 \pm 5$ & $13 \pm 8$ & $28 \pm 11$ & $13 \pm 7$ & $14 \pm 11$ & $6 \pm 7$ & $3 \pm 4$ & $2 \pm 3$ \\
\hline 20 & $35 \pm 4$ & $32 \pm 5$ & $23 \pm 8$ & $35 \pm 8$ & $25 \pm 10$ & $18 \pm 8$ & $15 \pm 11$ & $12 \pm 11$ & $7 \pm 3$ \\
\hline 30 & $33 \pm 4$ & $36 \pm 7$ & $13 \pm 4$ & $34 \pm 5$ & $31 \pm 8$ & $12 \pm 5$ & $19 \pm 9$ & $20 \pm 7$ & $6 \pm 2$ \\
\hline 40 & $35 \pm 5$ & $36 \pm 9$ & $12 \pm 8$ & $37 \pm 4$ & $30 \pm 9$ & $12 \pm 6$ & $24 \pm 7$ & $19 \pm 6$ & $5 \pm 2$ \\
\hline 50 & $37 \pm 5$ & $43 \pm 9$ & $10 \pm 8$ & $39 \pm 5$ & $38 \pm 8$ & $13 \pm 7$ & $26 \pm 6$ & $25 \pm 8$ & $7 \pm 6$ \\
\hline 60 & $39 \pm 6$ & $49 \pm 8$ & $22 \pm 8$ & $39 \pm 6$ & $44 \pm 6$ & $23 \pm 7$ & $30 \pm 8$ & $32 \pm 9$ & $16 \pm 8$ \\
\hline 70 & $42 \pm 5$ & $48 \pm 9$ & $31 \pm 5$ & $43 \pm 4$ & $46 \pm 5$ & $31 \pm 7$ & $34 \pm 8$ & $36 \pm 8$ & $23 \pm 7$ \\
\hline 80 & $44 \pm 4$ & $43 \pm 8$ & $39 \pm 6$ & $45 \pm 2$ & $42 \pm 4$ & $38 \pm 6$ & $38 \pm 7$ & $34 \pm 7$ & $31 \pm 5$ \\
\hline 90 & $43 \pm 5$ & $42 \pm 8$ & $43 \pm 6$ & $45 \pm 2$ & $41 \pm 4$ & $41 \pm 5$ & $39 \pm 6$ & $33 \pm 5$ & $37 \pm 2$ \\
\hline 100 & $43 \pm 5$ & NA & $42 \pm 6$ & $45 \pm 2$ & NA & $41 \pm 5$ & $39 \pm 5$ & NA & $37 \pm 2$ \\
\hline 110 & $41 \pm 4$ & NA & $39 \pm 7$ & $43 \pm 2$ & NA & $38 \pm 6$ & $38 \pm 4$ & NA & $35 \pm 2$ \\
\hline 120 & $45 \pm 4$ & NA & $39 \pm 8$ & $47 \pm 1$ & NA & $37 \pm 6$ & $43 \pm 5$ & NA & $34 \pm 3$ \\
\hline 130 & $43 \pm 4$ & NA & $43 \pm 6$ & $46 \pm 1$ & NA & $45 \pm 4$ & $42 \pm 5$ & NA & $40 \pm 4$ \\
\hline 140 & $42 \pm 4$ & NA & $44 \pm 6$ & $44 \pm 1$ & NA & $45 \pm 4$ & $41 \pm 3$ & NA & $41 \pm 5$ \\
\hline 150 & $44 \pm 3$ & NA & $45 \pm 6$ & $45 \pm 2$ & NA & $46 \pm 4$ & $44 \pm 3$ & NA & $42 \pm 6$ \\
\hline
\end{tabular}




\subsection{Chapter 5 Disentangling effects of altitude and shade cover on coffee fruit dynamics and vegetative growth in smallholder coffee systems}

\section{TableS1: Piecewise Structural Equation Model of microclimate and SWC Structural Equation Model of modelList}

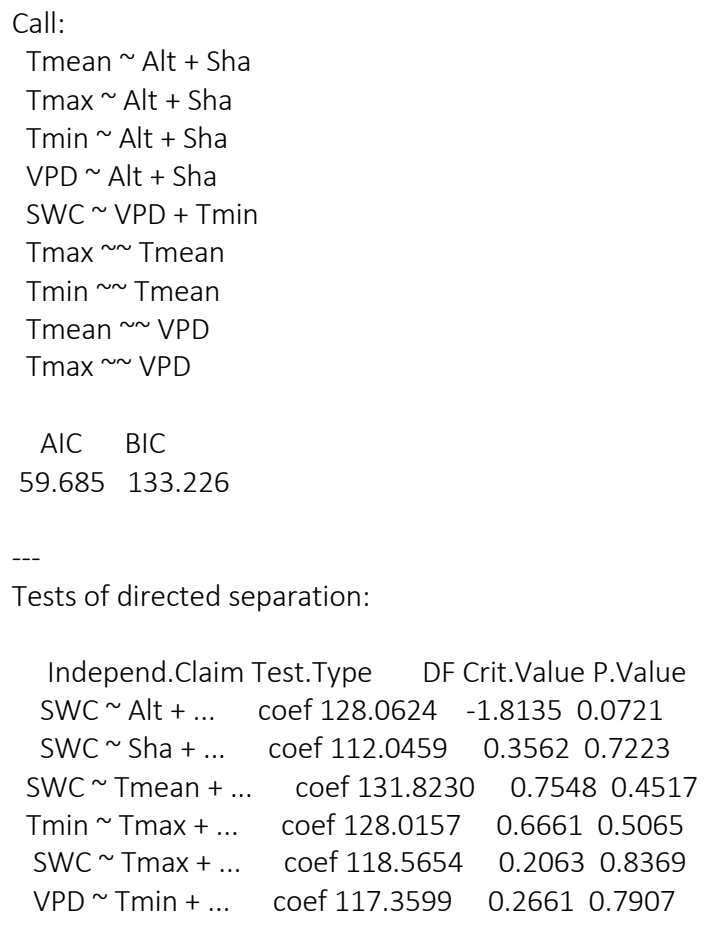




$\begin{array}{lcc}\text { Tmax none } & 0.22 & 0.64 \\ \text { Tmin none } & 0.68 & 0.82 \\ \text { VPD none } & 0.03 & 0.81 \\ \text { SWC none } & 0.35 & 0.45\end{array}$

\section{TableS2: Piecewise Structural Equation effect of altitude and shade cover on reproductive and vegetative growth for 2015 and 2016.}

StructuralEquationModelofmodelList

Call:

scale(Int Stem 2015 Week 0) scale(Shade cover)*scale(Altitude)

scale(LS per Stem 2015 Week 0) scale(Altitude)+scale(Int Stem 2015 Week 0)

scale(FS per stem 2015 Week 0) scale(Shade cover)+scale(Int Stem 2015 Week 0)+scale(LS per Stem 2015 Week 0)

scale(FD per Stem 2015) sscale(FS per stem 2015 Week 0)+scale(Shade cover)+scale(Int Stem 2015 Week 0)+scale(LS per

Stem 2015 Week 0)

scale(Int per Stem 2015 Harvest) sscale(FS per stem 2015 Week 0)+scale(FD per Stem 2015)+scale(Altitude)+scale(LS per

Stem 2015 Week 0)

scale(LS per stem 2015 Harvest) scale(Int per Stem 2015 Harvest)+scale(FS per stem 2015 Week 0)+scale(Shade

cover)*scale(Altitude)+scale(Int Stem 2015 Week 0)

scale(FS per stem 2015 Harvest) scale(Int per Stem 2015 Harvest)+scale(Int Stem 2015 Week 0)+scale(LS per Stem 2015

Week 0)

scale(Int per Stem 2016 Week 4) scale(LS per stem 2015 Harvest)+scale(FS per stem 2015 Week 0)+scale(FD per Stem

2015)+scale(Altitude)+scale(LS per Stem 2015 Week 0)

scale(LS per stem 2016 Week 4) scale(Int per Stem 2016 Week 4)+scale(FS per stem 2015 Week 0)+scale(Shade

cover)+scale(Int Stem 2015 Week 0)

scale(FS per stem 2016 Week 4) scale(LS per stem 2016 Week 4)+scale(Int per Stem 2016 Week 4)+scale(LS per stem 2015

Harvest)+scale(Int per Stem 2015 Harvest)+scale(FS per stem 2015 Week 0)+scale(Shade cover)+scale(Int Stem 2015 Week

0)+scale(LS per Stem 2015 Week 0)

scale(FD per Stem 2016) scale(LS per stem 2016 Week 4)+scale(FS per stem 2016 Week 4)+scale(FS per stem 2015

Harvest)+scale(LS per stem 2015 Harvest)+scale(Int per Stem 2015 Harvest)+scale(FS per stem 2015 Week 0)+scale(FD per

Stem 2015)+scale(Altitude)+scale(Int Stem 2015 Week 0)+

scale(Int per Stem 2016 Harvest) scale(FS per stem 2016 Week 4)+scale(LS per stem 2016 Week 4)+scale(FS per stem 2015

Harvest)+scale(LS per stem 2015 Harvest)+scale(FS per stem 2015 Week 0)+scale(LS per Stem 2015 Week 0)

scale(LS per stem 2016 Harvest) ssale(FD per Stem 2016)+scale(Int per Stem 2016 Harvest)+scale(FS per stem 2016 Week

4)+scale(Int per Stem 2016 Week 4)+scale(FS per stem 2015 Harvest)+scale(FD per Stem 2015)+scale(Shade

cover)*scale(Altitude)+scale(Int Stem 2015 Week 0)

scale(FS per stem 2016 Harvest) scale(FS per stem 2015 Harvest)+scale(LS per stem 2016 Harvest)+scale(Int per Stem 2016

Week 4)+scale(LS per stem 2015 Harvest)+scale(Int per Stem 2015 Harvest)+scale(FD per Stem 2015)+scale(Shade cover)

scale(Int Stem 2015 Week 0) scale(Int per Stem 2015 Harvest)

scale(LS per Stem 2015 Week 0) scale(LS per stem 2015 Harvest)

scale(FS per stem 2015 Week 0) scale(FS per stem 2015 Harvest)

scale(FD per Stem 2015) scale(FS per stem 2015 Harvest)

scale(Int Stem 2015 Week 0) scale(Int per Stem 2016 Week 4)

scale(Int per Stem 2015 Harvest) scale(Int per Stem 2016 Week 4)

scale(LS per Stem 2015 Week 0) scale(LS per stem 2016 Week 4)

scale(LS per stem 2015 Harvest) scale(LS per stem 2016 Week 4)

scale(Int Stem 2015 Week 0) scale(Int per Stem 2016 Harvest)

scale(Int per Stem 2015 Harvest) scale(Int per Stem 2016 Harvest)

scale(Int per Stem 2016 Week 4) scale(Int per Stem 2016 Harvest)

scale(LS per Stem 2015 Week 0) scale(LS per stem 2016 Harvest)

scale(LS per stem 2015 Harvest) scale(LS per stem 2016 Harvest)

scale(LS per stem 2016 Week 4) scale(LS per stem 2016 Harvest)

scale(FS per stem 2016 Week 4) scale(FS per stem 2016 Harvest)

scale(FD per Stem 2016) scale(FS per stem 2016 Harvest)

AICBIC

278.541764 .162

$-$

Testsofdirectedseparation: 
Independ.ClaimTest.TypeDFCrit.ValueP.Value scale(LS per Stem 2015 Week 0) scale(Shade cover)+...coef23.82190.0720.9432 scale(FS per stem 2015 Harvest) scale(Shade cover)+...coef25.4334-0.40030.6923 scale(FD per Stem 2016) scale(Shade cover)+...coef20.45131.19930.2441 scale(Int per Stem 2015 Harvest) scale(Shade cover)+...coef24.7512-1.18260.2482 scale(Int per Stem 2016 Week 4) scale(Shade cover)+...coef24.35-1.15010.2613 scale(Int per Stem 2016 Harvest) scale(Shade cover)+...coef25.2614-0.82670.4162 scale(FS per stem 2015 Week 0) scale(Altitude)+...coef23.2377-0.76120.4542 scale(FD per Stem 2015) scale(Altitude)+...coef19.2901-0.11340.9109 scale(FS per stem 2015 Harvest) scale(Altitude)+...coef22.7988-1.4520.1601 scale(LS per stem 2016 Week 4) scale(Altitude)+...coef21.99090.85640.401 scale(FS per stem 2016 Week 4) scale(Altitude)+...coef20.83340.35550.7258 scale(Int per Stem 2016 Harvest) $\sim$ scale(Altitude)+...coef22.8490.14510.8859 scale(FS per stem 2016 Harvest) $\sim$ scale(Altitude)+...coef21.4326-1.46080.1586 scale(FS per stem 2016 Harvest) $\sim$ scale(Int Stem 2015 Week 0)+...coef431.17640.99640.3196 scale(FS per stem 2016 Harvest) $\sim$ scale(LS per Stem 2015 Week 0)+...coef445.2201-0.89480.3714 scale(LS per stem 2016 Harvest) $\sim$ scale(FS per stem 2015 Week 0)+...coef451.18020.54570.5855 scale(FS per stem 2016 Harvest) $\sim$ scale(FS per stem 2015 Week 0)+...coef452.4518-0.92410.3559 scale(LS per stem 2015 Harvest) scale(FD per Stem 2015)+...coef454.5521-0.51480.6069 scale(LS per stem 2016 Week 4) scale(FD per Stem 2015)+...coef459.07070.31190.7552 scale(FS per stem 2016 Week 4) scale(FD per Stem 2015)+...coef412.5626-0.10930.913 scale(Int per Stem 2016 Harvest) scale(FD per Stem 2015)+...coef457.13450.54280.5876 scale(FS per stem 2015 Harvest) $\sim$ scale(LS per stem 2015 Harvest)+...coef457.27650.26040.7946 scale(LS per stem 2016 Week 4) $\sim$ scale(FS per stem 2015 Harvest)+...coef446.14850.48730.6263 scale(FS per stem 2016 Week 4) scale(FS per stem 2015 Harvest)+...coef365.6229-0.83630.4035 scale(Int per Stem 2016 Week 4) scale(FS per stem 2015 Harvest)+...coef459.8882-0.89180.373 scale(Int per Stem 2015 Harvest) scale(LS per stem 2016 Week 4)+...coef455.20270.24270.8084 scale(FS per stem 2016 Harvest) $\sim$ scale(LS per stem 2016 Week 4)+...coef456.9395-0.66930.5037 scale(Int per Stem 2016 Week 4) scale(FD per Stem 2016)+...coef455.2302-0.27730.7817 scale(Int per Stem 2016 Harvest) $\sim$ scale(FD per Stem 2016)+...coef450.4133-0.90.3686 scale(Int per Stem 2015 Harvest) scale(LS per stem 2016 Harvest)+...coef454.99320.32460.7457 scale(FS per stem 2016 Harvest) scale(Int per Stem 2016 Harvest)+...coef379.0249-0.74220.4584

Globalgoodness-of-fit:

Fisher'sC=44.541 withP-value=0.954andon62degreesoffreedom

Coefficients:

ResponsePredictorEstimateStd.ErrorDFCrit.ValueP.ValueStd.Estimate scale(Int Stem 2015 Week 0)scale(Shade cover)-0.16820.107723.7533-1.56170.13160 scale(Int Stem 2015 Week 0)scale(Altitude)0.01370.116720.74030.11770.90740.0019 scale(Int Stem 2015 Week 0)scale(Shade cover):scale(Altitude)0.0550.114625.17780.47960.63570.0208 scale(LS per Stem 2015 Week 0)scale(Altitude)-0.09260.07822.0467-1.18770.2476-0.058 scale(LS per Stem 2015 Week 0)scale(Int Stem 2015 Week 0)0.63590.0377460.52816.864102.9533*** scale(FS per stem 2015 Week 0)scale(Shade cover)-0.11080.078727.0527-1.40880.17030 scale(FS per stem 2015 Week 0)scale(Int Stem 2015 Week 0)0.27280.0496464.47465.501900.2415*** scale(FS per stem 2015 Week 0)scale(LS per Stem 2015 Week 0)0.33740.0478464.9847.05300.0643*** scale(FD per Stem 2015)scale(FS per stem 2015 Week 0)0.16860.0543463.70513.10330.00214.6453** scale(FD per Stem 2015)scale(Shade cover)-0.26080.088522.3418-2.94780.0074-0.005** scale(FD per Stem 2015)scale(Int Stem 2015 Week 0)0.22530.0599461.33883.76070.000217.3264*** scale(FD per Stem 2015)scale(LS per Stem 2015 Week 0)-0.11790.059463.9996-1.99890.0462-1.9519* scale(Int per Stem 2015 Harvest)scale(FS per stem 2015 Week 0)0.13630.0399463.42363.41870.00070.2213*** scale(Int per Stem 2015 Harvest)scale(FD per Stem 2015)0.01960.0338463.01870.57980.56240.0004 scale(Int per Stem 2015 Harvest)scale(Altitude)0.16290.076421.96122.13270.04440.0316* scale(Int per Stem 2015 Harvest)scale(LS per Stem 2015 Week 0)0.5290.0384463.703213.787300.1637*** scale(LS per stem 2015 Harvest)scale(Int per Stem 2015 Harvest)0.79680.0702411.156611.348601.6744*** scale(LS per stem 2015 Harvest)scale(FS per stem 2015 Week 0)0.03140.0448425.73910.7020.48310.1073 scale(LS per stem 2015 Harvest)scale(Shade cover)-0.09220.057522.229-1.60370.1229-0.0001 scale(LS per stem 2015 Harvest)scale(Altitude)-0.20360.059318.3664-3.43270.0029-0.083** scale(LS per stem 2015 Harvest)scale(Int Stem 2015 Week 0)-0.32680.0703425.4247-4.64670-0.9869*** scale(LS per stem 2015 Harvest)scale(Shade cover):scale(Altitude)-0.16810.061823.464-2.71760.0122-0.1925* scale(FS per stem 2015 Harvest)scale(Int per Stem 2015 Harvest)0.40690.0806464.91065.050900.7559*** 
scale(FS per stem 2015 Harvest)scale(Int Stem 2015 Week 0)-0.37530.0764464.8864-4.91160-1.0017*** scale(FS per stem 2015 Harvest)scale(LS per Stem 2015 Week 0)0.34240.0558464.56536.140100.1968*** scale(Int per Stem 2016 Week 4)scale(LS per stem 2015 Harvest)0.10220.0414462.99332.47020.01390.0388* scale(Int per Stem 2016 Week 4)scale(FS per stem 2015 Week 0)-0.02430.0418462.9823-0.58020.5621-0.0314 scale(Int per Stem 2016 Week 4)scale(FD per Stem 2015)0.09540.0354460.91842.69660.00730.0014** scale(Int per Stem 2016 Week 4)scale(Altitude)0.13020.077621.22261.6770.10820.0201 scale(Int per Stem 2016 Week 4)scale(LS per Stem 2015 Week 0)0.55740.0465462.976911.975700.1374*** scale(LS per stem 2016 Week 4)scale(Int per Stem 2016 Week 4)0.8310.0561463.821914.799401.1864*** scale(LS per stem 2016 Week 4)scale(FS per stem 2015 Week 0)0.17750.0427452.33684.15700.3278*** scale(LS per stem 2016 Week 4)scale(Shade cover)-0.11370.062326.3704-1.82310.07960 scale(LS per stem 2016 Week 4)scale(Int Stem 2015 Week 0)-0.46080.0608463.6624-7.57510-0.7532*** scale(FS per stem 2016 Week 4)scale(LS per stem 2016 Week 4)0.20790.0501443.20464.149700.1126*** scale(FS per stem 2016 Week 4)scale(Int per Stem 2016 Week 4)0.35530.0784437.39554.530300.2748*** scale(FS per stem 2016 Week 4)scale(LS per stem 2015 Harvest)0.6170.0492406.543612.549500.1809*** scale(FS per stem 2016 Week 4)scale(Int per Stem 2015 Harvest)-0.49380.0849330.6093-5.81730-0.3042*** scale(FS per stem 2016 Week 4)scale(FS per stem 2015 Week 0)-0.05930.0458345.1989-1.29430.1964-0.0593 scale(FS per stem 2016 Week 4)scale(Shade cover)-0.15170.049124.4053-3.09090.00490** scale(FS per stem 2016 Week 4)scale(Int Stem 2015 Week 0)0.19930.0747431.3742.66790.00790.1765** scale(FS per stem 2016 Week 4)scale(LS per Stem 2015 Week 0)-0.26740.0571386.1225-4.67840-0.051*** scale(FD per Stem 2016)scale(LS per stem 2016 Week 4)-0.0810.0509453.8112-1.59350.1117-3.2855 scale(FD per Stem 2016)scale(FS per stem 2016 Week 4)0.23420.0489457.98584.7912017.5339*** scale(FD per Stem 2016)scale(FS per stem 2015 Harvest)0.26690.0605451.47734.407506.6249*** scale(FD per Stem 2016)scale(LS per stem 2015 Harvest)-0.20490.0603456.934-3.39570.0007-4.496*** scale(FD per Stem 2016)scale(Int per Stem 2015 Harvest)0.20780.0877432.70342.36950.01829.5825* scale(FD per Stem 2016)scale(FS per stem 2015 Week 0)-0.16110.0648440.1996-2.48610.0133-12.0603* scale(FD per Stem 2016)scale(FD per Stem 2015)0.69750.0472448.712114.785700.601*** scale(FD per Stem 2016)scale(Altitude)0.12090.065219.96491.8530.07871.0812 scale(FD per Stem 2016)scale(Int Stem 2015 Week 0)-0.23930.0839412.5993-2.85310.0045-15.8603** scale(FD per Stem 2016)scale(LS per Stem 2015 Week 0)0.09920.0627447.72721.58230.11431.4157 scale(Int per Stem 2016 Harvest)scale(FS per stem 2016 Week 4)0.10870.0407451.36792.6710.00780.1239** scale(Int per Stem 2016 Harvest)scale(LS per stem 2016 Week 4)0.11640.0423457.76552.75320.00610.0719** scale(Int per Stem 2016 Harvest)scale(FS per stem 2015 Harvest)0.00550.0429458.21530.12780.89840.0021 scale(Int per Stem 2016 Harvest)scale(LS per stem 2015 Harvest)0.00620.048458.0510.12970.89680.0021 scale(Int per Stem 2016 Harvest)scale(FS per stem 2015 Week 0)0.04080.0475461.05860.85740.39170.0465 scale(Int per Stem 2016 Harvest)scale(LS per Stem 2015 Week 0)0.39540.0478456.97068.279500.0859*** scale(LS per stem 2016 Harvest)scale(FD per Stem 2016)-0.14890.0427451.2746-3.48870.0005-0.0038*** scale(LS per stem 2016 Harvest)scale(Int per Stem 2016 Harvest)0.52350.0735456.98387.122900.877*** scale(LS per stem 2016 Harvest)scale(FS per stem 2016 Week 4)0.09380.039448.46712.40120.01670.179* scale(LS per stem 2016 Harvest)scale(Int per Stem 2016 Week 4)-0.06120.0781451.0524-0.78360.4337-0.0903 scale(LS per stem 2016 Harvest)scale(FS per stem 2015 Harvest)0.26080.0413454.34856.316700.1652*** scale(LS per stem 2016 Harvest)scale(FD per Stem 2015)0.08730.0497454.21131.75610.07970.0019 scale(LS per stem 2016 Harvest)scale(Shade cover)-0.01130.099524.4422-0.11370.91040 scale(LS per stem 2016 Harvest)scale(Altitude)0.01480.107220.81660.13790.89170.0034 scale(LS per stem 2016 Harvest)scale(Int Stem 2015 Week 0)-0.16770.0593449.7564-2.82810.0049-0.2835** scale(LS per stem 2016 Harvest)scale(Shade cover):scale(Altitude)-0.25860.104124.4184-2.48390.0202-0.1657* scale(FS per stem 2016 Harvest)scale(FS per stem 2015 Harvest)-0.10570.0512420.0729-2.06280.0397-0.2754* scale(FS per stem 2016 Harvest)scale(LS per stem 2016 Harvest)0.10690.053420.9912.01760.04430.4399* scale(FS per stem 2016 Harvest)scale(Int per Stem 2016 Week 4)0.21030.0808436.98632.60330.00951.2779** scale(FS per stem 2016 Harvest)scale(LS per stem 2015 Harvest)0.34710.055460.50036.311500.7996*** scale(FS per stem 2016 Harvest)scale(Int per Stem 2015 Harvest)-0.26090.0888434.0219-2.93760.0035-1.2631** scale(FS per stem 2016 Harvest)scale(FD per Stem 2015)-0.10540.0481453.6814-2.19090.029-0.0095* scale(FS per stem 2016 Harvest)scale(Shade cover)-0.18590.072127.5058-2.57720.0156-0.0003* $\sim$ scale(Int Stem 2015 Week 0) scale(Int per Stem 2015 Harvest)0.5061-46912.665800.5061*** $\sim$ scale(LS per Stem 2015 Week 0) scale(LS per stem 2015 Harvest)0.3538-4698.166200.3538*** $\sim \sim$ scale(FS per stem 2015 Week 0) scale(FS per stem 2015 Harvest)0.5686-46914.920100.5686*** $\sim$ scale(FD per Stem 2015) scale(FS per stem 2015 Harvest)-0.3841-469-8.98140-0.3841*** $\sim \sim$ scale(Int Stem 2015 Week 0) scale(Int per Stem 2016 Week 4)0.4257-46910.156700.4257*** $\sim \sim$ scale(Int per Stem 2015 Harvest) scale(Int per Stem 2016 Week 4)0.6695-46919.455300.6695*** $\sim \sim$ scale(LS per Stem 2015 Week 0) scale(LS per stem 2016 Week 4)0.2004-4694.415800.2004*** $\sim$ scale(LS per stem 2015 Harvest) scale(LS per stem 2016 Week 4)0.3636-4698.424500.3636*** $\sim \sim$ scale(Int Stem 2015 Week 0) scale(Int per Stem 2016 Harvest)0.3492-4698.044300.3492*** $\sim \sim$ scale(Int per Stem 2015 Harvest) scale(Int per Stem 2016 Harvest)0.5241-46913.283300.5241*** $\sim \sim$ scale(Int per Stem 2016 Week 4) scale(Int per Stem 2016 Harvest)0.6641-46919.176700.6641*** scale(LS per Stem 2015 Week 0) scale(LS per stem 2016 Harvest)0.1415-4693.08650.00110.1415** 
scale(LS per stem 2015 Harvest) scale(LS per stem 2016 Harvest)0.1914-4694.210700.1914***

$\sim$ scale(LS per stem 2016 Week 4) scale(LS per stem 2016 Harvest)0.4096-4699.691200.4096***

$\sim \sim$ scale(FS per stem 2016 Week 4) scale(FS per stem 2016 Harvest)0.0843-4691.82590.03430.0843*

$\sim \sim$ scale(FD per Stem 2016) scale(FS per stem 2016 Harvest)-0.3121-469-7.09250-0.3121***

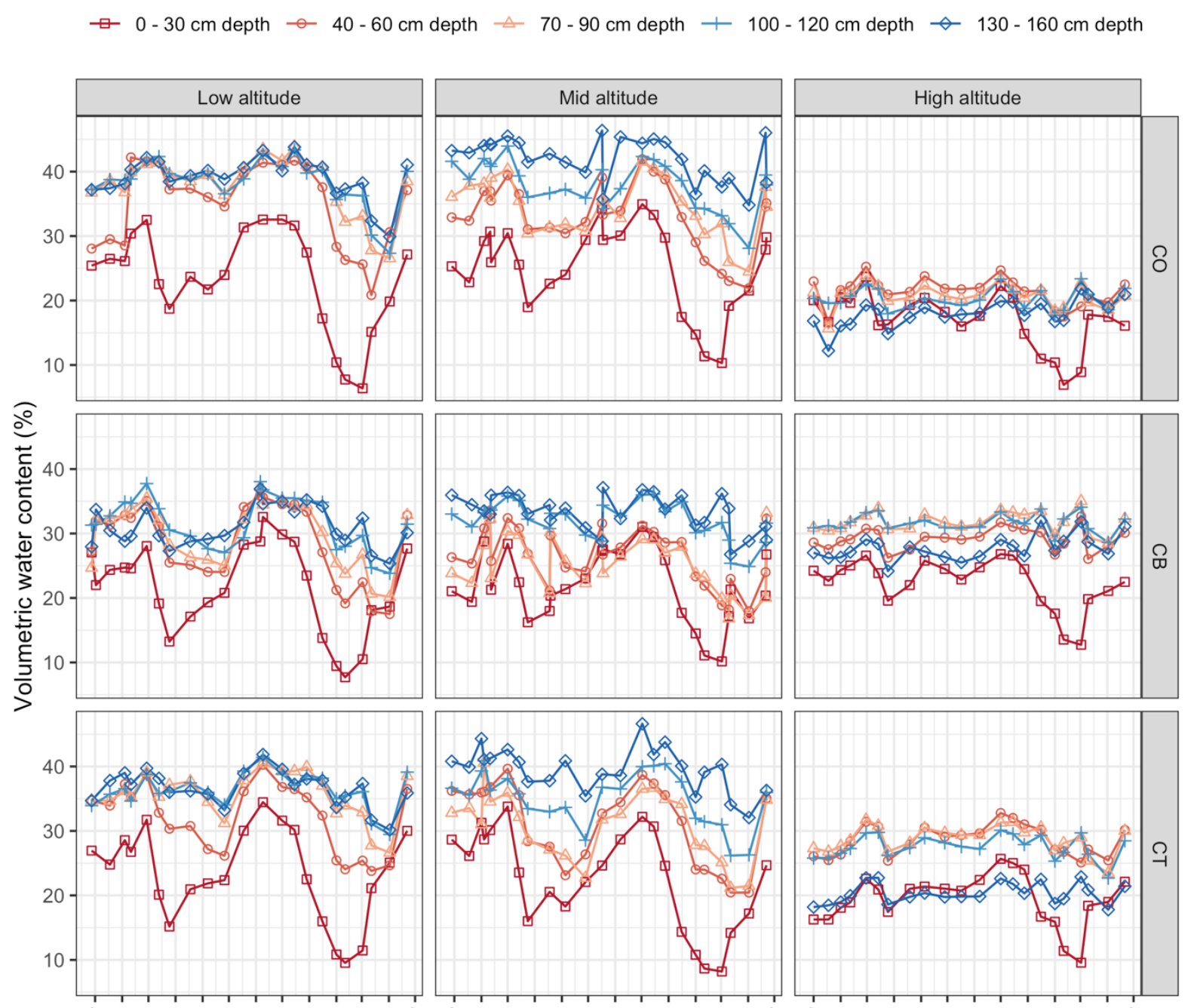

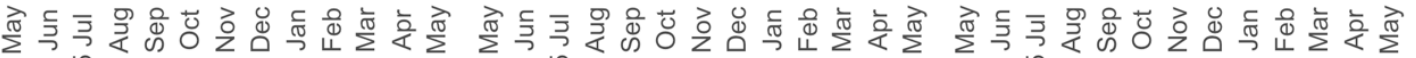

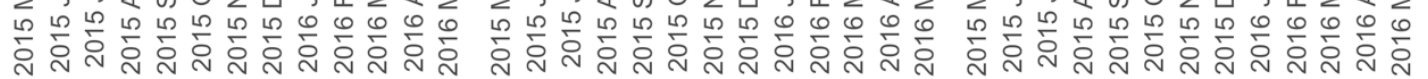
Date

Fig. S1. Timeline of volumetric water content from 0 to $160 \mathrm{~cm}$ depth averages by layers $(0-30 \mathrm{~cm}, 40-60 \mathrm{~cm}, 70-90 \mathrm{~cm}$, $100-120 \mathrm{~cm}$ and $120-160 \mathrm{~cm}$ ) displayed by altitude class (Low altitude $(1100-1400$ m.a.s.I.), mid altitude (1400 - 1700 m.a.s.I.) and high altitude (1700 - 2100 m.a.s.I.) and coffee cropping system (Coffee - Open (CO), Coffee - Banana (CB) and Coffee- shade tree (CT). 


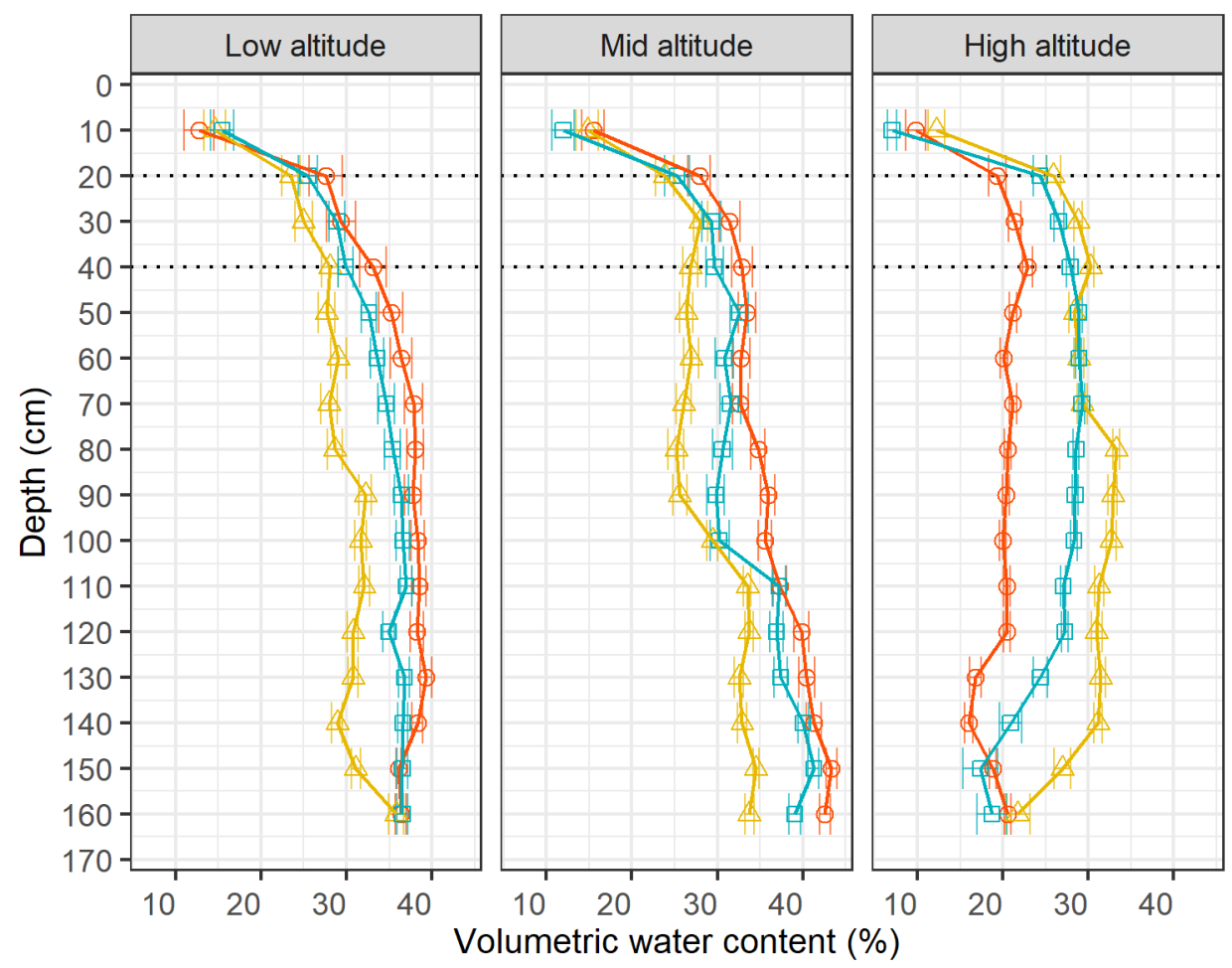

Fig.S1. Volumetric water content across the soil profile $(0-160 \mathrm{~cm}$ depth) for three altitude classes and coffee cropping systems. Colour and symbol indicates coffee cropping system (Coffee-Open = CO (Red circle), Coffee - Banana = CB (Yellow triangle), Coffee- shade tree $=$ CT (Blue suare) in three altitude classes altitude classes (Low altitude (1100 -1400 m.a.s.I.), mid altitude (1400 - 1700 m.a.s.I.) and high altitude (1700 - 2100 m.a.s.I). 


\subsection{Additional documents}

\subsubsection{Declaration}

Declaration on the proportion of own work performed Declarations

1. I, hereby, declare that this Ph.D. dissertation has not been presented to any other examining body either in its present or a similar form.

Furthermore, I also affirm that I have not applied for a Ph.D. at any other higher school of education.

Göttingen,

(Signature)

(Name in block capitals)

1. I, hereby, solemnly declare that this dissertation was undertaken independently and without any unauthorized aid.

Göttingen,

(Signature)

(Name in block capitals) 



\section{References}

Abdulai, I., Vaast, P., Hoffmann, M. P., Asare, R., Jassogne, L., Van Asten, P., . . Graefe, S. (2018). Cocoa agroforestry is less resilient to sub-optimal and extreme climate than cocoa in full sun. Glob Chang Biol, 24(1), 273-286. doi:10.1111/gcb.13885

Alégre, C. (1959). Climates et caféiers d' Arabie. Agronomia Tropical, 58, 14-23.

Allen, R. G., Pereira, L. S., Raes, D., \& Smith, M. (1998). FAO Irrigation and Drainage Paper. Food and Agriculture Organization of the United Nations, Rome, 56, 97-156. doi:http://www.fao.org/docrep/X0490E/X0490E00.htm.

Allen, R. G., Pereira, L. S., \& Smith, M. (1998). FAO Irrigation and Drainage Paper. Retrieved from Rome: http://www.fao.org/docrep/X0490E/X0490E00.htm

Altman, P. L., \& Dittmer, D. S. (1964). BIOLOGY DATA BOOK. AMRL-TR-64-100. Amrl tr, 1-631.

Alvim, P. d. T. (1960). Moisture stress as a requirement for flowering of coffee. Science, 132(3423).

Amaral, J. A. T., DaMatta, F. M., \& Rena, A. B. (2001). Effects of fruiting on the growth of Arabia Coffee trees as related to carbohydrate and nitrogen status and to nitrate reductase activity. Brazilian Journal of Plant Physiology, 13(1), 66-74.

Araújo, A. V., Partelli, F. L., Oliosi, G., \& Pezzopane, J. R. M. (2016). Microclimate, development and productivity of robusta coffee shaded by rubber trees and at full sun. Revista CiÊncia AgronÔmica, 47. doi:10.5935/1806-6690.20160084

Baca, M., Laderach, P., Haggar, J., Schroth, G., \& Ovalle, O. (2014). An integrated framework for assessing vulnerability to climate change and developing adaptation strategies for coffee growing families in Mesoamerica. PLoS One, 9(2), e88463. doi:10.1371/journal.pone.0088463

Baffes, J. (2006). Restructuring Uganda's Coffee Industry:

Why Going Back to Basics Matters. Oxford, UK: Blackwell Publishing.

Barradas, V. L., \& Fanjul, L. (1986). Microclimate characterization of shaded and open-grown coffee (Coffea arabica L.) plantations in Mexico. Agricultural and Forest Meteorology, 38, 101-112.

Barros, R. S., Maestri, M., \& rena, A. B. (1991). Physiology of Growth and Production of the coffee tree. A review. Journal of Coffee Research(27), 1-54.

Bartoń , K. (2019). MuMIn: Multi-Model Inference. Retrieved from https://CRAN.R-project.org/package=MuMln

Bates, D., Maechler, M., Bolker, B., \& Walker, S. (2015). Fitting Linear Mixed-Effects Models Using Ime4. Journal of Statistical Software, 67(1), 1-48. doi:doi:10.18637/jss.v067.i01.

Bauer, H., Wierer, R., Hatheway, W. H., \& Larcher, W. (1985). Photosynthesis of Coffea arabica after chilling. Physiologia Plantarum, 64(4), 449-454. doi:https://doi.org/10.1111/j.1399-3054.1985.tb08521.x

Bayala, J., Sanou, J., Teklehaimanot, Z., Ouedraogo, S. J., Kalinganire, A., Coe, R., \& Noordwijk, M. v. (2015). Advances in knowledge of processes in soil-tree-crop interactions in parkland systems in the West African Sahel: A review. Agriculture, Ecosystems \& Environment, 205, 25-35. doi:10.1016/j.agee.2015.02.018

Beer, J. (1987). Advantages, Disadvantages and Desirable Characteristics of Shade Trees for Coffee, Cacao and Tea. Agroforestry Systems, 5(1), 3-13. doi:https://doi.org/10.1007/BF00046410

Beer, J., Muschler, R., Kass, D., \& Somarriba, E. (1998). Shade management in coffee and cacao plantations. Agroforestry Systems(38), 139-164.

Bhagwat, S. A., Willis, K. J., Birks, H. J., \& Whittaker, R. J. (2008). Agroforestry: a refuge for tropical biodiversity? Trends Ecol Evol, 23(5), 261-267. doi:10.1016/j.tree.2008.01.005

Blaser, W. J., Oppong, J., Hart, S. P., Landolt, J., Yeboah, E., \& Six, J. (2018). Climate-smart sustainable agriculture in low-tointermediate shade agroforests. Nature Sustainability, 1(5), 234-239. doi:10.1038/s41893-018-0062-8

Boreux, V., Vaast, P., Madappa, L. P., Cheppudira, K. G., Garcia, C., \& Ghazoul, J. (2016). Agroforestry coffee production increased by native shade trees, irrigation, and liming. Agronomy for Sustainable Development, 36(3). doi:10.1007/s13593-016-0377-7

Bote, A. D., \& Vos, J. (2016). Branch growth dynamics, photosynthesis, yield and bean size distribution in response to fruit load manipulation in coffee trees. Trees(30), 1275-1285. doi:10.1007/s00468-016-1365-x

Bote, A. D., Zana, Z., Ocho, F. L., \& Vos, J. (2018). Analysis of coffee ( Coffea arabica L.) performance in relation to radiation level and rate of nitrogen supply II. Uptake and distribution of nitrogen, leaf photosynthesis and first bean yields. European Journal of Agronomy, 92, 107-114. doi:10.1016/j.eja.2017.10.006

Brett, E. A. (1992). Providing for the rural poor: institutional decay and transformation in Uganda. Brighton, UK: Institute of Development Studies, Brighton.

Brooks, M. E., Kristensen, K., van Benthem, K. J., Magnusson, A., Berg, C. W., Nielsen, A., . . Bolker, B. M. (2017). glmmTMB Balances Speed and Flexibility Among Packages for Zero-inflated Generalized Linear Mixed Modeling. The $R$

Journal, 9(2), 378-400.

Browning, G. (1975). Environmental control of flower bud dormancy in Coffea arabica L. In J. J. Landsberg \& C. V. Cutting (Eds.), Environmentall Effects on Crop Physiology. London, UK: Academic Press.

Bunn, C., Läderach, P., Ovalle Rivera, O., \& Kirschke, D. (2014). A bitter cup: climate change profile of global production of Arabica and Robusta coffee. Climatic Change, 129(1-2), 89-101. doi:10.1007/s10584-014-1306-x

Butler, D. R. (1977). COFFEE LEAF TEMPERATURES IN A TROPICAL ENVIRONMENT. Acta Botanica Neerlandica, 26(2), 129-140. doi:https://doi.org/10.1111/j.1438-8677.1977.tb01106.x

Camargo, A. P. (1985). O clima e a cafeicultura no Brasil. Agropec, 11, 13-26. 
Campanha, M. M., Silva Santos, R. H., De Freitas, G. B., Prieto Martinez, H. E., Ribeiro Garcia, S. L., \& Finger, F. L. (2004). Growth and yield of coffee plants in agroforestry and monoculture systems in Minas Gerais, Brazil. Agroforestry Systems, 63, 75-82.

Cannavo, P., Sansoulet, J., Harmand, J. M., Siles, P., Dreyer, E., \& Vaast, P. (2011). Agroforestry associating coffee and Inga densiflora results in complementarity for water uptake and decreases deep drainage in Costa Rica. Agriculture, Ecosystems \& Environment, 140(1-2), 1-13. doi:10.1016/j.agee.2010.11.005

Cannell, M. G. R. (1974). Factors affecting Arabica coffee bean size in Kenya. Journal of Horticultural Science, 49(1), 65-76. doi:10.1080/00221589.1974.11514552

Cannell, M. G. R. (1976). Crop physiological aspects of coffee bean yield - a review. Kenya Coffee, 41, 245-253.

Cannell, M. G. R. (1985). Physiology of the Coffee Crop. In M. N. Clifford \& K. C. Willson (Eds.), Coffee: Botany, Biochemistry and Production of Beans and Beverage (pp. 108-134). Boston, MA: Springer US.

Cannell, M. G. R., Van Noordwijk, M., \& Ong, C. K. (1996). The central agroforestry hypothesis: the trees must acquire resources that the crop would not otherwise acquire. Agroforestry Systems, 34, 27-31.

Capa, D., Pérez-Esteban, J., \& Masaguer, A. (2015). Unsustainability of recommended fertilization rates for coffee monoculture due to high N2O emissions. Agronomy for Sustainable Development, 35(4), 1551-1559. doi:10.1007/s13593-015-0316-z

Caramori, P. H., Ometto, J. C., Nova, N. A., \& Costa, J. D. (1986). Efeitos do vento sobre mudas de cafeeiro Mundo Novo e Catuaí Vermelho. Pesquisa Agropecuária Brasileira, 21, 1113-1118.

Carr, M. K. V. (2001). The water relations and irrigation requirements of coffee. Experimental Agriculture, 37, 1-36.

Carvalho, L. C. C., Silva, F. M. d., Ferraz, G. A. e. S., Stracieri, J., Ferraz, P. F. P., \& Ambrosano, L. (2017). Geostatistical analysis of Arabic coffee yield in two crop seasons. Revista Brasileira de Engenharia Agrícola e Ambiental, 21(6), 410-414. doi:10.1590/1807-1929/agriambi.v21n6p410-414

Castro-Tanzi, S., Flores, M., Wanner, N., Dietsch, T. V., Banks, J., Ureña-Retana, N., \& Chandler, M. (2014). Evaluation of a nondestructive sampling method and a statistical model for predicting fruit load on individual coffee (Coffea arabica) trees. Scientia Horticulturae, 167, 117-126. doi:10.1016/j.scienta.2013.12.013

Cerda, R., Allinne, C., Gary, C., Tixier, P., Harvey, C. A., Krolczyk, L., . . Avelino, J. (2017). Effects of shade, altitude and management on multiple ecosystem services in coffee agroecosystems. European Journal of Agronomy, 82, 308-319. doi:10.1016/j.eja.2016.09.019

Cerda, R., Avelino, J., Gary, C., Tixier, P., Lechevallier, E., \& Allinne, C. (2017). Primary and Secondary Yield Losses Caused by Pests and Diseases: Assessment and Modeling in Coffee. PLoS One, 12(1), e0169133. doi:10.1371/journal.pone.0169133

Cerda, R., Deheuvels, O., Calvache, D., Niehaus, L., Saenz, Y., Kent, J., ... Somarriba, E. (2014). Contribution of cocoa agroforestry systems to family income and domestic consumption: looking toward intensification. Agroforestry Systems, 88(6), 957-981. doi:10.1007/s10457-014-9691-8

Chain-Guadarrama, A., Martínez-Salinas, A., Aristizábal, N., \& Ricketts, T. H. (2019). Ecosystem services by birds and bees to coffee in a changing climate: A review of coffee berry borer control and pollination. Agriculture, Ecosystems \& Environment, 280, 5367. doi:10.1016/j.agee.2019.04.011

Chaves, A. R. M., Martins, S. C. V., Batista, K. D., Celin, E. F., \& DaMatta, F. M. (2012). Varying leaf-to-fruit ratios affect branch growth and dieback, with little to no effect on photosynthesis, carbohydrate or mineral pools, in different canopy positions of field-grown coffee trees. Environmental and Experimental Botany, 77, 207-218. doi:10.1016/j.envexpbot.2011.11.011

Clay, J. (2004). World Agriculture and the Environment: a commodity-by-commodity guide to impacts and practices. Washington: Island Press.

Clough, Y., Faust, H., \& Tscharntke, T. (2009). Cacao boom and bust: sustainability of agroforests and opportunities for biodiversity conservation. Conservation Letters, 2(5), 197-205. doi:10.1111/j.1755-263X.2009.00072.x

Coe, R., Sinclair, F., \& Barrios, E. (2014). Scaling up agroforestry requires research 'in' rather than 'for' development. Current Opinion in Environmental Sustainability, 6, 73-77. doi:10.1016/j.cosust.2013.10.013

Coste, R. (1992). Coffee: the plant and the product.

Craparo, A. C. W., Van Asten, P. J. A., Läderach, P., Jassogne, L. T. P., \& Grab, S. W. (2015). Coffea arabica yields decline in Tanzania due to climate change: Global implications. Agricultural and Forest Meteorology, 207, 1-10. doi:10.1016/j.agrformet.2015.03.005

Crawford, Y., P., S. N., \& H., R. T. (1981). Cooperatives and development: agricultural politics in Ghana and Uganda. Madison, Wisconsin: The University of Wisconsin.

Cunningham, S. A., Attwood, S. J., Bawa, K. S., Benton, T. G., Broadhurst, L. M., Didham, R. K., . . Lindenmayer, D. B. (2013). To close the yield-gap while saving biodiversity will require multiple locally relevant strategies. Agriculture, Ecosystems \& Environment, 173, 20-27. doi:10.1016/j.agee.2013.04.007

Da Matta, F. M., Maestri, M., Barros, R. S., \& Regazzi, A. J. (1993). Water relations of coffee leaves (Coffea arabica and C. canephora) in response to drought. Journal of Horticultural Science, 68(5), 741-746. doi:10.1080/00221589.1993.11516407

DaMatta, F. M. (2004). Ecophysiological constraints on the production of shaded and unshaded coffee: a review. Field Crops Research, 86(2-3), 99-114. doi:10.1016/j.fcr.2003.09.001

DaMatta, F. M., Avila, R. T., Cardoso, A. A., Martins, S. C. V., \& Ramalho, J. C. (2018). Physiological and Agronomic Performance of the Coffee Crop in the Context of Climate Change and Global Warming: A Review. J Agric Food Chem, 66(21), 5264-5274. doi:10.1021/acs.jafc.7b04537

DaMatta, F. M., Rahn, E., Läderach, P., Ghini, R., \& Ramalho, J. C. (2018). Why could the coffee crop endure climate change and global warming to a greater extent than previously estimated? Climatic Change, 152(1), 167-178. doi:10.1007/s10584-0182346-4 
DaMatta, F. M., \& Ramalho, J. C. (2006). Impacts of drought and temperature stress on coffee physiology and production: a review. Brazilian Journal of Plant Physiology, 18(1), 55-81.

DaMatta, F. M., Ronchie, C. P., Maestri, M., \& Barros, R. S. (2007). Ecophysiology of coffee growth and production. Brazilian Journal of Plant Physiology, 19(4), 485-510.

Daviron, B., \& Ponte, S. (2005). The coffee paradox: Global markets, commodity trade and the elusive promise of development. London: Zed Books.

De Bauw, P., Van Asten, P., Jassogne, L., \& Merckx, R. (2016). Soil fertility gradients and production constraints for coffee and banana on volcanic mountain slopes in the East African Rift: A case study of Mt. Elgon. Agriculture, Ecosystems \& Environment, 231, 166-175. doi:10.1016/j.agee.2016.06.036

De Beenhouwer, M., Aerts, R., \& Honnay, O. (2013). A global meta-analysis of the biodiversity and ecosystem service benefits of coffee and cacao agroforestry. Agriculture, Ecosystems \& Environment, 175, 1-7. doi:10.1016/j.agee.2013.05.003

de Carvalho, A. F., Fernandes-Filho, E. I., Daher, M., Gomes, L. d. C., Cardoso, I. M., Fernandes, R. B. A., \& Schaefer, C. E. G. R. (2020). Microclimate and soil and water loss in shaded and unshaded agroforestry coffee systems. Agroforestry Systems. doi:10.1007/s10457-020-00567-6

de Souza, H. N., de Graaff, J., \& Pulleman, M. M. (2011). Strategies and economics of farming systems with coffee in the Atlantic Rainforest Biome. Agroforestry Systems, 84(2), 227-242. doi:10.1007/s10457-011-9452-x

Delzon, S., Sartore, M., Granier, A., \& Loustau, D. (2004). Radial profiles of sap flow with increasing tree size in maritime pine. Tree Physiol, 24(11), 1285-1293. doi:10.1093/treephys/24.11.1285

Descroix, F., \& Snoeck, J. (2008). Environmental Factors Suitable for Coffee Cultivation. In Coffee: Growing, Processing, Sustainable Production (pp. 164-177).

Drinnan, J. E., \& Menzel., C. M. (1995). Temperature affects vegetative growth and flowering of coffee (Coffea arabica L.). Journal of Horticultural Science, 70(1), 25-34.

Dufour, B. P., Kerana, I. W., \& Ribeyre, F. (2019). Effect of coffee tree pruning on berry production and coffee berry borer infestation in the Toba Highlands (North Sumatra). Crop Protection, 122, 151-158. doi:10.1016/j.cropro.2019.05.003

Ernesto Méndez, V., Gliessman, S. R., \& Gilbert, G. S. (2007). Tree biodiversity in farmer cooperatives of a shade coffee landscape in western El Salvador. Agriculture, Ecosystems \& Environment, 119(1-2), 145-159. doi:10.1016/j.agee.2006.07.004

Fanjul, L. R., Arreola-Rodruiguez, R., \& Mendez-Castrejon, M. P. (1985). Stomatal Responses to Environmental Variables in Shade and Sun Grown Coffee Plants in Mexico. Experimental Agriculture, 21, 249-258.

FAO. (2014). World Reference Base for Soil Resources 2014 International soil classification system for naming soils and ceating leyends for soil maps. Retrieved from Rome, Italy:

FAO. (2015). FAO Coffee Pocketbook.

FAOSTAT. (2016). Food and Agriculture Organization of the United Nations. FAOSTAT Statistics Database.

FAOSTAT. (2018). Food and Agriculture Organiaztion of the United Nations. FAOSTAT Statistics Database.

Fick, S. E., \& Hijmans, R. J. (2017). WorldClim 2: new 1-km spatial resolution climate surfaces for global land areas. International Journal of Climatology, 37(12), 4302-4315. doi:10.1002/joc.5086

Fox, J., \& Wiesberg, S. (2019). An R Companion to Applied Regression. Retrieved from https://socialsciences.mcmaster.ca/jfox/Books/Companion/

Franck, N., \& Vaast, P. (2009). Limitation of coffee leaf photosynthesis by stomatal conductance and light availability under different shade levels. Trees, 23(4), 761-769. doi:10.1007/s00468-009-0318-z

Franck, N., Vaast, P., \& Dauzat, J. (2005). Coffee a shade-adapted plant: implications on its carbon balance and consequences on coffee yield and quality in agroforestry systems. ASIC.

Franco, C. m. (1958). Influence of temperature on growth of coffee plant. Retrieved from New York, NY:

Fridell, G. (2014). Coffee. Cambridge, UK: Polity Press.

Garcia, C. A., Bhagwat, S. A., Ghazoul, J., Nath, C. D., Nanaya, K. M., Kushalappa, C. G., . . Vaast, P. (2010). Biodiversity conservation in agricultural landscapes: challenges and opportunities of coffee agroforests in the Western Ghats, India. Conserv Biol, 24(2), 479-488. doi:10.1111/j.1523-1739.2009.01386.x

Garedew, W., Lemessa, F., \& Pinard, F. (2017). Assessment of berry drop due to coffee berry disease and non-CBD factors in Arabica coffee under farmers fields of Southwestern Ethiopia. Crop Protection, 98, 276-282. doi:10.1016/j.cropro.2017.04.012

Gay, C., Estrada, F., Conde, C., Eakin, H., \& Villers, L. (2006). Potential Impacts of Climate Change on Agriculture: A Case of Study of Coffee Production in Veracruz, Mexico. Climatic Change, 79(3-4), 259-288. doi:10.1007/s10584-006-9066-x

Gbur, E. E. (2012). Analysis of Generalized Linear Mixed Models in the Agricultural and Natural Resources Sciences. Madison, WI: American Society of Agronomy, Crop Science Society of America, Soil Science Society of America.

Gobbi, J. A. (2000). Is biodiversity-friendly coffee financially viable? An analysis

of five different coffee production systems in western $\mathrm{EI}$

Salvador. Ecological Economics, 33, 267-281.

Godfray, H. C. J. (2015). The debate over sustainable intensification. Food Security, 7(2), 199-208. doi:10.1007/s12571-015-0424-2

Godfray, H. C. J., \& Garnett, T. (2014). Food security and sustainable intensification. Philosophical Transactions of the Royal Society B: Biological Sciences, 369(1639). doi:10.1098/rstb.2012.0273

Gomes, L. d. C., Cardoso, I. M., Mendonça, E. d. S., Fernandes, R. B. A., Lopes, V. S., \& Oliveira, T. S. (2016). Trees modify the dynamics of soil $\mathrm{CO} 2$ efflux in coffee agroforestry systems. Agricultural and Forest Meteorology, 224, 30-39. doi:10.1016/j.agrformet.2016.05.001

Granier, A. (1987). Evaluation of transpiration in a Douglas-fir stand by means of sap flow measurements. Tree Physiol, 3(4), 309-320. doi:10.1093/treephys/3.4.309 
Gutiérrez, M. V., Harrington, R. A., Meinzer, F. C., \& Fownes, J. H. (1994). The effect of environmentally induced stem temperature gradients on transpiration estimates from the heat balance method in two tropical woody species. Tree Physiology, 14(2), 179-190. doi:10.1093/treephys/14.2.179

Haarer, A. E. (1958). Modern Coffee Production.

Heath, O. V. S., \& Orchard, B. (1957). Midday Closure of Stomata: Temperature Effects on the Minimum Intercellular Space Carbon Dioxide Concentration " $"$ ". Nature, 180(4578), 180-181. doi:10.1038/180180a0

Hergoualc'h, K., Blanchart, E., Skiba, U., Hénault, C., \& Harmand, J.-M. (2012). Changes in carbon stock and greenhouse gas balance in a coffee (Coffea arabica) monoculture versus an agroforestry system with Inga densiflora, in Costa Rica. Agriculture, Ecosystems \& Environment, 148, 102-110. doi:10.1016/j.agee.2011.11.018

Hernández-Santana, V., Martínez-Vilalta, J., Martínez-Fernández, J., \& Williams, M. (2009). Evaluating the effect of drier and warmer conditions on water use by Quercus pyrenaica. Forest Ecology and Management, 258(7), 1719-1730. doi:10.1016/j.foreco.2009.07.038

Hirons, M., Mehrabi, Z., Gonfa, T. A., Morel, A., Gole, T. W., McDermott, C., . . Norris, K. (2018). Pursuing climate resilient coffee in Ethiopia - A critical review. Geoforum, 91, 108-116. doi:10.1016/j.geoforum.2018.02.032

Hothorn, T., Bretz, F., \& Westfall, P. (2008). Simultaneous inference in general parametric models. Biom J, 50(3), 346-363. doi:10.1002/bimj.200810425

Hurlbert, S. H. (1984). Pseudoreplication and the Design of Ecological Field Experiments. Ecological Monographs, 54(2), $187-211$.

Hylander, K., Nemomissa, S., Delrue, J., \& Enkosa, W. (2013). Effects of coffee management on deforestation rates and forest integrity. Conserv Biol, 27(5), 1031-1040. doi:10.1111/cobi.12079

ICO. (2011). Annual Review.

ICO. (2018). Coffee Market Report.

IPCC. (2014). Climate Change 2014 Synthesis Report. Fifth Assessment Report of the Intergovernmental Panel on Climate Change, 151.

ITC. (2012). The Coffee Exporters's Guide. Retrieved from Geneva:

Janssen, B. H., Guiking, F. C. T., van der Eijk, D., Smaling, E. M. A., Wolf, J., \& van Reuler, H. (1990). A system for quantitative evaluation of the fertility of tropical soils (QUEFTS). Geoderma, 46(4), 299-318. doi:https://doi.org/10.1016/00167061(90)90021-Z

Jassogne, L., Läderach, P., \& van Asten, P. (2013). The Impact of Climate Change on Coffee in Uganda: Lessons from a case study in the Rwenzori Mountains. Retrieved from http://www.ingentaconnect.com/content/oxpp/oppccr/2013/00000009/00000001/art00004

Jassogne, L., van Asten, P. J. A., Wanyama, I., \& Baret, P. V. (2012). Perceptions and outlook on intercropping coffee with banana as an opportunity for smallholder coffee farmers in Uganda. International Journal of Agricultural Sustainability, 11(2), 144158. doi:10.1080/14735903.2012.714576

Jha, S., Bacon, C. M., Philpott, S. M., Ernesto Méndez, V., Läderach, P., \& Rice, R. A. (2014). Shade Coffee: Update on a Disappearing Refuge for Biodiversity. BioScience, 64(5), 416-428. doi:10.1093/biosci/biu038

Jung, E. Y., Otieno, D., Lee, B., Lim, J. H., Kang, S. K., Schmidt, M. W. T., \& Tenhunen, J. (2010). Up-scaling to stand transpiration of an Asian temperate mixed-deciduous forest from single tree sapflow measurements. Plant Ecology, 212(3), 383-395. doi:10.1007/s11258-010-9829-3

Kanechi, M., Uchida, N. U., Yasuda, T., \& Yamaguchi, T. (1995). Water stress effects on leaf transpiration and photosyntheis of Coffea arabica L. under different irradiance conditions. Paper presented at the 16th International Scientific Colloquium on Coffee, Kyoto, Japan.

Kimmins, J. P., Welham, C., Cao, F., Wangpakapattanawong, P., \& Christanty, L. (2008). The Role of Ecosystem-level Models in the Design of Agroforestry Systems for Future Environmental Conditions and Social Needs. In S. Jose \& A. M. Gordon (Eds.), Toward Agroforestry Design: An Ecological Approach (pp. 231-248). Dordrecht: Springer Netherlands.

Kissel, E., van Asten, P., Swennen, R., Lorenzen, J., \& Carpentier, S. C. (2015). Transpiration efficiency versus growth: Exploring the banana biodiversity for drought tolerance. Scientia Horticulturae, 185, 175-182. doi:10.1016/j.scienta.2015.01.035

Kumar, D., \& Tieszen, L. L. (1980a). Photosynthesis in Coffea arabica. I. Effects of Light and Temperature. Experimental Agriculture, 16(1), 13-19. doi:10.1017/S0014479700010656

Kumar, D., \& Tieszen, L. L. (1980b). Photosynthesis in Coffea arabica. II. Effects of Water Stress. Experimental Agriculture, 16(1), 2127. doi:10.1017/S0014479700010668

Kummar, D. (1979). Some aspects of the physiology of Coffea arabica L. A review. Kenya Coffee, 44, 9 - 47.

Kuznetsova , A., Brockhoff, P., \& Christensen, R. (2017). ImerTest Package: Tests in Linear Mixed Effects Models. Journal of Statistical Software, 82(13), 1-26. doi:doi: 10.18637/jss.v082.i13 (URL: https://doi.org/10.18637/jss.v082.i13).

Laderach, P., Lundy, M., Jarvis, A., Ramirez, J., Portilla, E. P., Schepp, K., \& Eitzinger, A. (2011). Predicted Impact of Climate Change on Coffee Supply Chains. In The Economic, Social and Political Elements of Climate Change (pp. 703-723).

Lara Estrada, L., Rasche, L., \& Schneider, U. A. (2017). Modeling land suitability for Coffea arabica L. in Central America. Environmental Modelling \& Software, 95, 196-209. doi:10.1016/j.envsoft.2017.06.028

Lasco, R. D., Delfino, R. J. P., Catacutan, D. C., Simelton, E. S., \& Wilson, D. M. (2014). Climate risk adaptation by smallholder farmers: the roles of trees and agroforestry. Current Opinion in Environmental Sustainability, 6, 83-88. doi:10.1016/j.cosust.2013.11.013

Lawton, R. O., Nair, U. S., Pielke Sr, R. A., \& Welch, R. M. Climatic Impact of Tropical

Lowland Deforestation on

Nearby Montane Cloud Forests. Science, 294(5542), 584-587. 
Lemmon, P. E. (1956). A Spherical Densiometer For Estimating Forest Overstory Density. Forest Science, 2(4), 314-320. doi:10.1093/forestscience/2.4.314

Li-COR, I. (2009). LAl-2200 Plant Canopy Analyzer Instruction Manual. Retrieved from

Liebig, T., Jassogne, L., Rahn, E., Laderach, P., Poehling, H. M., Kucel, P., . . . Avelino, J. (2016). Towards a Collaborative Research: A Case Study on Linking Science to Farmers' Perceptions and Knowledge on Arabica Coffee Pests and Diseases and Its Management. PLoS One, 11(8), e0159392. doi:10.1371/journal.pone.0159392

Lin, B. B. (2007). Agroforestry management as an adaptive strategy against potential microclimate extremes in coffee agriculture. Agricultural and Forest Meteorology, 144(1-2), 85-94. doi:10.1016/j.agrformet.2006.12.009

Lin, B. B. (2010). The role of agroforestry in reducing water loss through soil evaporation and crop transpiration in coffee agroecosystems. Agricultural and Forest Meteorology, 150(4), 510-518. doi:10.1016/j.agrformet.2009.11.010

Liu, H.-J., Cohen, S., Tanny, J., Lemcoff, J. H., \& Huang, G. (2008). Transpiration estimation of banana (Musa sp.) plants with the thermal dissipation method. Plant and Soil, 308(1-2), 227-238. doi:10.1007/s11104-008-9622-4

López-Bravo, D. F., Virginio-Filho, E. d. M., \& Avelino, J. (2012). Shade is conducive to coffee rust as compared to full sun exposure under standardized fruit load conditions. Crop Protection, 38, 21-29. doi:10.1016/j.cropro.2012.03.011

Lu, P., Woo, K. C., \& Liu, Z. T. (2002). Estimation of whole-plant transpiration of bananas using sap flow measurements. J Exp Bot, 53(375), 1771-1779. doi:10.1093/jxb/erf019

Luedeling, E., Kindt, R., Huth, N. I., \& Koenig, K. (2014). Agroforestry systems in a changing climate-challenges in projecting future performance. Current Opinion in Environmental Sustainability, 6, 1-7. doi:10.1016/j.cosust.2013.07.013

Maestri, M., \& Barros, R. S. (1977). Coffee. London, UK: Adameic Press.

Martins, M. Q., Rodrigues, W. P., Fortunato, A. S., Leitao, A. E., Rodrigues, A. P., Pais, I. P., . . Ramalho, J. C. (2016). Protective Response Mechanisms to Heat Stress in Interaction with High [CO2] Conditions in Coffea spp. Front Plant Sci, 7, 947. doi:10.3389/fpls.2016.00947

Matiello, J. (1998). Café Conillon: Como Plantar, Tratar, Colher, Preparar e Vender. Retrieved from Rio de Janeiro, Brazil:

Matiello, J. B., Santinato, R., Garcia, A. W. R., Almeida, S. R., \& Fernandes, D. R. (2002). Cultura de Café no Brasil: Novo Manual de Recomendações. Rio de Janeiro: MAPA/PROCAFÉ.

Mbogga, M. (2012). Climate Profiles and Climate Change Vulnerability Assessment for the Mbale Region of Uganda. Retrieved from

Mbow, C., Smith, P., Skole, D., Duguma, L., \& Bustamante, M. (2014). Achieving mitigation and adaptation to climate change through sustainable agroforestry practices in Africa. Current Opinion in Environmental Sustainability, 6, 8-14. doi:10.1016/j.cosust.2013.09.002

Mbow, C., Van Noordwijk, M., Luedeling, E., Neufeldt, H., Minang, P. A., \& Kowero, G. (2014). Agroforestry solutions to address food security and climate change challenges in Africa. Current Opinion in Environmental Sustainability, 6, 61-67. doi:10.1016/j.cosust.2013.10.014

Meinzer, F. C., Clearwater, M. J., \& Goldstein, G. (2001). Water transport in trees: current perspectives, new insights and some controversies. Environmental and Experimental Botany, 45, 239-262.

Meylan, L., Gary, C., Allinne, C., Ortiz, J., Jackson, L., \& Rapidel, B. (2017). Evaluating the effect of shade trees on provision of ecosystem services in intensively managed coffee plantations. Agriculture, Ecosystems \& Environment, 245, 32-42. doi:10.1016/j.agee.2017.05.005

Moat, J., Williams, J., Baena, S., Wilkinson, T., Gole, T. W., Challa, Z. K., ... Davis, A. P. (2017). Resilience potential of the Ethiopian coffee sector under climate change. Nat Plants, 3, 17081. doi:10.1038/nplants.2017.81

Moguel, P., \& Toledo, V. M. (1999). Biodiversity Conservation in Traditional Coffee Systems of Mexico. Conservation Biology, 13, 1121.

Morais, H., Caramori, P. H., de Arruda Ribeiro, A. M., Gomes, J. C., \& Sei Koguishi, M. (2006). Microclimatic characterization and productivity of coffee plants grown under shade of pigeon pea in Southern Brazil. Pesquisa Agropecuária Brasileira, 41, 763-770.

Morton, J. F. (2007). The impact of climate change on smallholder and subsistence agriculture. Proceedings of the national academy of science of the united states of america(104), 19680-19685.

Muschler, R. G. (2001). Coffee Quality in a Sub-Optimal Coffee-Zone of Costa Rica. Agriculture, Ecosystems \& Environment., 51(2), 131-139.

Muschler, R. G., \& Bonnemann, A. (1997). Potentials and limitations of agroforestry for changing land-use in the tropics: experiences from Central America. Forest Ecology and Management, 91, 61-73.

Nath, C. D., Pélissier, R., \& Garcia, C. (2009). Comparative efficiency and accuracy of variable area transects versus square plots for sampling tree diversity and density. Agroforestry Systems, 79(2), 223-236. doi:10.1007/s10457-009-9255-5

Nesper, M., Kueffer, C., Krishnan, S., Kushalappa, C. G., \& Ghazoul, J. (2017). Shade tree diversity enhances coffee production and quality in agroforestry systems in the Western Ghats. Agriculture, Ecosystems \& Environment, 247, 172-181. doi:10.1016/j.agee.2017.06.024

Njoroge, J. M., Waithaka, K., \& Chweya, J. A. (1992). The influence of tree training and plant density on growth, yield components and yield of Arabica coffee cv. Ruiru 11. Journal of Horticultural Science, 67(5), 695-702. doi:10.1080/00221589.1992.11516300

Nunes, M. A., Bierhuizen, J. F., \& Ploegman, C. (1968). STUDIES ON PRODUCTIVITY OF COFFEE: I. EFFECT OF LIGHT, TEMPERATURE AND CO2 CONCENTRATION ON PHOTOSYNTHESIS OF COFFEA ARABICA. Acta Botanica Neerlandica, 17(2), 93-102. doi:10.1111/j.1438-8677.1968.tb00109.x

Nzeyimana, I., Hartemink, A. E., \& de Graaff, J. (2013). Coffee Farming and Soil Management in Rwanda. Outlook on Agriculture, 42(1), 47-52. doi:10.5367/oa.2013.0118 
Odoul, P. A., \& Aluma, J. R. W. (1990). The banana (Musa spp.) - Coffee robusta: traditional agroforestry system of Uganda. Agroforestry Systems, 11, 213-226.

Okalebo, J. R., Gathua, K. W., \& Woomer, P. L. (1993). Laboratory Methods of Soil and Plant Analysis: A working Manual. Retrieved from

Ovalle-Rivera, O., Laderach, P., Bunn, C., Obersteiner, M., \& Schroth, G. (2015). Projected shifts in Coffea arabica suitability among major global producing regions due to climate change. PLoS One, 10(4), e0124155. doi:10.1371/journal.pone.0124155

Padovan, M. P., Brook, R. M., Barrios, M., Cruz-Castillo, J. B., Vilchez-Mendoza, S. J., Costa, A. N., \& Rapidel, B. (2018). Water loss by transpiration and soil evaporation in coffee shaded by Tabebuia rosea Bertol . and Simarouba glauca dc. compared to unshaded coffee in sub-optimal environmental conditions. Agricultural and Forest Meteorology, 248, 1-14. doi:10.1016/j.agrformet.2017.08.036

Padovan, M. P., Cortez, V. J., Navarrete, L. F., Navarrete, E. D., Deffner, A. C., Centeno, L. G., . . Rapidel, B. (2015). Root distribution and water use in coffee shaded with Tabebuia rosea Bertol. and Simarouba glauca DC. compared to full sun coffee in suboptimal environmental conditions. Agroforestry Systems, 89(5), 857-868. doi:10.1007/s10457-015-9820-z

Partelli, F. L., Araújo, A. V., Vieira, H. D., Dias, J. R. M., Menezes, L. F. T. d., \& Ramalho, J. C. (2014). Microclimate and development of 'Conilon' coffee intercropped with rubber trees. Pesquisa Agropecuária Brasileira, 49(11), 872-881. doi:10.1590/s0100$204 \times 2014001100006$

Pendergrast, M. (1999). Uncommon grounds: the history of coffee and how it transformed our world (Vol.

). New York, NY: Basic Books.

Pereira, H. C. (1957). Field measurements of water use for irrigation control in Kenya coffee. The Journal of Agricultural Science, 49(4), 459-466. doi:10.1017/S0021859600038466

Perfecto, I., Jiménez-Soto, M. E., \& Vandermeer, J. (2019). Coffee Landscapes Shaping the Anthropocene: Forced Simplification on a Complex Agroecological Landscape. Current Anthropology, 6O(S20), S236-S250. doi:10.1086/703413

Perfecto, I., Vandermeer, J., Mas, A., \& Pinto, L. S. (2005). Biodiversity, yield, and shade coffee certification. Ecological Economics, 54(4), 435-446. doi:10.1016/j.ecolecon.2004.10.009

Rahn, E., Liebig, T., Ghazoul, J., van Asten, P., Läderach, P., Vaast, P., . . Jassogne, L. (2018). Opportunities for sustainable intensification of coffee agro-ecosystems along an altitudinal gradient on Mt. Elgon, Uganda. Agriculture, Ecosystems \& Environment, 263, 31-40. doi:10.1016/j.agee.2018.04.019

Rahn, E., Vaast, P., Läderach, P., van Asten, P., Jassogne, L., \& Ghazoul, J. (2018). Exploring adaptation strategies of coffee production to climate change using a process-based model. Ecological Modelling, 371, 76-89. doi:10.1016/j.ecolmodel.2018.01.009

Ramalho, J. C., Quartin, V. L., Leitão, E., Campos, P. S., Carelli, M. L. C., Fahl, J. I., \& Nunes, M. A. (2003). Cold Acclimation Ability and Photosynthesis among Species of the Tropical Coffea Genus. Plant Biology, 5(6), 631-641. doi:10.1055/s-2003-44688

Rapidel, B., Ripoche, A., Allinne, C., Metay, A., Deheuvels, O., Lamanda, N., . . Gary, C. (2015). Analysis of ecosystem services tradeoffs to design agroecosystems with perennial crops. Agronomy for Sustainable Development, 35(4), 1373-1390. doi:10.1007/s13593-015-0317-y

Rice, R. A. (2008). Agricultural intensification within agroforestry: The case of coffee and wood products. Agriculture, Ecosystems \& Environment, 128(4), 212-218. doi:10.1016/j.agee.2008.06.007

Rice, R. A. (2011). Fruits from shade trees in coffee: how important are they? Agroforestry Systems, 83(1), 41-49. doi:10.1007/s10457-011-9385-4

Rodrigues, W. P., Martins, M. Q., Fortunato, A. S., Rodrigues, A. P., Semedo, J. N., Simoes-Costa, M. C., . . Ramalho, J. C. (2016). Long-term elevated air [CO2 ] strengthens photosynthetic functioning and mitigates the impact of supra-optimal temperatures in tropical Coffea arabica and C. canephora species. Glob Chang Biol, 22(1), 415-431. doi:10.1111/gcb.13088

Romero-Alvarado, Y., Soto-Pinto, L., García-Barrios, L., \& Barrera-Gaytán, J. F. (2002). ields and Soil Nutrients under the Shades of Inga Sp. vs. Multiple Species in Chiapas, Mexico. Agroforestry Systems, 54(3), 215-224.

Ronquim, J. C., Prado, C. H. B. A., Novaes, P., Fahl, J. I., \& Ronquim, C. C. (2006). CARBON GAIN IN COFFEA ARABICA DURING CLEAR AND CLOUDY DAYS IN THE WET SEASON. Experimental Agriculture, 42(2), 147-164. doi:10.1017/S0014479705003121

Ruane, A. C., Goldberg, R., \& Chryssanthacopoulos, J. (2015). Climate forcing datasets for agricultural modeling: Merged products for gap-filling and historical climate series estimation. Agricultural and Forest Meteorology, 200, 233-248. doi:https://doi.org/10.1016/i.agrformet.2014.09.016

Rutherford, M. A. (2006). Current knowledge of coffee wilt disease, a major constraint to coffee production in Africa. Phytopathology, 96(6), 663-666. doi:10.1094/PHYTO-96-0663

Sanchez, P. A. (1995). Science in Agroforestry. Agroforestry Systems, 30(5), 5-55.

Sarmiento-Soler, A., Vaast, P., Hoffmann, M. P., Jassogne, L., van Asten, P., Graefe, S., \& Rötter, R. P. (2020). Effect of cropping system, shade cover and altitudinal gradient on coffee yield components at Mt. Elgon, Uganda. Agriculture, Ecosystems \& Environment, 295. doi:10.1016/j.agee.2020.106887

Sarmiento-Soler, A., Vaast, P., Hoffmann, M. P., Rötter, R. P., Jassogne, L., van Asten, P. J. A., \& Graefe, S. (2019). Water use of Coffea arabica in open versus shaded systems under smallholder's farm conditions in Eastern Uganda. Agricultural and Forest Meteorology, 266-267, 231-242. doi:10.1016/j.agrformet.2018.12.006

Sauvadet, M., den Meersche, K. V., Allinne, C., Gay, F., de Melo Virginio Filho, E., Chauvat, M., ... Harmand, J. M. (2019). Shade trees have higher impact on soil nutrient availability and food web in organic than conventional coffee agroforestry. Sci Total Environ, 649, 1065-1074. doi:10.1016/j.scitotenv.2018.08.291

Sentek Pty Ltd. (2009). Diviner 2000 User Guide Version 1.5. Retrieved from Stepney South Australia 5069: 
Siles, P., Harmand, J.-M., \& Vaast, P. (2009). Effects of Inga densiflora on the microclimate of coffee (Coffea arabica L.) and overall biomass under optimal growing conditions in Costa Rica. Agroforestry Systems, 78(3), 269-286. doi:10.1007/s10457-0099241-y

Siles, P., \& Vaast, P. (2002). Comportamiento fisiólogico del café asociado con Eucalyptus deglupta, Terminalia ivorensis o sin sombra. Agroforesteria en las Américas, 9(35-36).

Silva, E. A., DaMatta, F. M., Ducatti, C., Regazzi, A. J., \& Barros, R. S. (2004). Seasonal changes in vegetative growth and photosynthesis of Arabica coffee trees. Field Crops Research, 89(2-3), 349-357. doi:10.1016/j.fcr.2004.02.010

Soto-Pinto, L., Perfecto, I., Castillo-Hernandez, J., \& Caballero-Nieto. (2000). Shade Effect on Coffee Production at the Northern Tzeltal Zone of the State of Chiapas, Mexico. Agriculture, Ecosystems \& Environment, 80((1-2)), 61-69.

Souza, H. N. d., de Goede, R. G. M., Brussaard, L., Cardoso, I. M., Duarte, E. M. G., Fernandes, R. B. A., . . Pulleman, M. M. (2012). Protective shade, tree diversity and soil properties in coffee agroforestry systems in the Atlantic Rainforest biome. Agriculture, Ecosystems \& Environment, 146(1), 179-196. doi:10.1016/j.agee.2011.11.007

Staver, C., Guharay, F., Monterroso, D., \& Muschler, R. G. (2001). Designing pest-suppressive multistrata perennial crop systems: shade-grown coffee in Central America. Agroforestry Systems(53), 151-170.

Tausend, P. C., Meinzer, F. C., \& Goldstein, G. (2000). Control of transpiration in three coffee cultivars: the role of hydraulic and crown architecture. Trees, 14, 181-190.

Tscharntke, T., Clough, Y., Bhagwat, S. A., Buchori, D., Faust, H., Hertel, D., . . W Wanger, T. C. (2011). Multifunctional shade-tree management in tropical agroforestry landscapes - a review. Journal of Applied Ecology, 48(3), 619-629. doi:10.1111/j.13652664.2010.01939.x

Tscharntke, T., Clough, Y., Wanger, T. C., Jackson, L., Motzke, I., Perfecto, I., . . Whitbread, A. (2012). Global food security, biodiversity conservation and the future of agricultural intensification. Biological Conservation, 151(1), 53-59. doi:10.1016/j.biocon.2012.01.068

Tscharntke, T., Klein, A. M., Kruess, A., Steffan-Dewenter, I., \& Thies, C. (2005). Landscape perspectives on agricultural intensification and biodiversity â " ecosystem service management. Ecology Letters, 8(8), 857-874. doi:10.1111/j.14610248.2005.00782.x

UCDA. (2013). Annual Report. Retrieved from https://ugandacoffee.go.ug/annual-reports

UCDA. (2015). Uganda National Coffee Strategy 2040 Plan for 2015/16 - 2019/20. Retrieved from Kampala, Uganda:

UCDA. (2016). Annual Report. Retrieved from https://ugandacoffee.go.ug/annual-reports

UCDA. (2018). Annual Report. Retrieved from https://ugandacoffee.go.ug/annual-reports

USDA. (2018). Coffee: World Markets and Trade. Retrieved from

Vaast, P., Bertrand, B., Perriot, J.-J., Guyot, B., \& Génard, M. (2006). Fruit thinning and shade improve bean characteristics and beverage quality of coffee (Coffea arabica L.) under optimal conditions. Journal of the Science of Food and Agriculture, 86(2), 197-204. doi:10.1002/jsfa.2338

Vaast, P., Harmand, J.-M., Rapidel, B., Jagoret, P., \& Deheuvels, O. (2016). Coffee and Cocoa Production in Agroforestry-A ClimateSmart Agriculture Model. In Climate Change and Agriculture Worldwide (pp. 209-224).

Vaast, P., \& Somarriba, E. (2014). Trade-offs between crop intensification and ecosystem services: the role of agroforestry in cocoa cultivation. Agroforestry Systems, 88(6), 947-956. doi:10.1007/s10457-014-9762-x

Vaast, P., Van Kanten, R., Siles, P., Angrands, J., \& Aguilar, A. (2008). Biophysical interactions between timber trees and Arabica coffee in suboptimal conditions of Central America. In Toward Agroforestry Design (pp. 133-146): Springer.

van Asten, P. J. A., Wairegi, L. W. I., Mukasa, D., \& Uringi, N. O. (2011). Agronomic and economic benefits of coffee-banana intercropping in Uganda's smallholder farming systems. Agricultural Systems, 104(4), 326-334. doi:10.1016/j.agsy.2010.12.004

Van Der Wolf, J., Jassogne, L., Gram, G. I. L., \& Vaast, P. (2016). Turning Local Knowledge on Agroforestry into an Online DecisionSupport Tool for Tree Selection in Smallholders' Farms. Experimental Agriculture, 55(S1), 50-66. doi:10.1017/s001447971600017x

Van Kanten, R., Schroth, G., Beer, J., \& Jiménez, F. (2005). Fine-root dynamics of coffee in association with two shade trees in Costa Rica. Agroforestry Forum, 63, 247-261.

van Kanten, R., \& Vaast, P. (2006). Transpiration of Arabica Coffee and Associated Shade Tree Species in Sub-optimal, Low-altitude Conditions of Costa Rica. Agroforestry Systems, 67(2), 187-202. doi:10.1007/s10457-005-3744-y

van Noordwijk, M., Namirembe, S., Catacutan, D., Williamson, D., \& Gebrekirstos, A. (2014). Pricing rainbow, green, blue and grey water: tree cover and geopolitics of climatic teleconnections. Current Opinion in Environmental Sustainability, 6, 41-47. doi:10.1016/j.cosust.2013.10.008

van Rikxoort, H., Schroth, G., Läderach, P., \& Rodríguez-Sánchez, B. (2014). Carbon footprints and carbon stocks reveal climatefriendly coffee production. Agronomy for Sustainable Development, 34(4), 887-897. doi:10.1007/s13593-014-0223-8

Verchot, L. V., Van Noordwijk, M., Kandji, S., Tomich, T., Ong, C., Albrecht, A., . . Palm, C. (2007). Climate change: linking adaptation and mitigation through agroforestry. Mitigation and Adaptation Strategies for Global Change, 12(5), 901-918. doi:10.1007/s11027-007-9105-6

Villatoro-Sánchez, M., Le Bissonnais, Y., Moussa, R., \& Rapidel, B. (2015). Temporal dynamics of runoff and soil loss on a plot scale under a coffee plantation on steep soil (Ultisol), Costa Rica. Journal of Hydrology, 523, 409-426. doi:10.1016/j.jhydrol.2015.01.058

Wairegi, L. W. I., van Asten, P. J. A., Tenywa, M. M., \& Bekunda, M. A. (2010). Abiotic constraints override biotic constraints in East African highland banana systems. Field Crops Research, 117(1), 146-153. doi:10.1016/j.fcr.2010.02.010 
Wallis, J. A. N. (1963). Water use by irrigated Arabica coffee in Kenya. The Journal of Agricultural Science, 60(3), 381-388. doi:10.1017/S0021859600011977

Wang, N., Jassogne, L., van Asten, P. J. A., Mukasa, D., Wanyama, I., Kagezi, G., \& Giller, K. E. (2015). Evaluating coffee yield gaps and important biotic, abiotic, and management factors limiting coffee production in Uganda. European Journal of Agronomy, 63, 1-11. doi:10.1016/j.eja.2014.11.003

Wickham, H. (2016). ggplot2: Elegant Graphics for Data Analysis: Springer-Verlag New York.

Wickham, H., François, R., Henry, L., \& Müller, K. (2019). dplyr: A Grammar of Data Manipulation. Retrieved from https://CRAN.Rproject.org/package $=$ dplyr

Willson, K. (1999). Coffee, cocoa and tea. Wallingford: CAB International.

Willson, K. C. (1985). Climate and Soil. In M. N. Clifford \& K. C. Willson (Eds.), Coffee: Botany, Biochemistry and Production of Beans and Beverage (pp. 97-107). Boston, MA: Springer US.

Wintgens, J. N. (2004). Coffee: Growing, Processing, Sustainable Production. Weinheim, Germany: Wiley-VCH Verlag GmbH \&Co.

Zhang, W., Ricketts, T. H., Kremen, C., Carney, K., \& Swinton, S. M. (2007). Ecosystem services and dis-services to agriculture. Ecological Economics, 64(2), 253-260. doi:10.1016/j.ecolecon.2007.02.024

Zullo, J., Pinto, H. S., Assad, E. D., \& de Ávila, A. M. H. (2011). Potential for growing Arabica coffee in the extreme south of Brazil in a warmer world. Climatic Change, 109(3-4), 535-548. doi:10.1007/s10584-011-0058-0 